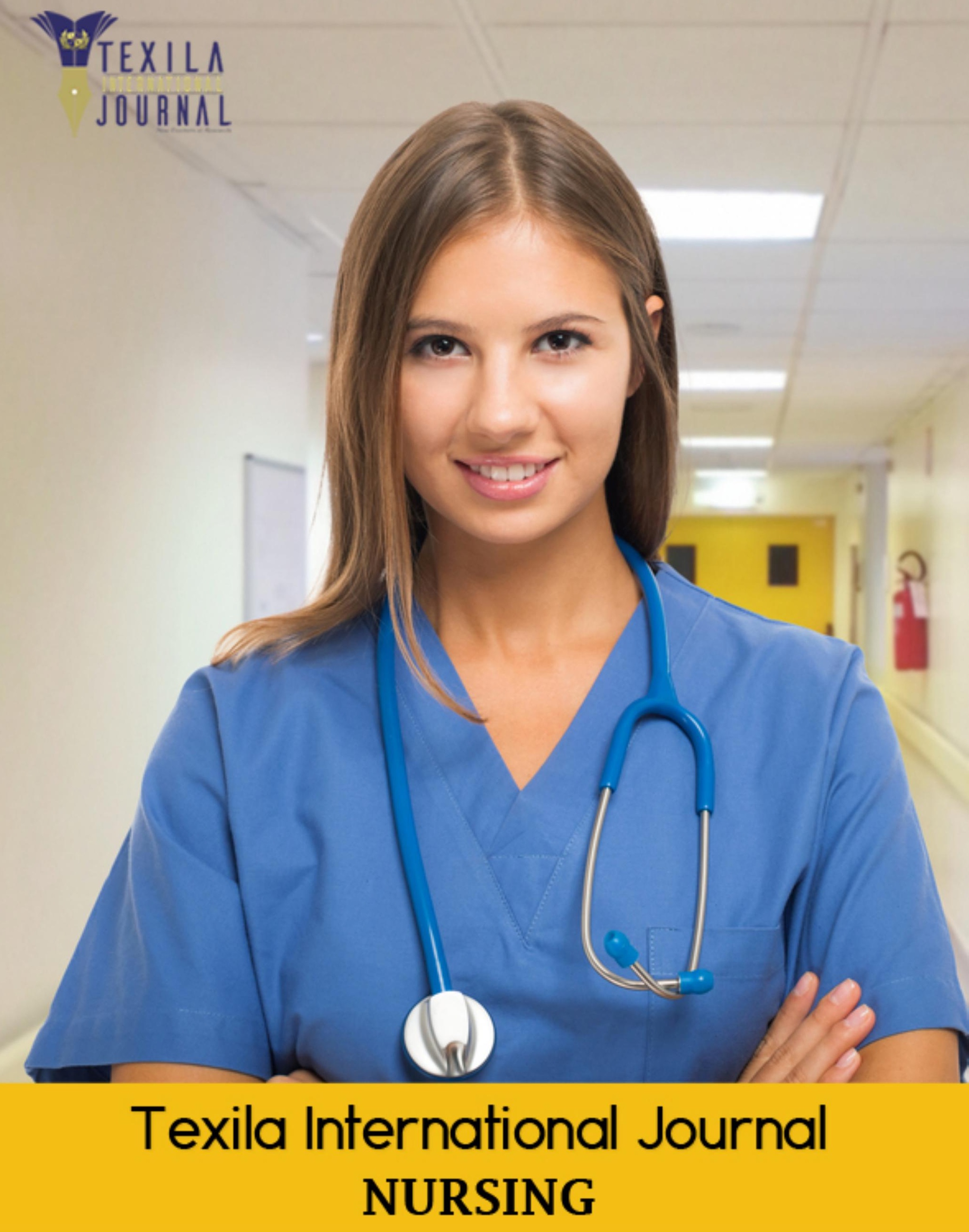

Volume 3 Issue $2 \quad$ ISSN : 2520-3126 


\section{EDITORIAL POLICY}

Papers must be submitted with the understanding that they have not been published elsewhere (except in the form of an abstract or as part of a published lecture, review, or thesis) and are not currently under consideration by another journal published or any other publisher. The submitting (Corresponding) author is responsible for ensuring that the article's publication has been approved by all the other coauthors. It is also the authors' responsibility to ensure that the articles coming from a particular institution are submitted with the approval of the necessary institution. Only an acknowledgment from the editorial office officially establishes the date of receipt. It is a condition for submission of a paper that the authors permit editing of the paper for readability. All enquiries concerning the publication of accepted papers should be addressed to ejournal.assist@tau.edu.gy.

\section{PEER REVIEWERS}

Dr. Rajesh Konnur, Associate Professor, Khfh College of Nursing.

Dr. Jefferson Garcia Guerrero, Assistant Professor, Al Ghad International College for Applied Medical.

Dr. Suresh Kumar Ray, Associate Professor, Bharati Vidyapeeth College of Nursing, Dhankawadi.

Dr. Jayanthi P, Professor, Omayal Achi College of Nursing.

Dr. Neerja Sood, Assistant Professor, Indira Gandhi National Open University.

Dr. Susila, Professorcum Principal, Billroth College of Nursing. 


\section{ABOUT PLAGIARISM}

Plagiarism is the use or close imitation of the language and ideas of another author and representation of them as one's own original work. Duplicate publication, sometimes called self plagiarism, occurs when an author reuses substantial parts of his or her own published work without providing the appropriate references. This can range from getting an identical paper published in multiple journals, where authors add small amounts of new data to a previous paper.

Plagiarism can be said to have clearly occurred when large chunks of text have been cut and pasted. Such manuscripts would not be considered for publication in TIJBMS Journal. But minor plagiarism without dishonest intent is relatively frequent, for example when an author reuses parts of an introduction from an earlier paper. The editors will judge any case of which they become aware (either by their own knowledge of and reading about the literature, or when alerted by referees) on its own merits.

The paper containing the plagiarism will be obviously returned back to the author's for review, but we earnestly request the authors to avoid submitting plagiarized 


\section{DISCLAIMER}

Texila International Journal of Nursing (TIJN) make every effort to ensure the accuracy of all the information (the "Content") contained in its publications. However, the TIJN and its agents make no representations or warranties whatsoever as to the accuracy, completeness or suitability for any purpose of the Content and disclaim all such representations and warranties whether express or implied to the maximum extent permitted by law. Any views expressed in this publication are the views of the authors and are not necessarily the views of the Editor's or Texila International Journal of Nursing. 


\section{TABLE OF CONTENT}

1 Knowledge and Practice of Telenursing among Nurses in Plateau State, Nigeria

Sunday Yohanna Dangyang

2 Factors Associated with the Choice of Nursing Profession among First

Year Students at Consolata Nkubu School of Nursing, Meru, Kenya

Catherine Joan Kawira Mundi

3 Nurses' Leadership Style in Tertiary Care Hospitals

Nauman Q. Godfrey

4 Knowledge and Use of Standardized Nursing Languages: A Study among

28 Nurses at the Federal Medical Centre, Owo, Ondo State, Nigeria

Abiodun-Sanni Falilat Iyabode

5 Stressors and Counselling Needs of Undergraduate Nursing Students in

Osogbo, Nigeria

Lilly-West, R.B

6 Attitudes of Student Nurses' Towards Adherence to Standard Precautions in the Clinical Area at a Large Teaching Hospital in Uganda

Faith R. K. Sebuliba

7 Impact of Mentoring on Nursing and Midwifery Educators and Students:

An Integrative

Elizabeth Namukombe Ekong

8 Knowledge of Bloom's Hierarchy of Cognitive Levels of Educational Objectives and its use in Setting Examinations by Nurse Educators in Lusaka and Eastern Provinces

Patricia Mambwe

9 Sickle Cell Disease in Pregnancy: Active Nursing Management

Anisley Fabars-Johnson

10 Effects of Shortage of Nurses at St. Dominic's Mission Hospital, Ndola, Zambia 
Elizabeth Njovu

\begin{tabular}{llc}
\hline 11 & Consequences of Teenage Pregnancy & 124 \\
& \multicolumn{2}{c}{ Catherine Malethola Lebina } \\
\hline 12 & $\begin{array}{l}\text { Factors Affecting the Utilization of Family Planning among Women } \\
\text { Attending Selected Health Centers in Ile Ife, Osun State, Nigeria } \\
\text { Agunbiade Funmilayo B }\end{array}$ & 134 \\
\hline 13 & $\begin{array}{l}\text { Role of Husband's Age in Percentage of Eggs that get Fertilized in Invitro } \\
\text { Fertilization Cycle }\end{array}$ & 142 \\
& \multicolumn{2}{c}{ Monisayo Olayemi Komolafe } \\
\hline
\end{tabular}

14 A Comparative Study to Determine the Knowledge and use of Breast Self- 149 Examination Technic among Female Student Nurses at St. Lukes School of Nursing, Rufunsa. Zambia

Toddy Sinkamba

15 Challenges Faced by Healthcare Providers in Providing Services to Key Population at Risks of HIV in Ethiopia

Nebiyu Lera Alaro

16 Perception of Patients about Cardiovascular Disease (CVD) and Effect of 168 Communication by Physician and the Assisting Registered Nurse to Enhance Assessment of Risk and Bridge a Gap of Accurate Perception of their Risk of CVD

Anette Marina Rodrigues

17 Perception of Reflective Journaling during Clinical Posting among Nursing Students

Musah K. Toyin

18 Knowledge, Attitude and Behavior on Overweight and Obesity, Health Consequence and Adaptation to Lifestyle Changes among Early Middle Age Medical and Non-medical Health Care Staffs of NMC Day Care Centre, Abu Dhabi, UAE

Anette Marina Rodrigues

19 Importance of Tuberculosis (TB) Infection Prevention among Nurses and Patients at St. Dominic Mission Hospital

Elizabeth Njovu

20 Common HIV/AIDS Clinical Symptoms among HIV-Positive Pregnant 198 Women under ARV Therapy: Clinical Indicators for Non- Adherence to Treatment

Admirabilis Kalolella

21 The Human immunodeficiency Virus sero-prevalence and AIDS- related 205 opportunistic infection patterns among Women with retained placenta in 
Admirabilis Kalolella 


\title{
Knowledge and Practice of Telenursing among Nurses in Plateau State, Nigeria
}

\author{
Article by Sunday Yohanna Dangyang \\ Nursing, Texila American University, Nigeria \\ E-mail:dangyangs@yahoo.com
}

\begin{abstract}
This study was designed to study the knowledge, perception and practice of Telenursing among Nurses in Plateau State, Nigeria. It aims at the need for good policy in health care delivery and implementation of Telenursing to reduce to a greater extend the consequences associated with inadequate health care distribution. A cross sectional study involving Nurses in Plateau State, Nigeria was carried out with information on socio-demographic characteristics, knowledge of telenursing, perception towards telenursing and team work, willingness and attitude of Nurses to use telenursing and challenges affecting the implementation of telenursing in Plateau state were collected, using a semi-structured questionnaire. Data was analysed using descriptive statistical and chi-square test. The level of significance was set at $p \leq$ 0.05. 270 Nurses participated in the study. Majority 148 (54.8\%) had not heard about telenursing though 117 (43.3\%) have heard. 90.7\% participants have never been engaged in telenursing, $84.4 \%$ stated inadequate resources affected telenursing practice. Majority (84.8\%), 52.3\% indicated interest for telenursing to be used and for improved communication and collaboration respectively between Nurses and other disciplines. Majority $66.5 \%$ agreed that telenursing is easy to use. Only $31.1 \%$ felt that telenursing may not bring any extra value to existing nursing practice when implemented. Lack of knowledge (47.4\%), funding (80\%), policy (15.2\%), Poverty (13.3\%), time/interest/will/attitude of nurses (2.6\%), Shortage/lack of manpower/workload (4.8\%), and Inadequate power supply (11.1), were pointed out by the participants as challenges that can affect the implementation of telenursing.
\end{abstract}

Keywords: Telehealth, telenursing, information, technology, knowledge, practice.

\section{Introduction}

Telenursing is the utilization of information communication technology to provide nursing care from a distance by Nurses. It covers all locations reducing the problem of inadequate and poor health care distribution, poor transportation system and topography, shortage of professional Nurses, Doctors. However, Nurses' knowledge, perception and practice need to be explore for effective utilization. Following verbal interviews of some nurses in the state indicated inadequate knowledge of telenursing. There is also no available data on telenursing policy and practice in any of the health institution in the state including the State Ministry of Health. The inequitable distribution of health facilities and services has contributed to the background preventable maternal, neonatal and infant deaths (as cited by Mutihir and Golit, 2016). This has led to various form of poor health habit by the people like opting for traditional or native medicine, rituals and some spiritual means all seeking for alternative care to bridge the gap of the shortage in health care provision. The advent of technology in medical practice has brought telemedicine, eHealth, Telehealthnursing or telenursing to advance the course of care. Telenursing is seen as a good method of care delivery that aims at overcoming the challenges of Poor healthcare facilities distribution, inadequate professional Nurses, poor accessibility to health facilities, poor transportation systems and distance location hampers quality nursing care and services. According to Abbott.; Coenen, 2008 and Milligan et al., 2011, it is the raise in elderly population, increasing health care demand, and a shortage of skilled health care providers, which is a pressing issue seeking alternative ways in which Information Communication Technology can be used to meet the world's health care needs. The advent of Telehealth 
DOI: 10.21522 /TIJNR.2015.03.02.Art001

ISSN: $2520-3126$

nursing is to bridge the gap created by such factors. Telehealthnursing is the delivery, management, and coordination of care and services provided via telecommunications technology within the domain of nursing (American Association of Ambulatory Nursing 2004). This allow for access of nursing care by individuals globally without any barriers (Rutledge, C. M., Haney, T., Bordelon, M., Renaud, M., \& Fowler, C., 2014).

The practice and acceptance of telenursing is dependent on the nurse's ability to apply the knowledge of sound communication and information technology in teaching of student nurses, delivering management and regulating of care and services when much or large physical distance exist between the nurse and patient or nurse and nurse or other health care providers. This method creates rapport with exchange of cultural ideas across communities and health care providers (Rutledge, C. M., Haney, T., Bordelon, M., Renaud, M., \& Fowler, C. 2014).

The practice of telenursing is centred on nursing protocols, attentive listening, sound clinical judgment, up-to-date scientific knowledge, and trust between telenurses and callers (Hagen, Morin \& Lupine, 2000). Nurses need to be advanced in the knowledge of the use of electromagnetic channels like wire, radio, and optical to transmit voice, data, and video communications signals, using electrical or optical transmissions between humans and/or computers (Skiba, D. J \& Barton, A.J;2000).

Despite the advantages of telenursing in bridging the gap created by patient, based on additional burden associated with man power shortage, transportation issues, time and consequences, cost and search for alternatives means to care for a large number of patients. Online (https://www.ncbi.nlm.nih.gov/books/NBK2687/, 24/1/17), the need to ascertain the competent level of the nurse based on practiced and knowledge gives quality assurance and evident-based practice. Hence the need to study the knowledge and practice of telenursing among nurses in Plateau state, Nigeria.

\section{Problem under study}

The search for alternatives health care is rising globally due to increasing demand of health care where the supply is inadequate especially in African countries where there is inadequate health care facilities and distributions, poor accessibility to care, high cost of health care and shortage of health care professionals especially nurses. The increasing search for alternatives has led to high patronage of other means of care like traditional and herbal medicine or traditional attendants. In Plateau state Nigeria the practice is not different due to poor distribution of facilities, policy, distance, transport system and gross shortage of trained Nurses. The need to reduce Physician and Nurses waiting least is much and the spirit to reach out to all people is the main goal. Telehealth has being in practice in the more advantaged countries but in the less advantages countries of Africa like Nigeria the practice of telenursing may be difficult, even where Information Technology is practiced. It may be faced with challenges of acceptability, knowledge and practice by Nurses.

Knowledge is the key factor in its application despite the advantages attached to its use in proving improved nursing care to the patients in remote or less privilege settlements. It is in this line that the researcher need to know the knowledge level of nurses and their preparedness to practice telenursing in their practice areas.

\section{Rationale of the study}

The outcome of the study will enhance the knowledge base of Nurses on the need to utilize telenursing in meeting patient nursing needs in the community especially in disadvantage areas and post hospital admission. Hospital management and other policy makers will see the need to establish telehealth and telenursing centres in order to decongest the facilities and also allow for patient follow up, thereby reducing the physician waiting list and allowing nurses time to attend to other clinical challenges.

\section{General objective}

The increased demand of health care services in Nigeria and the world has brought about many challenges like increases hospital visits, raise in discharge patient waiting follow up list, large distances in search of health care or expert care, poor transport system and its consequences and shortages of skilled 
manpower shall led to quest for alternative means of delivering health care especially nursing care to people. This brought about rendering of nursing care/service through telenursing to people from a large physical distance, utilizing ICT tools. Though this method has brought improvement in not only accessibility to health care facilities but also reduction in burden associated to delay. However, nurses' knowledge on the practice of telenursing is a key factor in providing quality care with reduced error. It is this possible gap that prompted the researcher to look at; knowledge and practice of telenursing among nurses in Plateau State.

\section{Specific objective}

1. To assess the general knowledge of the participants about telenursing.

2. To assess the perception of the participants towards telenursing and team work as it influences the use of telenursing.

3. To ascertain the attitude and willingness of the participants to use telenursing.

4. To explore possible challenges that may come up in the implementation of telenursing.

\section{Limitation of the study}

The study was limited by short period to collect data and analyse same. The respondent returned of questionnaire as a result of duty shift, absent from work due to excused duties and holidays/off duty. Respondent knowledge of the research problem.

\section{Methodology of the study}

\section{Introduction}

The method utilized for data gathering and study in order to draw a conclusion based on respondent's responses. The chapter also focused on research setting, population, sampling, and instrument for data collection.

\section{Study area}

The study was conducted in Plateau state located at the middle belt region of Nigeria covering an area of 26,899 square kilometers with an estimated population of about three million people. It has an estimated number of 1200 Nurses and Midwives covering the tertiary, secondary and primary health care institutions, though this record may not be reliable as a result of poor documentation and tumult or highly disadvantage settlements and the crisis situation that affected the state.

\section{Study population}

The target population composes of all nurses who are present within the period of recruitment in Plateau state, Nigeria covering tertiary, secondary and primary health care facilities.

\section{Study duration}

The study was conducted in January and February, 2017 (two months)

\section{Sampling method}

The researcher adapted a randomized convenience sampling technique in selecting the sample for the study. The sample was drawn from Tertiary (Teaching and Specialist hospitals), Secondary (General hospitals) and Primary (PHC) levels of health care in the state, using Jos university Teaching Hospital and Plateau Specialist Hospital, General hospital Barkin-Ladi and PHC Barkin-Ladi respectively.

\section{Sampling size}

Sample: to determine the sample size the researcher used the Yamani's formula 
DOI: 10.21522 /TIJNR.2015.03.02.Art001

ISSN: $2520-3126$

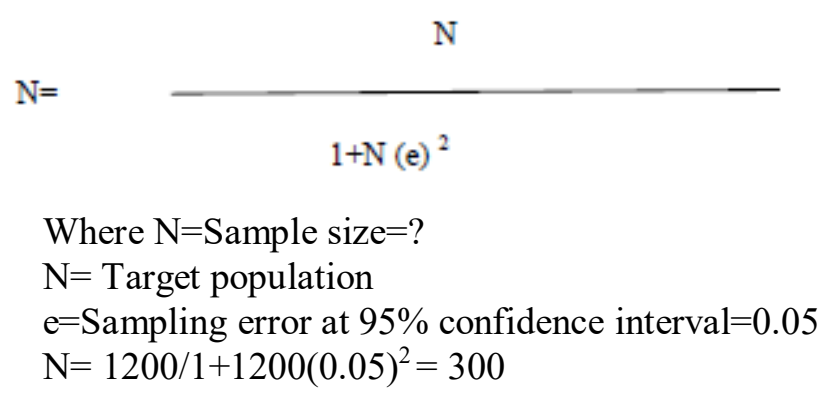

\section{Study tools}

The study tool was a self-developed close ended questionnaire with options. The tool is divided into two sections. Section A: socio-demographic data of the respondents and

Section B: comprises of questions to determine the knowledge level of nurses on telenursing, data to ascertain nurses' practice of telenursing, factors influencing the practice of telenursing among nurses and influence of socio demographic characteristics on knowledge of nurses on telenursing

\section{Reliability}

The instrument was rated by the project supervisor and another academic versed in research from the University of Jos.

A pilot study was carried out among nurses working in University of Jos clinic, Jos. The study was for instrument test retest. A reliability coefficient of 0.75 was achieved within the instrument and

$\mathrm{P}$ value of 0.05 . The instrument was found to be highly reliable.

\section{Collection of data}

The state commissioner health and the chairman ethical committee of the state ministry of health gave an ethical clearance yet permission was obtained from the research and ethic committee of the hospitals involved in the study. Three research assistances were trained for a day on methods of collecting data to assist with the data collection for a week.

\section{Data analysis}

Data collected were analyzed using statistical package for social sciences (SPSS) 23.0. Both descriptive statistics were used to analyze the data and Pearson correlation $r$ to test for hypothesis.

\section{Results}

\section{Characteristics of the study population}

A total of 270 questionnaires were filled and returned, out of 300 that were shared. The findings were on:

The majority of the respondents were female $215(79.6 \%)$ females and $55(20.4 \%)$ males. The respondents were nurses, this indicated that majority of nurses in plateau are female.

The table indicated that majority of the respondents are aged $40>$, signifying their level of practice which may be related to their level of knowledge in technology in nursing.

$98.5 \%$ of respondents had work for below 20years while the rest above 20years, signifying that respondents had work enough to have telenursing experience.

\section{To assess the knowledge level of the participants about telenursing}

$163(60.4 \%)$ respondents have certificate in nursing, $62(23.0 \%)$ of respondents have bachelor in nursing science degree with $3(1.1 \%)$ having Masters of nursing science. This shows that the knowledge level of respondent in the study area need to be encourage as those with advanced nursing qualification are 
inadequate to pilot nursing practice in this technological area. Table 4 indicated, Majority 112 (41.5\%) respondents do not have any form of training in respect to information communication technology, 104 (38.5\% respondents possess certificate in information communication technology, with $50(18.5 \%)$ had training to diploma level and Bachelor of Science in computer $1(.4 \%)$. This shows that nurses in the study area need more training in information communication technology.

From table 6, majority $148(54.8 \%)$ said they have not heard about telenursing before, while $117(43.3 \%)$ said they heard about it. This calls for more training on telenursing as some nurses were yet to hear of it.

From table 7, $48(17.8 \%)$ indicated that they heard about it from literatures on the internet, $36(13.4 \%)$ heard it from colleagues, 13 (4.9\%) heard it from books, seminars and workshops, from training institutions only $14(5.2 \%)$. However, majority 147 (54.9\%) did not hear of it. The chart showed that there is need for training of student nurses (future nurses) and more $\mathrm{CNE}$ is needed for nurses on telenursing in the study area.

Majority $245(91.1 \%)$ had no practice or engaged in telenursing practiced. The rest $23(8.6 \%)$ respondents had some experience with the practice, as seen in table 8 . This indicated inadequate awareness and exposure to the knowledge and practice of telenursing. Thus suggesting call for training.

Table 9 shows, $51(18.9 \%)$ have been to telenursing practicing health care centre but majority 215 (79.9\%) also indicated that they had not been to telenursing practicing health care centre before. Indicating inadequate knowledge and awareness..

When asked where, various options were noted; these were illustrated in Chart 3 above *. Their knowledge about telenursing using 7 questions which cut across the content, utilization, implementation and application of telenursing. This information is presented in the table below.

Table 10; Shows that, a greater number of respondents $117(43.3 \%), 102(37.8 \%)$ disagreed and strongly disagreed respectively when added up indicated that $219(81.1 \%)$ accepted none utilization of telenursing in the practice area. 9 (3.3) and 41 (15.2) making strongly agreed and agreed respectively, that is about $18.5 \%$ of the participants mentioned that they utilizes telenursing. This indicated that either most respondent are talking of formal practice or did not linked the use of ICT devices like phone, emails and video to telenursing.

\section{The Perception of participants towards telenursing and team work as it influences the use of telenursing}

Table 11, shows $75.2 \%$ supported the fact that telenursing allows for timely monitoring and provision of care to outpatient while the rest about 24.8 opposed to it.

Table 12; indicated $83 \%$ respondents do not see the need to use it in their unit to followup discharged patient, with $13.2 \%$ seeing the need to utilize it. This may be attributed to inadequate exposure, lack of training or difficulty in accepting new changes.

Teleconsultation by nurses and other health care providers be practiced in the area as seen in Table 13; indicated that $40.6 \%$ see it as an accepted possibility while majority about 58.5 did not agree. It seems impossible to majority due to lack of exposure to ICT usage and training or visit to telenursing institutions.

Table 14; shows the responds of nurses, when asked if Nurses can engage other nurses in telenursing conferencing to discuss and update knowledge, $46 \%$ agreed against the majority $52.9 \%$ that disagreed. This indicated either the lack of knowledge or non-engagement on teleeducation or inadequate knowledge or use of video calls like skype or chats using phone like whatsapp. Showing that the perception level is less.

Table 15, on whether there is generally a good team spirit among nurses utilizing telenursing, majority $64 \%$ responded positively, though 34.9 did not believe so. There is the need to motivate nurses on need for team work in order to provide quality care through telenursing.

Table 16, indicated that, when asked if there was enough resources put in place to ensure telenursing services for staff motivation, provision of information systems, ICT machines and equipment maintenance. Majority $(84.4 \%)$ were of the contrary opinion. Therefore, funding should be looked into and improve to ensure quality and wider telenursing services. 
DOI: 10.21522 /TIJNR.2015.03.02.Art001

ISSN: $2520-3126$

Table 17; The response was observed from respondents when asked if everyone's opinion was usually heard or listened to, many $65.1 \%$ indicated that this was not the case. This shows that respect for opinions need to be worked on as lack of respect for opinion may affect patient safety. Therefore, this gap need to be studied, while Table 18; 55.5\% and 56.7\% applauded the fact that their physicians and nurses work together as a well-coordinated team; and that disagreement is expressed in a constructive manner. Table 19 ; indicated a good number $(63.0 \%)$ affirmed that they were encouraged to report any concerns encountered during telenursing.

From table 20 it is clear that $192(71.1 \%)$ accepted that disagreement between team members in the practice of telenursing is discussed amicable, demonstrating good team spirit and correction of errors. Despite that, there is the need to improve on opinion sharing as the rest $29.1 \%$ still do not accept constructive manner of discussions. Table 21; indicated Majority (57.4\%) confirmed job satisfaction achievement with telenursing. The rest were on the contrary opinion, which may be attributed to possible lack of adequate knowledge or exposure.

\section{To ascertain the attitude and willingness of the participants to use telenursing}

Information on the willingness and attitude of participants towards the use of telenursing was also sourced for, Table 22; Majority (84.8\%), indicated that they wanted telenursing to be used in nursing practice, while the rest objected for possible reason of probably linked to inadequate knowledge of ICT or telenursing awareness. Thus, indicating that majority of the respondents need telenursing as part of nursing practice in the study area. Table 23: shows majority 185 (69.9\%) respondent disagreed with the assertion that nursing care is efficient without having to use telenursing. This is based on the knowledge of telenursing most probably again those that agreed.

Table 24; on Telenursing might waste time and can make our nursing practice less efficient majority 227 $(83.9 \%)$ respondents disagreed, while the rest $16.1 \%$ agreed. This signifies that majority agreed that telenursing does not waste time and it makes more efficient.

Table 25: shows that Telenursing made us have more confident and competent base on the findings that above average 194 (71.9\%) agreed that confident and skills are acquired with telenursing, 74 (27.4\%) disagreed. Table 26: majority 219 (81.1\%) asserted that using telenursing will improved communication and collaboration between nurses and other discipline contributing to wellbeing of the patient.

Table 27; indicated that $64.8 \%$ agreed that telenursing may not be very important as it has its own handicaps. This perception may be based on lack of willingness to utilize from thoughts of uncertainty. Table 28; indicated that $180(66.6 \%)$ respondents agreed that telenursing is easy to use, $88(32.6 \%)$ believed it is difficult. This calls for more training. Table 29 ; shows majority $74.8 \%$ agreed that it is important to use telenursing in nursing generally. This indicated the willingness of the respondents to change and attitude to ensure efficiency. Table 30; Indicated, majority (79.6\%) felt that telenursing may improve nurse-patient relationship. This may be related to the lifting of burden of transportation and frequent check on the condition with useful advice or nursing care.

Table 31; Transcultural nursing practice is likely to be improve through telenursing was an expression by $81.5 \%$ from the chart above. This may be the result of communication from all locations across the globe, race and tribes.

Table 31; Indicated a large number 237 (87.8\%) respondents believed that implementing telenursing is a good decision, $30(11.1 \%)$ do not want it implemented. The fear of the minority may not be unconnected with the thinking of losing of job with the advancement of ICT or attitude/willingness toward accepting change. Table 32; Shows $68.2 \%$ respondent disagreed that telenursing may not bring any extra value to existing nursing practice before its implementation, 84 (31.1\%) agreed. This signifies that more value will be achieved in nursing practice with telenursing.

Participants were asked whether if they were discharged as patient, they would prefer telenursing to be applied to them, Table 33; above average $179(66.8 \%)$ said they would want telenursing to be used on them if they were discharge patients, while $89(33.0 \%)$ said no. This shows that the willingness to utilize 
telenursing is yet to be accepted by some nurses. This called for further education on telenursing practice within the study area.

\section{HO2: There is no significant relationship between respondent's attitude and the utilization of telenursing}

From table 3 and the summary above, it is obvious that that there is significant relation between attitude and practice of telenursing, thus not in agreement with the hypothesis stated above.

\section{Possible challenges that may come up in the implementation of telenursing}

Table 34; Shortage/lack of manpower/workload on Nurses 13 (4.8\%), Lack of time/interest/will/attitude of nurses 7 (2.6\%), Lack of knowledge of telenursing from nurses 128 (47.4\%), lack of instruments and other equipment/ICT tools 42 (15.6) were pointed out by the participants as possible challenges that can affect the implementation of telenursing in Plateau state. Majority of the challenge as indicated was inadequate knowledge, which call for more training and retraining on telenursing for nurses and it should also be taught in various institution of training.

Table 35; Illustrated that 80 (29.6\%) saw lack of funding as a possible barrier to the implementation of telenursing, 41 (15.2\%), 36 (13.3), 30 (11.1) indicated lack of policy, poverty and inadequate power supply respectively as contributory factors or other barriers that affects telenursing implementation.

\section{Discussion}

\section{Knowledge of telenursing among the respondents}

From this study, participants had moderate knowledge of telenursing while majority had inadequate knowledge; which is contrary to a similar study in the South Africa (Siinclai, Wynchank, Jill F, 2010) where the knowledge and practice is high among nurses. The internet was the most mentioned source of information for respondents with adequate knowledge, this could be explained by the recent upsurge in information technology and social networking, and it also points to the fact that Nurses had good knowledge-seeking behaviour, this should be encouraged. Although their knowledge score was moderate and in line with prior findings, however there is still the need to further educate Nurses about telenursing, most $(84.2 \%)$ had not been to a centre where telenursing is practiced and did not know that one of the objective is to reduce hospital visits or return followup hospital visits by patient, Including the reason of allowing nursing care to be accessed from any location according to $68.0 \%$.respondents, Yet only $4.4 \%$ could not identify the five fundamental issues in the telenursing when asked. This called for adequate training and education for Nurses to acquire full knowledge of telenursing.

\section{H01: There is no significant relationship between respondent's level of knowledge and the practice of telenursing}

This hypothesis is proven to be incorrect as demonstrated above in table 1 , where more than half $(54.8 \%)$ have not heard about telenursing, 54.4\% did not respond when asked they have heard of where it is practiced, while $79.6 \%$ have never been to a centre where telenursing is practice, majority $98.1 \%$ claimed they have not seen it in practiced, while $90.7 \%$ accepted not ever engaged a patient in telenursing as a followup procedure in their centre, above half $(57.8 \%)$ have not sought for advice on how to manage a patient from a nurse in a distant facility that could have been referred, despite about $61.5 \%$ of nurses with more than 20 years working experience and the rest with about 1 to 19 years, indicating inadequate knowledge leads poor practice despite the availability of mobile phone and cheaper rates.

\section{Perception of the participants towards telenursing as it influences its implementation}

The inadequate utilization of telenursing in Plateau state among Nurses agreed with a similar study conducted by Siinclai et al, 2010 which indicated the several challenges in Africa as being responsible for the low usage of telenursing in developed countries of Africa. 
DOI: 10.21522 /TIJNR.2015.03.02.Art001

ISSN: $2520-3126$

There is also the need to improve upon telenursing as a means of allowing access health care to all and to reduce returned visits for discharged patient and good triaging before referral to hospital generally, the contrary opinion among the respondents about having enough resources put in place to ensure telenursing practice effectively is of great concern; they also indicate that people's opinion is not usually listened to similar perception was observed, this indicates that telenursing is not adequately applied or rather not in use, in Plateau state health care centres among Nurses, since almost all these areas are included and should be considered if telenursing was actually in use. There was also a recommendable attitude towards the timely followup of patients among the staff, which also shows that the participants have a good disposition about the interest of their clients.

However there is the need for improvement in terms of team work, since there still remain varying degree of opinion in respect to good team spirit among them and that their physicians and nurses work together as a well-coordinated team; many even concurred about disagreement on opinion not expressed in a constructive manner during telenursing. All these shows the level of interaction and social understanding among telenursing nurses and others and reflects some level of dichotomy, there should be better friendliness and associations among the staff, this will go a long way to bridge the gap that usually exists between the different professional categories and fosters co-operation which in turn improves service delivery.

\section{Willingness and attitude of participants to use telenursing}

This study shows that almost all the participants in Plateau stat are willing and have a positive attitude towards telenursing, they believed that telenursing would improve the clinical outcomes in their nursing practice and majority $(66.8 \%)$ said they would want telenursing to be used for them.; however the indifferent disposition expressed by some respondents as to whether the telenursing may bring any extra value to existing nursing practice before its implementation needs to be further assessed, one of the reasons might be that the full benefits and components of telenursing is not yet fully understood by the participants.

\section{Possible challenges/advice/suggestion towards the implementation of telenursing}

Lack of team spirit or dichotomy among the Nurses, though majority $64 \%$ shown a good team spirit yet the opinion of other respondent was a major challenge identified, this has been a major bottle-neck in Nigeria. Recently, conflicts and disagreements among Nurses, Doctors, and other health professionals have seriously affected medical service and health care delivery negatively. There have been strikes and slowdowns which have led to shutting down government hospitals for long periods and which unarguably has led to deaths which could have been prevented and meltdown of the health sector services. It is not surprising then, that more than a quarter (34.9) of the participants in this study has pointed out this issue as being a serious challenge that might also affect the implementation of telenursing in the state since in there are also Doctors and other health professionals working together in a team.

Secondly, inadequate supply of ICT device and other equipment/facilities and Shortage or lack of manpower were indicated as the next major challenges, without the structures, instruments and staff, cutting-edge strategies like telenursing would be difficult to implement.

Lack of commitment from the Administration or Management unit, the management has always been known to greatly influence the implementation of new policies and strategies in an establishment, the hospitals is not to be left out in this case. The leadership of any establishment plays a major role in adoption of new ideas, this is in line with the results in a previous studies (Kariyoi et al., 2013, Vats et al, 2010 and Edmondson, 2003). Also if the administration or management of this hospital considers the telenursing as priority, it is easier to obtain funds to train the nursing staff and purchase instruments or other equipment that must be in place to ensure the kick-off of the use of telenursing.

\section{Summary}

This study investigated the knowledge and practice of telenursing among Nurses in plateau state, Nigeria. The specific objective was to assess the general knowledge of the participants about telenursing, perception 
of the participants towards telenursing and team work as it influences the use of telenursing, ascertain the attitude and willingness of the participants to use telenursing, explore possible challenges that may come up in the implementation of telenursing and identify areas for change in the roles of the hospital administration towards implementation of telenursing.

\section{The summary of the findings are as follows}

270 Nurses participated in the study. Majority 148 (54.8\%) had not heard about telenursing though 117 (43.3\%) have heard. $90.7 \%$ participants have never been engaged in telenursing, $84.4 \%$ stated inadequate resources was in place to ensure telenursing practice. Majority $(84.8 \%), 52.3 \%$ indicated interest for telenursing to be used and for improved communication and collaboration respectively between Nurses and other disciplines. Majority $66.5 \%$ agreed that telenursing is easy to use. Only $31.1 \%$ felt that telenursing may not bring any extra value to existing nursing practice when implemented. Lack of knowledge (47.4\%), funding $(80 \%)$, policy (15.2\%), Poverty (13.3\%), time/interest/will/attitude of nurses $(2.6 \%)$, Shortage/lack of manpower/workload (4.8\%), and Inadequate power supply (11.1 were pointed out by the participants as challenges that can affect the implementation of telenursing

All the research hypotheses are invalid to the study. This is evidenced by majority of the participants' knowledge and utilization of information and communication technology in patient care.

\section{Limitation of the study}

This study though carried out in Plateau state, Nigeria. It covers all the three tires of the health system practiced in Nigeria for that it can be generalized as there are no known adequate publication on the subject under study, despite some constraints suffered like finance, inadequate time, sample size and knowledge of respondents on research methods.

\section{Conclusion}

Though there is variations of opinion on the knowledge of telenursing among nurses in Plateau, it can be said to be good, though complete knowledge about the components and application is not fully known. In conclusion efforts should be geared to more enhancing complete knowledge on why and how telenursing should be used. Patient safety was perceived to be of high priority however team work should be improved upon. Generally the Nursing staff were willing and have a positive attitude towards the implementation of the strategy if all other influencing factors are put in place. Challenges highlighted should be looked into and internally solutions should be sought to reduce or totally eradicate these problems, otherwise the implementation of new strategies like the telenursing would remain unachievable.

Finally the role of administration in the planning and implementation of telenursing cannot be overemphasized, there should be a collaboration of all unit heads particularly the nursing unit for a successful implementation. There is also need for training and frequent re-training of all the Nurses, this will foster a good understanding and implementation of telenursing.

\section{Recommendation and suggestion for further studies}

The need to improve health care through equitable distribution, enforcing PHC, increasing accessibility of expert nursing care, proper triaging of patients before referrals and reducing hospital visits, physician and nurses waiting list and transportation and its consequences in the Plateau and other states in Nigeria. Telenursing education and exposure for nurses should be employed. The practice of telenursing adequately linking the three tire of health system in Plateau need to be introduced. Funding, ICT tools, Man power development, and policy need to be in place through Government and other NGOs with interest in quality health care.

\section{Gaps in knowledge of telenursing and nursing practice}

Has led to argument on:

- Its acceptability for improving nursing practicing. 
DOI: 10.21522 /TIJNR.2015.03.02.Art001

ISSN: $2520-3126$

- Nursing care accessibility at all locations.

- Exposure to telenursing practice for nurses.

- Clinicians have been advised to ensure adequate utilization and training on telenursing. Caution should be applied in applying telenursing to prove nursing care.

\section{References}

[1].Adam D., Patricia R., Rita K., Linda F., Ellen E., Bonnie W., Anne E., Lancaster;http://online.liebertpub.com/doi/pdfplus/10.1089/tmj.2008.0021?src=recsys 28/1/17.

[2].Alexander, M. 1996. "Telemedicine in Australia. 1: The Health Communication Network." Journal Of Telemedicine and Telecare 2. http://jtt.sagepub.com/content/1/4/187.full.pdf 29/1/17z.

[3].Adewumi M.T. and Adekunle Y.A, (2013). Clinical Decision Support System for Diagnosis of Pneumonia in Children, International Journal of Advanced Research in Computer Science and Software Engineering Volume 3, issue 8 pg 40-43, www.ijarcsse.com.Retrieved 20/04/2016.

[4].Adeleke, I. T., Salami, A. A., Achinbee, M., Anamah, T. C., Zakari, I. B., \& Wasagi, M. H. (2015). ICT knowledge, Utilization, and Perception among Healthcare Providers at National Hospital Abuja, Nigeria. American Journal of Health Research. Special Issue: Health Information Technology in Developing Nations: Challenges and Prospects Health Information Technology. Vol. 3, No. 1-1, pp. 47-53. doi: 10.11648/j.ajhr.s.2015030101.17.

[5].Ajayi, I.A., (2010). Role of information and communication technology in health care delivery in Nigeria. International Professional Nursing Journal 71-10; 3 (1):19-25.American Psychological Association. (2007). APA style guide to electronic references. Washington, DC. Retrieved from http://www.worldcat.org/../162653855 on 14/4/2016 [6].American Telemedicine Association., (2010). TELEMEDICINE and e-HEALTH.

[7].Attewell, B. S. and Whitten, P., (2005). The diffusion of telemedicine: effect on educational practice. London; Oxford University Press.

[8].Bakken, S., Currie, L.M. and John, R., (2010). Information and communication technology infrastructure for evidence-based practice. In W.M. Holzemer (ed.) Improving Health through Nursing Research. Chichester: WileyBlackwell, 225-237.

[9].Bath, P.A., (2010). How ICT developments can support health care. British Journal of Healthcare Management 16(4), 5-9.

[10]. Bonnie W. Telenursing and Remote Access Telehealth Inger A.R., RN, Hilde S., Ida T.B., Dr.polit; Nursing Students' Perspectives on Telenursing in Patient Care After Simulation April 2015http://www.nursingsimulation.org/article/S1876-1399(15)00014-6/fulltext 29/1/17.

[11]. Bembridge, E., Levett-Jones, T., and Jeong, S. Y., (2011). The transferability of information and communication technology skills from university to the workplace: a qualitative descriptive study. Nurse Education Today, 31(3), 245-252. doi:10.1016/j.nedt.2010.10.020 [doi].

[12]. Covington, B., Koszalka, M. V., and Yocom, C. J., (2007). The use of technology to assist nurses in caring for patients. Retrieved from http://www.mbon.org/commision on 20/4/2016.

[13]. Daniel T.Telenursing: The Future Is Now.

[14]. Evaluation and Organizational Development, IFAS, University of Florida. PEOD-5.

[15]. Fairley, J. W., Computers in medicine. Journal of Royal Society of Medicine.1991; 84: 566 - 567.

[16]. Godlee, F., Pakenham-Walsh, N., Ncayiyana, D., Cohen, B., and Packer, A., (2004). Can we achieve health information for all by 2015? Lancet.2004; 364: 295-300.

[17]. Irinoye, O., and Fakunle, I., (2013). Nurses' Perception and Barriers to Use of Information Communication Technology in a Teaching Hospital in Nigeria. Retrieved from: https://www.researchgate.net/publication/249320391 on $16 / 4 / 2016$.

[18]. Karanbir, S., (2007). Computer for Nurses made easy. 2nd edition. New Delhi, India, Published by Jaypee Brothers Medical Publisher.

[19]. Israel, G. D., (1992). Sampling the Evidence of Extension Program Impact. Program

[20]. Lisa M., Williams., Olive D., Connie B., Glinkowski W., Pawłowska K., Kozłowska L. Telehealth and telenursing perception and knowledge among university students of nursing in Poland. 
[21]. Loretta S., Victoria E., Andrea D., Patient S. Telenursing, and Telehealth.

[22]. Leedy, P. D., and Ormrod, J. E., (2005). Practical Research Planning and Design, 5th ed, New Jersey: Pearson Merrill Prentice Hall.

[23]. Lewis, T., Synowiec, C., Lagomarsino, G. and Schweitzer, J. (2012). E-health in low and middle-income countries: findings from the Center for Health Market Innovations. Bulletin of the World Health Organization 90, 332-334.

[24]. Lipke, L., (2014). Nurses' Competence in Information and Communication Technology (ICT) Usage in Patient Care. Published by Helsinki Metropolia University of Applied Sciences. Retrieved from http://www.ICTLipke.pdf on 20/11/2015.

[25]. Molnar, K. and Sharda, R., (2005). "Using the internet for knowledge Acquisition in expert system development a case study" in journal of information technology. 1996; 11 (3): 44-51.

[26]. Nigeria National Health ICT Strategic Framework 2015-2020 // August 2015 Draft For Review. National Health Information and Communication Technology (Health ICT) Strategic Framework. Retrieved from http://www.national-health-ict-strategic.pdf on18/1/ 2016.

[27]. Nilsson, C., Skär, L. \& Söderberg, S., (2010). Swedish District Nurses' experiences on the use of information and communication technology for supporting people with serious chronic illness living at home - a case study. Scandinavian Journal of Caring Sciences 24, 259-265.

[28]. Olatokun, W. M., and Adeboyejo, O. C., (2009). Information and Communication Technology Use by Reproductive Health Workers in Nigeria: State of the Art, Issues, and Challenges. Human Technologists, 5 (2), 181207.

[29]. Oyekunle, R. A. and Afolayan, O. T., (2014). Availability, Accessibility and Frequency of Use of ICT Tools by Health Professionals in Ilorin Metropolis. Published by Covenant Journal of Informatics and Communication Technology (CJICT) Vol. 2, No.1.

[30]. Ozohu-Sulaiman, Y., (2006). Assessing the potentialities of traditional media and new communication technologies. A paper presented at the International Conference on Africa's Indigenous science and Knowledge system, Nasarawa State University.

[31]. Online (Home/Project Management/Lewin's Change Management Model)9/2/17.

[32]. Rouleau, G., Marie-Pierre G., \& Jose C., (2015) Impacts of information and communication technologies on nursing care: an overview of systematic reviews (protocol). Systematic Reviews DOI 10.1186/s13643-015-0062-y.

[33]. Sandhya G., Geetanjli K. Tele-nursing an Emerging Innovation in Health Sector.

[34]. Siinclair, Wynchank., Jill, Fortuin; Africa's Telenursing Today (and Tomorrow?, https://www.thinkmind.org/download.php?articleid=lifsci_v2_n34_2010_10 29/1/17.

[35]. https://nurseslabs.com/dorothea-orems-self-care-theory/ 6/2/17.

[36]. Villanueva, F. L., Hardey, M. J., \& Torrent, P. F., (2011). The Integration of Information and Communication Technology into nursing. Vol.80, Issue 2, pages 133-140. Retrieved from http://dx.doi.org/10.1016/j.ijmedinf.2010.001 on 20/4/2016.

[37]. Walker, L.O. and Avant, K.C., (2011). Strategies for Theory Construction in Nursing 5th Edition Boston: Prentice Hall.

[38]. Wallis, A., (2012). Survey Explores Nurses' Use of e-Health Tools. Nursing Management 18(10), 14-19.

[39]. Wheatley, B., (2013). Transferring care delivery through health information technology. Perm J. 2013; 17(1): 81-86.

[40]. Whetmore, E. J., (2006). Content and consequences of communication. 5Th edition California: Wardsward Puplishers.

[41]. While, A. and Dewsbury, G., (2011). Nursing and information and communication technology (ICT): A discussion of trends and future directions. International Journal of Nursing Studies 48(10), 1302 - 131.

[42]. Wojciech G., Katarzyna P,, and Lena K., Telemedicine and e-Health. July 2013, 19(7): 523-529. doi:10.1089/tmj.2012.0217.

[43]. World Health Organization, (2005). Department of essential health technologies, Information technology in support of health care. Geneva. Retrieved from: http://www.who.int/entity/eht/en/InformationTech.pdf on 10/3/2017. 
DOI: 10.21522 /TIJNR.2015.03.02.Art001

ISSN: $2520-3126$

[44]. http://online.liebertpub.com/doi/pdfplus/10.1089/tmj.2012.0196?src=recsys 28/1/17.

[45]. http://online.liebertpub.com/doi/pdfplus/10.1089/tmj.2012.0243?src=recsys 28/1/17.

[46]. http://online.liebertpub.com/doi/pdfplus/10.1089/tmj.2012.0011?src=recsys 28/1/17.

[47]. http://online.liebertpub.com/doi/pdfplus/10.1089/tmj.2008.0022?src=recsys 28/1/17.

[48]. https://academic.oup.com/cid/article/51/Supplement 2/S224/383896/Telemedicine-The-Future-of-Outpatient-

Therapy 29/1/17. 


\title{
Factors Associated with the Choice of Nursing Profession among First Year Students at Consolata Nkubu School of Nursing, Meru, Kenya
}

\author{
Article by Catherine Joan Kawira Mundi \\ Nursing, Texila American University, Kenya \\ E-mail: jkawiramundi@gmail.com
}

\begin{abstract}
The study was carried out between March and August 2017.The purpose of the study was to determine factors associated with choice of nursing profession among first Year students at Consolata Nkubu School of Nursing, Meru County, Kenya. The study adopted a cross-sectional design. The target population consisted of October 2016 and April 2017 classes. The total population during the year was 263 students. Census as a sampling method was used owing to the small sample population which was only 77 respondents'. 71 Self-administered questionnaires were distributed to the respondents who met the inclusion and exclusion criteria and 4 class representatives (Key informant) were interviewed using a checklist. The study reviewed that Majority of the students who joined the training were positive about nursing. A few students did not like nursing and were forced to join the profession. The result showed many students have changed their priorities and have settled on nursing profession after the introduction to the nursing curriculum. Given a second chance most (90\%) would still choose nursing as their career of choice. The researcher realized the need to sensitize the pupils and secondary school students on nursing profession through the media, career guidance and volunteer works to healthcare facilities. Generally the student nurses neither considered factors like well-paying career as the priority nor related to the occupation of the parents rather the desire to serve patients well was the greatest expectation after completing the course followed by advancing in the profession and desire to get a good job.
\end{abstract}

Keywords: Nursing, Profession, nurse, career, choice, associated Factors.

\section{Introduction}

The purpose of the study was to determine the factors associated with choice of nursing profession among the first year students pursuing nursing at Consolata Nkubu School of Nursing. Career has been considered as a profession which one trains and undertakes as permanent calling that entails activities and experiences encountered by an individual. Tomey and Alligood (1998), highlights that nursing as a unique function if the nurse is to assist the individual, sick or well, in the performance of those activities contributing to health or its recovery (or to peaceful death) that he would perform unaided if he had the necessary strength, will or knowledge.

Nursing education is the theoretical and practical training that is provided to nurses with the purpose of preparing them for the duties as nursing care professionals by nurses who are qualified and experienced for educational tasks (Allen, 2006).

Career choice entails a huge decision and it can be daunting. Paul (1996) clearly explains that career choices may be more difficult today than at any time in history, bearing in mind that there is infinitely more to choose from, and the levels of expectation are rising every other day. In fact, career choice involves life's decisions because it determines one's fulfillment, future happiness, income, choice of friends, dressing code, influence in society and the amount of risk to which a person is exposed to, just like a life partner and therefore it should not be a trial and error exercise.

Despite the increasing global workforce supply and demand as stated by The International council of nurses (WHO 2006 and Imison et al., 2009), there also exists a worldwide shortage of nurses in comparison with the required services (Attree et al., 2011). Therefore, it is understandable that most of the students are often not certain of their preference in choosing career choice, even in high school.

In reality, the shortages of nurses is experienced internationally so some motivating factors must be put in place for the crucial and satisfactions of performance in the chosen career, thus Law and Arthur (2003) shares a strong feeling that extrinsic factors such as parents, teachers, counselors, significant others, social influence, high salary and mass media and intrinsic pressures such as interest, ability, 
values altruistic reasons, physique and sex are also associated factors (MkhizeandNzimande.2007). According to the experience and the views of the researcher, nursing profession is filled with countless personal as well as professional rewards. Students choosing career in nursing need to understand that they are bound by the profession to spend their life giving and helping others since it is one of the flexible profession in the world. Nursing being an art and a science require compassion and caring expected to promote quality of life right from birth to death. As a career, nursing involves more of science than art and so it is often viewed as a vocation. As foreseen nurses shortage will continue more than before owing to the fact that people are living longer. Considering the many choices available for nurses after training, once the nurses qualify they do not experience difficulties in finding appointment to an entry level position due to significant shortage of nurses. Nurses work in a large variety of specialties where they work independently and as part of a team to assess, plan, implement, and evaluate care.

The perception of nursing students has a great impact on their self-esteem, self-concept, recruitment, performance and retention (Clare, 2007). According to Safadi, (2011), many students choosing nursing as a profession would imagine that being a nurse is just taking care of the patients, it is a fact that knowledge of technology, paper work and more stringent standards of care are also required which compels the nurses and nursing educators to assist students in the latest developments of caring, nurturing and critical thinking as well as acquiring latest knowledge in transformation through introduction of latest technological advances in healthcare systems.

Safadi ascertains that the perception of students on deciding to choose nursing profession as their career is highly influenced by the previous ideas about the career. Studies investigating the same showed that perception of the profession at the beginning of the programme the students had the idealistic where concepts of caring, compassion and nurturing but after exposure to the clinical experiences shifted to being more technical, documentation and procedural skills that must be acquired in the course of training and practice.

A careful analysis of this situation shows that the number of students that enroll for nursing as a training course is not as high as it should be, considering the level of demand for the nurses. This study focused on the factors that associated the choice of nursing as a profession in the Consolata Nkubu School of Nursing in order to explain the unmet demand for nurses in the country. While most studies related to the establishment of factors that determine career choice have been general about an individual and students at all levels of learning, this study's focus is on the students doing their first year academic studies at the Consolata Nkubu School of Nursing. The fact that the focus group is in their first year of study would go a long way towards getting factors that are academic-level specific when it comes to making conclusions about factors that influence career choice. The study will also come up with suggestions to improve quality nursing among newly qualified nurses as it is a concern for most of the administrators, owing to the fact that some of those joining nursing have different intentions or are pushed to do so, making it difficult to offer quality care to the patients especially the newly qualified nurses. An explanation of the choice of nursing as a profession among the students would go a long way into triggering an increase in the number of students pursuing nursing through careful strategic planning informed by the findings of this study.

Initially the respondents thought that nursing was a career with promising opportunities for advancement (27\%), was an interesting and exciting career (24\%), and provided availability of jobs (23\%), giving medicine and injections $(15 \%)$ while just a small percentage $3 \%$ and $1 \%$ respectively thought that it was a well-paying job and a dirty job. On the contrary some felt that they chose nursing because they did not have any other opportunity and at the same time some were forced to choose nursing and given a chance would shift to another career of their choice. Interesting enough a few respondents said nursing was a vocation / calling not just a career.

\section{Methods}

\section{Participants}

The target population in the study included a total of 77 first year students' pursuing nursing at Consolata Nkubu School of Nursing who were admitted in October2016 and April 2017 intakes. This includes 32 male students and 45 female students. Due to inclusion and exclusion criteria, a total of 75 students, 33 male students and 42 female students participated in the study. 


\section{Materials}

A three page questionnaire with well elaborated instructions for the participants was prepared and used for self-administration by the respondents and interview of the Key informants.

The respondents were briefed about the purpose of the study following an informed consent they were issued with numbered questionnaires. The key informants who included four class representatives, two male and two female students were informed about the intension of the interview. They were assured of the privacy of the information that was to be recorded through a mobile phone; they all agreed to take the process freely. For the purpose maintaining confidentiality and privacy they were given numbers as participant one to four. The interview took about thirty minutes.

\section{Procedure}

Permission to access the facility, students, space and equipment's was sought from the Administration of Consolata Hospital. Students were thoroughly explained and understood before agreeing to participate in the study. Students were assured of confidentiality. None of their names was to appear in any report instead identifiers were used. Census was used where 32 male students, 45 female students, among them 4 class representatives (Key informants) were interviewed. This was appropriate since the sample population was small. During data collection 71 students gathered and Self-administered structured questionnaires were distributed to them after obtaining their consent. $100 \%$ questionnaires were returned the same day. Key informants were interviewed using in one sitting and the participants give their answers without fear of intimidation or cohesion. After the process was completed, the students were thanked for their voluntary participation. Sick students were omitted in the study but were referred for attention to the relevant sections. Data from questionnaire was entered into SPSS version 18 for analysis. Descriptive statistics such percentages and fractions was used to describe the results. Presentation of the findings was done in form of tables, bar charts, pie charts and linear graphs as appropriate. The researcher used QSR International's NVivo 10 qualitative data analysis Software package for data from the key informant interviews. Data was organized and analyzed based on a theme (thematic analysis) which was developed from responses in relation to the study objectives. Findings were presented in verbatim form.

\section{Results}

Table 1. Gender of the students

\begin{tabular}{|l|l|l|}
\hline Gender & $\mathrm{n}=71$ & Percentage \\
\hline Male & 31 & $44 \%$ \\
\hline Female & 40 & $56 \%$ \\
\hline Total & 71 & $100 \%$ \\
\hline
\end{tabular}

Table 4 indicates that female were $56 \%$ while male students were $44 \%$.

Table2. Age distribution the students

\begin{tabular}{|l|l|l|}
\hline Age in years & $\mathrm{n}=71$ & percentage \\
\hline $17-23$ & 69 & $97 \%$ \\
\hline $24-29$ & 2 & $3 \%$ \\
\hline 30 and above & 0 & 0 \\
\hline Total & 71 & $100 \%$ \\
\hline
\end{tabular}

Table 2 Shows that most of the students were ranging between 17 to 23 years as presented by $97 \%$ of the respondents, while 24 to 29 years were $3 \%$ and none of the respondents was above 30 years of age. 
DOI: $10.21522 /$ TIJNR.2015.03.02.Art002

ISSN: $2520-3126$

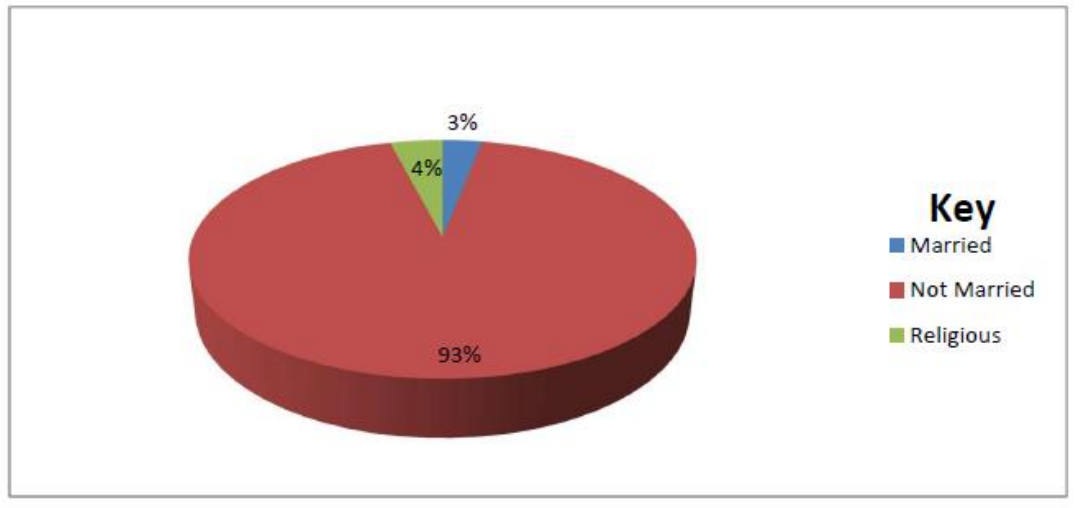

Figure 1. Marital status of the respondents

Figure 1 indicates that $93 \%$ of the respondents were not married, while $4 \%$ were religious and 3\% were married.

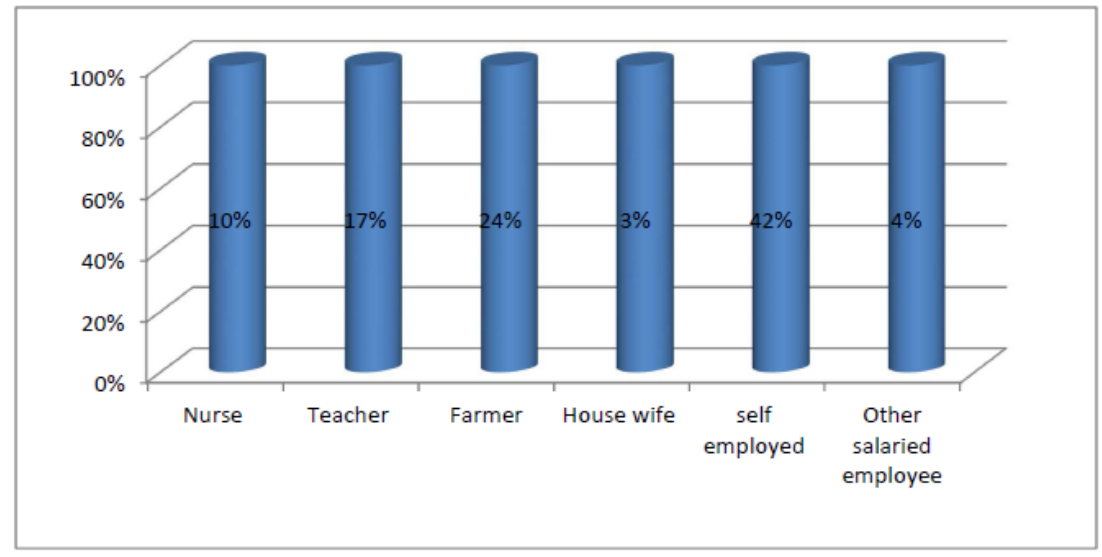

Figure 2. Occupation of the mothers

Figure 2 indicates that Mothers of 30\% (30) of the students were self-employed, 24\% (17) were farmers, $17 \%$ (12) were teachers, $10 \%$ (7) were nurses, $4 \%$ (3) fell under other salaried employees and $3 \%$ (2) were house wives.

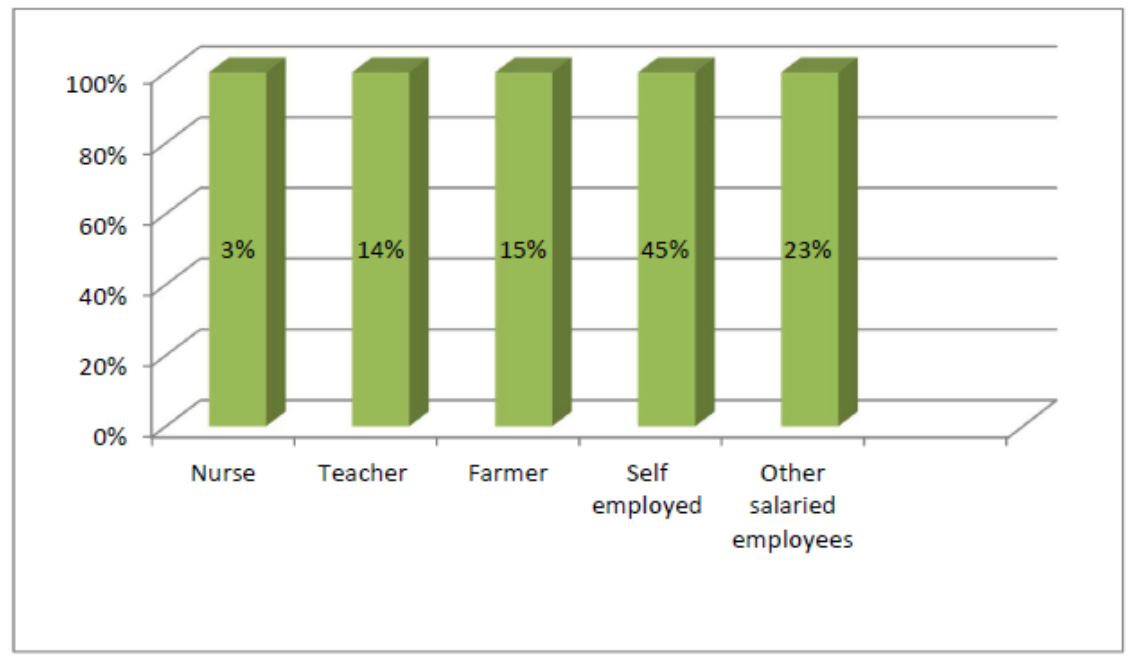

Figure 3. Occupation of the fathers

Figure 3 shows that Fathers $45 \%$ (32) to the students were self-employed, other salaried employees were $23 \%(16), 15 \%$ (11) were farmers, $14 \%$ (10) were teachers and $3 \%$ (2) were nurses. 
Table 3. Initial perception of the respondents about nursing

\begin{tabular}{|l|l|l|}
\hline & $\begin{array}{l}\text { Number of } \\
\text { respondents }\end{array}$ & $\begin{array}{l}\text { Percentag } \\
\text { e }\end{array}$ \\
\hline Well-paying career & 2 & $3 \%$ \\
\hline Dirty profession & 1 & $1 \%$ \\
\hline $\begin{array}{l}\text { Giving medicine and } \\
\text { injections }\end{array}$ & 11 & $15 \%$ \\
\hline Availability of jobs & 16 & $23 \%$ \\
\hline $\begin{array}{l}\text { Interesting and exciting } \\
\text { career }\end{array}$ & 17 & $24 \%$ \\
\hline Pathway for advancement & 19 & $27 \%$ \\
\hline Others & 5 & $7 \%$ \\
\hline Total & 71 & $100 \%$ \\
\hline
\end{tabular}

Table 3 reviews that varying responses were given by the respondents; pathway for advancement was the highest with $27 \%$, followed by Interesting and exciting career (24\%), availability of jobs $(23 \%)$ and $15 \%$ thought that nursing was about giving medicine and injections. On the contrary, nursing profession as a well-paying career carried only $3 \%$ while among others some respondents thought that nursing was a calling.

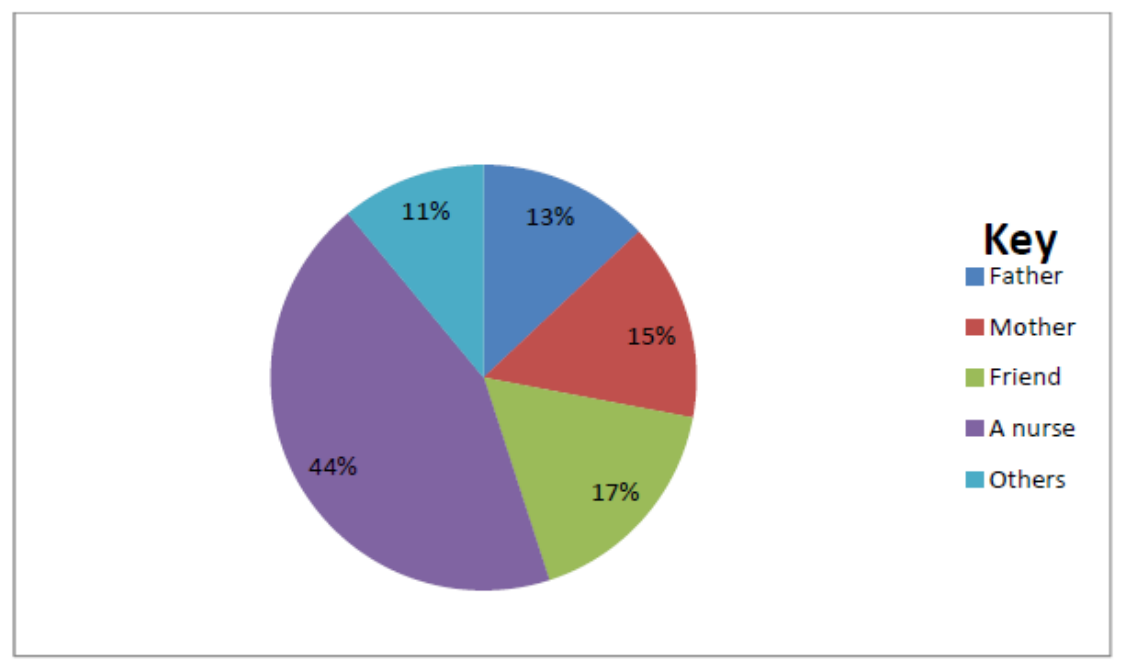

Figure 4. Role model of the respondents when choosing nursing as a profession

Figure 4 indicates that most of the role models to the students when choosing nursing were nurses accounting to $45 \%$, seconded by friends $17 \%, 15 \%$ were mothers, $13 \%$ from the fathers while $11 \%$ were from other family members.

Table 4. Factors associated with the choose nursing as your profession

\begin{tabular}{|l|l|l|l|l|}
\hline Associated factors & Yes & No & $\begin{array}{l}\text { No } \\
\text { response }\end{array}$ & Percentage \\
\hline Intrinsic & & & & \\
\hline My career of choice & $58(82 \%)$ & $5(7 \%)$ & $8(\mathrm{II} \%)$ & $100 \%$ \\
\hline $\begin{array}{l}\text { Ability to make contribution to } \\
\text { the society }\end{array}$ & $51(72 \%)$ & $5(7 \%)$ & $15(21 \%)$ & $100 \%$ \\
\hline Ability to help others & $57(80 \%)$ & $2(3 \%)$ & $12(17 \%)$ & $100 \%$ \\
\hline No other option & $3(4 \%)$ & $37(52 \%)$ & $31(44 \%)$ & $100 \%$ \\
\hline Extrinsic Factors & & & & \\
\hline Working opportunities & $42(59 \%)$ & $13(18 \%)$ & $16(23 \%)$ & $100 \%$ \\
\hline Parent(s) influence & $10(14 \%)$ & $49(69 \%)$ & $12(17 \%)$ & $100 \%$ \\
\hline Peer and friends & $10(14 \%)$ & $49(69 \%)$ & $12(17 \%)$ & $100 \%$ \\
\hline Career adviser/teacher's advise & $22(31 \%)$ & $32(45 \%)$ & $17(24 \%)$ & $100 \%$ \\
\hline
\end{tabular}


DOI: $10.21522 /$ TIJNR.2015.03.02.Art002

ISSN: $2520-3126$

\begin{tabular}{|l|l|l|l|l|}
\hline $\begin{array}{l}\text { Opportunities for advancement } \\
/ \text { promotion }\end{array}$ & $38(53 \%)$ & $19(27 \%)$ & $14(20 \%)$ & $100 \%$ \\
\hline Community respect for nurses & $35(49 \%)$ & $26(37 \%)$ & $10(14 \%)$ & $100 \%$ \\
\hline $\begin{array}{l}\text { The prestige attached to } \\
\text { profession }\end{array}$ & $37(52 \%)$ & $23(33 \%)$ & $11(15 \%)$ & $100 \%$ \\
\hline Job security & $27(38 \%)$ & $2(37 \%) 6$ & $18(25 \%)$ & $100 \%$ \\
\hline Opportunity to travel & $14(20 \%)$ & $37(52 \%)$ & $20(28 \%)$ & $100 \%$ \\
\hline
\end{tabular}

Table 4 indicates that the respondents' had a variety of choices on factors associated with the choice of nursing; career of choice was presented by (82\%), ability to help others (80\%), Ability to make contribution to the society (72\%), Working opportunities (59\%), Opportunities for advancement / promotion (53\%), prestige attached to profession (52\%) and 3\% had no other option apart from joining nursing among other choices.

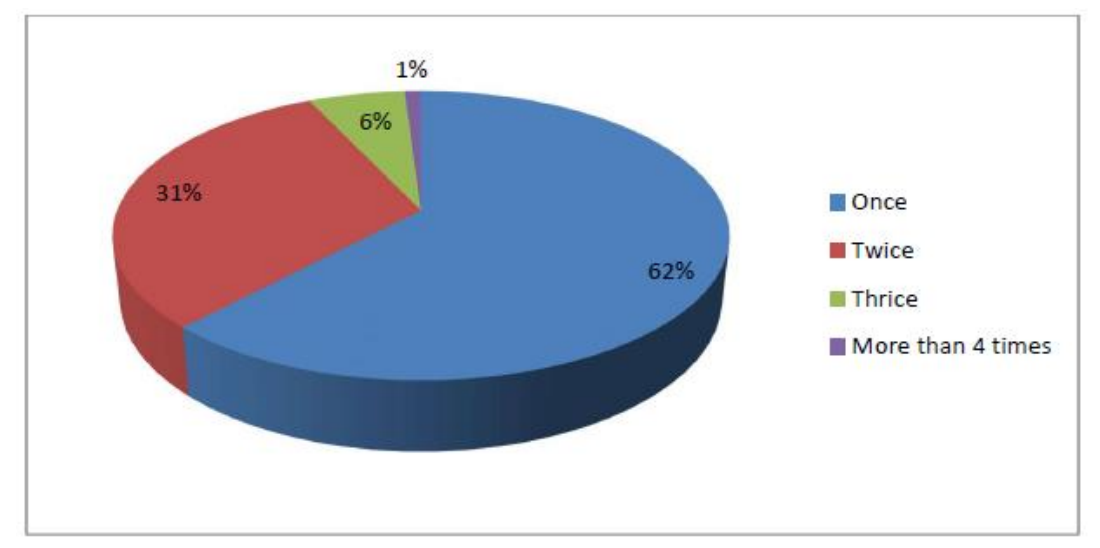

Figure 4. Trends in application for nursing before admission

Figure 4 implies that $62 \%$ of the students applied once, 31\% applied twice, $6 \%$ applied thrice whereas $1 \%$ of the students had applied more four times.

\section{Students' source of information about nursing career}

The respondents had different sources of information about nursing some had more than one sources. Generally the sources of information were: Books and pamphlets, Social media Personal interactions with the nurse(s), Career guidance teacher, as a patient, Parents/ relatives. The most common sources among the students at Consulate Nkubu School of nursing included personal interactions with nurses with a presentation of 40 respondents $(56 \%)$ followed by parents / relatives $16(23 \%)$ and social media $12(17 \%)$. Those who knew about nursing from career guidance teacher were $7 \%$ among other presentation. $3 \%$ did not respond to the question.

\section{Perception about nursing today}

The respondents had various perceptions from what they had before joining nursing. Among the choices were; It my career of choice, I don't like it, It is interesting and exciting, Given a chance I would choose another career and Am forced to do nursing. The highest percentage (77\%) perceived nursing as their career of choice, followed by $21 \%$ who felt that nursing was exciting and interesting, the rest were presented by $1 \%$. In addition $1 \%$ took it as a pathway for advancement while $3 \%$ did not respond to the question.

\section{Expectations of respondents after completing the nursing course}

The respondents had several opinions about their expectations after completing the nursing course as follows; to get a good job, to get a high salary, to advance in my career, to start my own clinic/hospital, to serve the patients well. Most of the respondents (52\%) expect to serve the patients well, $25 \%$ to advance in career, $13 \%$ to get a job, $8 \%$ to start their own clinics/ hospitals and $2 \%$ to get a job. Other purposes were to help the needy and to serve with dignity, while $3 \%$ were non responsive. 


\section{Interview of the key informants}

The key informants' interview of four class representatives reviewed that $100 \%$ of the participants ranged between 17 to 23 years of age and none of them was married. $50 \%$ of the mothers and fathers were farmers and nurses. Apart from availability of job opportunities and nursing being an interesting and exciting career, the participants also thought nursing was a vocation or a calling.

Out of the four participants only one expressed that nursing was not the career of choice. Majority choose nursing because of the ability to make contribution to the society and to help others; working opportunities; prestige attached to the profession, job security and opportunity to travel.

Given a chance to choose a profession after joining the profession all participants would choose the same profession. $50 \%$ of the participants applied once and twice respectively.

The expectation of majority of the participant after completing the nursing course is to get a good job, advance in career and to serve the patients well

\section{Discussion}

According to International Council of Nurses (2003), Nursing has emerged to be noble profession and nurses play a major role in the healthcare sector. It is true that there is an increase in shortage of nurses all over the world thus the need to recruit more nurses.

Despite the fact that nursing is believed to be the oldest profession, Florence Nightingale is believed to have played a major role in both nursing education and a central figure in the history of nursing. She fulfilled her dream by starting Nightingale School of nursing in the year 1869 (Booth, 2002), thus nurses are valued in the community as the advocates of the patients.

The total number of respondents who participated in the research (75), 71 voluntarily filled in the questionnaires while the four class representatives (key informants) were interviewed.

It was evident that $97 \%$ of the respondents were between the 17 to 23 years of age and $93 \%$ were not married.

The total population of female respondents was $56 \%$. Compared to male who were presented by $44 \%$ the same findings were reported by Romem and Anson (2005) that nursing is a more feminine career as opposed to males. This has been the perception since the era of Florence Nightingale and has been difficult to change in the minds of many people.

The study showed that the occupation of the parents did not necessarily change the knowledge and attitude of the participants since most of the parents were self-employed as reported by the respondents; Fathers of $45 \%$ and $30 \%$ of the mother of the students were self-employed as compared to those who were nurses, $10 \%$ (7) of the mothers and only $3 \%$ of the fathers were nurses.

Initially the respondents thought that nursing was a career with promising opportunities for advancement as presented by $(27 \%)$, was an interesting and exciting career $(24 \%)$, provided availability of jobs (23\%), giving medicine and injections (15\%) while just a small percentage $3 \%$ and $1 \%$ respectively thought that it was a well-paying job and a dirty job. On the contrary some felt that they chose nursing because they did not have any other choice and at the same time some were forced to choose nursing. Interesting enough a few respondents said nursing was a vocation / calling not just a career.

Despite the fact that most of the parents were not nurses by profession most of the students had encountered nurses as their role models in choosing nursing profession as presented by $45 \%$ of the respondents among many other choices, seconded by friends (17\%).

Majority of the respondents pointed out many factors associated with their choice of nursing but the frequently chosen were; career of choice $(82 \%)$, ability to help others $(80 \%)$, Ability to make contribution to the society (72\%), Working opportunities (59\%), Opportunities for advancement /promotion (53\%), and the prestige attached to profession (52\%) among other choices. Even with different knowledge and attitude initially, given a second chance, $(90 \%)$ would still choose nursing.

It was clear that the highest percentage (62\%) were admitted after the first interview, $22 \%$ after applying twice and $1 \%$ after attempting three times.

According to the study findings, it is evident that the idea of helping others people after training plays a significant role for the students in choosing profession. The same findings were identified from several studies that indicated that students choose nursing in order to serve the patients better. 


\section{Conclusions}

It was pointed out that majority of the students learnt about nursing profession through personal interaction with a nurse and yet nurses were the role models for many students who joined nursing. Factors associated with choice of career for many students were career of choice, Ability to make contribution to the society, ability to help others, working opportunities for advancement / promotion, and the prestige attached to profession. Even with different knowledge and attitude initially, given a second chance many would still choose nursing.

Despite the fact nursing was not a career of choice for few respondents and were forced to join the profession; majority $(90 \%)$ would still choose nursing as their profession for varying reasons. Therefore the perception of nursing changed after joining the training and $77 \%$ of the respondents have settled on nursing as their career of choice, $21 \%$ as an interesting and exciting job while the other percentage feel that nursing is not their career, they don't like nursing and also were forced to do nursing.

Generally the student nurses neither considered factors like well-paying career as the priority nor related to the occupation of the parents rather the desire to serve patients well was the greatest expectation after completing the course followed by advancing in the profession and desire to get a good job.

\section{Acknowledgement}

I acknowledge all who assisted me in any way to complete this manuscript. Rev. Sr. Adelina M. Muguna and her council member for their moral and financial support ,special thanks to Dr. Joseph Mutai for expertise support all through my study, Consolata Hospital Director, Rev. Fr. Silas and all study participants in a particular first year nursing students at Consolata Nkubu School of nursing. This manuscript was a requirement for the Master in Nursing at Texila American University, God blesses the University team for assisting me to grow in my career, special thanks to the Course Coordinator Madam A. Mary Jenitta and all other Coordinators who have supported me in the course of my studies.

\section{Recommendations}

1. School teachers and counselors need to be sensitized on nursing career in order to be able to give career guidance to the young people.

2. For publicity of the profession, the nursing profession requires interaction with the media and general public.

3. The secondary school students should be given opportunities to do volunteer works the healthcare facilities to assist them cultivate positive attitude towards nursing career

4. Since the role model in choosing nursing was a nurse and the sources of information was through interaction with nurse(s), nurses should handle their career with a lot of love and dedication, when treating the patients to avoid discouraging the young people from choosing nursing.

5. Nurses also need to have educative programmers in schools for example school health services to create a positive image towards nursing among the school going students.

\section{References}

[1].Allen, M., Allison, M. M., and Stevens, S. (2006). Mapping the literature of nursing education. Journal of the Medical Library Association, 94.

[2].Attree, M., Flinkman, M., Howley, B., Lakanmaa, R-L., L ima-Basto, M., \& Uhrenfeldt, L. (2011). A review of nursing workforce policies in Five European countries: Denmark, Finland, Ireland, Portugal and United Kingdom.

[3].Booth, R.Z. (2002).The nursing shortage: A worldwide problem. Revisto Latino-Careers in Nursing. A world of opportunities (2017) 10 Reasons Why You Should Choose Nursing. Registered Nurses Association of Ontario

[4].Clara B. Wallace (2007) Nursing students' perceptions of the public image of nursing. A Dissertation Presented in Partial Fulfillment of the Requirements for the Degree Doctor of Philosophy, Capella University. Conversion among student nurses. In A Sociology of Medical Practice (Cox, C. \& Mead, A. Ed). Macmillan, London, pp.116-131. 
Texila International Journal of Nursing Volume 3, Issue 2, Dec 2017

[5].Imison C, Buchan J, Xavier S (2009). NHS Workforce Planning: Limitations and possibilities. London: The King's Fund.

[6].International Council of Nurses. (2003). Global issues in the supply and demand of nurses. SEW News January- March. Retrieved July 17, 2006.

[7].Law W, Arthur D (2003) what factors influence Hong Kong school students in their choice of a career in nursing? International Journal of Nursing Studies 40: 23-32.

[8].Matejski, M. P. (1981). Nursing education, professionalism, and autonomy: social constraints and the Goldmark Report. Advances in Nursing Science, 3(3), 17-30.

[9].Mkhize S, Nzimande S (2007) Career choices in relation to nursing. Cross-sectional descriptive study investigating the career choices of school leavers in relation to nursing and what influences these choices. Report prepared by research programme of Health Systems Trust.

[10]. Paul, S. (1996). The Top 10 Steps for Choosing a Career. Retrieved September 24, 2008, from http://topten.org/public/AB/AB6.html.

[11]. Romem P. and Anson O. (2005) Israeli men in nursing: social and personal motives. JNurs Manag 13: 173 178.

[12]. Safadi, R.R., Saleh, M.Y. M., Nassar, O.S., Amre, H. M., Froelicher, E.S., 2011. Nursing Students perceptions of nursing: a descriptive study of four cohorts. International Nursing Review oct.2011 p.p.54.

[13]. Tomey, A. M., \& Alligood, M. R. (1998). Nursing theorists and their work (p. 102). St. Louis: Mosby.

[14]. World Health Organization (2006).World Health Report: Working Together for Health [PowerPoint Slides]. 


\title{
Nurses' Leadership Style in Tertiary Care Hospitals
}

\author{
Article by Nauman Q. Godfrey \\ MSN-Texila American University, M.Sc Psychology (Clinical), Pakistan \\ E-mail: enqamar@hotmail.com
}

\begin{abstract}
The present study showcases the leadership style of head nurses of Tertiary Care Hospitals in Pakistan (Lahore). Purpose is to see that what type of leadership style is mostly practiced / adapted. For data collection, quantitative methods are employed that includes a scale LPS (least preferred coworker scale) and checklists to assess head nurses that either they are relationship motivated or task motivated. Two lists were made named as A and B for getting data about autocratic and democratic style respectively. Total sample from the populating of nurses and head nurses was $65(n=65)$ among which 18 are head nurses and 47 are charge nurses. From 18 head nurses 3 are task motivated (17\% of total sample), 13 are relationship motivated (72\% of total sample) and 2 are mixed of mixed leadership style $(11.1 \%$ of total sample). The checklists revealed similar findings that remained consistent further strengthening the results. It was concluded that Democratic Leadership Style is most rampant in Tertiary Care Hospitals. The head nurses are very encouraging and they appreciate every creative idea from their colleagues. They promote collaborative work. They support every initiative taken for the betterment. The head nurses of Tertiary Care Hospitals share the decision making and problem-solving responsibilities with their colleagues. Charge nurses develop a greater sense of selfesteem due to importance given to their ideas and contribution.
\end{abstract}

Keywords: Nurse. Tertiary Care. Hospitals. Leadership. Styles.

\section{Introduction}

Leadership in nursing is an art, a science, an ambition. It is based on personal qualities, on strategic skills and also on the will to change the course and outcomes. It can occur in all clinical positions performed by a nurse. Nurses are the backbone of any healthcare system. This is the utmost reality and is the most significant statement that is heard almost all the time when talking about nurses and nursing profession. Leadership is generally associated with personal qualities. However, it is increasingly mentioned that it is also a professional competence. Therefore, it makes it mandatory to analyze the strengths and weaknesses of what is important to us and nursing profession. The present study is the leadership style of head nurses of Tertiary Care Hospitals in Pakistan (Lahore). Purpose is to see that what type of leadership style is mostly practiced / adapted.

For a national impact, it is necessary to invest places of power or influence, both within the profession and outside. In France, the order of nurses is weak and marginalized. Trade unions are strong, but they are opposed to the evolution of the profession; they are responsible for the status quo that prevails within the nursing discipline. Some nursing associations are present in the field, but lack visibility and dynamism. In Canada, within the nursing profession, clinical leadership is increasingly valued. It involves not only technical skills and a developed ethical sense, but also an ability to innovate and change care practices. This innovative leadership can coexist with multidisciplinary. In this way, the leader nurse conceives his / her role as a caregiver beyond care and dares to propose changes in practice, speak out, advocate for the interests of patients, take his place in the interdisciplinary team and define himself as an expert in care. Nursing leadership can be measured in terms of its area of influence from expert practitioners and reflective practitioners to the opinion leader and transformation agent of society. 
DOI: $10.21522 /$ TIJNR.2015.03.02.Art003

ISSN: $2520-3126$

\section{Methods}

Cross-sectional research design is used to carry out the research and it was hypothesized that nurses have the democratic style of leadership. The population included the head nurses and charge nurses of the tertiary care hospitals of Lahore, Pakistan and a sample of 65 nurses is selected for this study. Out of which 18 are head nurses and rest of the sample of 47 is collected systematically from sub-ordinates of each head nurse to get a fully represented sample. The research instruments include meticulously formulated checklist and least preferred co-worker scale. Which is interpreted as, if score is 73 or above, the person is a "relationship-motivated" leader; if score is 64 and below, the person is a "task-motivated" leader. If score is between 65 and 72, it's a mixture of the two.

\section{Results}

Scores of head nurses on least preferred coworker scale

\begin{tabular}{|c|c|c|c|c|c|c|c|c|c|c|c|c|c|c|c|c|c|c|}
\hline Sr. \# & 1 & 2 & 3 & 4 & 5 & 6 & 7 & 8 & 9 & 10 & $\begin{array}{l}1 \\
1\end{array}$ & $\begin{array}{l}1 \\
2\end{array}$ & 13 & $\begin{array}{l}1 \\
4\end{array}$ & $\begin{array}{l}1 \\
5\end{array}$ & 1 & $\begin{array}{l}1 \\
7\end{array}$ & $\begin{array}{l}1 \\
8\end{array}$ \\
\hline LPC & 4 & 9 & 8 & 10 & 6 & 11 & 9 & 10 & 9 & 10 & 7 & 7 & 12 & 9 & 8 & 8 & 7 & 6 \\
\hline $\begin{array}{l}\text { Scor } \\
\mathrm{e}\end{array}$ & 0 & 9 & 1 & 0 & 9 & 7 & 0 & 0 & 0 & 3 & 5 & 1 & 7 & 0 & 4 & 7 & 2 & 3 \\
\hline
\end{tabular}

Possible highest score of each individual $=144$ Possible lowest score each individual $=18$

Score of 73 or above $=$ Relationship-motivated Score of 64 and below $=$ Task-motivated

Score between 65 and $72=$ Mix of both

Mean $=1558 / 18$

Total score $=1558$

$=86.56$

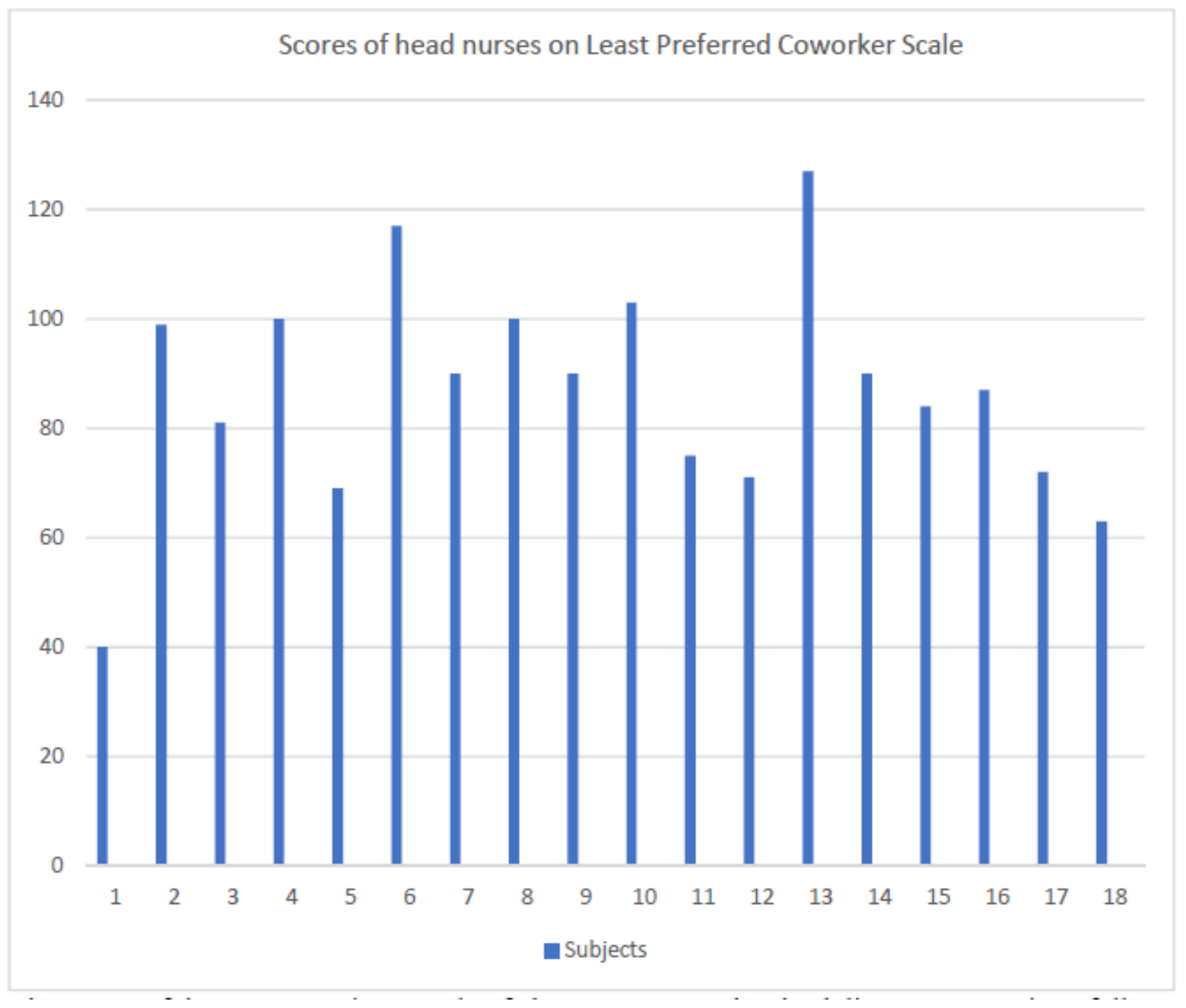


The scores of the representative sample of charge nurses on the check list " $A$ " \& "B" is as follows.

\begin{tabular}{|l|l|l|l|l|l|l|l|l|l|l|l|l|l|l|l|l|l|l|l|l|l|l|}
\hline Sr. \# & 1 & 2 & 3 & 4 & 5 & 6 & 7 & 8 & 9 & 10 & 11 & 12 & 13 & 14 & 15 & 16 & 17 & 18 & 19 & 20 & 21 & 22 \\
\hline List A & 6 & 7 & 8 & 4 & 2 & 2 & 7 & 7 & 7 & 8 & 5 & 7 & 4 & 9 & 6 & 5 & 9 & 9 & 6 & 5 & 6 & 4 \\
\hline List B & 7 & 8 & 4 & 7 & 10 & 10 & 4 & 9 & 9 & 10 & 7 & 7 & 7 & 8 & 10 & 1 & 4 & 5 & 9 & 9 & 10 & 3 \\
\hline
\end{tabular}

\begin{tabular}{|l|l|l|l|l|l|l|l|l|l|l|l|l|l|l|l|l|l|l|l|l|l|l|l|}
\hline 23 & 24 & 25 & 26 & 27 & 28 & 29 & 30 & 31 & 32 & 33 & 34 & 35 & 36 & 37 & 38 & 39 & 40 & 41 & 42 & 43 & 44 & 45 & 46 \\
\hline 7 & 4 & 3 & 9 & 5 & 6 & 2 & 2 & 7 & 5 & 3 & 3 & 7 & 5 & 7 & 5 & 2 & 4 & 2 & 5 & 4 & 5 & 6 & 1 \\
\hline 8 & 10 & 10 & 10 & 4 & 6 & 8 & 9 & 9 & 5 & 7 & 10 & 10 & 6 & 9 & 1 & 10 & 7 & 6 & 5 & 10 & 5 & 10 & 10 \\
\hline
\end{tabular}

Possible highest score on checklist $=10$ High score on checklist $\mathrm{A}=$ Autocratic Equal score on either checklist $=$ Mix of both Total score on checklist $\mathrm{A}=257$

Mean score on checklist $A=257 / 47=5.4$
Possible lowest score on checklist $=0$

High score on checklist $\mathrm{B}=$ Democratic

Total score on checklist $\mathrm{B}=276$

Mean score on checklist $B=276 / 47=5.8$

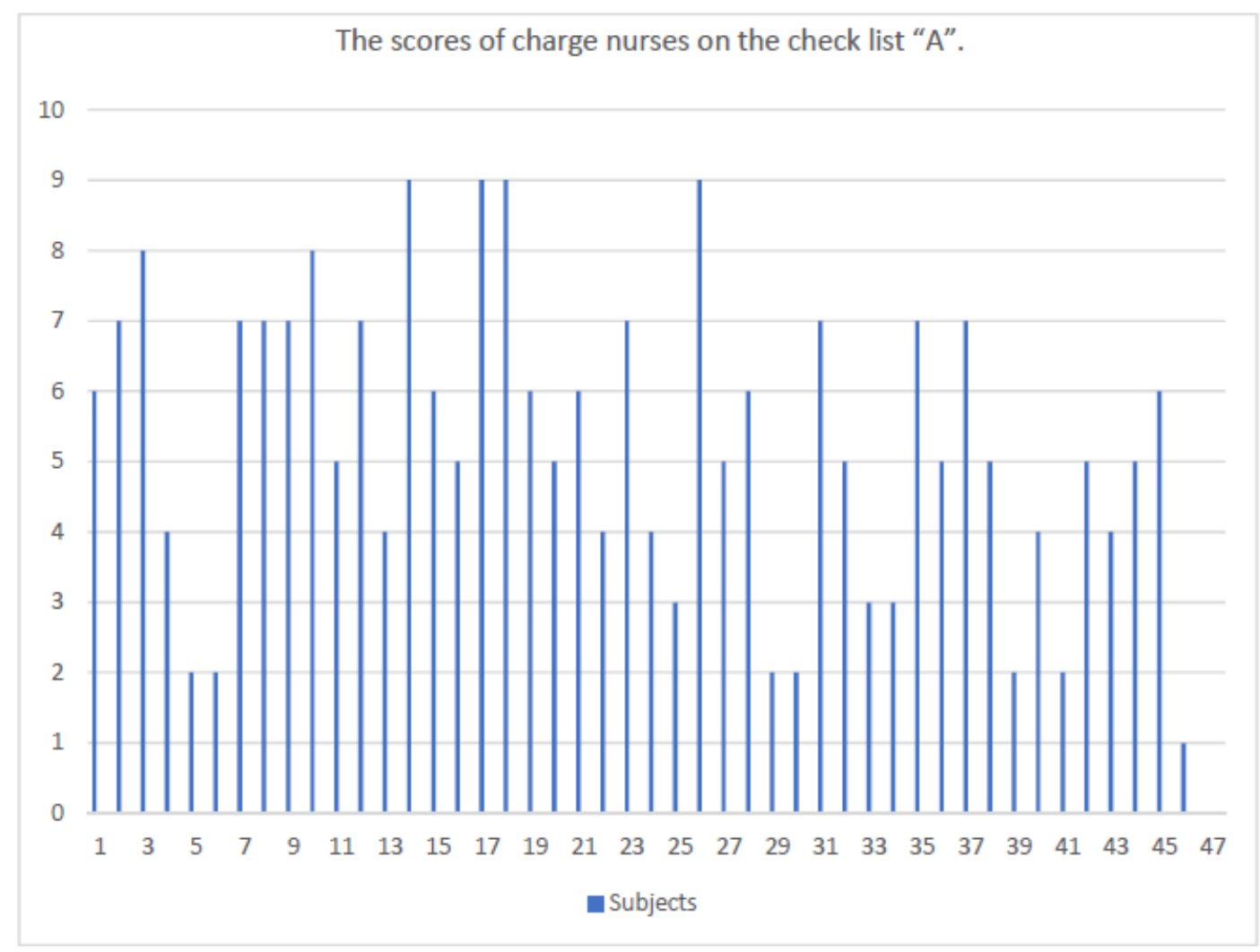


DOI: 10.21522 /TIJNR.2015.03.02.Art003

ISSN: $2520-3126$

The scores of charge nurses on the check list " $\mathrm{B}$ ".

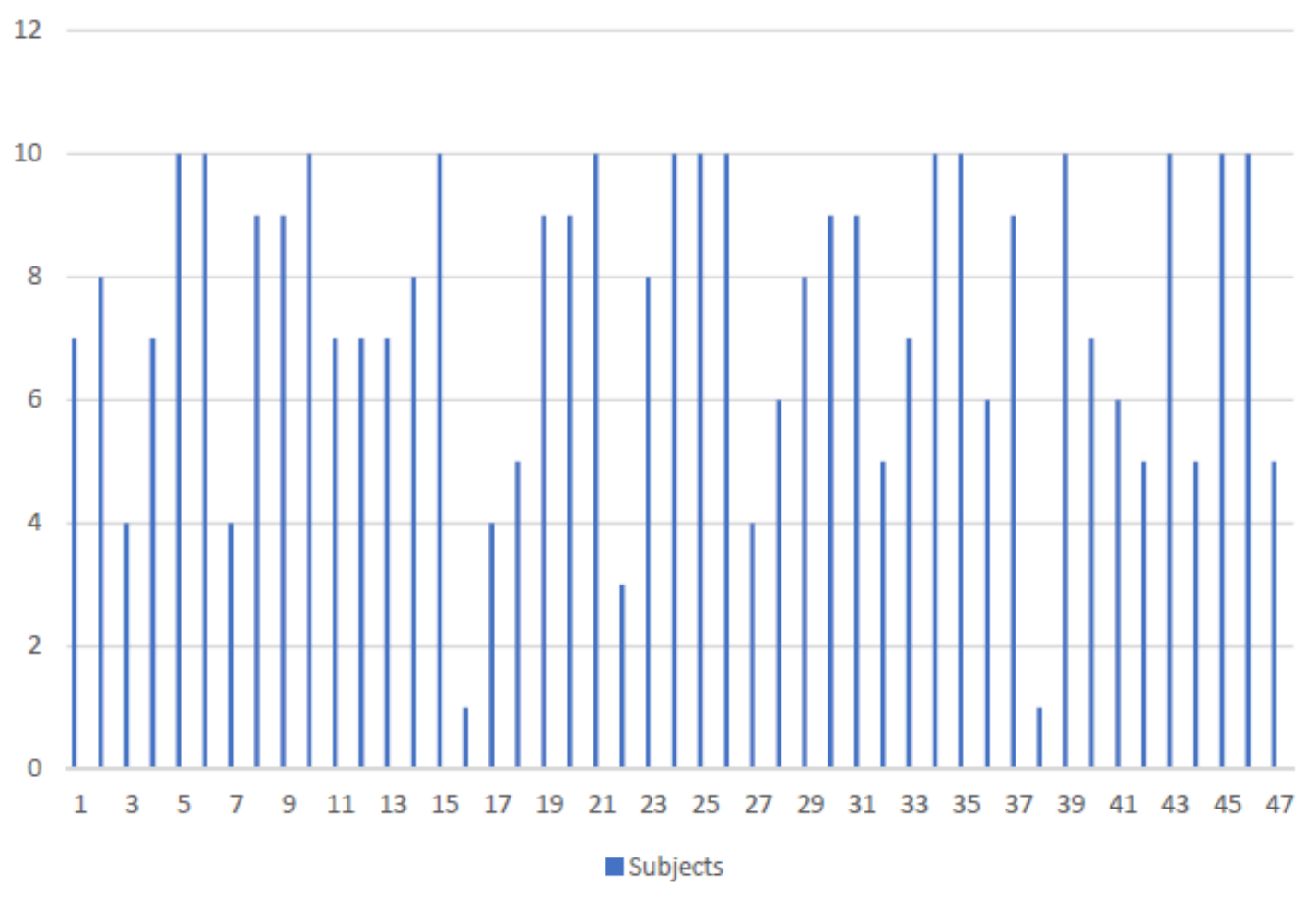

\section{Discussion}

The present study is about the leadership styles of head nurses in tertiary care hospitals. Carrying out this study \& by using observation skills, scale \& checklists it was revealed by results that Democratic leadership style is most pertinent to all head nurses in tertiary care hospitals. Democratic leadership style is the most effective style, group members are encouraged to share ideas and opinions, members of the group feel more engaged in the process. Creativity is encouraged and rewarded. Democratic leadership style leads to higher productivity. In democratic leadership staff will readily accept policies and decision that were conveyed by the head nurses.

When nurses are familiar with leadership theories, they can select and adapt the most appropriate proposals to deal with different situations. As a model, the Nursing leader can reduce the autocratic atmosphere and therefore, some conflicts of functions. Leaders do things right, accept the challenge of change, focus on goals and have a marked time in the future. They ask why and use strategies based on trajectories towards human potential. On the other hand, managers do things right, opt for continuity, and focus on current structures and procedures. They ask who, what, when, where and how because they use programs to reach the destination and evaluate human performance.

The different theories on leadership. The theory of the great man: this theory holds that a few people are born with the characteristics necessary to be great. They are very mature and simultaneously demonstrate an instrumental and support leadership behavior. Instrumental activities include the planning, organization and control of the activities of subordinates to achieve the objectives of the organization. Support leadership is socially oriented and allows subordinates to participate and consult on decisions that affect them. People who use both leadership, instrumental and support behaviors are considered "great men" and are supposed to be effective leaders in any situation. Many consider this theory unattractive since it states that leaders are born and are not made.

Theory of the Charism: People can be leaders because they are charismatic, which is a quality by which, with their presence alone. They make others feel better. The charismatic leader inspires by gaining the emotional commitment of the followers awakens strong feelings of loyalty and enthusiasm. Through this type of leadership, obstacles can be overcome that were believed insurmountable, however, because the charisma is so vague, some can perceive it while others do not. Charismatic 
leaders believe strongly in their opinions, have great self-confidence and the need for power. Followers of charismatic leaders trust the leader's opinions, have similar judgments, show affection, obedience and unquestioning acceptance towards the leader and are emotionally involved, so they feel they can contribute to the mission. The problem lies as we have mentioned earlier in that not all people perceive the charismatic leader in the same way.

Trait Theory: Until the mid-1940s, feature theory was the basis for most leadership research. Early studies in this area maintained that traits were hereditary, but later theories indicated that traits could be acquired through learning and experience. Researchers identified the following leadership traits: energy, strength, enthusiasm, ambition, aggressiveness, self-confidence, self-confidence, sympathy, affection, honesty, fairness, loyalty, security, technical mastery, and instructional ability. It is from the combination of these characteristics that arise the different types of leadership more known.

Autocratic: the autocratic leader makes the decisions alone by relying on the authority that provides his position. The management is exercised by issuing orders and waiting for compliance. They tend to be directive, critical and punitive. They are attributed a situation higher than the members of the group, which diminishes open communications and confidence. They also retain responsibility for all goals and decision making. Tend to a good performance, quantitatively and qualitatively, but under autonomy creativity or self-motivation; this is usually appropriate in emergency situations, when the leader knows what to do, but does not encourage people. The motivation is done by sanction / reward.

Participatory: The boss proposes different alternatives to the group that asks for an opinion, although the boss is ultimately the one who decides.

Democratic: Democratic leaders maintain less control, rather than asking for results, ask questions and suggestions, and involve the group in planning, problem-solving, and decision-making. Participation has to increase motivation and creativity. They work when people have knowledge and skills and work well as a team. It can be uncomfortable. It is often less effective than autocratic control.

Laissez faire or liberal: it consists of a very permissive, non-directive, passive and inactive type of leader. The person in charge has a role of mere facilitator of the team work, giving him information, but it is the subordinates who make the decisions. Group members can work independently and possibly with misunderstandings because there is no planning or coordination and little cooperation. Chaos may occur unless an informal leader emerges. This style can work with very mature and self-employed workers, but it is more likely to be ineffective and unproductive.

\section{Conclusion}

The mean score of 86.56 on LPC Scale reveals that head nurse's relationship oriented. The checklists revealed similar findings that remained consistent further strengthening the results. It was concluded that Democratic Leadership Style is most rampant in Tertiary Care Hospitals. The head nurses are very encouraging and they appreciate every creative idea from their colleagues. They promote collaborative work. They support every initiative taken for the betterment. The head nurses of Tertiary Care Hospitals share the decision making and problem-solving responsibilities with their colleagues. Charge nurses develop a greater sense of self-esteem due to importance given to their ideas and contribution. Leadership styles towards staff nurses show significant effects of productivity efficiency and reflects positive or negative patient outcome.

Leadership characteristics. Vision. An idea or perspective of the future and potential opportunities. From it results the purpose or the main reason of being of the organization (the mission), and the goals that establish its general direction. The vision must influence everyone who works in the organization. Vision means long-term thinking; look beyond the present day or the next few months, beyond the horizon. It means considering how other factors in the organization's environment can influence the organization and its future. Influence. The ability to contribute to change the thinking and behavior of others or create new policies or legal texts that will be important for the future. It may also mean (for nurse leaders) to influence the general managers of health services and make contributions to overall management decisions and policies. Motivation. Demonstrate commitment and energy to work for the realization of the vision and the achievement of the goals. Generate in others an enthusiasm, commitment and sense of purpose before shared goals, and a motivation to achieve them. Trust. Build trust in others by clearly outlining strategies for vision, and be sure that those strategies are appropriate. 
DOI: 10.21522 /TIJNR.2015.03.02.Art003

ISSN: $2520-3126$

Leaders have the ability to draw people toward shared goals. They have confidence in themselves and in what they are doing. Political competence. Understand and accept different goals and behaviors of different stakeholder groups. Understand the connections between the different events and influences that have an impact on the organization. Plan strategies to respond effectively to these influences. Select and use the best combination of talents in your team, to help achieve different goals. Review and change. "Renewal" means that processes and structures of the organization are not always accepted as they exist, rather they are reviewed in response to an assessment of results or changing needs. Turn problems into opportunities.

\section{References}

[1]. Careers, Finance and Investing. Money-zine.com. Retrieved March 16, 2012.

[2]. Coombs, M. \& Dilon, A. (2002). Crossing boundaries, re-defining care: the role of the critical care outreach team. Journal of Clinical Nursing, 11(3), 387-393.

[3]. Ericksson, J. \& Ditommassi, M. (2005). The clinical Nurse Leader: New in Name Only. J Nurs Educ, 44(3): 99-100.

[4]. Erben and Guneser, Gul and Ayse (November 2008). "The Relationship Between Paternalistic

[5]. Foster, D.E. (2002). "A Method of Comparing Follower Satisfaction with the Authoritarian, Democratic, and Laissez-faire Styles of Leadership." Communication Teacher 16 (2): 4-6.

[6]. Johnson, C. E.; Hackman, M. Z. (2003). Leadership, a communication perspective (4 Ed.). Waveland Press. p. 38. ISBN 9781577662846.

[7]. Leadership and Organizational Commitment: Investigating the Role of Climate regarding ethics". Journal of Business Ethics 82 (4): 955-968. Retrieved 12/1/2012.

[8]. Leadership Styles - Autocratic, Laissez Faire, Participative and Bureaucratic". Management Study Guide. Retrieved 19 March 2012.

[9]. Martindale, N (2011). "Leadership Styles: How to handle the different personas". Strategic Communication Management 15 (8): 32-35.

[10]. McCallin, A. (2003). Interdisciplinary team leadership: A revisionist approach for an old problem. Journal of Nursing Management. 11, 364-370.

[11]. McCallin, A. (1999). Pluralistic dialogue: a grounded theory of interdisciplinary practice. The American Journal of Rehabilitation Counselling, 5(2), 78-85.

[12]. Nelson, E., Batalden, PB, Huber, TP., Mohr, JJ., Godfrey, MM., \& Headrick, LA. (2002). Microsystems in health care, Part I: Learning from higher performance frontline clinical units. J Qual Improv. 2002; 28(9): 472493.

[13]. Porter-O'Grady, T. (2000). Vision for the 21st century: new horizons, new health care. Nursing Administration Quarterly, 25(1), 30-38.

[14]. Rowold, Jens; Schlotz, Wolff (Spring 2009). "Transformational and Transactional Leadership and Followers' Chronic Stress". Leadership Review (Kravis Leadership Institute) 9: 35-48.

[15]. Schultz \& Schultz, Duane (2010). Psychology and work today. New York: Prentice Hall. pp. 201-202. ISBN 0-205-68358-4.

[16]. Styles of Leadership". Assortment. Retrieved March 16, 2012.

[17]. Sabo, JA. Combere, PC. Rusch, A., \& Wilson, W. (2005). Developing an Outcome-based Multidisciplinary Care Planning Tool: Process and Outcome. J Nurs Care Qual 20(2). 145-155.

[18]. Scott, L. (2005). Shared governance and shared leadership: meeting the challenges of implementation. Journal of Nursing Management, 13, 4-12.

[19]. Tornabeni, J., Stanhope, M. \& Wiggins, M. (2006). Clinical Nurse Leader Evolution of a revolution. The CNL Vision. JONA. 36(3). 103- 108.

[20]. Woods, A.P. (2010). "Democratic leadership: drawing distinctions with distributed leadership". International Journal of Leadership in Education 7 (1): 3-36.

[21]. Wilson, N.L. \& Gleason, M. (2001). Team roles and leadership. In Interdisciplinary team leadership: A revisionist approach for an old problem. McCallin. 


\title{
Knowledge and Use of Standardized Nursing Languages: A Study among Nurses at the Federal Medical Centre, Owo, Ondo State, Nigeria
}

\author{
Article by Abiodun-Sanni Falilat Iyabode \\ Texila America University, Guyana, South America \\ E-mail: iyabode.faith@yahoo.com
}

\begin{abstract}
The Standardized Nursing Languages (SNLs) is a new innovation in nursing which is aimed at improving the standard of nursing practice and the professionalism of Nursing. This study was carried out to know the level of knowledge and utilization of Standardized Nursing languages among nurses at the Federal Medical centre Owo. It was aimed at identifying nurses familiarity with the Language, their level of knowledge, use in patient care and also to identify the possible barriers that might prevent the use of the Language in Practice. The use of SNLs is still not gaining popularity among nurses in this tertiary institution, despite its formal introduction to Nigeria since 2010, hence the need for this research work.

A descriptive/correlational design was employed using a self-structured questionnaire. A sample size of 250 nurses was targeted and sampled using a non-probability technique. The data was entered using the SPSS software and analysis done using tables of frequency and percentage, mean and standard deviation, chi test, Pearson correlation where necessary.

Result showed that nurses have a poor knowledge of SNLs. They are mostly familiar with NANDA. The major method of documentation was paper as they have no computer system in their unit. 54\% of respondents use SNLs at work most of which are not correct based on the responses given. Correlation showed that there is no significant difference between years of experience, qualification of nurses and their knowledge of SNLs. ( $p>0.05)$. The major challenges identified by the respondents include poor knowledge of the language, lack of basic amenities, poor policy, inefficient continuous education, shortage of manpower.

High quality nursing documentation promotes effective communication in the healthcare team, which facilitates continuity and individuality of care. The use of SNLs promotes quality nursing documentation and enhances the visibility of the contribution of nursing to patient care.
\end{abstract}

Keywords: Standardized Nursing Languages, Knowledge, Practice, NANDA-I, NIC, NOC.

\section{Introduction}

The changing mode of delivering health care has brought about the need to provide consumers of care with high quality services i.e. Client/patient centered care that is safe, based on best available evidence with quality indicators and clinical outcomes. Nursing care is highly important in the achievement of the objectives of health care delivery. In nursing practice, documenting the patient record is part of a nurse's daily routine. Documentation is essential for adequate, safe and efficient care (IOM, 2004). Inaccurate nursing documentation can cause misinterpretations, and can lead to unsafe patient care (Koczmara, C., Jelincic, V., Dueck, C. (2005). To identify potential areas for improvement the World Alliance for Patient Safety recommends further research toward medical and nursing documentation. This will enable best practices to be established to develop strategies for improving patient safety (WHO, 2007).

Fajemilehin (2014) observed that has become so difficult to measure the contribution of nurses to the health of their patients In other words, nurse-sensitive outcomes have been so difficult to describe. The reasons have been attributed to the nature of current nursing care. Currently, nurses documentations are usually not structured, presented in narrative forms and full of redundancies. It does not show which of the nurse-sensitive outcomes are obtained in patient situations. 
DOI: $10.21522 /$ TIJNR.2015.03.02.Art004

ISSN: $2520-3126$

Olaogun and Adejumo (2104) defined Standardized Nursing Languages as current standards that include terms which represent a focus of health problems ( diagnoses), interventions and outcomes consistent with the scope of nursing practice. Rutherford(2008) gave a similar definition that SNLs describe Nursing care concepts such as diagnosis, interventions and outcomes using common terms to communicate within and across health care systems, health care providers and other health care professionals.

For four decades now, nurses all over the world have been working on how to develop a standardized language for nursing practice, which can be used to serve this purpose. The evolution and development of standardized nursing language has included a systematic program of research over the past 32 years, resulting in significant advancements in nursing knowledge work. The Center for Nursing Classification at the University of Iowa has contributed to the creation of standardized nursing languages that capture nursing interventions (Nursing Interventions Classification [NIC], Dochterman \& Bulechek, 2004), and nurse-sensitive outcomes (Nursing Outcomes Classification [NOC], Moorhead, Maas, \& Johnson, 2003). When these interventions and outcomes are linked with NANDA diagnoses (NANDA International, 2005), all the standardized nursing language pieces (NANDA, NOC, and NIC or NNN) exist to represent relationships between and among nursing diagnoses, interventions, and outcomes (Johnson et al., 2006).

When these languages are used to structure nursing information systems in hospitals and other healthcare organizations, it will be possible to make nursing care and its associated activities and achievement of nursing-sensitive outcomes evident (Lunney, 2006).

Nurses lack training and education to work with a standardized language in actual patient situations. In situations where Nurses are aware of the standardized nursing languages, they have difficulty in transferring their own reasoning process which is related to the assessment of patient within the standardized nursing languages.

Above all, nursing documentation is majorly handwritten as most nurses don't have regular access to computer based tools which enable them to document their nursing assessments, interventions and outcomes in a structured way.

There is need for nurses to perform at a higher level and therefore communicate this contribution to patient care to their colleagues and other health professionals, else, whatever they have done remains invisible. (Hartley and Warren, 2012).

Fajemilehin (2014) also asserted that SNLs will facilitate communication among nurses and between nurses and other health care providers, provide inclusion of nurses in clinical information systems, provide easy access to evidence based knowledge stored in national and international databases, increase visibility of nursing interventions and improve patient care among other.

Significance: This study will create more awareness about SNLs and emphasize the need to fully incorporate the use of SNLs into nursing practice, provide a foundation for future efforts and studies concerned with inclusion of SNLs into nursing documentation within the clinical settings and also assist nursing management of health institutions to see the need to incorporate the use SNLs into nursing practice. This will go a long way in achieving the goal of transition from the traditional practice to evidence-based practice and also enhance communication between nurses and other healthcare professionals.

Objectives: The study is aimed at assessing the level of knowledge of SNLs among nurses, identify which of the SNLs the nurses are familiar with, ascertain if nurses make use of SNLs, and also identify the perceived barriers to its adoption.

\section{Research questions}

1. What is the level of knowledge of SNLs among nurses?

2. Which of the SNLs are nurses most familiar with?

3. Do nurses make use of SNLs?

4. What are nurses' perceived barriers to the adoption of SNLs? 
5. Is there a relationship between Nurses level of education, year of experience and knowledge of SNLs?

\section{Methods}

Research designs: The design is both descriptive and correlational. The correlational design is used to study the relationship between the situations examined (Burns and Groove, 2005). The descriptive part describes the demographic data, knowledge, adoption and perceived barrier to use.

Study area: The study was conducted at the Federal Medical Centre, Owo. It is an ancient city located in the south-western part of Nigeria. It is a 300-bedded hospital with a staff of about 1200 health professionals out of which nurses constitute about 350. The hospital was changed from a General Hospital to a federal Medical Centre in 1989 after being taken over by the Federal Government. It provides care at all the three levels (Primary, Secondary and Tertiary). It is located very close to Ikare-Owo Express Road. The hospital conducts residency training for doctors and serves an area of practical posting for student nurses.

Sampling method: A non-probability convenience sampling of the Nurses at the Federal Medical Centre, Owo, Nigeria.

Sample size: A total of two hundred and fifty (250) questionnaires were distributed with $98 \%$ response rate.

Inclusion/exclusion criteria: All nurses practicing in the various units in the hospital were considered for the study as they all have contact with patients one way or the other.

Instrument for data collection: A self-structured and administered questionnaire was used. It was divided into 4 parts:

1. The demographic data include gender, age, marital status, years of experience etc.

2. Knowledge variables were measured by assessing the nurses' knowledge of the definition of Standardized Nursing languages familiarity with the SNL, source of knowledge and the type of knowledge.

3. The implementation variables are measured by stating which of the languages the nurses are best familiar with and also stating whether the institution uses the SNL in documentation, education and research.

4. The barrier variables were determined by use of open ended question to know the Nurses' perceived barrier to the use of SNL

Ethical consideration: The study is of low risk to participating subjects and the facility.

Copies of the research proposal was submitted to the ethical review board of Federal Medical Centre, Owo for ethical approval of the study. After approval, the purpose of the study was explained to the study participants. Participation in the study was made voluntary and they were told they could withdraw from the study at any point if they wished without any negative consequence. Participants were assured that the information they had given would be treated with confidentially. Informed consent was sought from study participants and each of them signed the consent forms attached to their questionnaires prior to filling them. Respondents did not write their name for the purpose of confidentiality.

Process of data collection: A letter of permission to carry out study was obtained from the authority via the Research Review Committee. The questionnaires were administered to each nurse met in their various units/wards during the period of data collection. Same was collected back from the nurses after 23 days. Data collection lasted a period of 2 weeks in all.

Data analysis: The data was entered using the SPSS software version 22 and analysis done using tables of frequency and percentage, mean and standard deviation, chi test, Pearson correlation where necessary. 
DOI: $10.21522 /$ TIJNR.2015.03.02.Art004

ISSN: $2520-3126$

\section{Results}

\section{Demographic distribution}

The demographic distribution of the respondents revealed that majority $(97.1 \%)$ of the respondents was female and $2.9 \%$ are male. The age distribution showed that $8.2 \%$ of respondents were aged between 21 30 , majority $(61.2 \%)$ were aged between $31-40,26.5 \%$ were aged between $41-50$ and just few, $4.1 \%$. It is also revealed that majority of the respondents $78.4 \%$, are Christians while $21.6 \%$ are Muslims. None of the respondents is a traditionalist. Most of the respondents $(81.6 \%)$ are Yoruba, just few $(0.4 \%)$ are Hausa while $18 \%$ are Ibo. It is revealed in the statistics that majority of respondents $(78.8 \%)$ are married, $15.9 \%$ are single, $0.8 \%$ widowed $4.5 \%$ are separated. Distribution of the year of experience showed that $6.1 \%$ have only worked for less than 5 years, $32.7 \%$ have worked for 5-10 years, the larger numbers of respondents $(36.7 \%$ ) have worked for up to 15 years, and $16.3 \%$ have worked for up to 20 years while $8.2 \%$ have worked for more than 20 years. Only $2 \%$ of the respondents have a master's degree, $55 \%$ have a degree while $43 \%$ have only the RN RM qualification. $14.7 \%$ of respondents were Nursing Officer II, 9\% Nursing Officer I, 33.1\% Senior Nursing Officer, 15.9\% were Principal Nursing Officer, 12.2\% are Assistant Chief Nursing Officers, 14.3 are Chief Nursing Officers, 0.8\% are Assistant chief Nursing Officers.

\section{Knowledge}

Responses showed that all the nurses are familiar with standardized Nursing languages. Only $37.6 \%$ of respondents were able to give a correct definition of Standardized Nursing Languages while $62.4 \%$ gave a wrong definition. Only 30\% recognized NANDA, NIC AND NOC as Standardized Nursing Languages. $21 \%$ chose Evaluation, $18 \%$ chose diagnosis while $31 \%$ chose nursing process. Only $12.2 \%$ of respondents were able to recognize that 12 standardized Nursing languages exists. $14.3 \%$ responded 5 , $4.1 \%$ recognized $7,2.45 \%$ recognized $10,13.9 \%$ recognized $11,10.2$ responded $13,6.1 \%$ recognized 15 while the majority of respondents $(36.1 \%)$ does not know the number of standardized languages that currently exists. $39 \%$ of respondents got to know about Standardized Nursing Languages at the college, $15 \%$ in the ward, $69 \%$ knew about it from Journals and textbooks while $14 \%$ of respondents could not actually recognize how they got to know about it. When asked which of the languages nurses are most familiar with, majority $42 \%$ are most familiar with NANDA, $4.8 \%$ with aseptic technique, $6.5 \%$ familiar with Nursing Intervention classification, 2.4\% familiar with Nursing Outcome Classification, 8.9\% are familiar with Nursing care plan, $11.4 \%$ mentioned Nursing diagnosis, $4.9 \%$ mentioned Nursing Process

\section{Nurses' use of SNLs}

Responses showed that $100 \%$ of the respondents use paper method of documentation in the care of patients. $100 \%$ also confirmed that they do not have a functioning computer system in their ward. With paper documentation, 54\% of respondents use standardized Nursing languages at work most of which are not correct based on the responses given above, $45.3 \%$ do not use at all. Only $34.3 \%$ make use of Standardized Nursing Languages in their area specialization, $65.7 \%$ does not make use of it. $86 \%$ of the respondents confirmed that the hospital does not train nurses on the use of standardized Nursing Languages. $14 \%$ had no idea. $91 \%$ also confirmed that the hospital does not conduct any research on Standardized Nursing Languages. 9\% had no idea.

\section{Identification of barriers}

The challenges identified by the respondents are poor knowledge of the language (90\%), lack of basic amenities (89\%), inadequate computer literacy (48\%), nurses attitude to change $(62 \%)$, lack of policy and standard (77\%), poor leadership (81\%), inefficient continuous education (86\%), lack of management support (72\%), shortage of manpower $(88 \%)$, lack of time $(73 \%)$ 


\section{Discussion of finding}

\section{Nurses knowledge of standardized nursing languages}

Statistics showed that a larger percentage of the nurses are familiar with Standardized Nursing Languages, but has a poor knowledge of standardized nursing languages as only $37.6 \%$ of respondents were able to give a correct definition of Standardized Nursing Languages while $62.4 \%$ gave a wrong definition. Only 30\% recognized NANDA, NIC AND NOC as Standardized Nursing Languages. Personal interactions with the nurses showed that some of them only read about it in books and journals, only few learnt about it in the school. They were able to give correct definitions some of which were not given off hand but copied. This is in line with study done by Muller Stuab et al (2006) to assess nursing diagnoses, interventions and outcomes implementation. They reported a deficiency in accurately stating and documenting Nursing diagnosis and to relate them with nursing interventions and outcomes. (Table 4.1).

This is also similar to findings by Ehrenberg and Ehnfors (2001) in one of their studies in which they compared patient records against nurses' reports and found that between $41 \%$ and $89 \%$ of the patient problems identified by nurses 230 were not registered Standardized languages.

A different result was seen in a study conducted by Gusen et al (2016) which revealed that majority (70.9\%) had knowledge of NANDA, NIC and NIC.

It was revealed that most of the respondents are familiar with NANDA. This is similar to research by Olaogun et al, 2011 in their study conducted among nurses at the Obafemi Awolowo University Teaching hospital where it was revealed that Nurses are mostly familiar with NANDA. Also, in a survey by Thede and Schwirian 2011 to assess nurses' experience and attitude at the Ohio State University, in which about 1268 nurses were sampled. Only 4 out of the 12 were familiar. The most recognizable Nurses familiarity with standardized nursing languages being NANDA which over $1 / 3$ revealed that they have used in the school.

In a study by Donald Kautz et al (2006) to analyze the degree to which standardized nursing language was used by baccalaureate nursing students completing Outcome-Present State-Test (OPT) model worksheets in a clinical practicum. A scoring instrument was developed and 100 worksheets were retrospectively analyzed. NANDA nursing diagnoses were correctly stated in $92 \%$ of the OPT models. Nursing Outcomes Classification (NOC) outcomes were explicitly stated in $22 \%$, and implied in $72 \%$. Interventions matched appropriate Nursing Interventions Classification (NIC) activities in 61\%. NANDA, NIC, and NOC (NNN) language was used inconsistently by students in this sample.

\section{Method of documenting nursing care in the hospital?}

The major method of documenting nursing care in the hospital is the paper method. It was also revealed that none of the wards in the hospital has a functioning computer system. This is consistent with a case study by Matthew K et al (2014) to assess Nurses attitude towards computerization and also use of computer at work. Study was conducted at two hospitals (private and public) in Nairobi Kenya. It was revealed that only one $(6.6 \%)$ of the nurses have access to computer system at work in the government hospital. Computers perform a wide range of activities which help nurses to save time with documentation hence improving efficiency of health care. Various studies conducted on standardized Nursing Languages have shown that the use can be made easier with the use of the Electronic Health Record system.

\section{Nurses' perceived barriers to successful adoption of the standardized nursing languages?}

Major barriers identified in the study are include poor knowledge of the language, lack of basic amenities, poor policy, inefficient continuous education, shortage of manpower. This study is in line with the study conducted by Sani and Sani 2017 which revealed that the barriers to utilization of SNL include inadequate knowledge, lack of hospital policy and nurses shortage. Similarly, study by Thede and Schiwirian (2010) which revealed lack of knowledge of standardized nursing Languages as major barrier to its successful utilization. 
DOI: $10.21522 /$ TIJNR.2015.03.02.Art004

ISSN: $2520-3126$

In a study by P Flege in 2009, it was shown that even though classifications have been developed, most nurses have not been trained to use Standardized Nursing Languages. (It is reflected in this study that the hospital does not train nurses on the use of Standardized Nursing Languages).

At the Jos University Teaching Hospital, study by Abraham et al (2015) to determine the knowledge and utilization of SNL among nurses showed inadequate knowledge, lack of man power and lack of equipment as the major barrier.

\section{Relationship between the nurse's year of experience, educational qualification and their knowledge of SNLs}

According to Table 4.5 correlation revealed that there is no significant relationship between the nurses year of experience and their knowledge of Standardized Nursing Languages. (P value $>0.05$ ). This is in contrast to a study by Sani and Sani (2015) conducted in Sokoto which revealed that there is a significant difference between the knowledge of standardized nursing language and years of working experience among nurses in Sokoto, $(\mathrm{p}<0.02)$. Furthermore, post hoc analysis revealed that nurses with less than 5years working experience $(\mathrm{M}=6.32, \mathrm{SD}=1.68)$ and those with 5-10 years of working experience $(\mathrm{M}$ $=4.15, \mathrm{SD}=2.03$ ) had more knowledge of SNL, than those with more than 10years of working experience.

Table 4.6 also revealed that there is no significant relationship between the nurses year of experience and their knowledge of standardized nursing languages

\section{Conclusion and recommendation}

The evolution of standardized nursing languages (SNLs) has been occurring for more than four decades. The importance of this work continues to be acknowledged as an effective strategy to delineate professional nursing practice. In today's health care environment, the demand to deliver cost-effective, safe, quality patient care is an essential mandate embedded in all health reform policies. Communicating the contributions of professional nursing practice to other nurses, health providers, and other members of the health care team requires the articulation of nursing's focus of concern and responses to these concerns to improve patient outcomes.

The visibility of the electronic health record (EHR) in practice settings has accelerated the need for nursing to communicate its practice within the structure of the electronic format. The integration of SNLs into the patient record offers nurses an opportunity to describe the focus of their practice through the identification of nursing diagnosis, interventions and outcomes .Continued development, testing, and refinement of SNLs offers nursing an accurate and reliable way to use data elements across populations and settings to communicate nursing practice, enable nursing administrators and leaders in health care to delineate needed resources, cost out nursing care with greater precision, and design new models of care that reflect nurse-patient ratios and patient acuity that are data driven.

The continued use of nursing languages and acceleration of nursing research using this data can provide the needed evidence to help link nursing knowledge to evidence-driven, cost-effective, quality outcomes that more accurately reflect nursing's impact on patient care as well as the health care system of which they are a part. The evaluation of research to support the development, use, and continued refinement of nursing language is critical to research and the transformation of patient care by nurses on a global level. 


\section{List of tables}

Table 4.1. Socio-demographic distribution

\begin{tabular}{|c|c|c|}
\hline Variable & Frequency & Percentage \\
\hline $\begin{array}{l}\text { SEX } \\
\text { Male } \\
\text { Female }\end{array}$ & $\begin{array}{l}7 \\
238\end{array}$ & $\begin{array}{l}2.9 \\
97.1\end{array}$ \\
\hline $\begin{array}{l}\text { AGE } \\
\mathbf{2 1 - 3 0} \\
31-40 \\
41-50 \\
51-60\end{array}$ & $\begin{array}{l}20 \\
150 \\
65 \\
10\end{array}$ & $\begin{array}{l}8.2 \\
61.2 \\
26.5 \\
4.1\end{array}$ \\
\hline $\begin{array}{l}\text { Religion } \\
\text { Christian } \\
\text { Islam } \\
\text { Traditional }\end{array}$ & $\begin{array}{l}192 \\
53\end{array}$ & $\begin{array}{l}78.4 \\
21.6\end{array}$ \\
\hline $\begin{array}{l}\text { Tribe } \\
\text { Yoruba } \\
\text { Hausa } \\
\text { Ibo }\end{array}$ & $\begin{array}{l}200 \\
1 \\
44 \\
\end{array}$ & $\begin{array}{l}81.6 \\
0.4 \\
18 \\
\end{array}$ \\
\hline $\begin{array}{l}\text { Marital Status } \\
\text { Single } \\
\text { Married } \\
\text { Widowed } \\
\text { Separated }\end{array}$ & $\begin{array}{l}39 \\
193 \\
2 \\
11\end{array}$ & $\begin{array}{l}15.9 \\
78.8 \\
0.8 \\
4.5\end{array}$ \\
\hline $\begin{array}{l}\text { Years of } \\
\text { Experience } \\
\text { Under } 5 \\
5-10 \\
11-15 \\
16-20 \\
20 \text { and above } \\
\end{array}$ & $\begin{array}{l}15 \\
80 \\
90 \\
40 \\
20 \\
\end{array}$ & $\begin{array}{l}6.1 \\
32.7 \\
36.7 \\
16.3 \\
\end{array}$ \\
\hline $\begin{array}{l}\text { Qualification } \\
\text { Masters } \\
\text { BNSc } \\
\text { RN/RM } \\
\end{array}$ & $\begin{array}{l}5 \\
135 \\
105 \\
\end{array}$ & $\begin{array}{l}2.0 \\
55 \\
43 \\
\end{array}$ \\
\hline $\begin{array}{l}\text { Designation } \\
\text { NO II } \\
\text { NOI } \\
\text { SNO } \\
\text { PNO } \\
\text { ACNO } \\
\text { CNO } \\
\text { ADNS }\end{array}$ & $\begin{array}{l}36 \\
22 \\
81 \\
39 \\
30 \\
35 \\
2 \\
\end{array}$ & $\begin{array}{l}14.7 \\
9 \\
33.1 \\
15.9 \\
12.2 \\
14.3 \\
0.8\end{array}$ \\
\hline
\end{tabular}

Table 4.2. Knowledge of standardized nursing languages

\begin{tabular}{|l|l|l|}
\hline Variable & Frequency & Percentage \\
\hline
\end{tabular}


DOI: 10.21522 /TIJNR.2015.03.02.Art004

ISSN: $2520-3126$

\begin{tabular}{|c|c|c|}
\hline $\begin{array}{l}\text { 1. Are you familiar with standardized } \\
\text { nursing languages? } \\
\text { Yes } \\
\text { No }\end{array}$ & $\begin{array}{l}245 \\
0\end{array}$ & $\begin{array}{l}100 \\
0\end{array}$ \\
\hline $\begin{array}{l}\text { 2. If yes, define standardized nursing } \\
\text { languages }\end{array}$ & & \\
\hline $\begin{array}{l}\text { Correct definition } \\
\quad \text { Wrong definition }\end{array}$ & $\begin{array}{l}92 \\
153\end{array}$ & $\begin{array}{l}37.6 \\
62.4\end{array}$ \\
\hline $\begin{array}{l}\text { 3. Which of the following is a } \\
\quad \text { Standardized Nursing Language? } \\
\text { Evaluation } \\
\text { Diagnosis } \\
\text { NANDA, NIC and NOC } \\
\text { Nursing process }\end{array}$ & $\begin{array}{l}51 \\
44 \\
73 \\
77\end{array}$ & $\begin{array}{l}21 \\
18 \\
30 \\
31\end{array}$ \\
\hline $\begin{array}{l}\text { 4. How many standardized nursing } \\
5 \\
5 \\
7 \\
10 \\
11 \\
12 \\
13 \\
15 \\
\text { I donguages exist? } \mathrm{t} \text { know }\end{array}$ & $\begin{array}{l}35 \\
10 \\
6 \\
34 \\
30 \\
25 \\
15 \\
90\end{array}$ & $\begin{array}{l}14.3 \\
4.1 \\
2.45 \\
13.9 \\
12.2 \\
10.2 \\
6.1 \\
36.7\end{array}$ \\
\hline $\begin{array}{l}\text { 5. Which of the standardized languages are } \\
\quad \text { you most familiar with? } \\
\text { Aseptic technique } \\
\text { NANDA } \\
\text { NIC } \\
\text { NOC } \\
\text { Nursing care plan } \\
\text { Nursing Diagnosis } \\
\text { Nursing Process } \\
\text { No response }\end{array}$ & $\begin{array}{l}12 \\
103 \\
16 \\
6 \\
22 \\
28 \\
12 \\
56\end{array}$ & $\begin{array}{l}4.8 \\
42 \% \\
6.5 \\
2.4 \\
8.9 \\
11.4 \\
4.9 \\
22.85\end{array}$ \\
\hline $\begin{array}{l}\text { 6. What is your source of knowledge? } \\
\text { College } \\
\text { Ward level } \\
\text { Journal/Textbook }\end{array}$ & $\begin{array}{l}96 \\
44 \\
170\end{array}$ & $\begin{array}{l}39 \\
15 \\
69\end{array}$ \\
\hline
\end{tabular}

Table 4.3. Use of standardized nursing languages among nurses at federal medical centre, owo

\begin{tabular}{|l|l|l|}
\hline Variable & Frequency & Percentage \\
\hline Which method of documentation do you use in & & \\
patient care? & & \\
$\begin{array}{l}\text { Paper } \\
\text { Electronic health record }\end{array}$ & 245 & 100 \\
\hline $\begin{array}{l}\text { Do you have a functioning computer system in your } \\
\text { ward? }\end{array}$ & - & - \\
\hline Yes & - & - \\
\hline No & 245 & 100 \\
\hline
\end{tabular}


Texila International Journal of Nursing Volume 3, Issue 2, Dec 2017

\begin{tabular}{|l|l|l|}
\hline $\begin{array}{l}\text { Do you make use of standardized nursing languages } \\
\text { at work In planning and documenting care? }\end{array}$ & & \\
\hline Yes & 134 & 54.7 \\
\hline No & 111 & 45.3 \\
\hline $\begin{array}{l}\text { Do you make use of Standardized Nursing } \\
\text { Languages in Your area of specialization? }\end{array}$ & & \\
\hline Yes & 84 & $34.3 \%$ \\
\hline No & 161 & $65.7 \%$ \\
\hline $\begin{array}{l}\text { Does your hospital train nurses on the use of } \\
\text { Standardized Nursing Languages? }\end{array}$ & & \\
\hline Yes & - & $86 \%$ \\
\hline No & 210 & $14 \%$ \\
\hline I have no idea & 35 & \\
\hline $\begin{array}{l}\text { Does your facility conduct research on Standardized } \\
\text { Nursing Languages? }\end{array}$ & & \\
\hline Yes & - & $91 \%$ \\
\hline No & 223 & $9 \%$ \\
\hline I have no idea & 22 & \\
\hline
\end{tabular}

Table 4.4. Possible barriers facing the use of standardized nursing languages at fmc, owo

\begin{tabular}{|l|l|l|}
\hline Variables & Frequency & Percentage \\
\hline $\begin{array}{l}\text { Nurses poor knowledge and of Standardized Nursing } \\
\text { Languages }\end{array}$ & 221 & 90 \\
\hline $\begin{array}{l}\text { Non availability of basic amenities e.g. computer } \\
\text { system, }\end{array}$ & 219 & 89 \\
\hline Continuous power supply, internet facilities etc. & 119 & 48 \\
\hline Inadequate Computer Literacy & 152 & 62 \\
\hline Nurses attitude to change & 188 & 77 \\
\hline Lack of policy/standard & 199 & 81 \\
\hline Poor Leadership & 210 & 86 \\
\hline Inefficient continuous education & 178 & 72 \\
\hline Lack of support from Management & 216 & 88 \\
\hline Staff Shortage & 178 & 73 \\
\hline Lack of time & & \\
\hline & & \\
\hline
\end{tabular}

Table 4.5. Relationship between nurse's year of experience and their knowledge of standardized nursing language

\begin{tabular}{|c|c|c|c|c|c|c|}
\hline & & \multicolumn{2}{|c|}{ Knowledge of SNL* } & \multirow[t]{2}{*}{ Total } & \multirow[b]{2}{*}{$\mathbf{X}^{2}$} & \multirow[b]{2}{*}{ P-value } \\
\hline & & Poor & Fair & & & \\
\hline \multirow[t]{2}{*}{ Under 5 years } & Count & 10 & 5 & 15 & 5.246 & 0.117 \\
\hline & $\%$ of Total & $4.1 \%$ & $2.0 \%$ & $6.1 \%$ & & \\
\hline \multirow[t]{2}{*}{$5-10$ years } & Count & 25 & 55 & 80 & & \\
\hline & $\%$ of Total & $10.2 \%$ & $22.4 \%$ & $32.7 \%$ & & \\
\hline $11-15$ years & Count & 50 & 40 & 90 & & \\
\hline
\end{tabular}


DOI: 10.21522 /TIJNR.2015.03.02.Art004

ISSN: $2520-3126$

\begin{tabular}{|l|l|l|l|l|l|l|}
\hline & $\%$ of Total & $20.4 \%$ & $16.3 \%$ & $36.7 \%$ & & \\
\hline \multirow{2}{*}{$16-20$ years } & Count & 10 & 30 & 40 & & \\
\cline { 2 - 8 } & $\%$ of Total & $4.1 \%$ & $12.2 \%$ & $16.3 \%$ & & \\
\hline \multirow{2}{*}{20 and above } & Count & 10 & 10 & 15 & & \\
\cline { 2 - 8 } & $\%$ of Total & $4.1 \%$ & $2.0 \%$ & $6.1 \%$ & & \\
\hline \multirow{2}{*}{ No response } & Count & 0 & 5 & 5 & & \\
\cline { 2 - 8 } & $\%$ of Total & $.0 \%$ & $2.0 \%$ & $2.0 \%$ & & \\
\hline \multirow{2}{*}{ Total } & Count & 105 & 140 & 145 & & \\
\cline { 2 - 8 } & $\%$ of Total & $42.9 \%$ & $57.1 \%$ & $100.0 \%$ & & \\
\hline
\end{tabular}

- Knowledge level was determined using questions 1-4 (Table 4.2). Poor (0-1), fair (2-3), good (4)

Table 4.6. Relationship between Nurses Qualification and Knowledge of Standardized Nursing Languages

\begin{tabular}{|c|c|c|c|c|c|c|}
\hline & \multicolumn{2}{|c|}{ Knowledge of SNL* } & \multirow[t]{2}{*}{ Total } & \multirow[b]{2}{*}{$X^{2}$} & \multirow[b]{2}{*}{ P-value } \\
\hline & & Poor & Fair & & & \\
\hline \multirow[t]{2}{*}{ RNRM } & Count & 44 & 51 & 95 & 1.442 & 0.114 \\
\hline & $\%$ of Total & $18 \%$ & $20.8 \%$ & $38.8 \%$ & & \\
\hline \multirow[t]{2}{*}{$\mathrm{BNSc}$} & Count & 53 & 72 & 125 & & \\
\hline & $\%$ of Total & $22 \%$ & $29 \%$ & $51.0 \%$ & & \\
\hline \multirow[t]{2}{*}{$\mathrm{MSc}$} & Count & 0 & 5 & 5 & & \\
\hline & $\%$ of Total & $.0 \%$ & $10.0 \%$ & $10.0 \%$ & & \\
\hline \multirow[t]{2}{*}{ No response } & Count & 4 & 16 & 20 & & \\
\hline & $\%$ of Total & $10.0 \%$ & $31 \%$ & $41 \%$ & & \\
\hline \multirow[t]{2}{*}{ Total } & Total & 21 & 28 & 245 & & \\
\hline & $\%$ of Total & $42.9 \%$ & $57.1 \%$ & $100.0 \%$ & & \\
\hline
\end{tabular}

\section{References}

[1].Abraham Ajayi, Richard Adeola, Okpe Daniel, Nanbu Stephen, Nanle Gusen, Ajayi A, Adeola (2015): Knowledge And Utilization Of Standardized Nursing Language Among Nurses In Jos University Teaching Hospital Plateau State, Nigeria. International Professional Nursing Journal and Research. 2015 Sep 18 [Last Modified: 2015 Nov 18]. Edition 1. Doi: 10.001/26ae0c1 f377469682e0e989cdae2e6dc.

[2].Erdemir F, Altun E. (2003): Nursing students' self-assessments and opinions about using nursing diagnosis in clinical practice. International Journal of Nursing Terminology Classification.

[3].Everett M. Rogers (2003): Diffusion of Innovations, Fifth Edition, Free Press, New York, p221.

[4].Hebda, Toni lee; czar, Patricia (2013): handbook of informatics for nurses \& healthcare professionals, 5th edition, (C) 2013. Reprinted by permission of Pearson education, inc., upper saddle river, nj.

[5].John, M. E. (2010): Innovations in nursing education and practice (Standardized nursing languages. A paper presented during 2-day scientific conference on innovation and change. Organized by FAME, West African College of Nursing on $18^{\text {th }}-20^{\text {th }}$ May, 2010, at College of Health Technology, Calabar, Cross River State.

[6].Johnson, M., Bulechek, G., Butcher, H., Dochterman, J. M., Maas, M., Moorhead, S., \& Swanson, E. (2006): NANDA, NOC and NIC Linkages. ( $2^{\text {nd }}$ ed.), St. Louis, Missouri: Mosby, Inc.

[7].Jones, D., Lunney, M., Keenan, G., \& Moorehead, S. (2010). Standardized nursing languages: Essential for the nursing work force. Annual Review of Nursing Research, 28(1), 253-294.

[8].Kaminski, J. (Spring 2011).Diffusion of Innovation Theory Canadian Journal of Nursing Informatics, 6(2). Theory in Nursing Informatics Column. http://cjni.net/journal/?p=1444.

[9].Keenan, G. (1999): Use of standardized nursing language will make nursing visible. Michigan Nurse, 72(2), 1213.

[10]. Kennedy, R. (2003). The nursing shortage and the role of technology. Nursing Outlook, 51(3), S33-34. 
[11]. Klehr J, Hafner J, Spelz L M, Steen S., Weaver K(2009): Implementation of Standardized Nomenclature in the electronic Medical Record. International Journal of Nursing Classification. 2990 Oct-Dec 20(4) 160-80. Doi. 10.1111/j.1744-618.2009.01.132.x.

[12]. Korst LM, Eusebio-Angeja AC, Chamorro T, et al. (2003): Nursing documentation time during implementation of an electronic medical record. J Nurs Adm 2003; 33(1):24-30.

[13]. Language for clinical reasoning with the Outcome-Present State-Test (OPT) Model. International Journal of Nursing Terminologies and Classifications, 17, 129-138. DOI: 10.1111/j.1744-618X.2006.00033.x.

[14]. Lee, E., Park, H., Nam, M., \& Whyte, J. (2011). Identification and comparison of interventions performed by Korean school nurses and U.S. school nurses using the nursing interventions classification (NIC). Journal of School Nursing, 27 (2), 93-101. doi: 10.1177/1059840510391095.

[15]. Moss J, Damrongsak M, Gallichio K. (2005): Representing critical care data using the clinical care classification. AMIA Annual Symposium Proceedings. 2005:545-549.

[16]. Müller-Staub, M., Needham, I., Odenbreit, M., Lavin, M.A., \&van Achterberg, T. (2007). Improved quality of nursing documentation: Results of a nursing diagnoses, interventions and outcome implementation study. International Journal of Nursing Terminologies and Classifications, 18, 5-17.

[17]. NANDA International. (2012). nursing diagnosis: Definitions and classification, 2012-2014. Oxford: WhileyBlackwell.

[18]. National Institute of Medicine (IOM), Robert Wood Johnson Foundation. (2010). the future of nursing: Leading change, advancing health. Washington, D.C.: The National Academies Press.

[19]. Olaogun, A., Oginni, M., Oyedeji, T. A., Nnahiwe, B., and Olatubi, I., ( 2011) Assessing the Use of the NANDA- International Nursing Diagnoses at the Obafemi Awolowo University Teaching Hospital Ile Ife, Nigeria. International Journal of Nursing Terminologies and Classifications. Vol 22(4). Oct- Dec pp 157-161.

[20]. Pearson, A. (2003). The role of documentation in making nursing work visible. International Journal of Nursing Practice, 9(5), 271.

[21]. Poissant L, Pereira J, Tamblyn R, et al. The impact of electronic health records on time efficiency of physicians and nurses: a systematic review. J Am Med Inform Assoc 2005; 12:505.

[22]. Rogers, E. M. (2003). Diffusion of innovations (5th ed). New York: Free Press.

[23]. Rutherford, M. A. (2008). Standardized nursing language: What does it mean for nursing practice? The Online Journal of Issues in Nursing, 13. doi: 10.3912/OJIN.Vol13No01PPT05.

[24]. Rutherford, M. A. (2008). Standardized nursing language: What does it mean for nursing practice? Online Journal of Issues in Nursing, OJIN: 13 (1) retrieved 23/11/2011 from http://www.nursingworld.org.

[25]. Sani S, Sani AM. (2015): Relationship between knowledge of standardized nursing language and working experience among nurses in Sokoto, Nigeria. International Journal of Science Resources 2015 .4(2):1008-10.

[26]. Sani S, Sani AM. (2015): Nurses attitude and barriers towards utilization of Standardized Nursing Languages in Sokoto State Nigeria. Asian Journal of Medicine and health, 2(2): 1-6, 2017; Article no. AJMAH.29433.

[27]. Schwirian, P., Thede, L., (May 21, 2012) "Informatics: The Standardized Nursing Terminologies: A National Survey of Nurses' Experience and Attitudes-SURVEY II Participants, Familiarity and Information Sources" OJIN: The Online Journal of Issues in Nursing Vol. 17 No. 2.2.

[28]. Smith K, Smith V, Krugman M, et al. evaluating the impact of computerized clinical documentation. Comput Inform Nurs 2005; 23 (3):132-8.

[29]. World Health Organization (2007). Communication during Patient Hand-Over, Patient Safety Solutions, 1 (3) Solution.pdf accessed: 01 June 2010. 


\title{
Stressors and Counselling Needs of Undergraduate Nursing Students in Osogbo, Nigeria
}

\author{
Article by Lilly-West, R.B \\ Medical Department, Shell Petroleum Development, Port Harcourt, Nigeria \\ E-mail: buloala2002@yahoo.com
}

\begin{abstract}
Background: Education is important in the development of any profession. It is the process of transferring knowledge from a generation of professionals to another. Stress can be beneficial in the education of a student, motivating them to reach their full potential. However, nursing education has its peculiar attendant stress that can be harmful when excessive. Majority of nursing students around the world have reported a level of stress in their academic pursuit. Objective: The study was carried out to determine the stress level of students in the various levels of the nursing education, to examine the pattern of stress amidst the students according to their sociodemographic, and to determine the relationship between the various coping mechanisms adopted and the overall stress score through a questionnaire- based study in a government school of nursing in Osun state, Nigeria. Method: A descriptive crosssectional study was carried out at the Osun state school of nursing, Asubiaro, Osogbo, Osun state. A sample of 120 students was drawn from all the classes of the school using a multistage sampling method of proportional allocation. To achieve the objective of the study, a questionnaire was designed that contained three sections; A. Sociodemographic data, B. The perceived stress scale (PSS) and C. The brief coping orientation for problem experiences (COPE). Data were entered and analysed using the statistical package for social sciences (SPSS) version 20.0. Results: The mean age of the respondents was $22.11 \pm 4.14$ years with the median and range being 21.00 and 30.00 years respectively. About $78 \%$ of the respondents are females and $70 \%$ are Christians. Using the PSS, $48.3 \%$ of the respondents sometimes become upset because of something that happened unexpectedly, 17.5\% becomes upset fairly often, $12.5 \%$ almost never becomes upset among the others. Equal number of respondents (5.8\%) never or almost never felt nervous or stressed in the last month, others sometimes (44.2\%), fairly often (19.2\%) and very often (25.0\%) feel nervous or stressed. Other responses about the PSS are presented in table 2. There is a significant difference between the stress score of the respondents in between the sexes (16.70 vs 19.17; $p=0.045)$. Also, the proportion of the females that are stressed is significantly more than the proportion of the males $(66.7 \%$ vs $87.1 \%$; $p=0.018$ ). The odds of respondents who practice behavioural disengagement to be highly stressed is 0.262 (95\% CI, 0.117 - 1.483) times that of respondents who practice other coping mechanisms. Conclusion: The level of stress in the population studied is relatively low when compared with the results from other studies both locally and internationally. The various stressors identified are basically as a result of lack of control over academic events, nervousness, inability to handle personal problems, irritations, and anger. The nursing education authority should look into these stressors with the view to find ways of mitigating them, thereby providing an optimum learning environment for the students. Some of the students already practice both active and avoidant coping techniques.
\end{abstract}

Keywords: stressors, counselling, perceived stress scale (PSS), coping orientation for problem experiences (COPE).

\section{Introduction}

Stress in nursing education is beginning to get the attention of nurse educators and nurse researchers in the recent years because its effects on learning, persistence and the overall students' satisfaction and wellbeing have been recognized (DelPrato et al, 2011). 
Nursing education exposes students to a greater level of stress when compared to students undergoing other education (Gibbons et al, 2007). Among other potential sources of stress, the peculiarity of the educational standard is a risk factor for higher stress levels. These peculiarities range from insecurity about clinical experience to excessive assignments and interpersonal conflicts with other nurses (Nancy, 2011). As a result of these experiences, the student nurses undergo some long term negative changes in their physical and mental well-being, often becoming irritable, lacking concentration, academically poor, emotionally unstable and showing truancy (Chang et al, 2005, Gibbons, 2010; Al-Kandari \& Vidal, 2007).

Absenteeism in the students is critical because it can lead to a decline in the number of students graduating from the nursing schools and a corresponding shortage in the number of professional nurses available to serve the population (Deary et al, 2003; Watson et al, 2008). This is also important because these "drop-outs" might end up establishing quack health centres in some remote locations, claiming to the people that they are graduates. A study by Leodoro, 2013 has shown that the stresses encountered by nursing students are severe enough to cause some mental health problems such as depression and anxiety (Leodoro, 2013).

Going through a rather stressful education, numerous nursing students have utilized several coping strategies in times past, these includes self- distraction, active coping, denial, substance use and religion among others (Seyedfatemi et al, 2007; Sheu et al, 2002).

\section{Research problem}

Nursing education cannot be overlooked in the quest to ensure that the nurses in the health sector are professionals who are up to the task of quality healthcare delivery. Generally, this part of the world has inadequate data on the various stressors of the students and how stressed they are in their nursing education, there is little or no information how these students have been coping with the various stressors making interventions difficult and the learning process harder.

The earlier reports were made using scales that were not standardized and universal. There is a need to assess these subjects using a universal scale so that there can be basis for proper comparism between the local data and data from other nursing institution in the world.

\section{Significance of the study}

Understanding the various stressors that the students encounter in their nursing education will help the nurse educators and the nursing council to better create a supportive environment for the students, and reduce the likelihood and incidence of the negative events associated with excessive stress.

This study will provide information concerning the stress level of the nursing students in their nursing education. It will also provide information about the various ways in which they have been trying to cope with their stresses. This study could help the nursing education authorities in designing a better learning environment which reduces the stress that students will go through. Knowing the various coping mechanism already employed can also direct the relevant authorities on where to focus more while trying to reduce the stress of the students.

\section{Objectives of the study}

The objectives of the study are: to determine the stress level of the students in the various levels of the nursing education, to examine the pattern of stress amidst the students according to their sociodemographic, and to determine the relationship between the various coping mechanisms adopted and the overall stress score.

\section{Research questions}

What is the stress level of the students in the various levels of the nursing education what is the stress pattern amidst the students?

What is the relationship between the various coping mechanisms and the overall stress scores? 
What coping factors determine a higher overall stress level among the students?

\section{Scope of the study}

The study assessed the stress levels and associated factors among first year, second year and third year students of the school of nursing Osogbo, Osun State, Nigeria. The questionnaire was self-administered and the nurses that took part ranged from both freshers and finalists all within the undergraduate nursing education.

\section{Literature review}

\section{Introduction}

This section presents the relevant literature taken from primary and secondary sources of either research or conceptual literature.

Stress and stressors-- In 1984, stress was defined as "a particular relationship between the person and the environment that is appraised by the person as taxing or exceeding his or her resources and endangering his or her wellbeing" (Lazarus \& Folkman, 1984). Stress in itself is not always negative, and in some circumstances, it can be positive, motivating students and enhancing their performance. However, in conditions of excessive stress there are negative impacts on the students' physical and mental health.

Stress is a dynamic interaction between an individual and his environment. The environment of an individual plays a prominent role in their psychosocial life, and in extension their physical and mental well-being (Kohler et al, 2006; Pulido-Martos et al, 2011; Chang et al, 2005). As a result of the caring nature of the nursing profession, a lot of professional nurses undergo a lot of work-related stress, the nursing students are exposed to the same stressors the professional nurses are exposed to and they are also exposed to the education-related stress of a student (Lim et al, 2010; Pryjmachuk \& Richards, 2007).

Even among nursing students, stress levels vary depending on the educational levels of the students and the different nursing programmes (Lindop, 2000; Burnard et al, 2008). The various stressors encountered by the nursing students can be broadly classified into four groups (Pryjmachuk \& Richards, 2007; Deary et al, 2003; Brown et al, 2000; Nancy, 2011);

Academic stress: These are stress that the students go through as a result of direct academic pressures on them. These includes workload, examinations, lecturing methods, assignment submission, excessive homework, assessment deadlines, unclear assignments, uncomfortable classrooms and the pressure resulting from the fear of elimination from the training.

Clinical practice related stress: This kind of stress arises from the exposure of the nursing students to clinical training. These include lack of competence, shifting, insecurity about clinical competence, interpersonal relations with patients (especially the dead and dying), supervision and assessment among others.

Relational stress: These are the stress the students experience as a result of their relationships in the nursing education. These include interacting with patients, interpersonal conflicts with other nurses, and relations with faculty members.

Intrapersonal stress: These stresses are particularly attributable to the personal state of the students themselves. These include gender, age, lack of motivation, poor social life coupled with the transition from the family background to the school environment, family structure, financial burdens, time pressure and job roles.

In 2010, Liu et al published a report that detailed the transition of nursing education from the conventional hospital based three-year programme to the current tertiary education based baccalaureate degree program. The reform also includes the shift in clinical practice from supervision and assessment of nursing students to a cooperative work between the university nursing faculty and clinical nurses (Liu et al, 2010). This shift in the structure of nursing education has also brought attendant increment in the stress levels of the students.

In a 2011 study in India, it was discovered that change in environment, inadequate telephone facilities, change in eating pattern, engagement/marriage induced stress in $100 \%$ of the students, while the least stressors are missing too many classes (16\%), inadequate water supply 
DOI: 10.21522 /TIJNR.2015.03.02.Art005

ISSN: $2520-3126$

(19\%), conflict with roommates $(30 \%)$, inadequate electricity supply (32\%), change in religious beliefs (46\%), lack of close and intimate friends (49\%) among others (Sharma \& Kaur, 2011). They concluded that stress cannot be eliminated but it can be reduced.

Coping strategies/mechanisms: Coping strategies can be defined as the "specific efforts, both behavioural and psychological, that people employ to master, tolerate, reduce, or minimize stressful events" (Ajibade et al, 2016). MacArthur (2014) categorized coping strategies according to figure 1 .

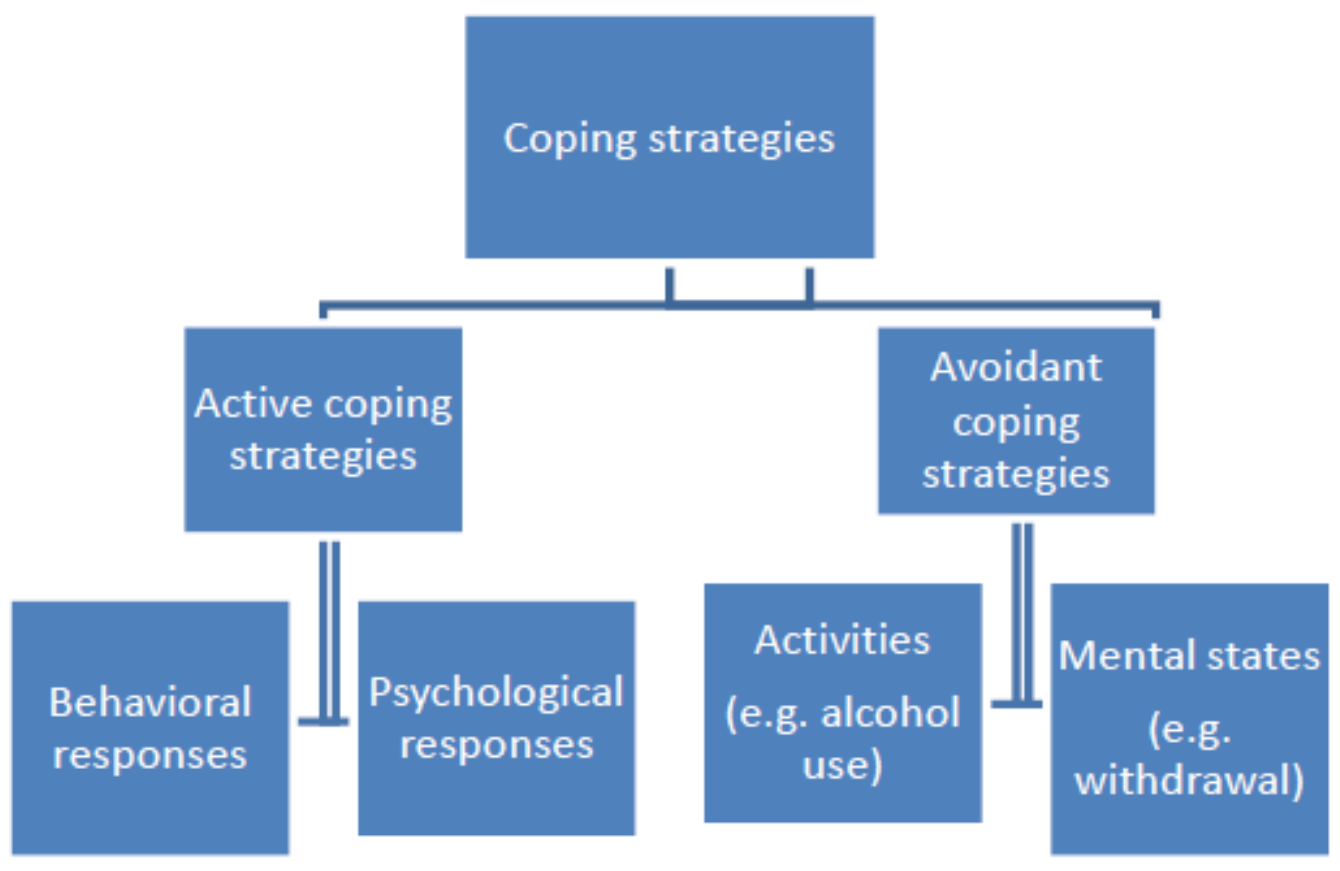

Figure 1. Classification of coping strategies according to MacArthur (2014)

The stress level of the students can be modified by the adoption of various coping strategies. When the coping strategy employed by the student is effective, there is a significant improvement in their educational results. As a result of relieved stress (Khater et al, 2014). The various coping mechanisms employed by the students are largely dependent on the educational level of the student and also the type of stress the student is going through. However, the overall aim of the students is to survive, grow, and maintain their individual integrity (Nancy, 2011).

Stress-coping strategies in nursing education require creating a change in the educational environment and empowering the students to be able to cope better with their encountered stress (DelPrato et al, 2011).

Mentorship together with guidance and counselling can be a very useful strategy in the bid to reduce anxiety in the students when they go through clinical attachment (Aston \& Molassiotis, 2011; Frankel, 2009; Papastsvrous et al, 2010). Senior nursing students can help the juniors nursing to understand some scenarios better (Aston \& Molassiotis, 2011). Members of staff can personally mentor some of these students; guiding them and helping them acclimatize to the new learning environment. Mentorship can graduate into role-modelling and these nursing students can have an already made professional to look up to, reducing the tendencies of drop out and increasing their motivation and in extension academic performance (Papp et al, 2003). The students also learn leadership skills from their mentors apart from academic direction.

Adopting a caring environment can also go a long way in helping the students to cope with excessive stress. A 2005 study implied that creating a caring environment defined as an environment where the lecturer know and responds to "the feelings of stress and anxiety that are experienced by the students" shows value, respect and support in between the faculty and 
the students, further promoting learning in a manner that is less stressful. (Hughes, 1992; Bankert \& Kozel, 2005)

A 2016 multicentre study in south-western Nigeria identified four major coping mechanisms used by undergraduate nursing students. They show that most of the students utilize "problem solving" and "staying optimistic" the most as coping mechanisms in their academic pursuit (Ajibade et al, 2016). They report that the students do not especially use "avoidance and transference". Avoidance as a coping strategy has been associated with increased stress on the long run and is a sign of a possible underlying psychological problem (Sheu et al, 2002; Boyes, 2013).

\section{Methodology}

\section{Study location}

The study was carried out in the school of nursing Osogbo. The school was established by the Osun state ministry of health to cater for the need for nurses training in the state. Osogbo is the capital of Osun state in South western, Nigeria. The school is located inside the compound of the state hospital, Asubiaro.

\section{Type of study}

This study was a cross-sectional study of stress levels of nursing students in the school of nursing Osogbo. Data was collected from a representative subset of nursing students studying in the school.

\section{Sample Size/population}

The study population consisted first year, second year and third year students of the school, which were estimated to be four hundred (400) in number.

\section{Sample and sampling strategy}

A sample of one hundred and twenty (120) students was selected by convenience sampling through a multi-stage sampling of proportional allocation by taking $40 \%$ of the first year students, $20 \%$ of the second year students and $40 \%$ of the third year students. Sampling in a class was through simple random sampling using the ballot system.

\section{Selection criteria for the subjects}

\section{Inclusion criteria}

i. Nursing students in the school of nursing, Osun State

ii. Nursing students older than 18 years.

iii. Students that gave informed consent to be enrolled.

\section{Exclusion criteria}

i. Those who declined consent

\section{Materials}

A questionnaire was used to obtain the various information. It was pre-tested before the study. The questionnaire had three sections; section A requested information about sociodemographic data like age, gender, educational level, religion etc. section B contained the perceived stress scale (PSS), this is a 10-item scale designed to gather examine the stress level of the students. Section $\mathrm{C}$ contained the brief coping orientation for problem experiences (COPE) scale

The questionnaire (Appendix A) consists of three sections in two pages: section A, section $\mathrm{B}$ and section C. Section A contained sociodemographic data like age, sex, educational level, religion etc. Section B contained the perceived stress scale (PSS), a 10-item scale with responses in a liekart scale ranging from Never to Almost Never to Sometimes to Fairly Often to Very Often. Section $\mathrm{C}$ contained the brief coping orientation for problem experiences 
DOI: 10.21522 /TIJNR.2015.03.02.Art005

ISSN: $2520-3126$

(COPE), a 28-item tool developed to evaluate the coping mechanisms by students. It has responses on a liekart scale ranging from "I haven't been doing this at all" to "I've been doing this a little bit" to "I've been doing this a medium amount" to "I've been doing this a lot".

\section{Subject assessment}

Informed consent obtained from all the subjects participating in the study. They were then assessed using the study questionnaire.

\section{Statistical analysis}

The data was analysed using Statistical Package for the Social Sciences (SPSS Inc, Chicago, IL version 20.0) software. Categorical variables were described using frequencies and percentages. Also, continuous variables were described using the measures of central tendency (mean, median) and measures of dispersion (range, standard deviation) as appropriate. Statistical significance of differences between means was determined using student's T-test and analysis of variance (ANOVA) where appropriate (Table 3). Significant association of individual coping mechanisms with high stress level among the respondents was tested using Pearson's Coefficient of Correlation for quantitative variables. Regression analysis made done using cumulative odds ordinal logistic regression with proportional odds. Statistical significance was considered at $\mathrm{P}<0.05$.

\section{Ethical clearance}

Ethical clearance was obtained from the Ethics and Research Committee of the (Nursing dept.) Ministry of health, Osogbo, Osun State, Nigeria.

\section{Results}

This section presents the results of the study based on the sequence by which the research questions were raised. The profile of the respondents is presented first followed by the results and discussion.

\section{Respondent's profile (age, gender and religion)}

The mean age of the respondents was $22.11 \pm 4.14$ years with the median and range being 21.00 and 30.00 years respectively as shown in table 1 . Majority $(71.7 \%)$ of the respondents were also in the $18-22$ years age group, others are $23-27$ years $(19.2 \%), 28-32(6.7 \%)$ and $>32(2.5 \%)$. Ninety three $(77.5 \%)$ were females. Religious distribution showed that Christianity accounts for $70.0 \%$ of the religion followed by Islam (30.0\%).

\section{Respondent's profile (educational level, ethnicity and accommodation type)}

Equal proportions (40.0\%) of the respondents were in their first year and the third years of study while the remaining $20.0 \%$ were in their second year of study. Almost all $(92.5 \%)$ of them are Yoruba by ethnicity, others are Igbo $(6.7 \%)$ and Hausa $(0.8 \%)$. The dominant accommodation type was "school hostel" $-80.0 \%$.

\section{Respondent's profile (average monthly income and family type)}

Majority (81.7\%) of the respondents have less than 20,000 naira as their average monthly income and only one person $(0.8 \%)$ earned more than 100,000 naira per month, others are inbetween. Also, eighty nine $(74.2 \%)$ are from a monogamous family setting. 
Table 1. Sociodemographic characteristics of the respondents.

\begin{tabular}{|c|c|c|c|}
\hline \multirow{2}{*}{\multicolumn{2}{|c|}{ Variable }} & \multicolumn{2}{|l|}{$N=120$} \\
\hline & & \multirow{2}{*}{ Frequency } & \multirow{2}{*}{ Percentage } \\
\hline Age (Years) & & & \\
\hline & $18-22$ & 86 & 71.7 \\
\hline & $23-27$ & 23 & 19.2 \\
\hline & $28-32$ & 8 & 6.7 \\
\hline & $>32$ & 3 & 2.5 \\
\hline & Mean \pm SD & \multicolumn{2}{|l|}{$22.11 \pm 4.14$} \\
\hline & $\begin{array}{l}\text { Median } \\
\text { (Range) }\end{array}$ & \multicolumn{2}{|l|}{$21.0(30.0)$} \\
\hline \multicolumn{4}{|l|}{ Gender } \\
\hline & Male & 27 & 22.5 \\
\hline & Female & 93 & 77.5 \\
\hline \multicolumn{4}{|l|}{ Religion } \\
\hline & Christianity & 84 & 70.0 \\
\hline & Islam & 36 & 30.0 \\
\hline & Traditional & 0 & 0.0 \\
\hline \multirow{4}{*}{$\begin{array}{l}\text { Educational } \\
\text { Level }\end{array}$} & & & \\
\hline & First year & 48 & 40 \\
\hline & Second year & 24 & 20 \\
\hline & Third year & 48 & 40 \\
\hline \multirow{4}{*}{ Ethnicity } & & & \\
\hline & Yoruba & 111 & 92.5 \\
\hline & Igbo & 8 & 6.7 \\
\hline & Hausa & 1 & 0.8 \\
\hline \multirow{3}{*}{$\begin{array}{l}\text { Accommodation } \\
\text { type }\end{array}$} & & & \\
\hline & $\begin{array}{l}\text { School } \\
\text { Hostel }\end{array}$ & 96 & 80.0 \\
\hline & Off Campus & 24 & 20.0 \\
\hline \multirow{5}{*}{$\begin{array}{l}\text { Average } \\
\text { Monthly Income }\end{array}$} & & & \\
\hline & $<20,000$ & 98 & 81.7 \\
\hline & $20-50,000$ & 16 & 13.3 \\
\hline & $\begin{array}{l}50- \\
100,000\end{array}$ & 5 & 4.2 \\
\hline & $>100,000$ & 1 & 0.8 \\
\hline \multirow[t]{3}{*}{ Family Type } & & & \\
\hline & $\begin{array}{l}\text { Monogamou } \\
\mathrm{s}\end{array}$ & 89 & 74.2 \\
\hline & Polygamous & 31 & 25.8 \\
\hline
\end{tabular}

$\mathrm{SD}=$ standard deviation

\section{Stressors among the respondents}

Using the PSS, $48.3 \%$ of the respondents sometimes become upset because of something that happened unexpectedly, $17.5 \%$ becomes upset fairly often, $12.5 \%$ almost never becomes upset among the others. Equal number of respondents (5.8\%) never or almost never felt nervous or stressed in the last month, others sometimes (44.2\%), fairly often (19.2\%) and very often $(25.0 \%)$ feel nervous or stressed. Other responses about the PSS are presented in table 2. 
Table 2. The response of the respondents to the perceived stress scale

\begin{tabular}{|c|c|c|c|}
\hline & Question statement & $\mathbf{N}$ & $\%$ \\
\hline 1 & $\begin{array}{l}\text { In the last month, how often have you been upset } \\
\text { because of something that happened unexpectedly? } \\
\text { Never } \\
\text { Almost Never } \\
\text { Sometimes } \\
\text { Fairly Often } \\
\text { Very Often }\end{array}$ & $\begin{array}{l}12 \\
15 \\
58 \\
21 \\
14\end{array}$ & $\begin{array}{l}10.0 \\
12.5 \\
48.3 \\
17.5 \\
11.7\end{array}$ \\
\hline 2 & $\begin{array}{l}\text { In the last month, how often have you felt that you } \\
\text { were unable to control the important things in your } \\
\text { life? } \\
\text { Never } \\
\text { Almost Never } \\
\text { Sometimes } \\
\text { Fairly Often } \\
\text { Very Often }\end{array}$ & $\begin{array}{l}26 \\
18 \\
36 \\
23 \\
17\end{array}$ & $\begin{array}{l}21.7 \\
15.0 \\
30.0 \\
19.2 \\
14.2\end{array}$ \\
\hline 3 & $\begin{array}{l}\text { In the last month, how often have you felt nervous } \\
\text { and "stressed"? } \\
\text { Never } \\
\text { Almost Never } \\
\text { Sometimes } \\
\text { Fairly Often } \\
\text { Very Often }\end{array}$ & $\begin{array}{l}7 \\
7 \\
53 \\
23 \\
30\end{array}$ & $\begin{array}{l}5.8 \\
5.8 \\
44.2 \\
19.2 \\
25.0\end{array}$ \\
\hline 4 & $\begin{array}{l}\text { In the last month, how often have you felt confident } \\
\text { about your ability to handle your personal } \\
\text { problems? } \\
\text { Never } \\
\text { Almost Never } \\
\text { Sometimes } \\
\text { Fairly Often } \\
\text { Very Often }\end{array}$ & $\begin{array}{l}9 \\
17 \\
25 \\
32 \\
37\end{array}$ & $\begin{array}{l}7.5 \\
14.2 \\
20.8 \\
26.7 \\
30.8\end{array}$ \\
\hline 5 & $\begin{array}{l}\text { In the last month, how often have you felt that } \\
\text { things were going your way? } \\
\text { Never } \\
\text { Almost Never } \\
\text { Sometimes } \\
\text { Fairly Often } \\
\text { Very Often }\end{array}$ & $\begin{array}{l}9 \\
17 \\
33 \\
34 \\
27\end{array}$ & $\begin{array}{l}7.5 \\
14.2 \\
27.5 \\
28.3 \\
22.5\end{array}$ \\
\hline 6 & $\begin{array}{l}\text { In the last month, how often have you found that } \\
\text { you could not cope with all the things that you had } \\
\text { to do? } \\
\text { Never } \\
\text { Almost Never } \\
\text { Sometimes } \\
\text { Fairly Often } \\
\text { Very Often }\end{array}$ & $\begin{array}{l}20 \\
32 \\
33 \\
25 \\
10\end{array}$ & $\begin{array}{l}16.7 \\
26.7 \\
27.5 \\
20.8 \\
8.3\end{array}$ \\
\hline
\end{tabular}




\begin{tabular}{|c|c|c|c|}
\hline 7 & $\begin{array}{l}\text { In the last month, how often have you been able to } \\
\text { control irritations in your life? } \\
\text { Never } \\
\text { Almost Never } \\
\text { Sometimes } \\
\text { Fairly Often } \\
\text { Very Often }\end{array}$ & $\begin{array}{l}9 \\
15 \\
43 \\
36 \\
17\end{array}$ & $\begin{array}{l}7.5 \\
12.5 \\
35.8 \\
30.0 \\
14.2\end{array}$ \\
\hline & $\begin{array}{l}\text { In the last month, how often have you felt that you } \\
\text { were on top of things? } \\
\text { Never } \\
\text { Almost Never } \\
\text { Sometimes } \\
\text { Fairly Often } \\
\text { Very Often }\end{array}$ & $\begin{array}{l}8 \\
18 \\
41 \\
34 \\
19\end{array}$ & $\begin{array}{l}6.7 \\
15.0 \\
34.2 \\
28.3 \\
15.8\end{array}$ \\
\hline 9 & $\begin{array}{l}\text { In the last month, how often have you been angered } \\
\text { because of things that were outside of your control? } \\
\text { Never } \\
\text { Almost Never } \\
\text { Sometimes } \\
\text { Fairly Often } \\
\text { Very Often }\end{array}$ & $\begin{array}{l}13 \\
23 \\
43 \\
25 \\
16\end{array}$ & $\begin{array}{l}10.8 \\
19.2 \\
35.8 \\
20.8 \\
13.3\end{array}$ \\
\hline 10 & $\begin{array}{l}\text { In the last month, how often have you felt } \\
\text { difficulties were piling up so high that you could not } \\
\text { overcome them? } \\
\text { Never } \\
\text { Almost Never } \\
\text { Sometimes } \\
\text { Fairly Often } \\
\text { Very Often }\end{array}$ & $\begin{array}{l}17 \\
24 \\
41 \\
25 \\
13\end{array}$ & $\begin{array}{l}14.2 \\
20.0 \\
34.2 \\
20.8 \\
10.8\end{array}$ \\
\hline
\end{tabular}

$\mathrm{n}=$ frequency, $\%=$ percentage

Table 3 shows the relationship between these stressors and the sociodemographic characteristics of the respondents. There is a significant difference between the stress score of the respondents in between the sexes $(16.70$ vs $19.17 ; p=0.045)$. Also the proportion of the females that are stressed is significantly more than the proportion of the males $(66.7 \%$ vs $87.1 \%$; $p=0.018$ ). 
DOI: 10.21522 /TIJNR.2015.03.02.Art005

ISSN: $2520-3126$

Table 3. Relationship between the sociodemographic characteristics of the respondents and the stress level

\begin{tabular}{|c|c|c|c|c|c|c|}
\hline \multirow{2}{*}{\multicolumn{2}{|c|}{ Variable }} & \multicolumn{2}{|c|}{ Stress Score } & \multicolumn{3}{|c|}{ Abnormal stress level } \\
\hline & & & & & & \\
\hline \multirow{4}{*}{ Gender } & & & \multirow{4}{*}{$\begin{array}{l}0.045 \\
*\end{array}$} & & & \multirow{4}{*}{$\begin{array}{l}6.049(0.018 \\
*)\end{array}$} \\
\hline & & & & & & \\
\hline & Male & $\begin{array}{l}16.70 \pm 6.3 \\
6\end{array}$ & & 18 & 66.7 & \\
\hline & Female & $\begin{array}{l}19.17 \pm 5.3 \\
2\end{array}$ & & 81 & 87.1 & \\
\hline \multirow{4}{*}{$\begin{array}{l}\text { Educational } \\
\text { Level }\end{array}$} & & & \multirow[t]{4}{*}{0.191} & & & \multirow[t]{4}{*}{$0.087(0.958)$} \\
\hline & First Year & $\begin{array}{l}18.46 \pm 5.5 \\
7\end{array}$ & & 39 & 81.2 & \\
\hline & $\begin{array}{l}\text { Second } \\
\text { Year }\end{array}$ & $\begin{array}{l}20.42 \pm 6.8 \\
6\end{array}$ & & 20 & 83.3 & \\
\hline & Third Year & $\begin{array}{l}17.88 \pm 4.9 \\
1\end{array}$ & & 40 & 83.3 & \\
\hline \multirow{3}{*}{$\begin{array}{l}\text { Accommodati } \\
\text { on type }\end{array}$} & & & \multirow[t]{3}{*}{0.380} & & & \multirow[t]{3}{*}{$2.828(0.087)$} \\
\hline & $\begin{array}{l}\text { School } \\
\text { Hostel }\end{array}$ & $\begin{array}{l}18.84 \pm 5.7 \\
1\end{array}$ & & 82 & 85.4 & \\
\hline & Off Campus & $\begin{array}{l}17.71 \pm 6.3 \\
4\end{array}$ & & 17 & 70.8 & \\
\hline \multirow{5}{*}{$\begin{array}{l}\text { Average } \\
\text { Monthly } \\
\text { Income }\end{array}$} & & & \multirow[t]{5}{*}{0.096} & & & \multirow[t]{5}{*}{$7.532(0.057)$} \\
\hline & $<20,000$ & $\begin{array}{l}18.83 \pm 5.5 \\
7\end{array}$ & & 84 & 85.7 & \\
\hline & $20-50,000$ & $\begin{array}{l}17.06 \pm 4.0 \\
4\end{array}$ & & 11 & 68.8 & \\
\hline & $\begin{array}{l}50- \\
100,000\end{array}$ & $\begin{array}{l}21.60 \pm 9.1 \\
0\end{array}$ & & 4 & 80.0 & \\
\hline & $>100,000$ & 8.00 & & 0 & 0.0 & \\
\hline \multirow[t]{3}{*}{ Family Type } & & & \multirow[t]{3}{*}{0.662} & & & \multirow[t]{3}{*}{$0.612(0.314)$} \\
\hline & $\begin{array}{l}\text { Monogamo } \\
\text { us }\end{array}$ & $\begin{array}{l}18.48 \pm 5.9 \\
1\end{array}$ & & 72 & 80.9 & \\
\hline & Polygamous & $\begin{array}{l}19.00 \pm 4.8 \\
2\end{array}$ & & 27 & 87.1 & \\
\hline
\end{tabular}

*=significant, $S D=$ standard deviation

\section{Predictors of high stress level among the respondents}

There was a significant positive correlation between the stress level of the respondents and the following coping mechanisms: Denial $(r=0.152, p=0.048)$, Behavioural disengagement $(r=0.212, p=0.010)$, Self-blame $(r=0.241, p=0.004)$. While there was a significant negative correlation between the stress level of the respondents and the following coping mechanisms: Use of emotional support $(r=-0.172, p=0.030)$, Use of instrumental support $(r=-0.192$, $p=0.018)$, Acceptance $(r=-0.153, p=0.047)$. Others are as shown in table 4 . 
Table 4. Correlation between the individual coping mechanism and high stress level among the respondents

\begin{tabular}{|l|l|l|l|}
\hline Question & N & $\mathbf{R}$ & $\begin{array}{l}\boldsymbol{p}- \\
\text { value }\end{array}$ \\
\hline Self-distraction & 120 & 0.063 & 0.247 \\
\hline Active coping & 120 & -0.110 & 0.115 \\
\hline Denial & 120 & 0.152 & $0.048^{*}$ \\
\hline Substance use & 120 & 0.098 & 0.144 \\
\hline Use of emotional support & 120 & -0.172 & $0.030^{*}$ \\
\hline Use of instrumental support & 120 & -0.192 & $0.018^{*}$ \\
\hline Behavioural disengagement & 120 & 0.212 & $0.010^{*}$ \\
\hline Venting & 120 & -0.051 & 0.291 \\
\hline Positive reframing & 120 & -0.080 & 0.194 \\
\hline Planning & 120 & -0.067 & 0.235 \\
\hline Humour & 120 & -0.064 & 0.243 \\
\hline Acceptance & 120 & -0.153 & $0.047^{*}$ \\
\hline Religion & 120 & -0.107 & 0.122 \\
\hline Self-blame & 120 & 0.241 & $0.004^{*}$ \\
\hline
\end{tabular}

On multiple regression analysis, the odds of respondents who practice behavioural disengagement to be highly stressed is $0.262(95 \% \mathrm{CI}, 0.117-1.483)$ times that of respondents who practice other coping mechanisms, a statistically significant effect, $p=0.022$. (Table 5).

Table 5. Regression analysis of the predictors for a high overall stress score amidst the respondents

\begin{tabular}{|c|c|c|c|c|c|c|}
\hline \multirow[t]{2}{*}{ Variable } & \multirow[t]{2}{*}{ df } & \multirow[t]{2}{*}{$\mathbf{t}$} & \multirow{2}{*}{$\begin{array}{l}\text { Odds } \\
\text { Ratio }\end{array}$} & \multicolumn{2}{|c|}{$95 \% \mathrm{CI}$} & \multirow[t]{2}{*}{$p$ - value } \\
\hline & & & & Upper & Lower & \\
\hline Self-distraction & 1 & 1.554 & 0.157 & -0.142 & 1.174 & 0.123 \\
\hline Active coping & 1 & -0.696 & -0.073 & -1.026 & $0 . .493$ & 0.488 \\
\hline Denial & 1 & 1.117 & 0.115 & -0.308 & 1.103 & 0.266 \\
\hline Substance use & 1 & -0.517 & -0.054 & -0.871 & 0.511 & 0.606 \\
\hline Use of emotional support & 1 & -0.781 & -0.094 & -1.136 & 0.494 & 0.436 \\
\hline Use of instrumental support & 1 & -1.442 & -0.164 & -1.186 & 0.187 & 0.152 \\
\hline Behavioural disengagement & 1 & 2.323 & 0.262 & 0.117 & 1.483 & $0.022 *$ \\
\hline Venting & 1 & -0.784 & -0.081 & -1.022 & 0.443 & 0.435 \\
\hline Positive reframing & 1 & 0.106 & 0.012 & -0.742 & 0.826 & 0.916 \\
\hline Planning & 1 & 0.511 & 0.061 & -0.610 & 1.034 & 0.611 \\
\hline Humour & 1 & -1.484 & -0.161 & -1.080 & 0.155 & 0.141 \\
\hline Acceptance & 1 & -1.125 & -0.125 & -1.232 & 0.340 & 0.263 \\
\hline Religion & 1 & -0.287 & -0.035 & -0.896 & 0.669 & 0.774 \\
\hline Self-blame & 1 & 1.736 & 0.181 & -0.091 & 1.371 & 0.086 \\
\hline
\end{tabular}

\section{Discussion of findings}

The major finding of this study is that denial, behavioural disengagement and self-blame all positively correlate with a higher stress score using the PSS. Meanwhile seeing a student who practices behavioural disengagement can predict a very high stress level among other coping mechanisms used by the students. These finding are in agreement with findings by Abasimi et al, 2015 in a Ghanaian population, Yamashita et al, 2012, Kaneko \& Momino, 2015 in a Japanese population, and Kirkland, 1998 in a female African American population. The use of emotional support, use of instrumental support, and acceptance all had significant negative correlation with the overall stress level of the respondents. Ab Latif \& Mat Nor, 2016 showed the beneficial effects of acceptance as an effective coping mechanism among undergraduate nursing students. Students who have accepted the reality of the peculiarity of nursing education 
and are learning to live with it are less likely to be as stressed as their counterparts who still live in denial.

Stress management in the male gender is better than in the females, this has been documented in times past (Benavente \& Costa, 2011). Generally speaking, male students in the health sciences feel less stressed compared to their female counterparts (Backović et al, 2012). Our study shows this gender difference in the stress level of the students. The lower stress level of the male students could also be attributable to the fact that the make gender is always exposed to more stress in this part of the world. Right from childhood, the boy-child is made responsible over his siblings; he plays more rough games with his peers and is even punished harder when he errs. All this background might make him less prone to the stress peculiar to nursing education. The male students approach stress differently from the female students (Sulaiman $e t$ al, 2009; Pourrajab et al, 2014).

In this study, unexpected happenings is a major stress contributor among other factors, about half of the respondents sometimes feel upset as a result of something that happened unexpectedly. This can be compared to a study in India where $56.7 \%$ of the nursing students also sometimes feel upset for the same reason (Nancy, 2011). Using the PSS, the she discovered that the inability of the students to control the things happening to them is the single most important factor contributing to their overall stress level. Also, in Saudi Arabia, unexpected happenings contributed significantly to stress (Eswi et al, 2013).

In a more recent Kano study using the PSS conducted by Asani et al, the overall stress score of the nursing students are higher in all domains when compared with the results from this study (Asani et al, 2016). The study also demonstrated the gender difference in the stress level of the respondents. The overall stress level in our respondents is also much lower that reported by Samson-Akpan et al, 2015 in Calabar and by Omigbodun et al, 2004 in Ibadan, Nigeria.

\section{Summary, limitations, conclusions, and recommendations}

\section{Summary}

This study examined the various stressors and coping strategies of nursing students attending the Osun state school of nursing, Osogbo, Osun state. It has examined the stress level of the students and the relationship between the sociodemographic characteristics of the students and their stress level, showing the association between various coping strategies and the overall stress score and their predictors. This was done using a pretested 2 paged questionnaires. The questionnaire had three sections: 1 . the sociodemographic data, 2. the perceived stress scale (PSS), and 3. The brief coping orientation for problem experiences (COPE). One hundred and twenty nurses were interviewed and their responses were recorded and analysed. Categorical variables were described using frequencies and percentages, while the continuous variables were described using measures of central tendencies and measures of dispersion (Mean, median, standard deviation and range) as appropriate. Differences between means was determined using analysis of variance (ANOVA) and a $\mathrm{P}$ value of $<0.05$ was considered statistically significant. Pearson's Coefficient of Correlation for quantitative variables was used to determine association between the various coping strategies and the overall stress score. Regression analysis made done using cumulative odds ordinal logistic regression with proportional odds. The results show that the level of stress in the students is lower when compared with other studies. The female students have a significant higher stress level as compared with their male counterparts and denial, behavioural disengagement and self-blame correlate positively with a higher stress score. On multiple regression analysis, the odds of respondents who practice behavioural disengagement to be highly stressed is 0.262 (95\% CI, $0.117-1.483$ ) times that of respondents who practice other coping mechanisms.

\section{Limitations}

The researcher was limited by the number of student nurses that were available in the nursing school. Also, the researcher could have made it a multi-centre study but the researcher was 
restrained by financial constraints as there was no funding from any source to finance the study. This put all the financial burden of the research on the researcher.

\section{Conclusion}

The level of stress in the population studied is relatively low when compared with the results from other studies both locally and internationally. The various stressors identified are basically as a result of lack of control over academic events, nervousness, and inability to handle personal problems, irritations, and anger. The stress level in the females is significantly more than in the males and the proportion of stressed females is also significantly higher.

The students are already employing some coping mechanisms to combat their stress experience and students who are practicing behavioural disengagement are highly stressed. Deliberately seeking out these students for proper counselling could help prevent unpleasant life events later in the course of their study. The nursing education authority should look into these stressors with the view to find ways of mitigating them, thereby providing an optimum learning environment for the students. Some of the students already practice other active and avoidant coping techniques.

\section{Recommendation}

A multi-centre study with larger sample size and covering larger population could be beneficial to really get the outlook of other nursing students on a larger scale. This study will be designed to include both public and private nursing schools and also nursing students in the universities. It could be a regional planned study covering the whole of south-western, Nigeria. The benefits of a fully motivating and distress- free nursing education cannot be overemphasized.

\section{References}

[1].Ab Latif, R., \& Mat nor, M. Z. (2016). Stressors and coping strategies during clinical practices among diploma nursing students. Education in Medicine Journal. 8(3):21-33. http://dx.doi.org/10.5959/eimj.v8i3.422.

[2].Abasimi, E., Atindanbila, S., Gai, X., \& Mahamah, M. M., (2015). Analysis of Stress Coping Strategies among Diploma Nursing Students in Ghana. International Journal of Applied Psychology. 2015; 5(2): 26-32. doi: 10.5923/j.ijap.20150502.02.

[3].Ajibade B.L, Olabisi O.O, Fabiyi B, Ajao O.O, \& Ayeni A. (2016). Stress, types of stressors and coping strategies amongst selected nursing schools' students in south-west, Nigeria. European Journal of Biology and Medical Science Research. 4(3): 1-15.

[4].Al-Kandari, F., \& Vidal, V. (2007) Correlation of the health-promoting lifestyle, enrolment level, and academic performance of College of Nursing students in Kuwait. Nurs Health Sci. 9(2):112e9.

[5].Asani, M. O., Farouk, Z., \& Gambo, S., (2016). Prevalence of perceived stress among clinical students of Bayero University Medical School. Niger J Basic Clin Sci, 13: 55-58.

[6].Aston, L., \& Molassiotis, A. (2011). Supervising and supporting student nurses in clinical placements: the peer support initiative. Nurse Educ Today. 23(3):202-210.

[7].Backović, D. V., Živojinović, J. I., Maksimović, J., Maksimović, M. (2012). Gender Differences in Academic Stress and Burnout among Medical Students in Final years of education. Psychiatria Danubina, 24(2): 175-181.

[8].Bankert, E., \& Kozel, V. (2005) Transforming pedagogy in nursing education: a caring learning environment for adult students. Nurs Educ Pers. 26(4):227-229.

[9].Benavente, S. B. T., \& Costa, A. L. S. (2011). Physiological and emotional responses to stress in nursing students: an integrative review of scientific literature. Acta paul. enferm. 24(4). http://dx.doi.org/10.1590/S0103-21002011000400019.

[10]. Brown, H., \& Edelmann, R. P. (2000) A study of expected and experienced stressors and support reported by students and qualified nurses. J Adv Nurs 31(4):857e64. 
DOI: $10.21522 /$ TIJNR.2015.03.02.Art005

ISSN: $2520-3126$

[11]. Burnard, P., Edwards, D., Kim, B., Thaibah, H., Tothova, V., \& Baldacchino, D. (2008) A comparative, longitudinal study of stress in student nurses in five countries: Albania, Brunei, the Czech Republic, Malta and Wales. Nurse Educ Today, 28(2):134e45.

[12]. Chang, E. M., Hancock, K. M., Johnston, A., Daly, J., \& Jackson, D. Role stress in nurses: review of related factors and strategies for moving forward. Nurs Health Sci. 7(1):57e65.

[13]. Deary, I., Watson, R., \& Hogston, R. (2003). A longitudinal cohort study of burnout and attrition in nursing students. J Adv Nurs, 43(1):71e81.

[14]. Del Prato, D., Bankert, E., Grust, P., \& Joseph, J. (2011). Transforming nursing education: a review of stressors and strategies that support students' professional socialization. Advances in Medical Education and Practice. 2: 109-116.

[15]. Eswi, A. S., Radi, S., \& Youssri, H. (2013). Stress/ stressors as perceived by baccalaureate Saudi nursing students. Middle East Journal of Scientific Research. 14(2):193-202.

[16]. Frankel, A. (2009). Nurses' learning styles: promoting better integration of theory into practice. Nurs Times. 105(2):24-27.

[17]. Gibbons, C. (2010). Stress, coping and burn-out in nursing students. International Journal of Nursing Studies, 47, 1299-1309.

[18]. Gibbons, C., Dempster, M., \& Moutray, M. (2007). Stress and eustress in nursing students. Journal of Advanced Nursing, 61(3): 282-290.

[19]. Hughes, L. (1992) Faculty-student interactions and the student-perceived climate for caring. Adv Nur Sci; 14(3):60-71.

[20]. Kaneko S, \& Momino, K. (2015) Stress Factors and Coping Behaviors in Nursing Students during Fundamental Clinical Training in Japan. Int J Nurs Clin Pract 2: 138.

[21]. Khater, W. A. Akhu-Zaheya, L. M. Shaban, I. A. (2014) Sources of Stress and Coping Behaviors in Clinical Practice among Baccalaureate Nursing Students International Journal of Humanities and Social Science. 6(4).

[22]. Kirkland, M. L. (1998). Stressors and coping strategies among successful female African American baccalaureate nursing students. J Nurs Educ. 37(1): 5-12.

[23]. Kohler, J. M., Munz, D. C., \& Grawitch, M. J. (2006). Test of a dynamic stress model for organizational change: do males and females require different models? Appl Psychol Int Rev, 55(2): $168 \mathrm{e} 91$.

[24]. Lazarus R, Folkman S. Stress, appraisal, and coping. New York, NY: Springer, 1984.

[25]. Leodoro, J. L. (2013). Stress, stressors, and stress responses of student nurses in a government nursing school. Health Science Journal. 7(4): 424-435.

[26]. Lim, J., Bogossian, F., \& Ahern, K., (2010) Stress and coping in Australian nurses: a systematic review. Int Nurs Rev, 57: 22e31.

[27]. Lindop, E. (1999). A comparative study of stress between pre- and post-Project 2000 students. J Adv Nurs, 29(4):967e73.

[28]. MacArthur (2014) Coping strategies. Retrieved from http//: www.macses.ucsf.eduon 26/04/2017.

[29]. Nancy, R. K., (2011). Stress and Coping Strategies among Nursing Students. Nursing and Midwifery Research Journal, 7(4).

[30]. Omigbodun, O. O., Onibokun, A. C., Yusuf, B. O., Odukogbe, A. A., \& Omigbodun, A. O. (2004). Stressors and Counselling Needs of Undergraduate Nursing Students in Ibadan, Nigeria. Journal of Nursing Education. 43(9): 412-415.

[31]. Papastavrous, E., Lambrinou, L., Tsangan, H., Saarikoski, M., \& Leino-Kilpi, H. (2010) Student nurses experience of learning in the clinical environment. Nurs Educ Practice. 10(3):176-182.

[32]. Papp, I., Markkanen, M., \& von Bonsdorff, M. (2003) Clinical environment as a learning environment: student nurses' perceptions concerning clinical learning experiences. Nurs Educ Today, 23(4):262-268.

[33]. Pourrajab, M., Rabbani, M., \& Kasmaienezhadfard, S. (2014). Different effects of stress on male and female students. The Online journal of Counselling and Education, 3(3): 31-39.

[34]. Pryjmachuk, S., \& Richards, D. A. (2007) Mental health nursing students differ from other nursing students: some observations from a study on stress and coping. Int J Ment Health Nurs, 16(6):390e402. 
[35]. Pulido-Martos, M., Augusto-Landa, J. M., Lopez-Zafra, E. (2011) Sources of stress in nursing students: a systematic review of quantitative studies. Int Nurs Rev, 59(1):15e25.

[36]. Samson-Akpan, P. E., John, M. E., Edet, O. B., Ella, R. E. (2015). Stress and Coping Strategies among Undergraduate Nursing Students in University of Calabar, Nigeria. Scientific Poster Session 2 at the 43rd Biennial convention of Sigma Theta Tau International, Las Vegas, Nevada, USA.

[37]. Seyedfatemi, N., Tafreshi, M., \& Hagani, H. (2007). Experienced stressors and coping strategies among Iranian nursing students. Biomedical Nursing, 6 (11): 1-10.

[38]. Sharma, N., Kaur, A. (2011) Factors associated with stress among nursing students. Nursing and Midwifery Research Journal, 7(1): 12-21.

[39]. Sheu, S., Lin, H-S., \& Hwang, S. L. (2002). Perceived stress and physio-psycho-social status of nursing students during their initial period of clinical practice: the effect of coping behaviours. International Journal of Nursing Studies, 39, 165-175.

[40]. Sulaiman, T., Hassan, A., Sapian, V. M., \& Abdullah, S. K. (2009). The Level of Stress among Students in Urban and Rural Secondary Schools in Malaysia. European Journal of Social Sciences, 10(2): 179-184.

[41]. Watson, R., Deary, I., Thompson, D., \& Li, G. (2008). A study of stress and burnout in nursing students in Hong Kong: A questionnaire survey. International Journal of Nursing Studies, 45 (10): 15341542.

[42]. Yamashita, K., Saito, M., Toshihiro, T. T. (2012). Stress and coping styles in Japanese nursing students. International Journal of Nursing Practice. 18(5): 489-496. http://dx.doi.org/10.1111/j.1440172X.2012.02056.x. 


\title{
Attitudes of Student Nurses' towards Adherence to Standard Precautions in the Clinical Area at a Large Teaching Hospital in Uganda
}

\author{
Article by Faith R. K. Sebuliba \\ Nursing Department, Uganda Christian University, Mukono, Uganda \\ E-mail: sebulibafaith@gmail.com
}

\begin{abstract}
Standard precautions guidelines are the effective cornerstone W.H.O and CDCC measures of infection control and management used to reduce healthcare associated infections among healthcare workers and patients. However, healthcare workers especially students do not always adhere to them. The purpose of this study was to assess attitudes of student nurses and midwives towards adhering to standard precautions. A quantitative, exploratory study using a self-report questionnaire was carried out on 53 third year diploma nursing and midwifery students at a large teaching hospital in Uganda. Only $81 \%$ of the respondents scored at least $80 \%$ on the attitude scale that was measured using constructs from Rosenstock's, (1974) Health Belief Model. The construct of perceived benefits (84.9\%), self-efficacy (63.5\%), and perceived barriers (62.3\%) rated higher than the rest. The attitudes towards adherence to standard precautions was lower than expected, revealing a gap that may lead to nonadherence to SP and continued predisposition to nosocomial infections in the hospital setting. Findings had implications for nurse educators, administrators, and practitioners to promote nurse's attitudes towards adherence to standard precautions.
\end{abstract}

Keywords: Standard precautions, universal precautions, occupational risks, nosocomial infections, compliance, adherence, health belief model, nurses, healthcare workers.

\section{Introduction}

Standard precautions (SP) are recognized as a cornerstone of effective infection control and management measures that have been demonstrated as effective in reducing healthcare associated infections among patients and healthcare workers. They are the standardized procedures that reduce the risk for exposure to all recognized and unrecognized sources of infection in the hospital (WHO, 2007) and fundamental behaviors expected of all healthcare workers to protect themselves, their patients, and society against the transmission of nosocomial infections. Hospitals harbor high populations of virulent strains of microorganisms resistant to antibiotics that are often transmitted unknowingly by health workers. To prevent the spread of nosocomial infections, the Center for Disease Prevention and Control (CDC), and its Hospital Infection Control Practices Advisory Committee (HICPAC) in 1996 developed a set of protective behaviors, the standard precautions. The SP comprises of measures to guide hand hygiene, use of protective gear, prevention of needle stick injuries, environmental control, prevention of injury from sharp devices, and patient placement (Smeltzer \& Bare, 2004; Potter \& Perry, 2005). WHO, (2007) recommend their use as the minimum level of precautions to be taken when providing care for all patients. The SP's have since been adopted by Ministry of Health in Uganda for use in all health units to help maintain an aseptic field and prevent cross-contamination between the healthcare providers, healthcare providers and patients, and between patients. In addition to reducing the risk of spreading nosocomial infections, SP are designed to protect healthcare workers from occupational hazards like accidental injuries such from sharp instruments.

Nurses, especially students in the clinical area, provide direct patient care and in the process, they engage in risky practices that promote the spread of nosocomial infections. They carry out procedures such as clearing surgical equipment; handling soiled surgical dressings; replacing or removing cannulas; rinsing soiled linen; and collecting specimens that are body tissues, fluids, or blood. During such practices, without any form of protection, the tools nurses use may injure, exposing them to blood and body fluids which may 
DOI: $10.21522 /$ TIJNR.2015.03.02.Art006

ISSN: $2520-3126$

contain infectious microorganisms such as Human Immunodeficiency Virus (HIV) and hepatitis B (Wilburn, 2004). About one in eight healthcare workers receive a needle stick injury, and American healthcare workers suffer 800,000 to 1 million needle stick injuries annually (NIOSH, 2000), not including the vast numbers that go unreported. There were more than 100,000 needle sticks injuries annually in the United Kingdom (ICN, 2009), and in developing countries, such injuries are not adequately documented, but it probably equals or exceeds that in the industrial world.

Despite the presence of the guidelines in hospitals and health units, nurses, especially students, do not always adhere to them. Several studies have described the adherence to SP as inconsistent or inadequate (Harris \& Nicolai, 2010; Haile, Engeda, \& Abdo, 2017), suboptimal ( Doebbeling et al., 2003; Fawole, Sadoh, Oladimeji, \& Sotiloye, 2006; Jeong, Cho, \& Park, 2008; Sadoh, Amin \& Wehedy, 2009), rare (Jeong, Cho, \& Park, 2008), low (Rubinson, Wu, Haponik, \& Diette, 2005; Luo, He, Zhou, \& Luo, 2010; Haile, Engeda, \& Abdo, 2017), and unsatisfactory (Lymer, Richt, \& Isaksson, 2004). Professionals have been reported to have exposed themselves and their patients to unnecessary risks of infection when they did not wash hands or use gloves to puncture blood vessels (Cirelli, Figueiredo, \& Zem-Mascarenhas, 2007).

\section{Purpose of the study}

The purpose of the study was to assess the attitude of student nurses towards adhering to standard precautions during placement in the clinical area so the knowledge gained would be used to design strategies to improve adherence to SP and promote safety of healthcare workers, their families, and patients.

\section{Literature review}

An attitude is a tendency for an individual to respond positively or negatively towards a situation, and in healthcare, it is has been mostly associated with one's response or reaction towards infection control recommendations (Oliveira, Marziale, Paiva, \& Lopes, 2009). Attitude influence an individual's choice of action and responses to stimuli that may present as a challenge, an incentive, or reward. Attitudes may be affective responses such as how an individual feel about work following frustration from burnout or no perceived benefit from rendering a service. Behaviors too, may express an attitude, for example when nurses do not adhere to standard precautions, and mental processes such as perceptions also demonstrate attitude. Attitudes can be positive or negative, and positive attitudes have been found to influence compliance to infection control measures (Jimmieson et al., 2016). In this study, the attitudinal object is pertaining to practicing a health behavior of adhering to standard precautions. Student nurse's attitudes towards adhering to standard precautions were explored using The Health Belief Model to describe what attitudes influenced adherence.

\section{The health belief model}

This study used the concepts in the HBM that hold that behavior is a function of the individual's sociodemographic characteristics, knowledge, and attitude. The HBM has been used in several studies and considered useful in health care promotion and prevention. It was considered for study based on the understanding that it would help to describe why nurses adhere or not adhere to SP in practice, if they felt by doing so they would prevent the transmission of nosocomial infections to themselves and their patients. The HBM developed by Rosenstock, (1974), was intended to predict which individuals would or would not use preventive measures such as screening for early detection of cancer. Becker modified the model in 1974 to include individual perceptions (perceived susceptibility, and perceived seriousness), modifying factors (demographic, sociopsychological and structural variables), and others likely to affect initiating actions. These constructs were used to explore nurses' behavior as it relates to adhering to SP. See Figure 1 for a schematic representation of the Health Belief Model. 


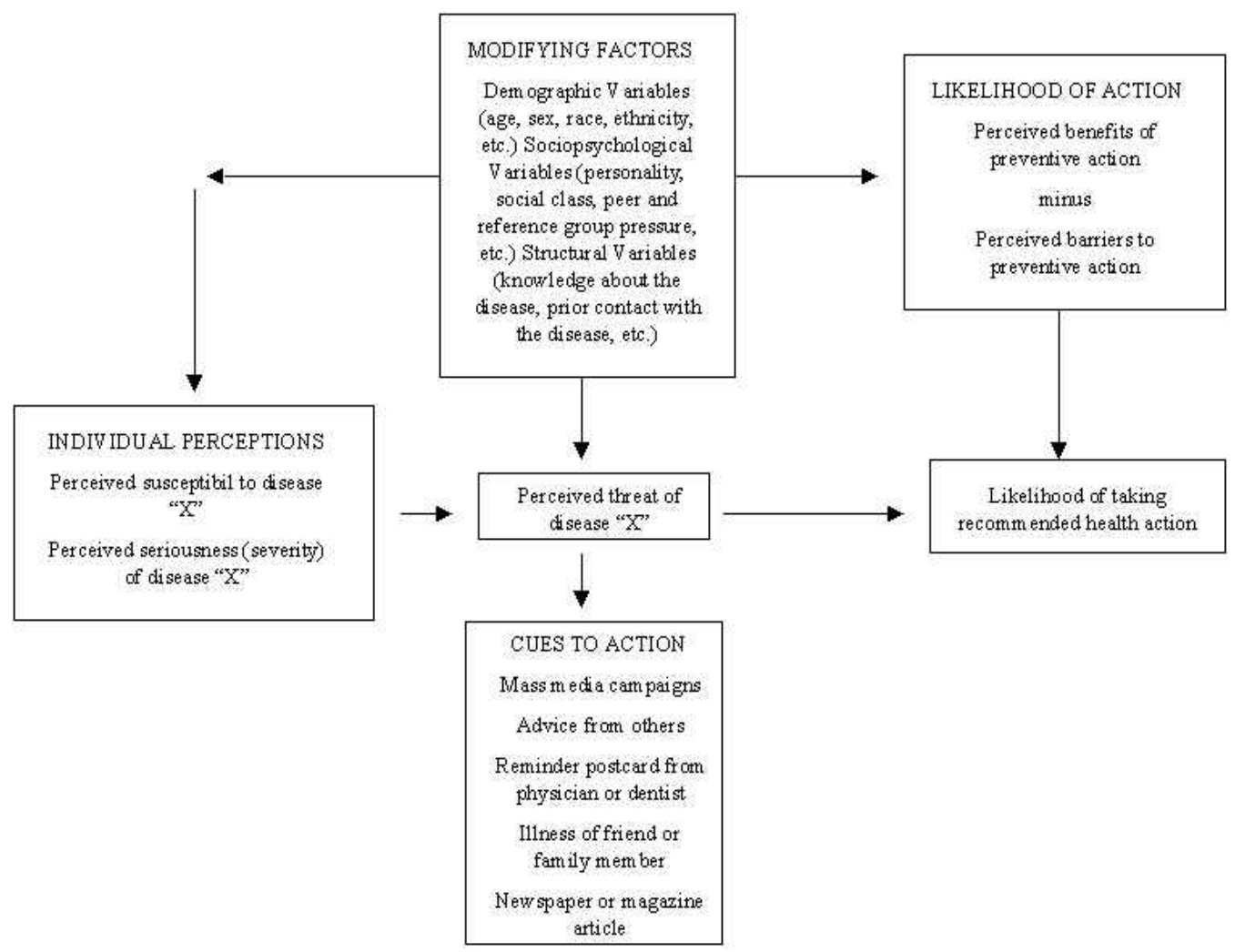

Figure 1. The health belief model (Rosenstock, 1974)

\section{Individual characteristics and experiences}

The HBM holds that each person has unique personal characteristics and experiences that affect subsequent actions (Rosenstock, 1974). These characteristics include prior related behaviors and personal factors that indirectly affect a person's beliefs, affect, and enactment of the health-promoting behavior. The components of the model involve individuals' perceptions of susceptibility to an illness, individuals' perceptions of seriousness of the illness, and likelihood that a person will take a preventive action.

\section{Perceived susceptibility}

Reflects a person's opinion of chances of getting a condition. Nurses work in a hospital environment where they are constantly exposed to risks of contracting infectious diseases. They engage in activities that bring them in direct contact with blood and body fluids that are likely to be infected. Therefore, adhering to SP will prevent them from acquiring or transmitting infections. Studies show that hospital workers perceive a level of susceptibility to acquiring a hospital infection among themselves and their patients, or secondary infection to their family members (Lewis \& Thompson, 2009; Ganczak \& Szych, 2007), and therefore, adhere to the SP because of fear of spreading the infections to their families, patients, and themselves. Other healthcare workers $(\mathrm{HCW})$ revealed fears of contracting infections from work following their engagement in risky behaviors of recapping needles where they sustained needle stick injuries, or working with an abrasion or cut on their hands and were in a situation where the routes for reporting and managing occupational exposures were absent (Reda, Fisseha, Mengistie, \& Vandeweerd, 2010). Healthcare workers in another study perceived an increase in; infections for all, use of antibiotics, morbidity and mortality of patients, and extended hospital stay, if they did not take extra precautions to adhere to hand hygiene (Jimmieson et al., 2016). 
DOI: $10.21522 /$ TIJNR.2015.03.02.Art006

ISSN: $2520-3126$

\section{Perceived severity}

This is a person's opinion of the seriousness and consequences of a condition. The concept is based on how much a person knows about the disease and can result in a change of health behavior. Healthcare workers tend to modified their behavior in accordance with their own subjective assessment of patients' likelihood of having bloodborne viral infections (Ferrer et al., 2009; Cutter \& Jordan, 2004). Most professionals, when they were making decisions about the use of protective clothing they were selective in adherence basing on the nationality, lifestyle, sexual orientation, or perceived low risk patient (Jahangiri, Rostamabadi, Hoboubi, Tadayon, \& Soleimani, 2016; Harris \& Nicolai, 2010;Cutter \& Jordan, 2004). Individuals who do not perceive personal risks from a direct action may not fully understand the severity of not engaging in an action-like adhering to SP.

\section{Likelihood of action}

\section{Perceived benefits}

Perceived benefits are beliefs of individuals in the value of adhering to health-related measures to prevent or reduce the illness or disease. Anticipated benefits or outcomes affect the person's plan to participate in health-promoting behaviors and may facilitate continued practices. The student nurses will use SP during practice when they believe that the measures prescribed will protect them from acquiring infections. Studies have found those nurses who perceived benefit of protection and their family from contracting infections were more likely to adhere to SP (Efstathiou, Papastavrou, Raftopoulos, \& Merkouris, 2011). For example nurses who participated in an education program to improve hand hygiene in a neonatal unit adhered to SP that led to the reduction in bloodstream infections in the neonates (Helder, Brug, Looman, Goudoever, \& Kornelisse, 2010; Chhapola \& Brar, 2015). Other perceived benefits include improvement in hand hygiene (Picheansathian, Pearson, \& Suchaxaya, 2008; Oh, Hamzah, Yan, \& Ang, 2012), and reduction in needle stick injuries.

\section{Perceived barriers}

These are factors that may constrain commitment to action and mediate behavior. The perceived barriers either imagined or real reflect a person's perception about available time, inconvenience, expense, and difficulty performing an activity (Kozier, Erb, Berman \& Snyder, 2004, p. 124). For example, in emergency situations, pausing to follow SP would put the life of a patient at risk (Ferguson, Waitzkin, Beekmann, \& Doebbeling, 2004), or interfere with difficult patient situations when direct care may be required to provide optimal care. Factors such as limited time, type of clinical procedure, irregular education on SP, and nurses' limited involvement in the policy-making process have also been found to contribute to non-adherence to SP (Barrett \& Randle, 2008; Jeong et al., 2008). Similarly, busyness, forgetfulness, and perceptions of skin irritation, inconvenience, poor role modeling, lack of monitoring and feedback have been found to cause barrier to hand hygiene (Foote \& El-Masri, 2016; Pedersen et al., 2017), and non-availability of equipment (Amoran \& Onwube, 2013).

\section{Modifying factors}

Modifying factors are pre-requisite factors whose presence enable an individual to engage in a health behavior and whose absence deter the desired behavior (Kalua \& Nyasulu, 2007). Peers and healthcare providers have been found to be important modifying factors who can increase or decrease commitment to engagement in health-promoting behavior. For example, in-charge nurses who are role models and interested in safety questions, or those who search for and share knowledge about infection control were describes as a great motivation to their peers (Lymer et al., 2004; Foote \& El-Masri, 2016). The location of the hospital, type of unit and number of clinical placements is another modifying factor to adherence to SP (Foote \& El-Masri, 2016). Nurses working in municipal hospitals were more compliant than those in academic hospitals (Ganczak \& Szych, 2007), while those who worked in critical care areas like intensive care units, operating room, or emergency departments, were less likely to consistently adhere to SP as 
compared to those working in the laboratory (Doebbeling et al., 2003).

\section{Cues to action}

Cues to action are the things that may heighten awareness or trigger interest in performing a healthrelated activity such as adhering to SP to prevent acquiring or transmitting HAI. The cues may be internal such as knowledge of outcome of nonadherence, or may be external such as display of information on SP and other infection control measures. Hospitals recommend that guidelines be displayed in places where all care providers can easily access them. Organizational factors such as provision of protective equipment, safety guidelines and occupational characteristics such as frequency of educational programs regarding SP are associated with consistency with adherence to SP (Vaughan et al., 2004). Greater levels of management support such as regular check-ups and supervision were associated with more consistent adherence, whereas negative feedback and increased job demand were associated with a lower likelihood of consistent adherence (Lymer et al., 2004). Increased rates of non-adherence are reported in units where staff do not access guidelines (Maja \& Motshudi, 2009). Prior positive experiences motivate students such as knowledge and display of SP at the places of work, and by observing others engaged in the behavior such as washing hands before and after patient contact.

Although standard precautions are evidence-based measures recommended by CDC/WHO to promote safe practice by preventing spread of HAI, several factors have been found to affect adherence of health care workers to SP. Among those identified, none describes what healthcare worker's attitudes have towards adhering to standard precautions, especially nurses. Adherence to SP is a simple and inexpensive measure used to reduce risk of transmission of infection (Kelcíkova, Skodova, \& Straka, 2011), yet studies show healthcare workers do not always adhere to them. Adherence among student nurses in Uganda has not been studied and may not be different. This study assessed the attitudes of student nurses towards adherence to standard precautions.

\section{Methodology}

\section{Study setting}

The study was carried out at a nursing school that is attached to and uses the large government hospital in Kampala as a clinical area. The hospital models various health promotion projects including infection control. The students receive training conducted at the highest level of professional standards that ensures the nurses exercise professionalism in all their undertakings after they qualify. Given the conditions under which the students' work, the training endeavors to equip them with the skills needed to promote health and prevent devastating consequences resulting from spread of hospital acquired infections.

\section{Design and sampling}

A quantitative, and non-experimental design was carried out to describe what attitudes students had towards adherence to SP. Only 53 third-year nursing and midwifery students who were completing the first or second diploma courses participated in the study, selected by convenience sampling method. The students had worked independently before as staff nurses and used the SP as a measure to prevent spread of infection in the units they worked prior to enrolling in the diploma completion nursing program. At the time of the study, the students had covered a component of infection control and used the measures in their current education program. They had rotated in the medical, surgical, gynecology and obstetrics units for clinical experience where they practiced in the real-world setting the infection prevention measures prescribed in the CDC Standard Guidelines or guidelines by Ministry of Health (MOH) in Uganda.

\section{The questionnaire}

A 30 minute, self-administered questionnaire was distributed to students in the classroom to complete using a self-report approach. It comprised of two sections: a) The demographic data that established information about the respondents, and b) the attitude section that contained statements organized by the 
DOI: $10.21522 /$ TIJNR.2015.03.02.Art006

ISSN: $2520-3126$

constructs of the HBM. The questionnaire was adopted with permission from Lewis \& Thompson, (2009) study to assess clinical employees' perceptions about infection control practices. The tool was considered because of its similarity in the variables under study and the high reliability of the constructs. The Cronbach $\alpha$ for reliability for the subscales in the tool was: perceived severity 0.81 , perceived susceptibility 0.70 , perceived benefits 0.75 , perceived barriers 0.73 , cues to action 0.76 , and self-efficacy 0.65 .

A four-point Likert-type statements related to the recommendations in the SP were used to which the respondents either agreed or disagreed to reflect their attitude towards adherence to SP. Each statement in the constructs was rated, where strongly agreeing with the correct statement or strongly disagreed with a false statement reflected positive attitudes, and a score of 4 points was given. Strongly disagreeing with a correct statement, and strongly agreeing with a false statement scored one point. There were 37 statements and an expected score of 4 points for the most positive response per statement. A total score of $80 \%$ from all constructs was thought to be positive attitude.

\section{Data analysis}

The data from the study were analyzed using quantitative methods. Data was entered twice into Epidata manager software to ensure data integrity and uniformity and exported into SPSS software for analysis. Frequency distribution was run on all data to identify the characteristics and enable description of findings. Tables and graphs were used to present the data. Statistical tests (t-test) was done to establish significant differences between student nurses and midwives attitude towards adhering to SP.

\section{Protection of human subjects}

Permission was sought from the university's Ethical Review Board, and the administration of the nursing training school where the study was conducted. The students volunteered and consented to the study after explaining the nature and benefits.

\section{Results}

\section{Socio-demographic characteristics}

The findings presented were from 53 nursing students, a $94.6 \%$ response rate. The ages of the respondents ranged between 25 and 50 years where the mean and median was 33 and 32 respectively (Figure 2). Most respondents (Table 1) were female (92.5\%). The student midwives were 54.7\% and 45.3\% student nurses. The majority (47.2\%) were attached to the maternity and labor units, $30.2 \%$ medical ward, and the rest combined, were in gynecology, surgical, and other units. Most respondents $(60.0 \%)$ had been in the unit for a period of 1-4 weeks, and the rest had been for longer period of 5-8 weeks (7.6\%) and longer than 9 weeks (26.4\%). Most students had prior working experience ranging between 2 and 27 years, and an average of 8 years, of whom $71.7 \%$ had worked as qualified nurses for a period between 2 and 8 years before joining the present course of study (Figure 3). 


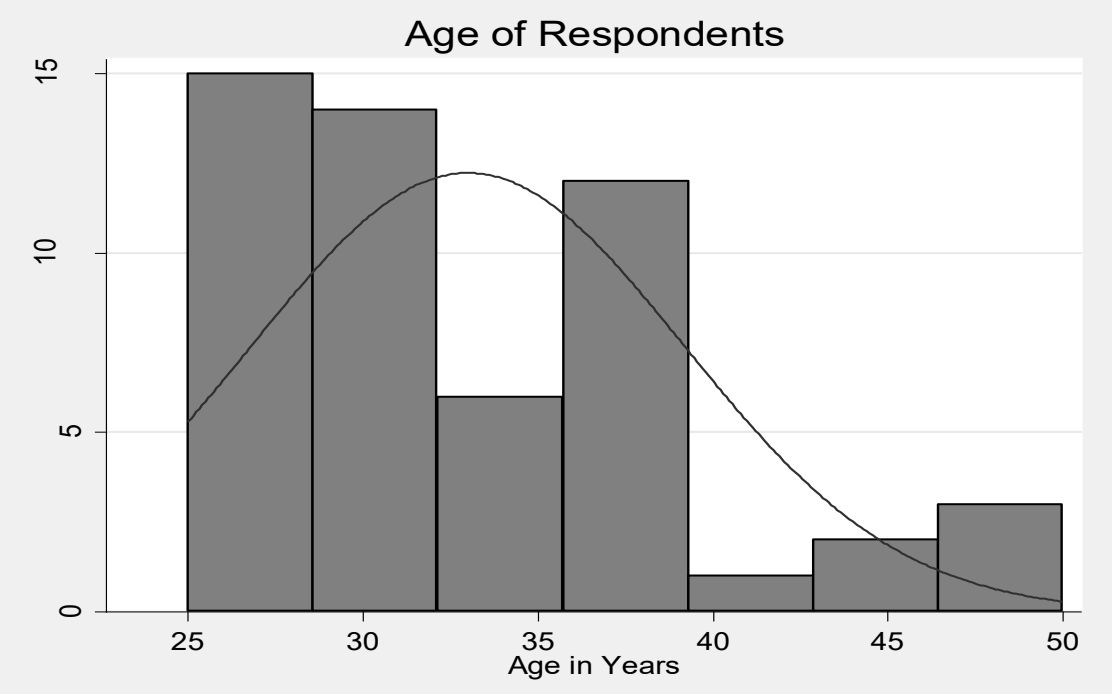

Figure 2: Ages of respondents

Table 1. Socio-demographic characteristics

\begin{tabular}{lll}
\hline Characteristics & Frequency & $\%$ \\
Sex & & \\
Male & 4 & 7.5 \\
Female & 49 & 92.5 \\
\hline Course of study & & \\
Nursing & 24 & 45.3 \\
Midwifery & 29 & 54.7 \\
Area of attachment & & \\
Medical & 15 & 30.2 \\
Surgical & 2 & 3.8 \\
Theater & 1 & 1.9 \\
Maternity & 25 & 47.2 \\
Gynecology & 4 & 7.5 \\
Other units & 5 & 9.4 \\
\hline Length of stay in present & & \\
clinical attachment in weeks & & \\
1-4 weeks & 35 & 60.0 \\
5-8 weeks & 4 & 7.6 \\
$>9$ weeks & 14 & 26.4 \\
\hline
\end{tabular}


DOI: $10.21522 /$ TIJNR.2015.03.02.Art006

ISSN: $2520-3126$

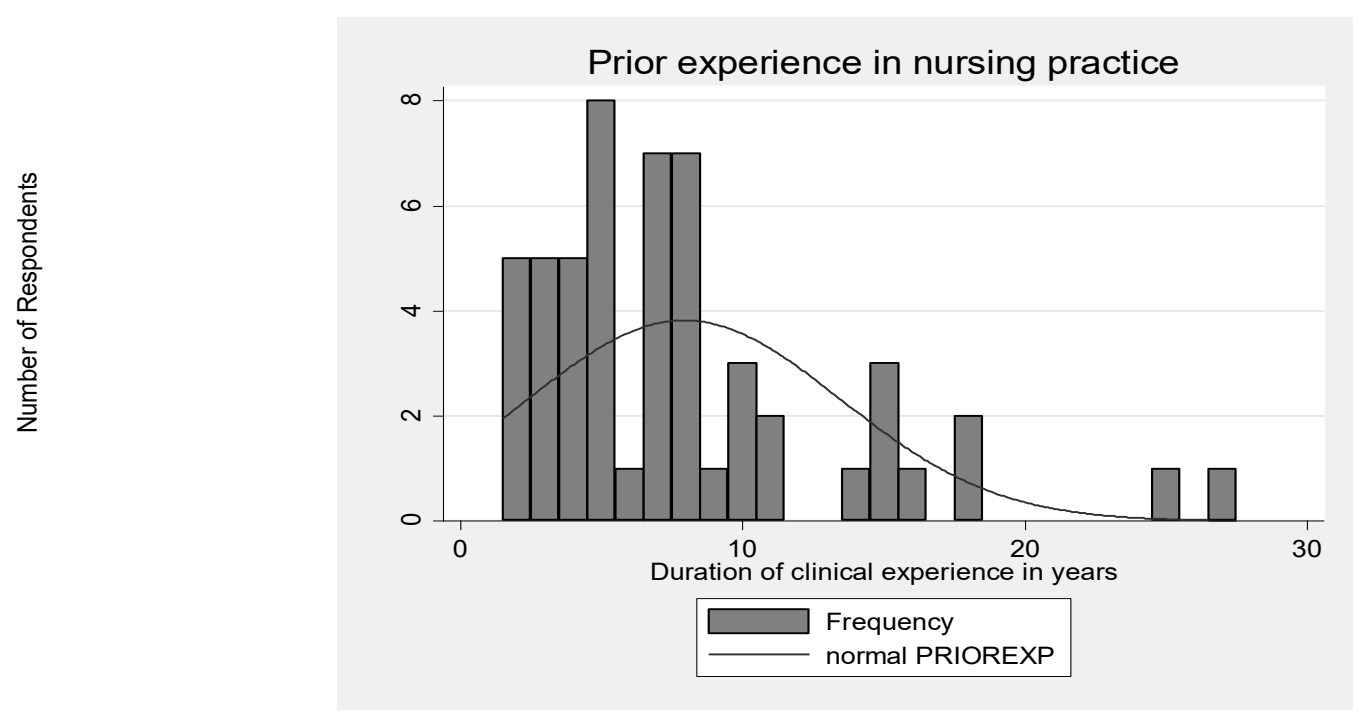

Figure 3. Prior experience before joining course in years

\section{Attitudes}

In this section, Table 2-7 present responses of the nurses regarding their attitude towards adherence to standard precautions as measured per constructs of the HBM. Table 2 and 3 presents the mean, standard deviation, and frequencies of responses for each of the statements in the construct to indicate individual perceptions in the perceived severity and perceived susceptibility respectively.

\section{Individual perceptions}

\section{Perceived severity}

Most respondents in Table 2 strongly agreed or agreed on most of the statements indicating they perceived the severity of acquiring a hospital infection. However, there were some who disagreed to the statement "a patient who obtains a hospital-acquired infection could die (mean 2.60) and "having a patient obtain a hospital acquired infection could cause me trouble" (mean 2.85) indicating these participants may not perceive the severity of acquiring a hospital infection when they did not adhere to SP.

\section{Perceived susceptibility}

In Table 3 respondents agreed with most of the statements on perceived susceptibility to acquiring a hospital infection. Everybody agreed to having infection control as their top concern as healthcare professionals, and most agreed that they could spread infections to their patients if they did not engage in proper infection control (mean 3.64), and they practiced proper infection control because they were concerned for their health and family (mean 3.53). However, most did not perceive the susceptibility of acquiring the hospital infections and disagreed with statement on getting sick with hospital acquired infection all the time. 
Table 2. Perceived severity

\begin{tabular}{|c|c|c|c|c|c|c|}
\hline \multirow[t]{2}{*}{ Perceived Severity Items } & \multirow[t]{2}{*}{ Mean } & \multirow{2}{*}{$\begin{array}{l}\text { Standard } \\
\text { deviation }\end{array}$} & \multicolumn{4}{|c|}{ Frequency of responses } \\
\hline & & & $\begin{array}{l}1 \\
\text { SD }\end{array}$ & $\begin{array}{l}2 \\
D\end{array}$ & $\begin{array}{l}3 \\
A\end{array}$ & $\begin{array}{l}4 \\
\text { SA }\end{array}$ \\
\hline $\begin{array}{l}\text { 1. Having a patient with a hospital } \\
\text { acquired infection is a very serious } \\
\text { problem for this hospital. }\end{array}$ & 3.06 & 1.027 & 5 & 11 & 13 & 24 \\
\hline $\begin{array}{l}\text { 2. Having a patient with hospital } \\
\text { acquired infection is a very serious } \\
\text { problem for the patient. }\end{array}$ & 3.43 & .636 & 1 & 1 & 25 & 26 \\
\hline $\begin{array}{l}\text { 3. Having a patient with a } \\
\text { hospital-acquired infection is a very } \\
\text { serious problem for me. }\end{array}$ & 3.13 & .761 & 2 & 6 & 28 & 17 \\
\hline $\begin{array}{l}\text { 4. A patient who obtains a } \\
\text { hospital-acquired infection could } \\
\text { die. }\end{array}$ & 2.60 & 1.080 & 11 & 12 & 17 & 13 \\
\hline $\begin{array}{l}\text { 5. Having a patient obtain a } \\
\text { hospital-acquired infection could } \\
\text { cause financial strain for the patient } \\
\text { and the hospital }\end{array}$ & 3.19 & .982 & 6 & 3 & 19 & 25 \\
\hline $\begin{array}{l}\text { 6. Having a patient obtain a } \\
\text { hospital-acquired infection could } \\
\text { cause me trouble }\end{array}$ & 2.85 & .841 & 5 & 8 & 30 & 10 \\
\hline
\end{tabular}

\section{Likelihood of action}

Table 4 and 5 present the means, standard deviation, and frequency of response for each item for the subscales perceived benefits and perceived barriers that demonstrate the individual's likelihood of acting to prevent spread of infection.

\section{Perceived benefits}

For perceived benefits subscale (Table 4), most respondents agreed with all the statements on engaging in infection control measures indicating they perceived the benefits, and only who did not perceive the benefit of health facility saving money (mean 3.49).

\section{Perceived barriers}

The statements to assess perceived barriers in Table 5 were negatively worded to reduce response set among respondents. A respondent who strongly disagreed or disagreed with the statements demonstrated a positive attitude towards engaging in SP practices. Most respondents disagreed with the statements, revealing their likelihood of engaging in infection control measures, while the few who agreed with the statements such as "engaging in proper infection control is expensive" (1.72) and I do not have enough knowledge about infection control" (1.82) perceived the barriers and were likely not to engage in the 
DOI: 10.21522 /TIJNR.2015.03.02.Art006

ISSN: $2520-3126$

recommended infection control measures.

Table 3. Perceived susceptibility

Perceived Susceptibility Items

Mean Standard Frequency of responses

deviation

$\begin{array}{llll}1 & 2 & 3 & 4 \\ & & \text { A } & \text { SA }\end{array}$

1. If I do not engage in proper infection

3.91

.861

2 control practices, I could spread infection to my family.

2. If I do not engage in proper infection control practices, I could spread infection to my patients.

3. I get sick with

$2.00 \quad .941$

$20 \quad 16$

143

communicable/infectious diseases all the time.

4. Getting a hospital-acquired infection is easy in any health care setting

$\begin{array}{llllll}3.13 & 1.24 & 4 & 10 & 19 & 19\end{array}$

5. Getting a hospital-acquired infection

.866

3

10

23

17

is easy in this health care setting.

6. Infection control is one of my top

3.77

.423

$0 \quad 0$

12

41

concerns as a health care professional

7. I practice proper infection control because I am concerned for my own health.

8. I practice proper infection control 3.53

3.5

.724

1

$15 \quad 33$

because I am concerned for the health of my family. 
Table 4. Perceived benefits

\begin{tabular}{|c|c|c|c|c|c|c|}
\hline \multirow[t]{2}{*}{ Perceived Benefits } & \multirow[t]{2}{*}{ Mean } & \multirow{2}{*}{$\begin{array}{l}\text { Standard } \\
\text { deviation }\end{array}$} & \multicolumn{4}{|c|}{ Frequency of responses } \\
\hline & & & $\begin{array}{l}1 \\
\text { SD }\end{array}$ & $\begin{array}{l}2 \\
\mathrm{D}\end{array}$ & $\begin{array}{l}3 \\
\mathrm{~A}\end{array}$ & $\begin{array}{l}4 \\
\text { SA }\end{array}$ \\
\hline $\begin{array}{l}\text { 1. Engaging in proper infection } \\
\text { control measures protects the health } \\
\text { care provider and the patient. }\end{array}$ & 3.94 & .233 & 0 & 0 & 3 & 50 \\
\hline $\begin{array}{l}\text { 2. Engaging in proper infection } \\
\text { control measures could prevent or } \\
\text { reduce the risk of hospital-acquired } \\
\text { infections. }\end{array}$ & 3.81 & .395 & 0 & 0 & 10 & 43 \\
\hline $\begin{array}{l}\text { 3. Improving my infection control } \\
\text { practices could prevent my patients } \\
\text { from getting hospital-acquired } \\
\text { infections. }\end{array}$ & 3.66 & .586 & 1 & 0 & 15 & 37 \\
\hline $\begin{array}{l}\text { 4. I feel good about myself when I } \\
\text { engage in proper infection control } \\
\text { practices. }\end{array}$ & 3.79 & .863 & 0 & 0 & 16 & 36 \\
\hline $\begin{array}{l}\text { 5. Engaging in proper infection } \\
\text { control measures could save the } \\
\text { health care facility money. }\end{array}$ & 3.49 & .800 & 2 & 4 & 13 & 34 \\
\hline
\end{tabular}

\section{Cues to action}

Most respondents in Table 6 agreed with the statements regarding cues to action notably, "attending professional development seminars on infection control would help them remember to engage in proper infection control activities" (3.36). However, some respondents strongly disagreed with statements "if a poster was in the duty room, I would remember to wash my hands" (mean 2.66) and "if a coworker or infection control practitioner reminded regularly to engage in infection control practices, I would remember" (mean 2.58), revealing that cues may not be enough to remind individuals to engage in infection control measures.

\section{Self-efficacy}

Table 7 show high means (3.02 to 3.75) from the responses indicating the respondents believed their self-efficacy to involve in infection control measures. Most respondents agreed to all statements, notably "my compliance with infection control recommendations can reduce infections" (mean 3.75). However, some disagreed to their behavior making a difference in a patient acquiring infection (mean 3.27), and the effectiveness of the hand sanitizers to control infection (mean 3.02). 
DOI: $10.21522 /$ TIJNR.2015.03.02.Art006

ISSN: $2520-3126$

Table 5. Barriers to action

\begin{tabular}{|c|c|c|c|c|c|c|}
\hline \multirow[t]{3}{*}{ Barrier Items } & \multirow[t]{3}{*}{ Mean } & \multirow{3}{*}{$\begin{array}{l}\text { Standard } \\
\text { deviation }\end{array}$} & \multicolumn{4}{|c|}{ Frequency of responses } \\
\hline & & & 1 & 2 & 3 & 4 \\
\hline & & & SD & D & A & SA \\
\hline $\begin{array}{l}\text { 1. Engaging in proper infection } \\
\text { control practices is expensive. }\end{array}$ & 1.72 & .818 & 26 & 17 & 9 & 1 \\
\hline $\begin{array}{l}\text { 2. I do not feel that I have enough } \\
\text { knowledge about infection control } \\
\text { practices. }\end{array}$ & 1.82 & .709 & 19 & 25 & 9 & 0 \\
\hline $\begin{array}{l}\text { 3. I do not like engaging in proper } \\
\text { infection control practices. }\end{array}$ & 1.32 & .581 & 38 & 14 & 0 & 1 \\
\hline $\begin{array}{l}\text { 4. I do not feel that engaging in } \\
\text { proper infection control practices in } \\
\text { my practice is my responsibility. }\end{array}$ & 1.36 & .736 & 40 & 9 & 2 & 2 \\
\hline $\begin{array}{l}\text { 5. I feel that it takes too much time } \\
\text { to engage in proper infection control } \\
\text { measures. }\end{array}$ & 1.40 & .599 & 35 & 15 & 3 & 0 \\
\hline $\begin{array}{l}\text { 6. I feel that engaging in proper } \\
\text { infection control measures is too } \\
\text { hard. }\end{array}$ & 1.32 & .581 & 38 & 14 & 0 & 1 \\
\hline $\begin{array}{l}\text { 7. Infection control practices } \\
\text { interfere with patient care. }\end{array}$ & 1.34 & .553 & 37 & 14 & 2 & 0 \\
\hline
\end{tabular}

Table 6. Cues to action

\begin{tabular}{|c|c|c|c|c|c|c|}
\hline \multirow[t]{3}{*}{ Cues to Action Items } & \multirow[t]{3}{*}{ Mean } & \multirow{3}{*}{$\begin{array}{l}\text { Standard } \\
\text { deviation }\end{array}$} & \multicolumn{4}{|c|}{ Frequency of responses } \\
\hline & & & 1 & 2 & 3 & 4 \\
\hline & & & SD & $\mathrm{D}$ & A & SA \\
\hline $\begin{array}{l}\text { 1. Taking courses in infection } \\
\text { control could prevent a patient from } \\
\text { getting a hospital-acquired } \\
\text { infection. }\end{array}$ & 3.09 & .904 & 5 & 4 & 25 & 19 \\
\hline $\begin{array}{l}\text { 2. If a poster was present in the } \\
\text { duty room, I would remember to } \\
\text { wash my hands. }\end{array}$ & 2.66 & .999 & 9 & 11 & 22 & 11 \\
\hline
\end{tabular}


Texila International Journal of Nursing

Volume 3, Issue 2, Dec 2017

\begin{tabular}{lllllll}
\hline $\begin{array}{l}\text { 3. If a coworker or infection } \\
\text { control practitioner reminded me } \\
\text { regularly to engage in infection } \\
\text { control practices, I would } \\
\text { remember. }\end{array}$ & 2.58 & 1.027 & 10 & 13 & 19 & 11 \\
$\begin{array}{l}\text { 4. Attending professional } \\
\text { development seminars on infection } \\
\text { control would help me remember to } \\
\text { engage in proper infection control }\end{array}$ & 3.36 & .653 & 0 & 5 & 24 & 24 \\
$\begin{array}{l}\text { activities. } \\
\begin{array}{l}\text { 5. Seeing my supervisor wash } \\
\text { hands in between procedures } \\
\text { motivates me to wash mine }\end{array}\end{array}$ & 3.09 & .766 & 2 & 7 & 28 & 16 \\
\hline
\end{tabular}

Table 7. Self-efficacy

\begin{tabular}{|c|c|c|c|c|c|c|}
\hline \multirow[t]{2}{*}{ Self-Efficacy Items } & \multirow[t]{2}{*}{ Mean } & \multirow{2}{*}{$\begin{array}{l}\text { Standard } \\
\text { deviation }\end{array}$} & \multicolumn{4}{|c|}{ Frequency of responses } \\
\hline & & & $\begin{array}{l}1 \\
\mathrm{SD}\end{array}$ & $\begin{array}{l}2 \\
D\end{array}$ & $\begin{array}{l}3 \\
\mathrm{~A}\end{array}$ & $\begin{array}{l}4 \\
\text { SA }\end{array}$ \\
\hline $\begin{array}{l}\text { 1. My behavior can make a difference } \\
\text { in whether a patient acquires an } \\
\text { infection while hospitalized. }\end{array}$ & 3.27 & .795 & 2 & 5 & 22 & 23 \\
\hline $\begin{array}{l}\text { 2. Information I obtain on infection } \\
\text { control practices can improve patient } \\
\text { care. }\end{array}$ & 3.65 & .590 & 1 & 0 & 15 & 36 \\
\hline $\begin{array}{l}\text { 3. My compliance with infection } \\
\text { control recommendations can reduce } \\
\text { infections. }\end{array}$ & 3.75 & .440 & 0 & 0 & 13 & 38 \\
\hline $\begin{array}{l}\text { 4. I follow infection control } \\
\text { recommendations regularly. }\end{array}$ & 3.17 & .617 & 0 & 6 & 31 & 15 \\
\hline $\begin{array}{l}\text { 5. I often use soap and water to wash } \\
\text { my hands while working in the health } \\
\text { care setting to reduce spread of } \\
\text { infections. }\end{array}$ & 3.38 & .661 & 0 & 5 & 22 & 25 \\
\hline $\begin{array}{l}\text { 6. Hand sanitizers, when available, } \\
\text { are as effective as hand washing in } \\
\text { controlling infection. }\end{array}$ & 3.02 & .804 & 3 & 7 & 28 & 14 \\
\hline
\end{tabular}

\section{Comparison of subscales}

To rate which construct respondents revealed best attitudes towards adhering to SP, the total score for each statement in the subscale were summed and the findings are presented in Table 8. 
DOI: $10.21522 /$ TIJNR.2015.03.02.Art006

ISSN: $2520-3126$

Table 8. Comparison of item score per construct

\begin{tabular}{|c|c|c|c|c|c|c|c|c|c|}
\hline \multicolumn{2}{|c|}{ Subscales } & \multicolumn{8}{|c|}{ Total item score frequency and percent's (\%) } \\
\hline & & 1 & 2 & 3 & 4 & 5 & 6 & 7 & 8 \\
\hline 1. & Severity & 0 & $\begin{array}{l}3 \\
(5.7)\end{array}$ & $\begin{array}{l}10 \\
(18.9)\end{array}$ & $\begin{array}{l}7 \\
(13.2)\end{array}$ & $\begin{array}{l}14 \\
(26.4)\end{array}$ & $\begin{array}{l}19 \\
(35.8)\end{array}$ & - & - \\
\hline 2. & Susceptibility & 0 & 0 & 0 & $\begin{array}{l}1 \\
(1.9)\end{array}$ & $\begin{array}{l}9 \\
(17.0)\end{array}$ & $\begin{array}{l}11 \\
(20.8)\end{array}$ & $\begin{array}{l}24 \\
(45.3)\end{array}$ & $\begin{array}{l}8 \\
(15.1)\end{array}$ \\
\hline 3. & Benefits & 0 & 0 & 0 & $\begin{array}{l}8 \\
15.1\end{array}$ & $\begin{array}{l}45 \\
(84.9)\end{array}$ & - & - & - \\
\hline 4. & Cues & $\begin{array}{l}4 \\
(7.5)\end{array}$ & $\begin{array}{l}8 \\
(15.1)\end{array}$ & $\begin{array}{l}6 \\
(11.3)\end{array}$ & $\begin{array}{l}12 \\
(22.6)\end{array}$ & $\begin{array}{l}23 \\
(43.4)\end{array}$ & - & - & - \\
\hline 5. & Barriers & 0 & 0 & 0 & $\begin{array}{l}1 \\
(1.9)\end{array}$ & $\begin{array}{l}7 \\
(13.2)\end{array}$ & $\begin{array}{l}12 \\
(22.6)\end{array}$ & $\begin{array}{l}33 \\
(62.3)\end{array}$ & - \\
\hline 6. & Self-efficacy & 0 & 0 & $\begin{array}{l}1 \\
(1.9)\end{array}$ & $\begin{array}{l}7 \\
(13.5) \\
\end{array}$ & $\begin{array}{l}11 \\
(21.2) \\
\end{array}$ & $\begin{array}{l}33 \\
(63.5) \\
\end{array}$ & - & - \\
\hline
\end{tabular}

The highest scores (100\%) per construct in Table 8 are as follows: perceived severity $35.8 \%$, perceived susceptibility $15.1 \%$, perceived benefits $84.9 \%$, cues to action $43.4 \%$, perceived barriers $62.3 \%$, and selfefficacy $63.5 \%$, where perceived benefits, self-efficacy, and perceived barriers showed greater percentage. The overall score for the individual participants was summed and a total was categorized into two groups: the score of $80 \%$ and above was rated positive, favorable attitude or acceptable, and $79 \%$ and below was rated not acceptable. Most respondents (81.1\%) scored $80 \%$ and above indicating an acceptable attitude towards adherence to standard precautions (Table 9). An independent $t$-test to determine the mean differences in the nurses and midwives' attitudes showed midwives demonstrated a more acceptable attitude than the nurses, however, it was not statistically significant $(p=.220, t=-.618)$.

Table 9. Total attitude score

\begin{tabular}{llll}
\hline & \multicolumn{3}{l}{ Percentage total attitude score } \\
\cline { 2 - 4 } Course & $<79$ & $>80$ & Total \\
Student nurse & 3 & 21 & 24 \\
Student midwife & 7 & 22 & 27 \\
Total & 10 & 43 & 53 \\
\hline
\end{tabular}

\section{Discussion}

This chapter discusses the findings from the study to assess factors influencing non-adherence to standard precautions (SP) among student nurses and midwives at a large training school in Uganda. This study explored the students' attitudes towards adherence to SP guided by the constructs from The Health Belief Model (HBM) that have been used successfully previously to study human behavior and attitudes including adhering to standard precautions (Osborne, 2003; Lewis \& Thompson, 2009; Efstathiou, Papastavrou, Raftopoulos, \& Merkouris, 2011). The study, despite the perceived barriers, found $81 \%$ of the respondents scored $80 \%$ and above on the attitude scale and concluded the students demonstrated a positive or more acceptable attitude towards adherence to standard precautions.

\section{Attitude}

Attitude of an individual is very important in predicting behavior. The respondents demonstrated an acceptable attitude towards adherence to SP. Respondents agreed with most statements, however, there were some surprises. The constructs of the HBM were useful in identifying the attitudes students had 
towards adhering to SP as has been found in other studies carried out on reasons for non-compliant behavior.

\section{Perceived severity}

Most respondents perceived the severity of acquiring or transmitting the hospital-acquired infections when they did not adhere to SP, however, some did not perceive the seriousness of the problem in the hospital and associated costs and death of patient. This is in agreement with Efstathiou et al., (2011) findings. It is not unusual for nurses to get terrified by the idea or cost of getting infected by a hospital acquired infection and passing it on to family or to be terrified by death. The fear of getting infected make the nurses adhere to SP. In the same way Lewis and Thompson (2009) in a study to assess health professionals' perceptions and knowledge of infection control found that while professionals perceived the severity of acquiring hospital infections, they did not perceive any problems or trouble resulting from a patient obtaining a hospital acquired infection while in their care. Nurses who do not perceive the seriousness of the hospital-acquired infections or those who do not perceive the threat of a patient dying from a hospital infection may not engage in safe practices such as adherence to standard precautions.

\section{Perceived susceptibility}

The respondents perceived the susceptibility to hospital infections to themselves, their patients and family if they did not engage in infection control practices. All agreed infection control was their top concern. The finding corresponds with a study by Efstathiou et al., (2011) where nurses perceived the vulnerability to acquiring hospital infections that led them to take preventive measures such as using protection during patient care. However, there were students who did not perceive the threat, especially those who did not perceive acquiring a communicable or infectious disease, and those who did not perceive how easy it was to acquire infection from the hospital. The finding was like Lewis and Thompson's study in 2009. The healthcare workers perceived the risk of hospital acquired infections but no personal risks. Such individuals who do not perceive personal risks are more likely not to engage in practices recommended to reduce transmission of infection such as adhering to SP.

\section{Perceived benefits}

The respondents perceived the benefits of adhering to SP such as protecting the health care provider and the patient from getting a hospital-acquired infection and preventing or reducing the risk of hospitalacquired infection to themselves, their patients, and families. Understanding the benefits implies that the individual is ready to undertake the health protective behavior such as adhering to SP. Perceived benefits are associated with high rates of compliance. This is in line with earlier studies where occupation health student nurses perceived the benefits of compliance to SP that resulted in reduced rates of needle stick injuries (Maja \& Motshudi, 2009).

\section{Cues to action}

Whereas many respondents were motivated by cues that reminded them to comply with SP, many respondents disagreed or strongly disagreed to remembering to wash hands when an infection control practitioner reminded them or by the regular reminder from poster in the duty room. The finding is like that of Lewis and Thompson (2009). Not adhering despite the presence of cues to motivate action is surprising as individuals may still not adhere. Studies have found cues that influence adherence such as: patient considered high risk, previous exposure, and continuous reminders (Efstathiou et al., 2011). Nurses believed that continuous reminders (cues) about need to implement SP improved compliance. Contrary to the recommendation and hospital policy to display cues, Maja \& Motshudi, (2009), found the guidelines that would provide clues to the students were always kept away in sisters in-charge room. The guidelines were not readily available for students to refer and clarify issues when supervisors and mentors were not available, a factor that may increase nonadherence. 
DOI: $10.21522 /$ TIJNR.2015.03.02.Art006

ISSN: $2520-3126$

\section{Perceived barriers}

The respondents identified many factors influencing non-adherence to SP however, non-availability of equipment, inconvenience caused by ineffective equipment, emergency and interference with patient care were the most common among them. Several studies have found similar and more barriers (Osborne, 2003; Ferguson et al., 2004; Jeong et al., 2008; Efstathiou et al., 2011). For example, equipment not being available to order; supplies that are rationed or stored away to keep costs low; or equipment available but not of right size or types required; and emergency situations as of life or death where the nurses ration their time to provide care instead of taking time to use protective equipment (Efstathiou et al., 2011). Other healthcare workers perceived barriers such as the expense of engaging in infection control practices. Despite the perceived barriers, most students' attitude towards engaging in infection control practices remained acceptable at $85.7 \%$ and above. This finding shows a more acceptable attitude of the respondents than Lewis and Thompson (2009) finding.

Perceived barriers may contribute to non-adherence but it should be kept in mind that change to adopt new behaviors is not something that comes easily for some individuals. Studies have shown that respondents disclosed that when nurses gain experience they become confident about their capabilities and may not perceive risks (Efstathiou et al., 2011). Feeling confident may not be considered a barrier but resistant to change. Osborne, (2003) found older nurses more resistant to adopting new ways of working which would make them unlikely to adopt new ways of practice such as adhering to recommended guidelines.

\section{Self-efficacy}

The finding show high self-efficacy among respondents suggesting their confidence and readiness to engage in infection control practices. This finding is better than Efstathiou et al., (2011) where nurses in the study disclosed a difficulty to change behavior, even though they knew what they were doing was not correct. This suggests a lack of self-efficacy to engage in infection control practices due to the difficulty in changing behavior.

\section{Limitations}

The study sample comprised of only 53 student nurses and midwives on diploma completion program at a large training school in Uganda. The sample represented only $13.8 \%$ of the student population in the school, and the time for study did not allow to access the entire population of the students. Secondly, a selfreport questionnaire other than an observation study was used to generate subjective views. There was likely to be a tendency to overestimate what an individual knows subjecting findings to bias.

\section{Conclusions}

It emerged from the study that the students demonstrated an acceptable attitude towards adherence to SP. The scores on the measured attitudes using the constructs from The Health Belief Model were found to be higher than $80 \%$ for most students, but fell less than the expected $100 \%$. The student midwives demonstrated more acceptable attitude than the student nurses, although the differences were not statistically significant. The attitudes of the students may therefore, not be the factor that influence nonadherence to SP, but other variables not included in the study. A conclusion was arrived at, that certain conditions may have led to non-adherence to SP other than attitudes.

\section{Recommendations}

There was a gap in the student nurses and midwives' attitudes towards adhering to standard precautions that nurse educators need to address. In planning for the educational needs for students, educators should endeavor to plan activities that increase students' attitudes as they relate to the HBM regardless of the construct for the students to maintain acceptable attitudes that promote adherence. In addition, student nurses and midwives should in their training endeavor to know and practice protective measures that are 
intended to prevent illness and promote health such as the standard precautions. Administrators should organize educational seminars, workshops, or in-service training for their staff to constantly update their knowledge on measures to prevent illness and promote health such as the standard precaution guidelines. Ward in-charges should provide support supervision to students and remind them constantly to carry out protective activities such as washing hands whenever health worker-patient contact is anticipated regardless of nurse's attitudes. In-charges should in addition, provide students cues that attract and motivate them to adhere to the expected behaviors.

Further studies should be carried out to identify factors influencing adherence to standard precautions that were not employed in this study. An observation method on adherence to SP to compliment self-report should be considered to validate attitudes towards, and actual practice of adhering to SP. A heterogeneous sample is recommended to strengthen findings that will enable generalization to other healthcare populations.

\section{Summary}

Standard precautions are the standardized procedures that reduce the risk for exposure to all recognized and unrecognized sources of infection in the hospital, and are fundamental behaviors expected of all nurses to protect themselves, their patients and society against the transmission of communicable diseases. Despite their presence, studies on compliance have revealed non-compliance among all health care workers. This study explored the attitudes of student nurses and midwives towards adherence to SP. Fifty-three (53) students responded to a self-report questionnaire organized by the constructs from the HBM, a model that has been used by other researchers to study compliance. The findings of the study revealed an acceptable attitude from the students. The construct of perceived benefits $(84.9 \%)$, self-efficacy $(63.5 \%)$, and perceived barriers $(62.3 \%)$ rated higher than the rest.

\section{Acknowledgement}

My deepest gratitude to Connie Clark and Karen Drake whose assistance in undertaking this study I treasure and the student who participated.

\section{References}

[1]. Amin, T., \& Wehedy, A. Al. (2009). Healthcare providers' knowledge of standard precautions at the primary healthcare level in Saudi Arabia. Healthcare Infection, 14, 65-72. http://doi.org/10.1071/HI09107.

[2]. Amoran, O., \& Onwube, O. (2013). Infection control and practice of standard precautions among healthcare workers in northern Nigeria. Journal of Global Infectious Diseases, 5(4), 156. http://doi.org/10.4103/0974777X.122010.

[3]. Barrett, R., \& Randle, J. (2008). Hand hygiene practices : nursing students ' perceptions. Journal of Clinical Nursing, 17, 1851-1857. http://doi.org/10.1111/j.1365-2702.2007.02215.x.

[4]. Chhapola, V., \& Brar, R. (2015). Impact of an educational intervention on hand hygiene compliance and infection rate in a developing country neonatal intensive care unit. International Journal of Nursing Practice, 21, 486-492. http://doi.org/10.1111/ijn.12283.

[5]. Cirelli, M. A., Figueiredo, R. M. de, \& Zem-Mascarenhas, S. helena. (2007). Adherence to standard precaution in the peripheral vascular access 1. Rev Latino-Am Enfermagem, 15(3), 512-514. Retrieved from www.scielo.br/pdf/rlae/v15n3/v15n3a24.

[6]. Cutter, J., \& Jordan, S. (2004). Uptake of guidelines to avoid and report exposure to blood and body fluids. Journal of Advanced Nursing, 46, 441-452.

[7]. Doebbeling, B. N., Vaughn, T. E., Mccoy, K. D., Beekmann, S. E., Woolson, R. F., Ferguson, K. J., \& Torner, J. C. (2003). Percutaneous injury, blood exposure, and adherence to standard precautions : Are hospital-based health care providers still at risk ? Clinical Infectious Diseases, 37, 1006-1013.

[8]. Efstathiou, G., Papastavrou, E., Raftopoulos, V., \& Merkouris, A. (2011). Factors influencing nurses ' compliance with standard precautions in order to avoid occupational exposure to microorganisms: A focus group study. BMC Nursing, 10(1), 1-12. Retrieved from http://www.biomedcentral.com/1472-6955/10/1. 
DOI: $10.21522 /$ TIJNR.2015.03.02.Art006

ISSN: $2520-3126$

[9]. Ferguson, K. J., Waitzkin, H., Beekmann, S. E., \& Doebbeling, B. N. (2004). Critical incidents of nonadherence with standard precautions guidelines among Community Hospital-based health care workers. Journal of General Internal Medicine, 19(7), 726-731. http://doi.org/10.1111/j.1525.1497.2004.20424.x.

[10]. Ferrer, L. M., Cianelli, R., Norr, K. F., Cabieses, B., Araya, A., Irarra, L., \& Bernales, M. (2009). Observed use of standard precautions in Chilean community clinics. Public Health Nursing, 26(5), 440-448. http://doi.org/10.1111/j.1525-1446.2009.00802.x.

[11]. Foote, A., \& El-Masri, M. (2016). Self-perceived hand hygiene practices among undergraduate nursing students. Journal of Rsearch in Nursing, 21(1), 8-19. http://doi.org/10.1177/1744987115606959.

[12]. Ganczak, M., \& Szych, Z. (2007). Surgical nurses and compliance with personal protective equipment. Journal of Hospital Infection, 66(4), 346-351. http://doi.org/10.1016/j.jhin.2007.05.007.

[13]. Haile, T. G., Engeda, E. H., \& Abdo, A. A. (2017). Compliance with standard precautions and associated factors among healthcare workers in Gondar University Comprehensive Specialized Hospital, Northwest Ethiopia. Journal of Environmental and Public Health, 2017, 1-9. http://doi.org/10.1155/2017/2050635.

[14]. Harris, S. A., \& Nicolai, L. A. (2010). Occupational exposures in emergency medical service providers and knowledge of and compliance with universal precautions. American Journal of Infection Control, 38(2), 86-94. http://doi.org/10.1016/j.ajic.2009.05.012.

[15]. Helder, O. K., Brug, J., Looman, C. W. N., Goudoever, J. B. Van, \& Kornelisse, R. F. (2010). The impact of an education program on hand hygiene compliance and nosocomial infection incidence in an urban neonatal intensive care unit : An intervention study with before and after comparison. International Journal of Nursing Studies, 47, 12451252. http://doi.org/10.1016/j.ijnurstu.2010.03.005.

[16]. Jahangiri, M., Rostamabadi, A., Hoboubi, N., Tadayon, N., \& Soleimani, A. (2016). Needle stick injuries and their related safety measures among nurses in a University Hospital, Shiraz, Iran. Safety and Health at Work, 7(1), 72-77. http://doi.org/10.1016/j.shaw.2015.07.006.

[17]. Jeong, I., Cho, J., \& Park, S. (2008). Compliance with standard precautions among operating room nurses in South Korea. American Journal of Infection Control, 36(10), 739-742. http://doi.org/10.1016/j.ajic.2008.04.253.

[18]. Jimmieson, N. L., Tucker, M. K., White, K. M., Liao, J., Campbell, M., Brain, D., ... Graves, N. (2016). The role of time pressure and different psychological safety climate referents in the prediction of nurses ' hand hygiene compliance. Safety Science, 82, 29-43. http://doi.org/10.1016/j.ssci.2015.08.015.

[19]. Kalua, F., \& Nyasulu, Y. (2007). A review of the role of modifying factors in health education programmes. Malawi Medical Journal, 19(1), 30-31. Retrieved from http://www.pubmedcentral.nih.gov/articlerender.fcgi?artid=3615310\&tool=pmcentrez\&rendertype $=$ abstract $\% 5 \mathrm{Cn}$ http://www.ncbi.nlm.nih.gov/pubmed/23878630\%5Cn

http://www.pubmedcentral.nih.gov/articlerender.fcgi?artid=PMC3615310.

[20]. Kelcíkova, S., Skodova, Z., \& Straka, S. (2011). Effectiveness of hand hygiene education in a basic nursing school curricula. Public Health Nursing, 29(2), 152-159. http://doi.org/10.1111/j.1525-1446.2011.00985.x.

[21]. Lewis, K. L., \& Thompson, J. M. (2009). Health care professionals ' perceptions and knowledge of infection control practices in a community hospital. The Health Care Manager, 28(3), 230-239.

[22]. Luo, Y., He, G., Zhou, J., \& Luo, Y. (2010). Factors impacting compliance with standard precautions in nursing , China. International Journal of Infectious Diseases, 14(12), e1106-e1114. http://doi.org/10.1016/j.ijid.2009.03.037.

[23]. Lymer, U., Richt, B., \& Isaksson, B. (2004). Blood exposure: Factors promoting health care workers ' compliance with guidelines in connection with risk. Journal of Clinical Nursing, 13, 547-554.

[24]. Maja, T., \& Motshudi, M. J. (2009). Precautions used by occupational health nursing students during clinical placements. Curationis, 32(1), 14-20.

[25]. NIOSH. (2000). ICN on Preventing needlestick injuries. Retrieved from www.who.int/occupational_health/activities/2icnneed.

[26]. Oh, E., Hamzah, H. B. M., Yan, C. C., \& Ang, E. (2012). Enhancing hand hygiene in a polyclinic in Singapore. International Journal of Evidence-Based Healthcare, 10, 204-210. http://doi.org/10.1111/j.1744-1609.2012.00277.x.

[27]. Oliveira, A. C., Marziale, M. H. P., Paiva, M. H. R. S., \& Lopes, A. C. S. (2009). Knowledge and attitude regarding standard precautions in a Brazilian public emergency service: A cross-sectional study. Rev Esc Enferm 


\section{Texila International Journal of Nursing}

Volume 3, Issue 2, Dec 2017

USP, 43(2), 313-319. Retrieved from www.ee.usp.br/reeusp/.

[28]. Osborne, S. (2003). Influences on compliance with standard precautions among operating room nurses. American Journal of Infection Control, 31(7), 415-423. http://doi.org/10.1067/mic.2003.68.

[29]. Pedersen, L., Elgin, K., Peace, B., Masroor, N., Doll, M., Sanogo, K., ... Bearman, G. (2017). Barriers , perceptions, and adherence: Hand hygiene in the operating room and endoscopy suite. AJIC: American Journal of Infection Control, 45(6), 695-697. http://doi.org/10.1016/j.ajic.2017.01.003.

[30]. Picheansathian, W., Pearson, A., \& Suchaxaya, P. (2008). The effectiveness of a promotion programme on hand hygiene compliance and nosocomial infections in a neonatal intensive care unit. International Journal of Nursing Practice, 14, 315-321. http://doi.org/10.1111/j.1440-172X.2008.00699.x

[31]. Polit, D. F., \& Beck, C. T. (2008). Nursing research, generating and assessing evidence for nursing practice (8th ed.). Philadelphia, PA. Lippincott Williams \& Wilkins.

[32]. Potter, P., \& Perry, A.G., (2005). Fundamentals of nursing (6th ed.). St Louis: Mosby.

[33]. Reda, A. A., Fisseha, S., Mengistie, B., \& Vandeweerd, J. (2010). Standard precautions : Occupational exposure and behavior of health care workers in Ethiopia. PLoS ONE, 5(12), 1-6. http://doi.org/10.1371/journal.pone.0014420. [34]. Rosenstock, I. M. (1974). Historical origins of The Health Belief Model. Health Education \& Behavior, 2(4), 328-335. http://doi.org/10.1177/109019817400200403.

[35]. Rubinson, L., Wu, A. W., Haponik, E. F., \& Diette, G. B. (2005). Why is it internists do not follow guidelines for preventing intravascular catheter infections? Infection Control and Hospital Epidemiology, $26(6), 525-533$. Retrieved from https://pdfs.semanticscholar.org/5ca2/34cf7ac919b536c1a8a0684c465ea017213a.

[36]. Smeltzer, S. C., \& Bare, B. G., (2004). Brunner and Suddarth's textbook of medical-surgical nursing (10th ed). Philadelphia, PA: Lippincott Williams \& Wilkin.

[37]. WHO. (2007). Standard precautions in health care key elements at a glance (No. CH-1211). Infection Control. Geneva. Retrieved from http://www.who.int/injection_safety/sign/en/.

[38]. Wilburn, S. Q. (2004). Needlestick and sharps injury prevention. The Online Journal of Issues in Nursing, 9(3), 1-10. Retrieved from.

http://www.nursingworld.org/MainMenuCategories/ANAMarketplace/ANAPeriodicals/OJIN/TableofContents/Volu me92004/No3Sept04/InjuryPrevention.html. 


\title{
Impact of Mentoring on Nursing and Midwifery Educators and Students: An Integrative
}

\author{
Article by Elizabeth Namukombe Ekong ${ }^{1}$, Sun J. Carolyne ${ }^{2}$, \\ ${ }^{1}$ PhD, Uganda Christian University, Uganda \\ ${ }^{2}$ Sloan Kettering Institute \\ E-mail: ekongelizabeth@yahoo.com
}

\begin{abstract}
Background: Academic staff shortages exist in training institutions within the developed and developing world. Mentoring is thought to enhance teachers' competencies, strengthen social abilities, and promote learning and career development; however, not much is known about mentoring in developing countries and its impact on nursing academia. The aim of this literature review was to explore existing evidence on the impact of mentoring on nurse and midwifery teaching competencies and students' learning and social abilities, and the pre-requisites for establishing an effective mentoring program.

Methodology: A comprehensive literature search was performed using HINARI, PubMed, SAGE, WILEY, Science direct, Google scholar, and Google search. Hand searching was too done through bibliographies to identify related articles. Results were screened to select studies that reported benefits and challenges of mentoring to nurse and midwifery educators, student nurses and midwives, and successful mentoring programs. After screening, a total of 15 articles met the inclusion criteria and were reviewed and analysed.

Results: Senior faculty mentoring junior faculty provides or enhances accomplishments of some nurse educator core competencies, provides opportunities to develop teaching knowledge base, and promotes exposure to required resources for growth in the teaching career. It further stimulates personal and social growth. Mentored student nurses and midwives experience reduced anxiety, and mentoring provides a supportive learning environment and increased self-awareness of one's own values and beliefs, confidence, maturity and responsibility. Lack of time, dual responsibility, heavy workload, personality, and attitude may negatively impact the mentoring process. An effective mentoring program requires a relevant mentoring model and clear definitions of its context, structure, and goals.
\end{abstract}

Conclusion: Mentoring has the potential to strengthen teaching competencies as well as students' learning and professional growth.

Keywords: Effective Mentoring program, Impact of mentoring, Midwifery educators, Nurse Educators, nursing education, social abilities, student midwives, student nurses, teaching competencies

\section{Background}

Staff shortages in nursing academia continue to be a challenge both in developed and developing countries (Norwell, White, Marklas, \& Norris, 2015). The problem has been attributed to: lack of nurse educators to be recruited in nurse training institutions; lack of enthusiasm by registered nurses to pursue nursing education as a career path; discrepancies in remuneration; and few registered nurses with sufficient education to meet university standards for employment (Nowell, White, Mrklas, \& Norris, 2015). Nurse and midwifery educators should identify or develop models or approaches that can strengthen faculty relationships, enhance new nurse educators' teaching capabilities, and attract them into nursing education, academics and research (NLN, 2006).

Mentoring is one of the models associated with bridging the shortage of academic staffing by reducing the effects of increased workload, stress, and burnout with subsequent staff turnover; and enhancing motivation, growth, and self-esteem among new faculty nurses with the subsequent outcome of job satisfaction and retention (Sawatzky and Enns, 2009; Block, Claffey, Korow, 
Mccaffrey, \& Services, 2005). The mentoring relationship builds an individual's communication and people skills as well as personal development, including how to demonstrate equality and deal with diversity (Scotland, 2007).

The concept of mentoring has been explored in different ways to provide evidence on its role in nursing education, practice, leadership, and administration. Concept analysis was conducted by Hodgson and Scanlan (2013) in relation to nursing leadership. The analysis provided a clear understanding of the definition of mentoring, its use, characteristics, related terms, and defining attributes and explained through clear examples of borderline, related, and contrary cases. The analysis also outlined antecedents (the pre-requisites to mentoring) (Metcalfe, 2010) and results of mentoring, which included job satisfaction, staff retention, empowerment, motivation and professional development (Sawatzky and Enns, 2009; Block, et al, 2005).

Other sources of evidence have been sought through systematic literature reviews to establish the effectiveness and application of mentorship programs for recently registered nurses (Chen and Lou, 2014) and mentorship programs in nursing academia (Nowell, Norris, Mrklas and White, 2017). The systematic reviews found were in academic medicine and education (Kashiwagi, Varkey \& Cook, 2013; Pi-Jen Lin, 2007). In summary, the literature on the importance of mentoring is scarce, and there is an important gap in knowledge to be filled with an integrative review on how mentoring enhances the teacher's competencies. Therefore, this integrative approach was undertaken to seek existing evidence on the impact of mentoring on nurse and midwifery teaching competencies and students' learning abilities, and the pre-requisites for establishing an effective mentoring program. The aim was that the findings would inform best practices for the integration of mentoring into nursing education to strengthen teaching and learning abilities.

\section{Significance to nursing}

Concrete knowledge of the concept of mentoring is key to strengthening a working relationship among nurses and midwives in all sectors: practice, education, leadership and research (Sawatzky and Enns, 2009); (Block et al., 2005). Established evidence on the impact of mentoring on a nurse's and midwife's teaching competencies navigates into possibilities of introducing a mentorship program in an educational institution inclusive of nursing (RCN, 2015). New innovations require evidence-based guidelines. Evidence on pre-requisites for an effective mentoring program would enhance the implementation process of the desired mentoring model in an institution.

\section{Methodology}

A comprehensive literature search was conducted using HINARI, PubMed, SAGE Publications Wiley online library, and Science Direct online databases. Hand search was also done using biographies of retrieved articles. Table 1 is a summary of the databases and other sources used.

Table 1. The search terms and databases and other sources used

\begin{tabular}{|l|l|l|}
\hline Search terms & $\begin{array}{l}\text { Databases and other } \\
\text { sources }\end{array}$ & $\begin{array}{l}\text { Articles retrieved } \\
\text { for screening }\end{array}$ \\
\hline Mentoring and nursing, & HINARI & 0 \\
\hline Mentoring and midwifery & Pub Med-Oxford Journal & 4 \\
\hline $\begin{array}{l}\text { Mentoring and nursing } \\
\text { education }\end{array}$ & SAGE & 20 \\
\hline Impact of mentoring on faculty & Wiley Online Library & 15 \\
\hline $\begin{array}{l}\text { Mentoring and student } \\
\text { nurses/midwives }\end{array}$ & Science Direct & 18 \\
\hline $\begin{array}{l}\text { Effective Mentoring programs } \\
\text { Mentoring and nursing, }\end{array}$ & Google Search & 56 \\
\hline $\begin{array}{l}\text { Mentorship, nursing and } \\
\text { midwifery students }\end{array}$ & SAGEgle Scholar & 13 \\
\hline Total articles to be screened & & 13 \\
\hline
\end{tabular}


During the screening, inclusion criteria included studies or reviews published from 2000 to 2017, and included information on the impact or benefits and challenges of mentoring to nurse and midwifery educators or teacher's competencies, and nursing and midwifery students. Additionally, articles or papers that described successful mentoring models and frameworks were included. Only articles written in English language were reviewed. Figure 1 below summarises the identification and screening process.

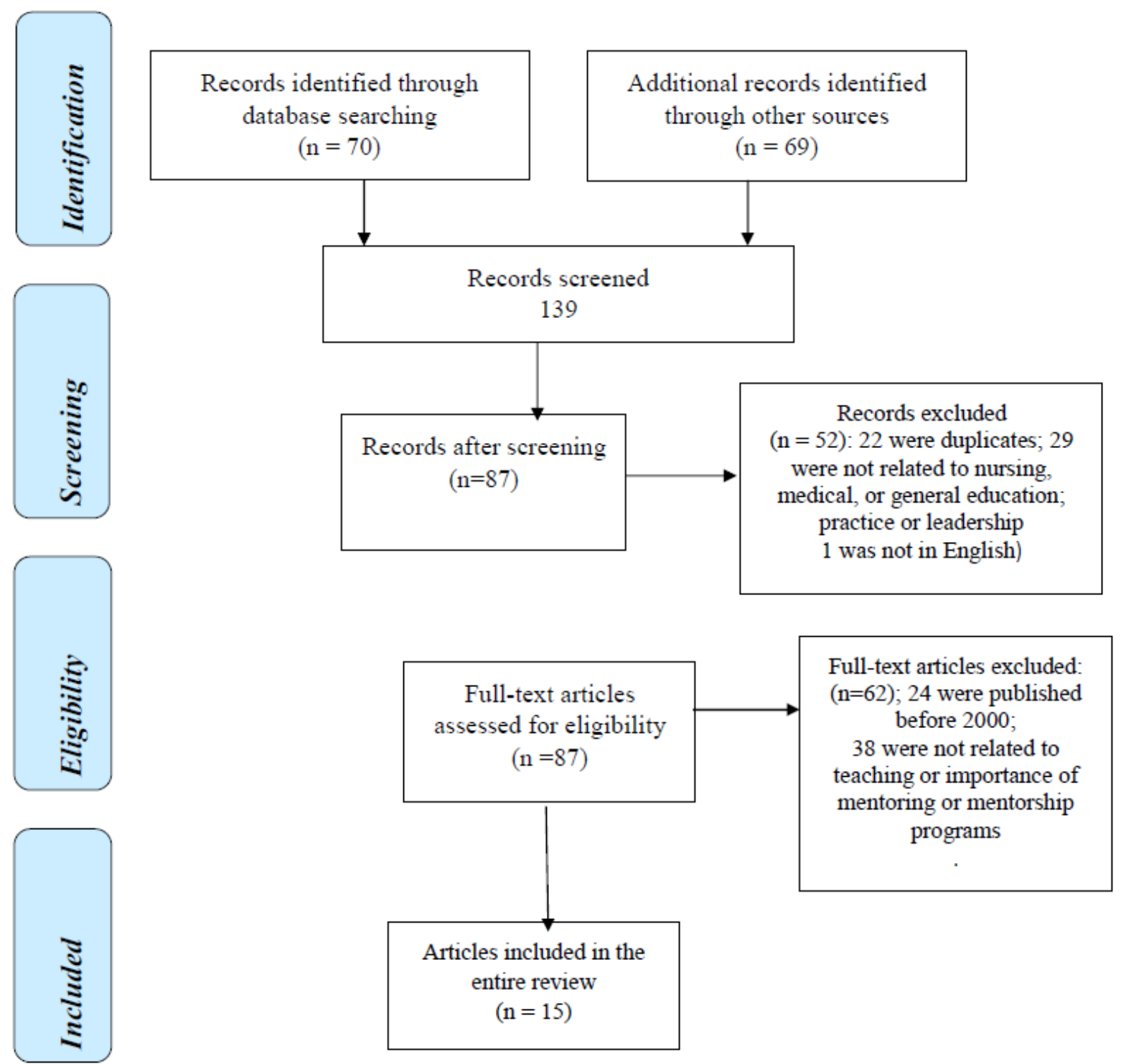

Figure 1. Identification, screening, inclusion and exclusion criteria

Articles were reviewed to answer the stated questions: What is the impact of mentoring on nurse and midwifery educator's teaching competencies, their social relationships, and student nurses' learning? What are the pre-requisites for establishing an effective mentoring program? Since this was an integrative review of literature, the search was not limited to nursing but extended to other disciplines like medicine, psychology, education in general, and leadership and management

A matrix was completed to analyse the results (Table 2). As each article was reviewed and entered in a matrix, key findings were generated under the following headings: impact of mentoring on nurse and midwifery educator's teaching competencies, impact of mentoring on nurse and midwifery educator's social relationships and student nurses' learning, and requirements for an effective mentoring program. 


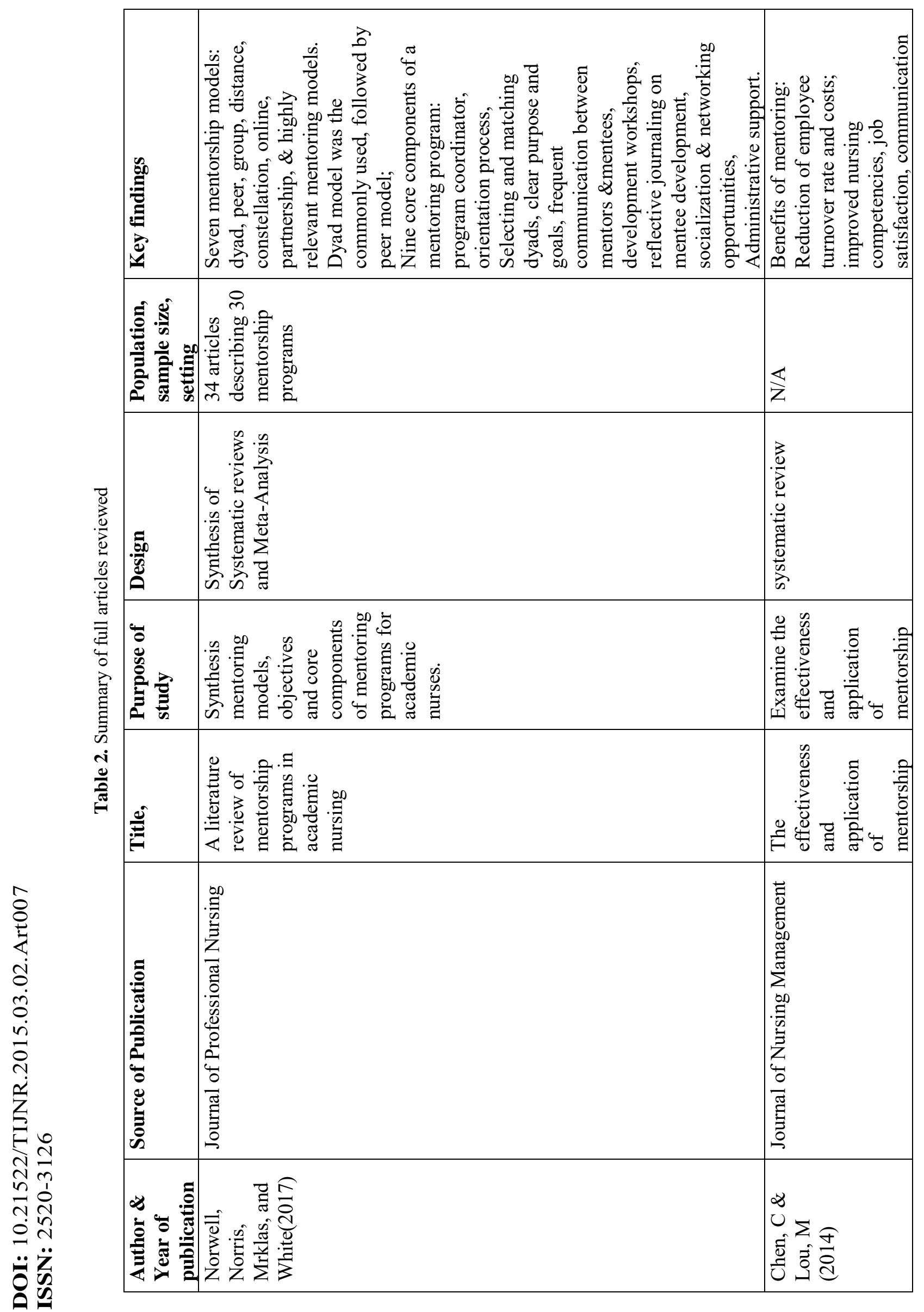




\begin{tabular}{|c|c|c|c|}
\hline 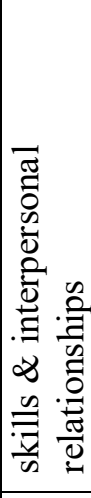 & 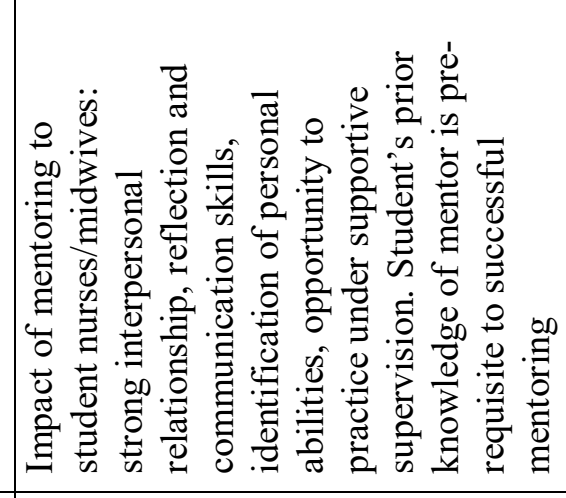 & 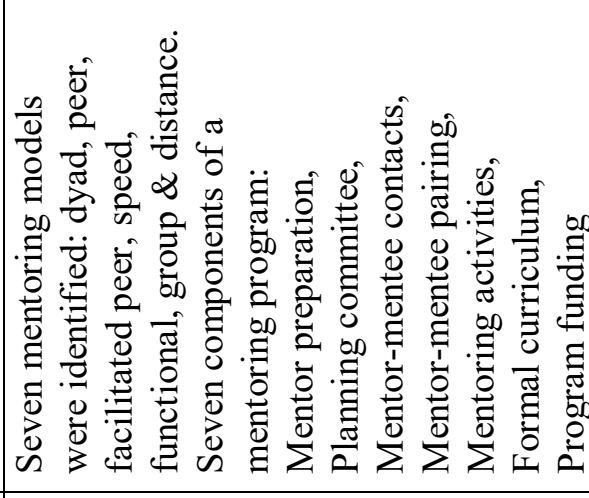 & 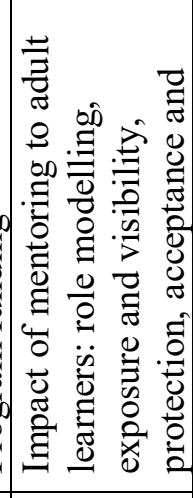 \\
\hline & 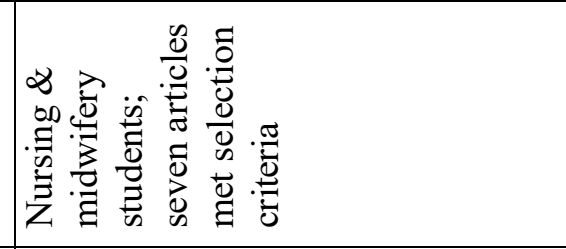 & 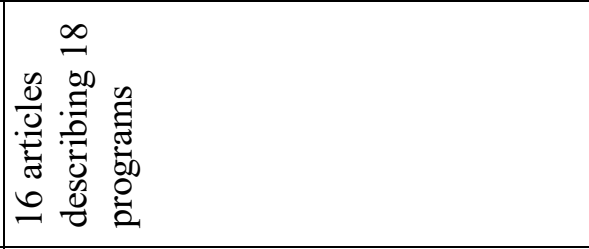 & $\overleftrightarrow{\Delta}$ \\
\hline & 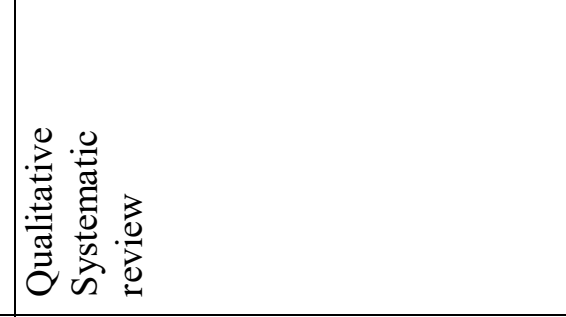 & 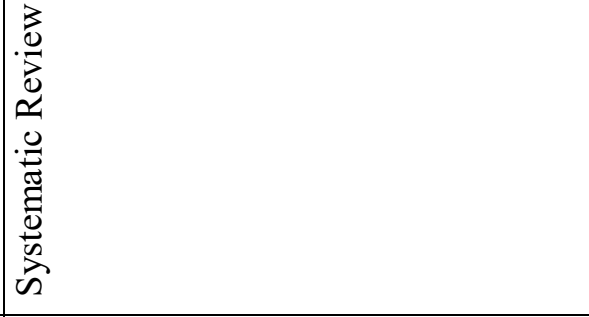 & 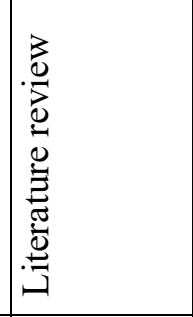 \\
\hline & 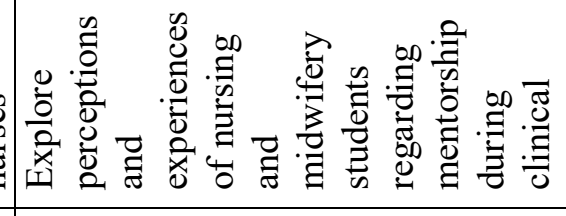 & 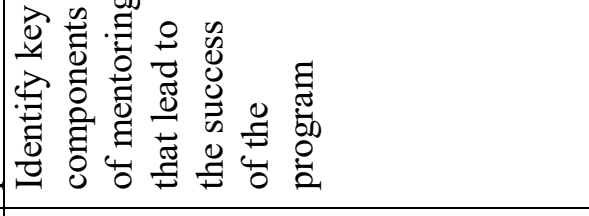 & 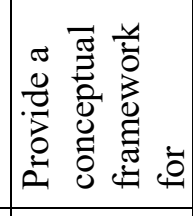 \\
\hline & 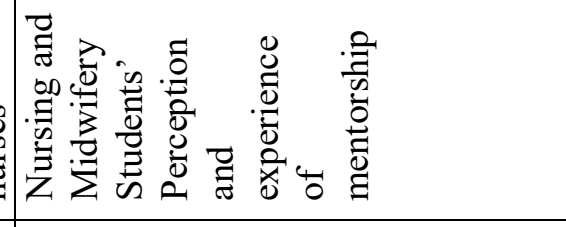 & 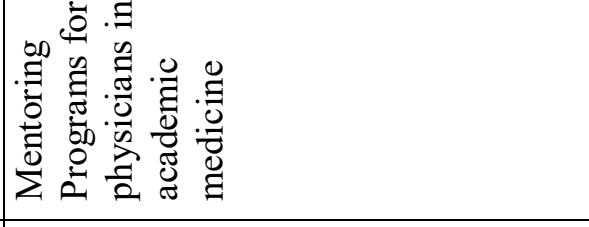 & 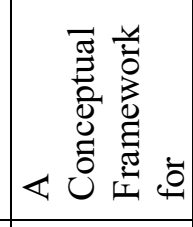 \\
\hline & 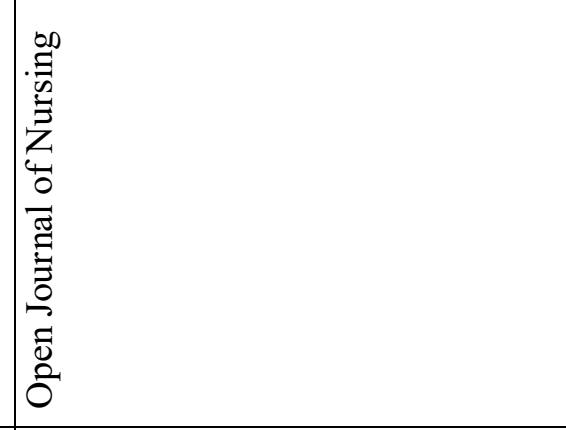 & 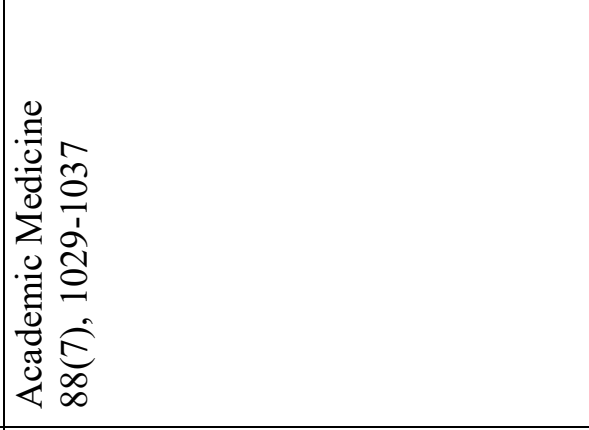 & 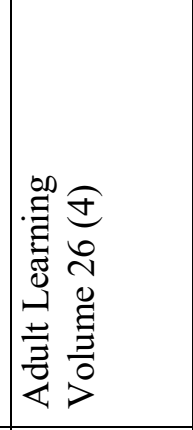 \\
\hline & 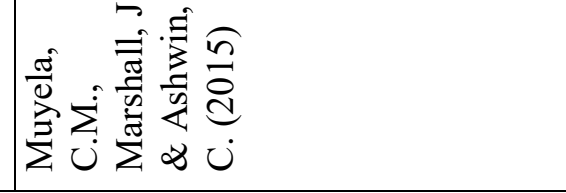 & 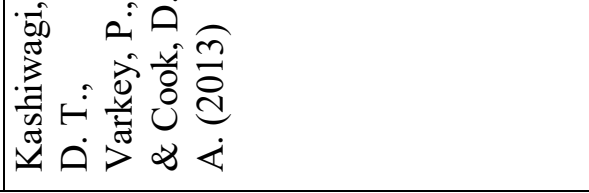 & 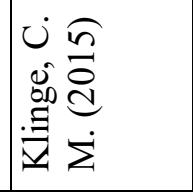 \\
\hline
\end{tabular}




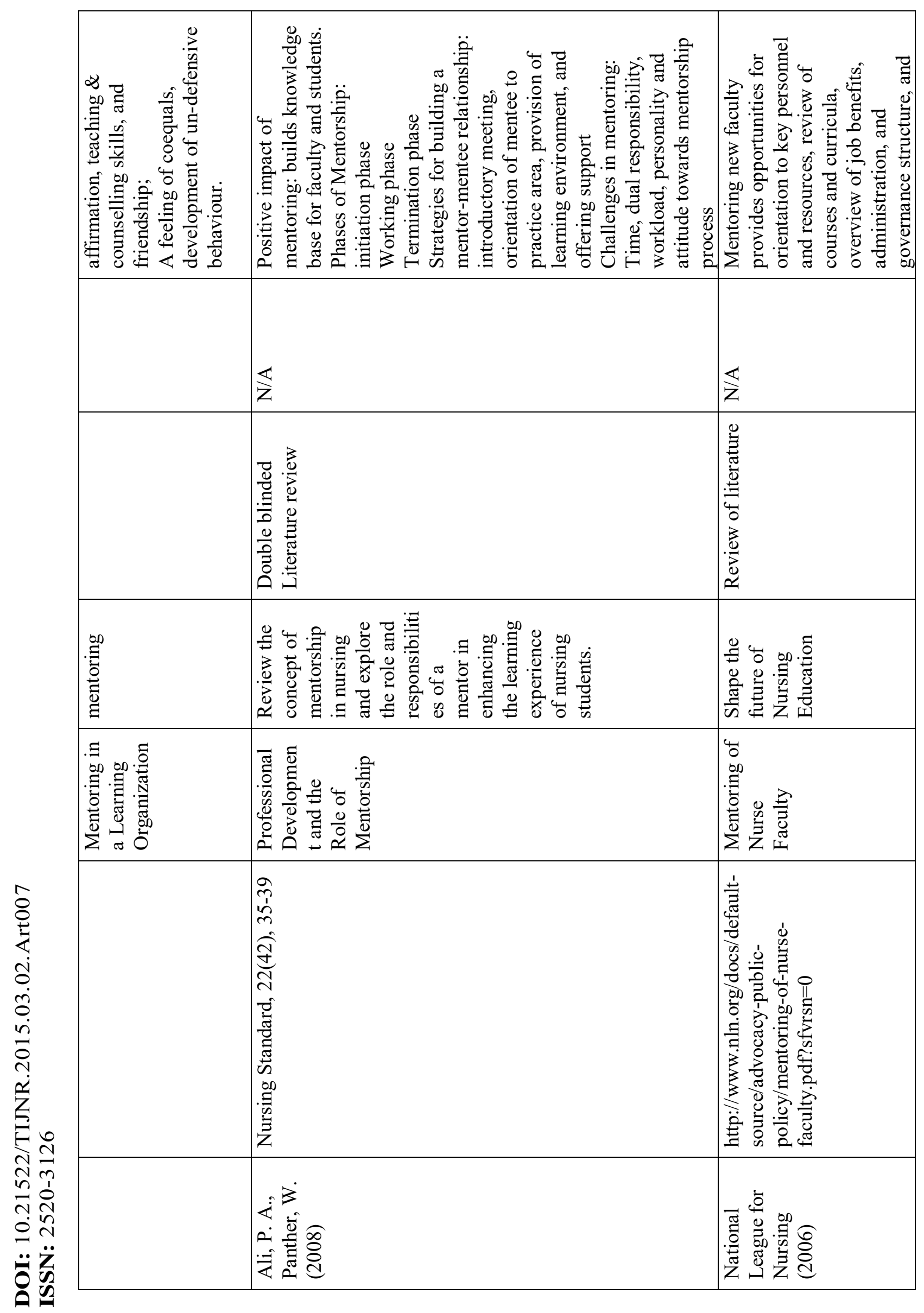




\begin{tabular}{|c|c|c|}
\hline 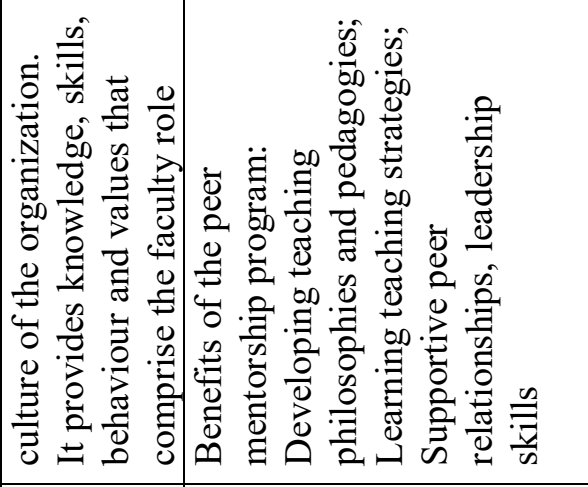 & 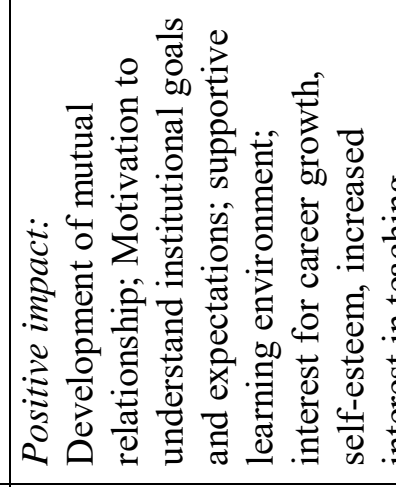 & 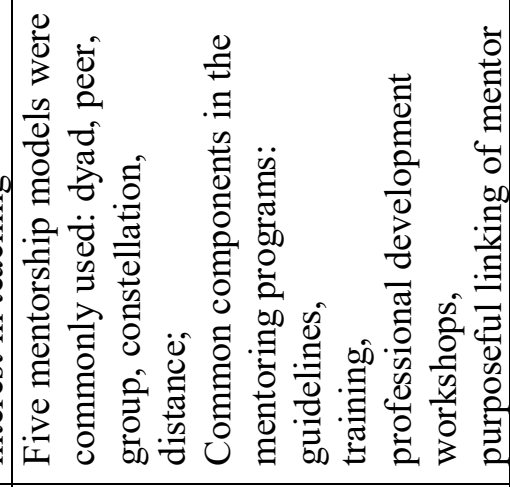 \\
\hline 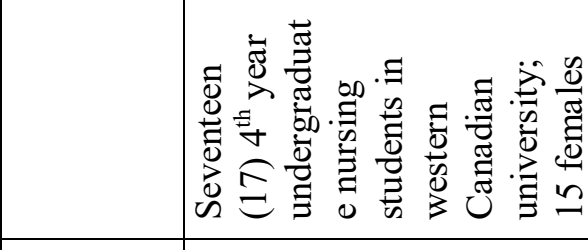 & 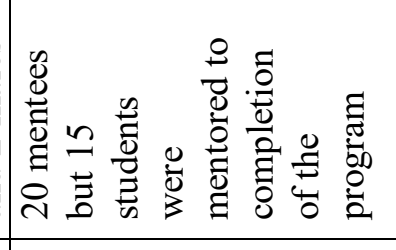 & 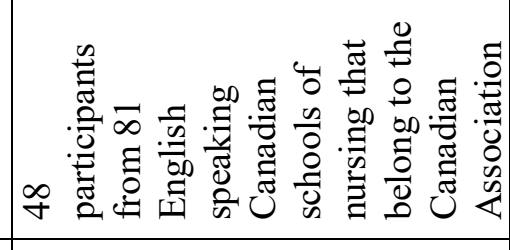 \\
\hline 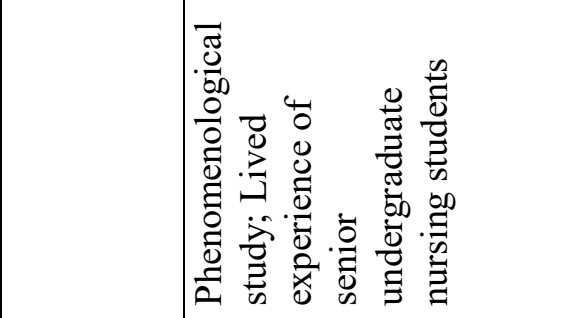 & 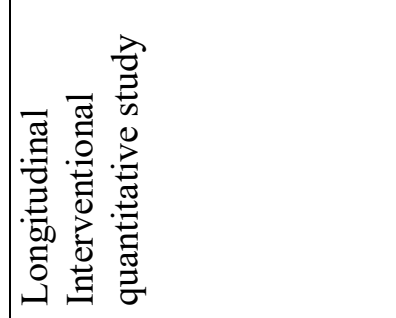 & 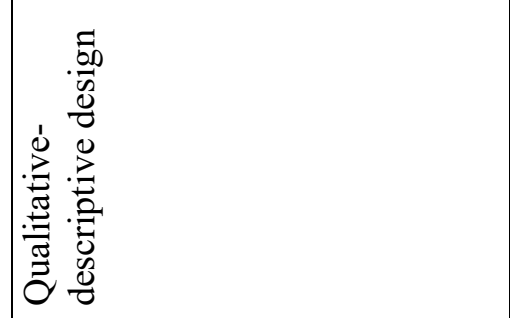 \\
\hline 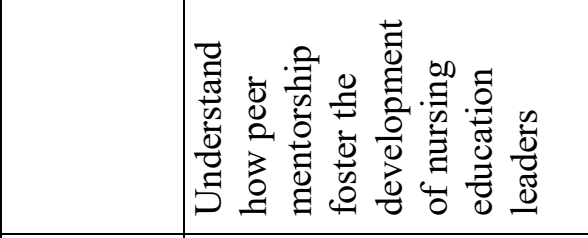 & 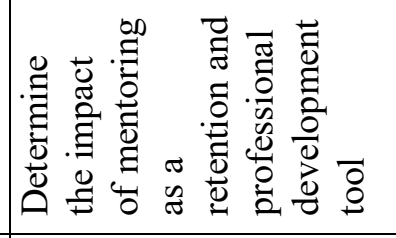 & 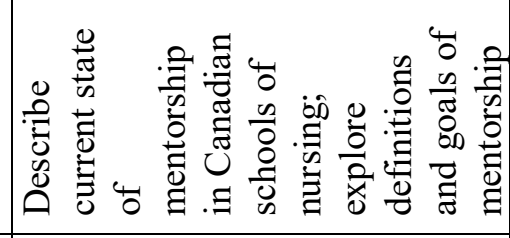 \\
\hline 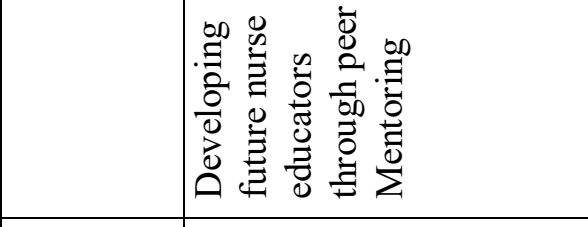 & 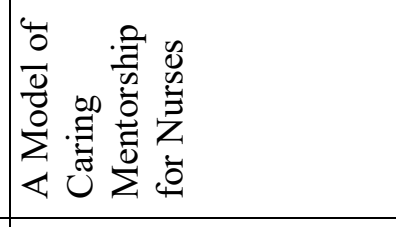 & 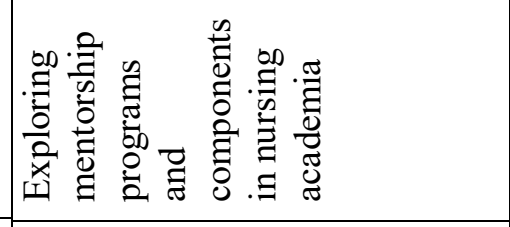 \\
\hline 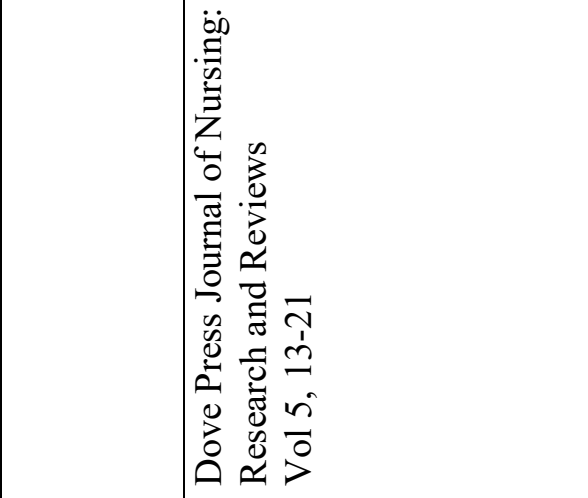 & 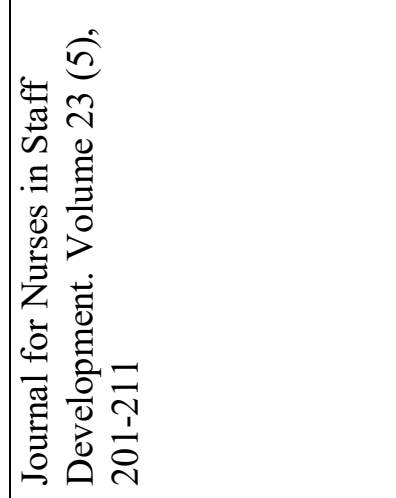 & 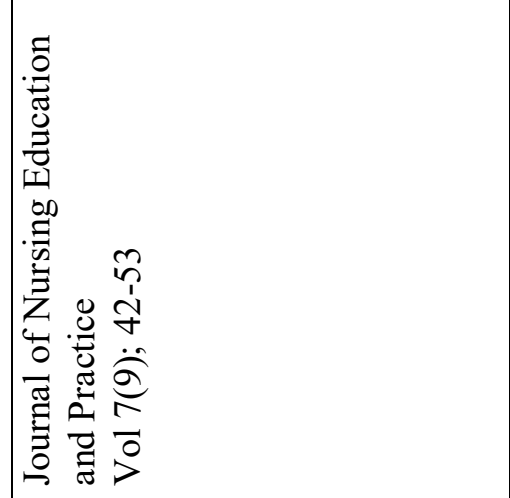 \\
\hline 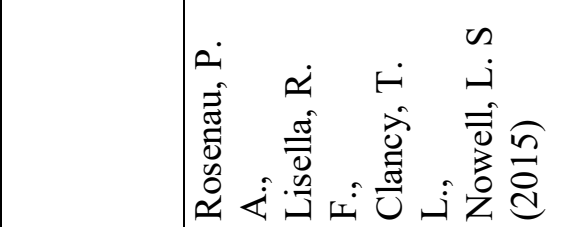 & 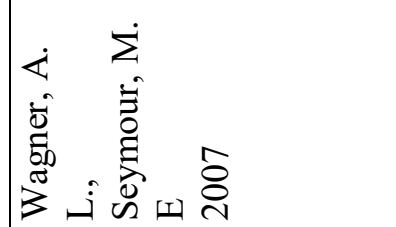 & 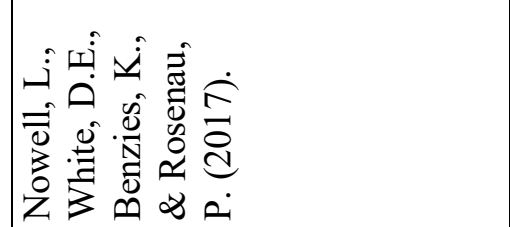 \\
\hline
\end{tabular}




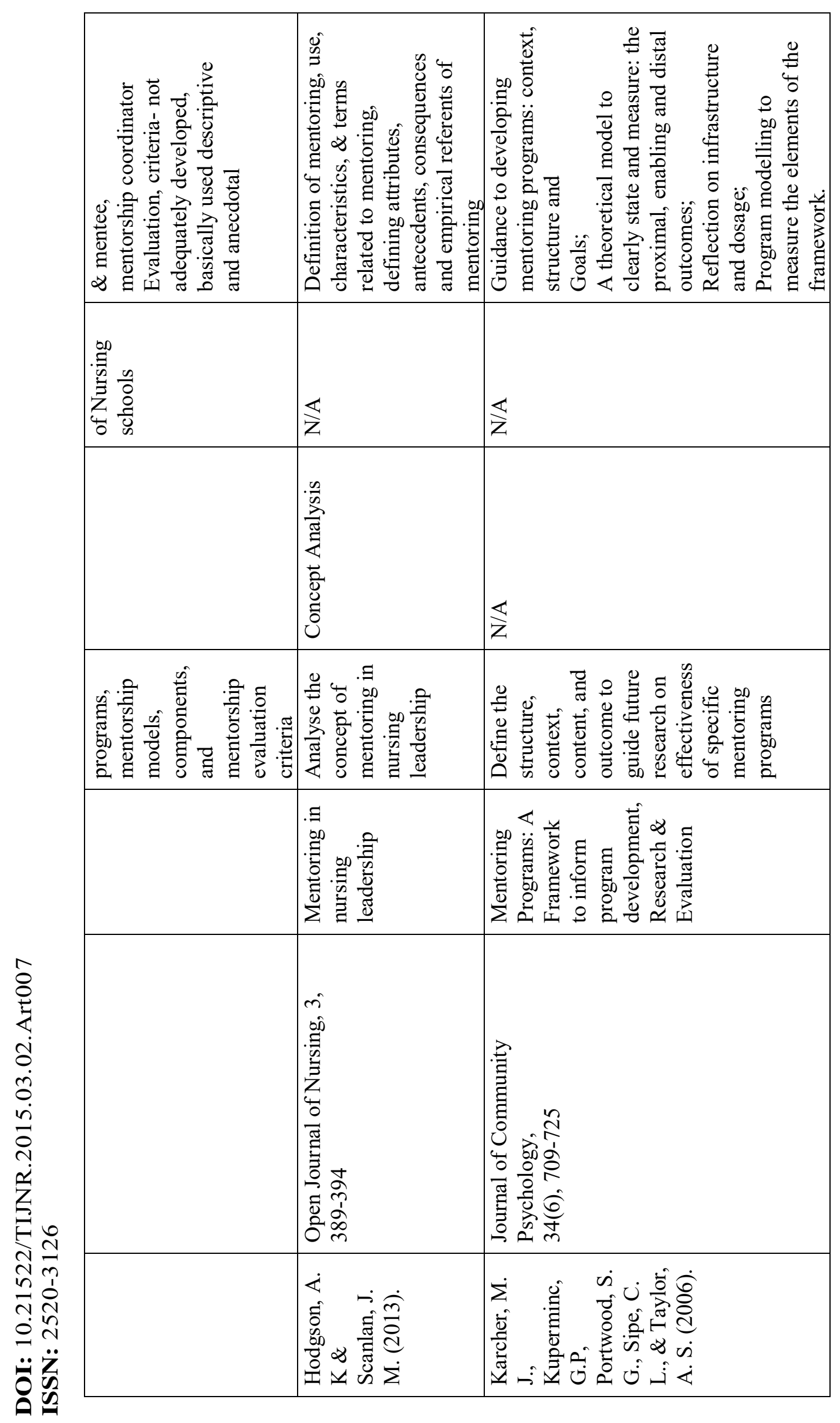




\begin{tabular}{|c|c|c|}
\hline 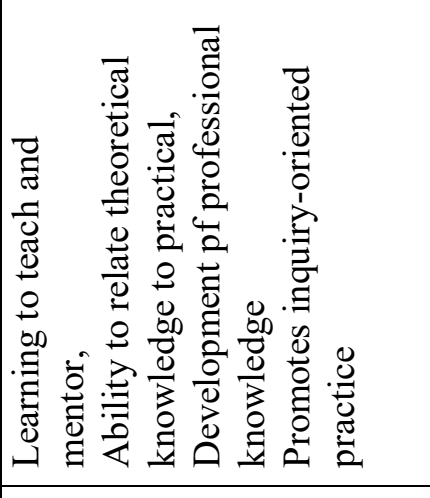 & 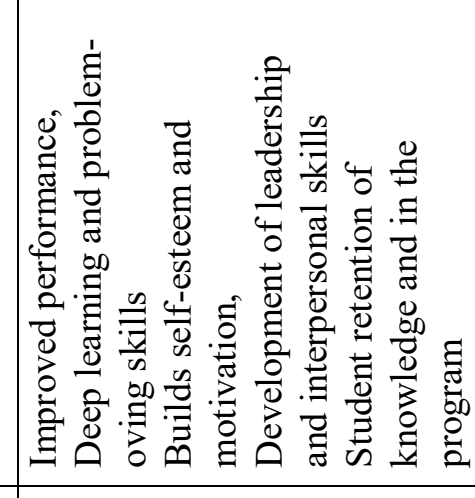 & 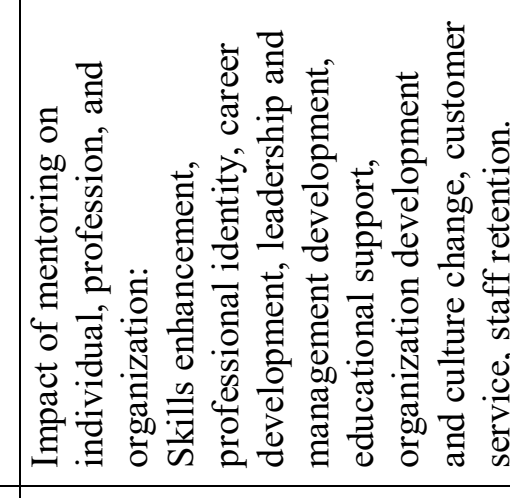 \\
\hline 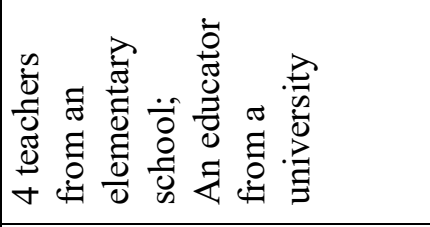 & $\frac{\mathbb{Z}}{z}$ & $\mathbb{z}$ \\
\hline & 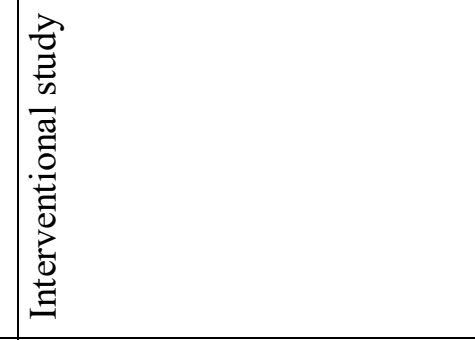 & 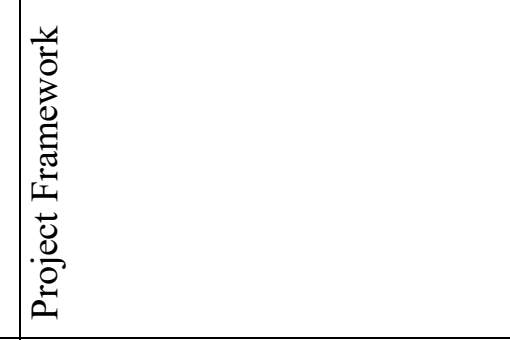 \\
\hline 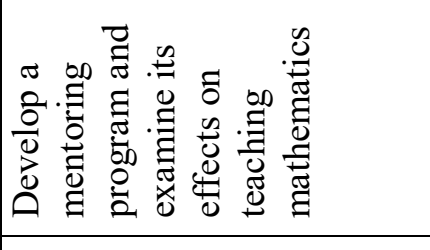 & 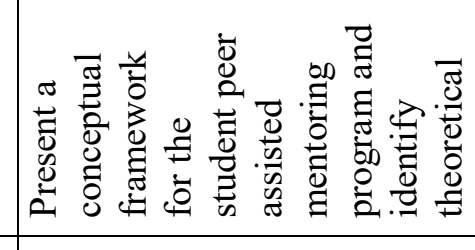 & 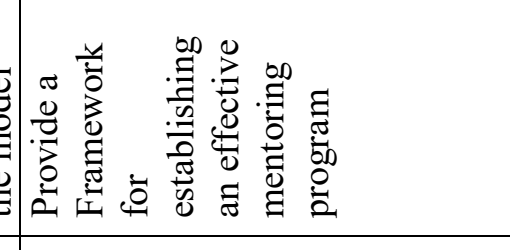 \\
\hline 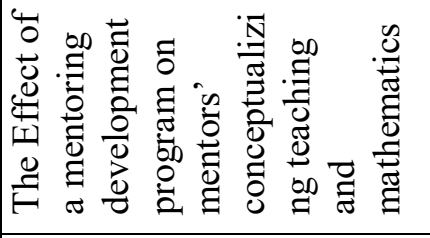 & 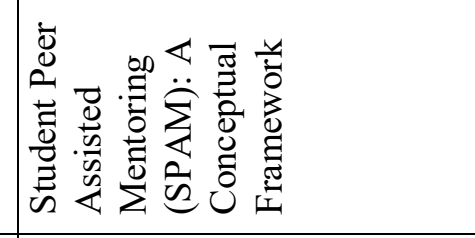 & 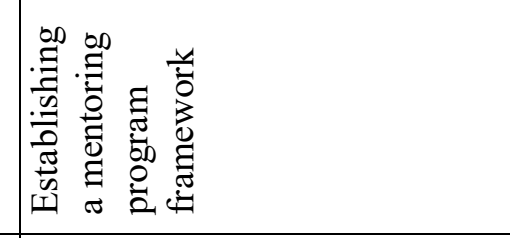 \\
\hline 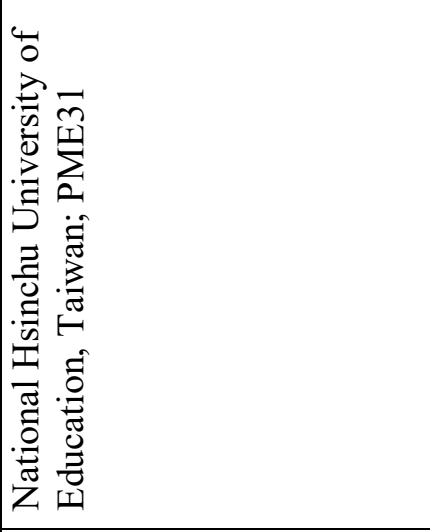 & 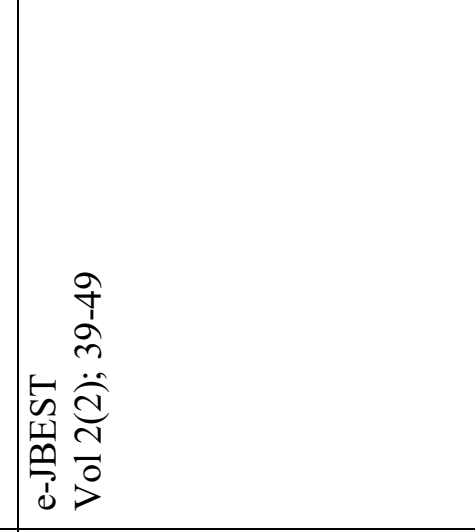 & $\begin{array}{l}0 \\
0 \\
0 \\
0 \\
0 \\
0\end{array}$ \\
\hline 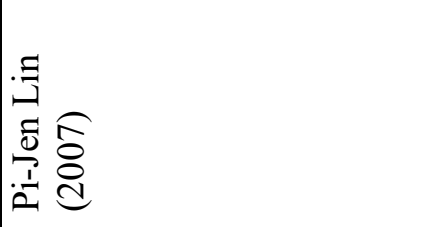 & 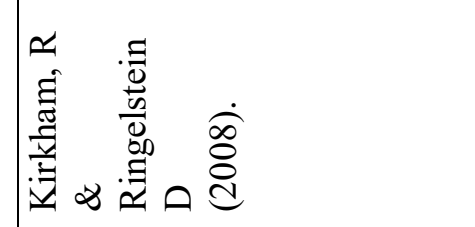 & 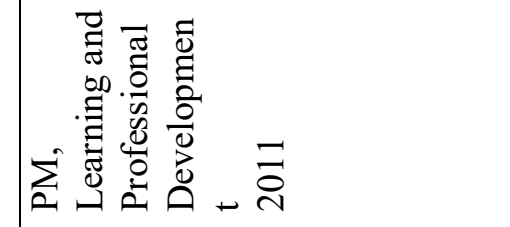 \\
\hline
\end{tabular}




\section{Results}

The search resulted in 139 articles; 22 duplicates were removed (Figure 1). The remaining 117 were screened by title and abstract, 30 were excluded because they did not meet the inclusion criteria. The full text was reviewed in the 87 articles remaining; 24 were excluded because they were published before 2000 , and 8 were excluded because they were not related to teaching or importance of mentoring or mentorship programs, resulting in 15 studies included in the review and entered into the summary matrix (Table 2).

The key thematic statements formulated after analysis included: educator competence development, student learning enhancement, and lastly, personal and social development. The subthemes under each thematic statement are outlined in table 3. On the whole, the general findings are presented following the stated specific objectives

\section{Importance of mentoring}

According to Ali \& Panther (2008), mentoring prepares individuals to develop technical psychomotor, interpersonal, and communication skills; put theory into practice in order to develop a professional identity; and enhances practical experience through support, guidance, and supervision. Mentoring is further associated with a trusting relationship, promoting stability, providing encouragement and hope, and facilitating positive self-efficacy for the student learner (Rosenau, Lisella, Clancy, \& Nowell, 2015).

\section{Impact of mentoring on nurse and midwifery educator's teaching competencies}

Mentoring was found to have both a positive and negative impact (Muleya, Marshall, and Ashwin, 2015; Ali \& Panther, 2008; Lin, 2007); however, the positive impact outweighs the negative impact. It was also noted that the negative impact can be overcome with prior recommended preparation for the mentoring program. On the whole, mentoring was found to increase participants' interest in teaching, self-esteem, and confidence. It also renewed their interest for career growth (Wagner and Seymour, 2007; Rosenau et al, 2015) (Table 3).

Table 3. Thematic statements and their sub-themes

\begin{tabular}{|c|c|c|}
\hline $\begin{array}{l}\text { Educator competence } \\
\text { development }\end{array}$ & $\begin{array}{l}\text { Student Learning } \\
\text { Enhancement }\end{array}$ & $\begin{array}{l}\text { Personal, career, \& social } \\
\text { development }\end{array}$ \\
\hline $\begin{array}{l}\text { Establishment of foundational } \\
\text { teaching skills (philosophies, } \\
\text { pedagogies) with defined roles } \\
\text { and responsibilities of nurse } \\
\text { educators (nurse educator } \\
\text { competencies } 1,2,3,5,6 \text { \& } 7 \text { ); } \\
\text { Development of course and } \\
\text { curriculum review skills } \\
\text { Inspiration for teaching } \\
\text { throughout career; } \\
\text { Motivation to understand } \\
\text { institutional goals and } \\
\text { expectations; } \\
\text { Increased interest in teaching; } \\
\text { Being mindful of learners; } \\
\text { Ability to identify teaching } \\
\text { methods that suit student } \\
\text { learning; } \\
\text { Ability to provide timely and } \\
\text { constructive feedback; } \\
\text { Co-teaching skills }\end{array}$ & $\begin{array}{l}\text { Reduced anxiety; } \\
\text { Supportive \& non-judgemental } \\
\text { learning environment; } \\
\text { Reflection and communication } \\
\text { skills; } \\
\text { Identification of personal } \\
\text { abilities; opportunity to practice } \\
\text { under supportive supervision; } \\
\text { Increased confidence, self- } \\
\text { esteem, and maturity; } \\
\text { Facilitated problem } \\
\text { identification and solving } \\
\text { skills; } \\
\text { Application of new knowledge } \\
\text { in daily tasks; } \\
\text { Benefit from timely \& } \\
\text { constructive feedback, not } \\
\text { criticism; } \\
\text { Development of deep learning }\end{array}$ & $\begin{array}{l}\text { Inspiration for continued } \\
\text { learning; } \\
\text { Role modelling to juniors; } \\
\text { Building of a valued personal, } \\
\text { social, mutual and academic } \\
\text { relationship; } \\
\text { Exposure and visibility; } \\
\text { Protection; } \\
\text { Acceptance; } \\
\text { Affirmation; } \\
\text { Renewed interest for career } \\
\text { growth; } \\
\text { Transformation of the cognitive } \\
\text { and affective domains; } \\
\text { A feeling of coequals \& } \\
\text { openness; } \\
\text { Development of un-defensive } \\
\text { behaviour. }\end{array}$ \\
\hline
\end{tabular}


Apart from the impact on teaching competencies, mentoring was found to create a trusting, supportive, dynamic, respectful, and non-judgmental environment between mentor and mentee (Klinge, 2015). It enabled the participants learn other skills like problem identification and solving, reflection, public speaking, leadership, communication, collaboration, patience, and skills of seeking feedback (Rosenau et al, 2015; Klinge, 2015; Wagner \& Seymour, 2007; Lin, 2007). Successful mentoring develops into a mutual relationship that translates into friendship and subsequent professional growth of the mentor and mentee (Wagner \& Seymour, 2007).

In a study that explored student nurses' and midwives' perception about mentoring, it was found that mentoring increased students' desire to become leaders and enhanced a strong relationship between learner and trainer (Muleya et al., 2015). Students developed reflective and other preferred skills during the period of mentorship (Table 3). Finally, students felt supported when they were given the opportunity to practice after observing their mentor; constructive and timely feedback; and when their own abilities were elucidated (Muleya et al., 2015). Accoring to (Kirkham, 2008),student peer mentoring promotes togetherness, development of deeper learning, and problem-solving skills. It futher enhances commitment to the program and student retention of knowledge.

\section{Negative impact of metoring on nursing and midwifery students and educators}

Time, dual responsibility, workload, personality, and attitude towards the mentorship process came out as the key challenges mentees and mentors experienced (Wagner and Seymour, 2007). Other challenges included students' level of learning, number of students allocated to a mentor, mentor's knowledge about the mentoring process, and tri-or-quadric-collaboration: mentor, mentee, teacher, and coordinator; the team found difficulties in having a common time and agreeing on a common goal since it was not originally stated (Muleya et al., 2015).

\section{Pre-requisites for an effective mentoring program}

Table 4 summarizes some of the pre-requisites for a mentoring program. Establishment of an effective mentoring program requires identification of a relevant model, outlining the components of the program, and clearly defining the context, structure, content, and outcomes (Norwell, Norris, Mrklas, and White,

2017; Nowell, White, Benzies, \& Rosenau, (2017; Kashiwagi, Varkey, \& Cook, 2013; Karcher, Kuperminc, Portwood, Sipe, \& Taylor, 2006).

Table 4. Pre-requisites for an effective mentoring program

\begin{tabular}{|c|c|c|}
\hline Possible mentoring models & $\begin{array}{l}\text { Components/ Elements of a } \\
\text { mentoring program }\end{array}$ & Relevant definitions \\
\hline $\begin{array}{l}\text { Dyad, peer, group, online, } \\
\text { distance, } \\
\text { partnership, \& highly relevant } \\
\text { mentoring models. }\end{array}$ & $\begin{array}{l}\text { 1. Formal curriculum with: } \\
\text { - clear purpose \& goals } \\
\text {-selection criteria of mentor } \\
\text { \&mentee } \\
\text {-orientation process } \\
\text {-communication strategy } \\
\text { between mentors \&mentees } \\
\text { - Number \& purpose of } \\
\text { mentor-mentee training } \\
\text { workshops } \\
\text { - Foundational /theoretical } \\
\text { basis of selected model } \\
\text {-Evaluation criteria for } \\
\text { mentor \& mentee \& networking } \\
\text { - Socialization \& netwitios } \\
\text { opportunities } \\
\text { 2. Program funding } \\
\text { 3. Program coordinator }\end{array}$ & $\begin{array}{l}\text { Context } \\
\text { Structure } \\
\text { Content } \\
\text { Outcome } \\
\text { A theoretical model to } \\
\text { clearly state and measure: the } \\
\text { proximal, enabling and distal } \\
\text { outcomes }\end{array}$ \\
\hline
\end{tabular}




\begin{tabular}{|l|l|l|}
\hline & $\begin{array}{l}\text { 4. Administrative support } \\
\text { 5. Monitoring and evaluation } \\
\text { criteria for the entire program } \\
\text { 6. research process }\end{array}$ & \\
\hline
\end{tabular}

\section{Discussion}

Mentoring is key to nursing and midwifery educators since they have the mandate to prepare a future generation of professionals. This section presents an analysis and some interpretations of the results, with a goal of determining whether mentoring can be integrated into nursing training institutions to strengthen the teaching and learning of student nurses and midwives.

\section{Impact of mentoring on nurse and midwifery educator's teaching competences}

This integrative literature review identified tremendous sources of positive impact of mentoring on the nurse and midwifery educators' teaching competencies (Rosenau, Lisella, Clancy, \& Nowell, 2015; Klinge, 2015; Ali, \& Panther, 2008). Senior nurse educators act as role models to the junior. For example, as a senior nurse educator exhibits his/her teaching philosophy, the junior nurse will be motivated to develop a personal philosophy about teaching. Through sharing, caring and nurturing, which are characteristics of mentoring, senior nurse educators pass on pedagogical skills to the junior ones.

According to Campbell (2011), mentoring is a foundational strategy for accomplishing the nurse educator core competences. For example, Competence 1 requires the nurse educator to demonstrate an understanding of the up-to-date educational theories, principles, and models of adult learning (WHO, 2016). Concepts in educational theories require a consistent approach of delivery in a well-articulated, non-judgmental and supportive environment, which the mentoring approach offers. In the same way, some of the tasks within competencies 2, 3, 5, 6 and 7 as outlined by WHO (2016) can effectively be demonstrated or achieved through mentoring, as the literature revealed (Rosenau, Lisella, Clancy, \& Nowell, 2015).

The senior working together with the junior provides exposure, visibility, protection, and acceptance of the new staff. It gives a feeling of affirmation to the new teacher, developing their teaching, and counselling skills (Klinge, 2015). It was futher noted that mentoring creates a feeling of coequals among junior nurse educators (Klinge, 2015). Individuals working together as equals are more likely to be open to one another. This promotes a common understanding between the mentor and mentee, giving room for a closer working relationship, risk taking, and development of undefensive behaviour (Rosenau, Lisella, Clancy, \& Nowell, 2015). These findings can be related to what Hubbard, Foley, and Robert (2010) noted that mentoring tends to produce nurse educators who are commited, caring, and dedicated to producing future generation nurses.

\section{Impact of mentoring to student nurses' and midwives' learning}

Some of the factors that interfere with student nurses 'and midwives' learning include lack of motivation, clinical environment, and shortage of clinical staff and tutors (Mwale \& Kalawa, 2016). Reviewed literature revealed that mentoring creates a supportive and an enabling learning environment, motivates students to practice skills, and enhances retention and job satisfaction (Sawatzky and Enns, 2009; Block et al, 2005). This strengthens the recommendation made by Campbell (2010) to introduce mentorship programs in graduate and undergraduate nursing education for professional development. The benefits of mentoring realized by the student nurses and midwives in the literature review further ascertain that through mentoring, their learning abilities will be enhanced.

\section{Impact of mentoring on educators' and students' personal and career development and social abilities}

According to Wagner \& Seymour (2007) and Chen \& Lou, (2014), mentoring promotes development of mutual relationship, friendship, and subsequent professional growth of the mentor and mentee. This affirms one of the defining characteristics of mentoring outlined by Hodgson and 
Scanlan (2013) as a "relationship based on mutual respect and common goals." The common goals may be related to career, personal, or social development (Lamb, 2005). The impact of mentoring on nurse educators' personal and career development seem to address some of the challenges related to shortage. An established mutual relationship that provides insight into career and personal development motivates a mentee to pursue the career. A study carried out by Flinkman, IsopahkalaBouret, and Salanterä (2013) on young registered nurses' intention to leave the profession and professional turnover in their early career revealed that working environment is one of the contributing factors. This review of literature revealed that a supportive and trusted working environment increases the interest of junior nurses in career development (Muyela et al, 2015; Rosenau et al, 2015; Klinge, 2015; Wagner and Seymour, 2007).

\section{Pre-requisites for an effective mentoring program}

Developing an effective mentoring program requires selection of a relevant mentorship model. Although the reviewed literature did not outline the rationale for selecting a mentoring model, it seems to be influenced by the expected outcome or desired goal. However, dyad and peer mentoring models were mostly used in the reviewed mentoring programs (Norwell, Norris, Mrklas, and White, 2017; Nowell, White, Benzies, \& Rosenau, 2017; Kashiwagi, Varkey, \& Cook, 2013) The reviewed literature revealed varying components of a mentoring program. This can be associated with the different sources of information in relation to professional disciplines, although no specific evidence was found.

Before establishing a mentoring program, it is important to define the context. This means writing clear statements on who will coordinate the program, the level of communication between mentor and mentee (whether mutual, professional, or academic), when to communicate or interact (time), and where to meet (location) (Klinge, 2015; Karcher, et al, 2006). Such details are outlined to ease the process of identifying measuring indicators for the expected outcome. The content is determined by the set goals and are all structured to guide development of a standardized assessment criteria. This is aided by an educational theoretical framework to facilitate problem identification and solving to meet the learner's desired outcome (Klinge, 2015). This means that developing and implementing a mentoring program in a learning institution requires the coordinator to define the characteristics of the likely mentors and mentee in order to select an appropriate theoretical framework to guide the mentoring process. This is because both mentor and mentee undergo a learning process during mentoring. According to Wagner \& Seymour (2007), several failures in the mentor- mentee relationship are attributed to non-commitment to the program, role overload, unrealistic expectations of mentoring, and not valuing the opportunity. Based on evidence found in the literature, further research on mentoring should focus on exploring the rationale for selecting a mentoring model and evaluation of mentoring programs.

\section{Conclusion}

This integrative review of literature coalesces existing evidence on how mentoring impacts nurse educator's teaching competencies and student nurses'/midwives' learning positively. Although there are challenges, they can be overcome if required preparations and principles are followed. Establishing an effective mentoring program should be guided by a relevant mentoring model and the components of a mentoring program, specifically the curriculum, funding, coordination process, administrative support, monitoring, evaluation and research processes.

\section{Implications of the findings to nursing and midwifery practice.}

Nurse and midwifery educators, particularly those in developing countries, should embrace the implementation of mentoring programs to facilitate teaching and learning in their institutions for better professional and health service outcomes.

Nurse and midwifery educators intending to establish a mentoring program should:

- Clearly define the context, structure, and goals (desired outcome) of the program for proper monitoring and evaluation;

- Select a mentoring model basing on the desired outcome of the program; 
DOI: $10.21522 /$ TIJNR.2015.03.02.Art007

ISSN: $2520-3126$

- Encourage mutual selection of mentor and mentee to allow the flow of chemistry yield the expected outcome;

- Introduce mentoring in the early years of students' training for better impact or at the recruitment stage of staff to allow ample time of the mentoring process and better outcomes.

\section{References}

[1].Ali, P. A., \& Panther, W. (2008). Professional Development and the Role of Mentorship. Nursing Standard, 22(42), pp. 35-39.

[2].Block, L. M., Claffey, C., Korow, M. K., Mccaffrey, R., \& Services, H. (2005). The Value of Mentorship within Nursing Organizations. Nursing Forum, 40(4), 134-140.

[3].Chen, C. M., \& Lou, M. F. (2014). The effectiveness and application of mentorship programmes for recently registered nurses: A systematic review. Journal of Nursing Management, 22(4), 433-442. http://doi.org/10.1111/jonm.12102

[4].Hodgson, A. K \& Scanian, J. M. (2013). Mentoring in nursing leadership. Open Journal of Nursing, 3; 389394

[5].Karcher, M. J., Kuperminc, G.P, Portwood, S. G., Sipe, C. L., \& Taylor, A. S. (2006). Mentoring Programs: A Framework to inform program development, Research \& Evaluation. Journal of Community Psychology 34(6), 709-725

[6].Kirkham, R. \& Ringelstein, D. (2008). Student Peer Assisted Mentoring (SPAM): A Conceptual Framework, e-JBEST 2(2), 39-49.

[7].Klinge, C. M. (2015). A conceptual framework for mentoring in a learning organization. Journal of Adult Learning, 26(4);

[8].Lin, P. (2007). The effect of a mentoring development program on mentors' conceptualizing mathematics teaching and mentoring, 3, 201-208.

[9].Muleya, C. M., Marshall, J., \& Ashwin, C. (2015). Nursing and Midwifery Students' Perception and Experiences of Mentorship: A Systematic Review. Open Journal of Nursing, (June), 571-586. http://doi.org/10.4236/ojn.2015.56061

[10]. Nowell, L., White, D. E., Benzies, K., \& Rosenau, P. (2017). Exploring mentorship programs and components in nursing academia. Journal of Nursing Education and Practice, 7(9); 42-53

[11]. Nowell, L., White, D. E., Mrklas, K., \& Norris, J. M. (2015). Mentorship in nursing academia: a systematic review protocol, 1-9. http://doi.org/10.1186/s13643-015-0007-5

[12]. Learning and Professional Developmental (2011). Establishing a mentoring program framework. Ohio Das, PM. R etrieved August 2017 from: http://www.das.ohio.gov/PJR.PDF?CER=2012-08-15-142823083RCN. (2015). RCN Mentorship Project 2015.

[13]. Sawatzky, J., Enns, C. L. (2009). (1) A Mentoring Needs Assessment_Validation _ Jo-ann Sawatzky Academia.pdf. Journal of Professional Nursing, 25(3), 145-150.

[14]. Scotland, N. E. (2007). National Approach to Mentor Preparation for Nurses and Midwives.

[15]. Wagner, A. L., \& Seymour, M. (2007). A Model of Caring Mentorship for Nursing. Journal for Nurses in Staff Development, 23(5), 201-211.

[16]. WHO (2016). Nurse Educator Core Competencies. 


\title{
Knowledge of Bloom's Hierarchy of Cognitive Levels of Educational Objectives and its use in Setting Examinations by Nurse Educators in Lusaka and Eastern Provinces
}

\author{
Article by Patricia Mambwe \\ Lecturer, Rusangu University, Department of Nursing Sciences, School of Health Sciences, \\ Monze, Zambia \\ E-mail:mambwe.patricia@yahoo.com /mambwepatricia105@gmail.com
}

\begin{abstract}
Background: The use of Bloom's hierarchy of cognitive levels of educational objectives as a tool for classroom assessments is rapidly increasing therefore, Nurse Educators' knowledge of the tool is vital.

Objective: The first prime objective of this study was to investigate nurse educators' knowledge of Bloom's hierarchy of cognitive levels of educational objectives.

Materials and Methods: A cross sectional study was conducted in nursing training schools of Lusaka and Eastern provinces of Zambia. The study sample comprised of 63 Nurse Educators who were selected using purposive sampling method. A self-administered questionnaire was used to collect data from the respondents. Statistical Package for Social Sciences (SPSS) version 20 was used to analyse data. The Chi Square test was used to compare the proportions. A result yielding a $P$ value of less than 5 percent was considered to be statistically significant.

Results: The findings were that 64\% of nurse educators had low knowledge, $22 \%$ had moderate knowledge while 14\% had high knowledge on Bloom's hierarchy of cognitive levels of educational objectives. Results from the study indicated that $90 \%$ of nurse educators affirmed that Continuing Professional Development meetings on assessment techniques were not conducted in the schools of nursing while $10 \%$ indicated that they had them.

Conclusion: Though the nurse educators undergo training on Bloom's taxonomy, their knowledge on this topic is low and calls for Continuous Professional Development Meetings. This will improve quality and standards of examinations in nursing education which will in turn improve the performance of nurses in the clinical area.
\end{abstract}

Keywords: Knowledge, use, Bloom's hierarchy, cognitive levels, educational objectives, setting examinations, Nurse Educators

\section{Introduction/Background}

Nurse educators are expected to produce critical thinking nurses. Critical thinking can only be stimulated from both classroom teaching and assessments using a classification such as Bloom's taxonomy. Assessments are most effective when more test items are written at the application or higher levels of cognition (De Young, 2009 and Garekwe, 2010). Zambia, being part of the global community, is expected to train critical thinking nurses. Studies done in other parts of the world such as the United States of America and South Africa indicated that nurse educators were concentrating more on setting knowledge/recall questions when evaluating students (Masters et al., 2001 and Garekwe, 2010).

\section{Statement of the problem}

Statistically, a study in America found that, $6 \%$ of the test items were prepared at the analysis level compared to $46 \%$ written at the knowledge level of Bloom's cognitive domain

(Masters et. al., 2001). In a related research done in South Africa, $57 \%$ of the questions were prepared at lower cognitive levels while $43.4 \%$ were at higher cognitive levels (Garekwe, 2010). This is in direct 
DOI: 10.21522 /TIJNR.2015.03.02.Art008

ISSN: $2520-3126$

conflict when it comes to producing a critical thinking nurse for it is important to see to it that assessments match the philosophy of the curriculum and reflect all its educational outcomes (Garekwe, 2010; Azer, 2006; Mkandawire, 2013).

Questions in the lower order category of Bloom's cognitive domain do not promote critical thinking in a nurse instead; they become fertile manure in the production of a timid, dependent and robot-like nurse.

The researcher noted that from the inception of post basic nursing education in 1978 in Zambia (General Nursing Council of Zambia, 2002), no research has been conducted on questioning techniques during assessments. Literature has also reviewed that there is no information concerning nurse educators' use of Bloom's taxonomy during the preparation of test items for examinations. This is crucial as nurse educators' aim at producing critical thinking nurses.

It is against this backdrop that a study to evaluate the knowledge and usage of Bloom's hierarchy of cognitive levels of educational objectives in setting examinations by nurse educators has been undertaken.

\section{Materials and methods}

A cross sectional study was conducted in three (3) government nursing schools in the eastern part of Zambia namely Mwami, Chipata and St Francis nursing schools, one (1) government nursing school in Lusaka province namely Lusaka school of nursing, two (2) private nursing schools based in Lusaka province namely Dovcott College of Nursing and Lusaka Health Institute college of Nursing. Convenience sampling method was used to select nursing schools. Purposive also called judgemental sampling method was used to select nurse educators from selected nursing schools in Eastern and Lusaka provinces of Zambia to answer the questionnaire. The study sample comprised 63 nurse educators. The study used self-administered questionnaires.

Results: The findings were that $64 \%$ of nurse educators had low knowledge, $22 \%$ had moderate knowledge while $14 \%$ had high knowledge on Bloom's hierarchy of cognitive levels of educational objectives. Results from the study indicated that $90 \%$ of nurse educators affirmed that Continuing Professional Development meetings on assessment techniques were not conducted in the schools of nursing while $10 \%$ indicated that they had them.

\section{Presentation of the research findings}

\section{Respondents' knowledge levels on bloom's taxonomy}

The study solicited for information from the nurse educators on how they defined Bloom's taxonomy. The results have been shown in the figure below.

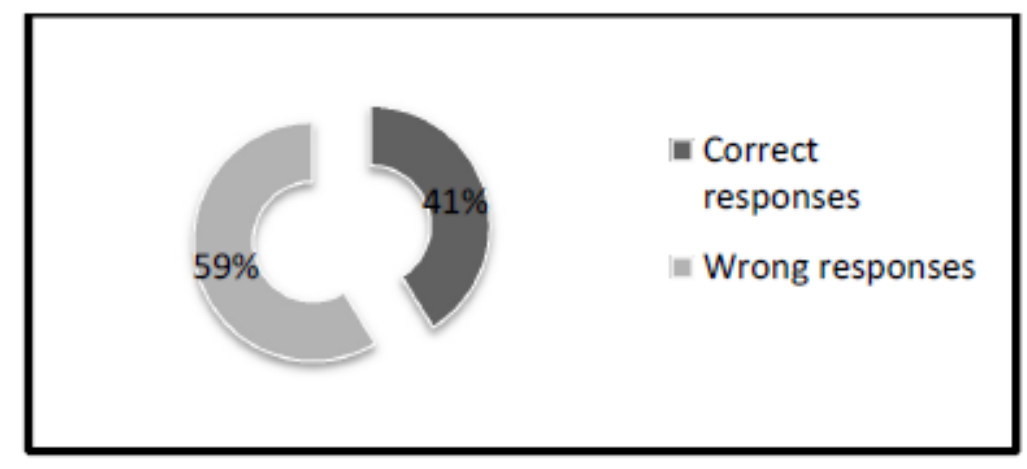

Figure 1. Definition of bloom's taxonomy

According to Figure 1 above, 26 (41\%) of the respondents defined Blooms Taxonomy correctly while $37(59 \%)$ did not define it correctly. Blooms Taxonomy is a tool used to classify learning objectives and to assess students' abilities (Krathwohl, 2002; Ferris and Azizi, 2005). 
In addition, the study also gathered information on the specific words used to classify test items in the lowest level of cognitive domain. The majority, $41(65 \%)$ of the respondents correctly stated that the words define, state and identify are the ones used to classify test questions in the lowest levels of cognitive domain.

Only $8(13 \%)$ of the respondents mentioned that the words state, explain, and convert are the ones used to classify test questions in the lowest levels of cognitive domain. $9(14 \%)$ thought the words explain, convert and create are the ones used whereas $5(8 \%)$ of the respondents thought create, identify and define are the words used. The mean was 1.6508 and the standard deviation was 1.00256 . The responses are illustrated in figure 2 below.

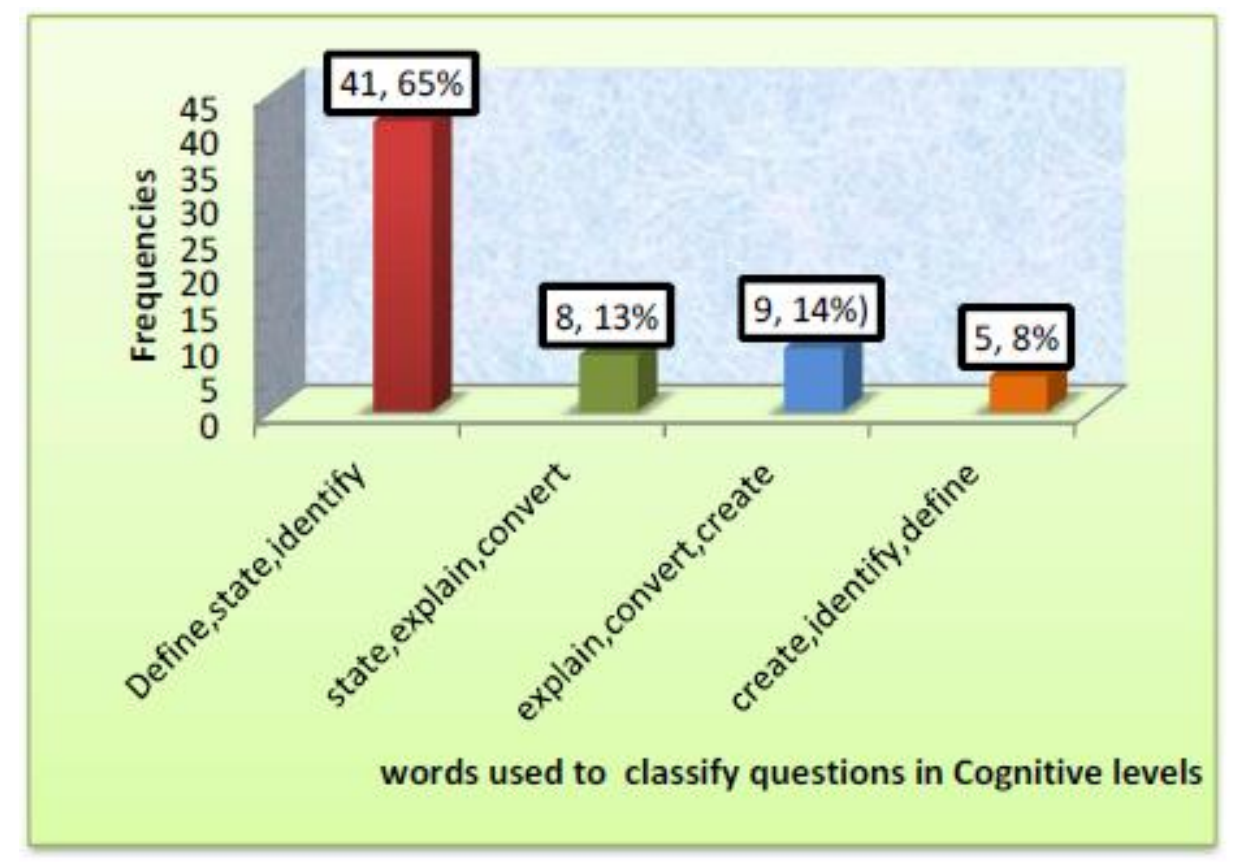

Figure 2. Words used to classify test questions in the lowest Level of cognitive domain $(n=63)$

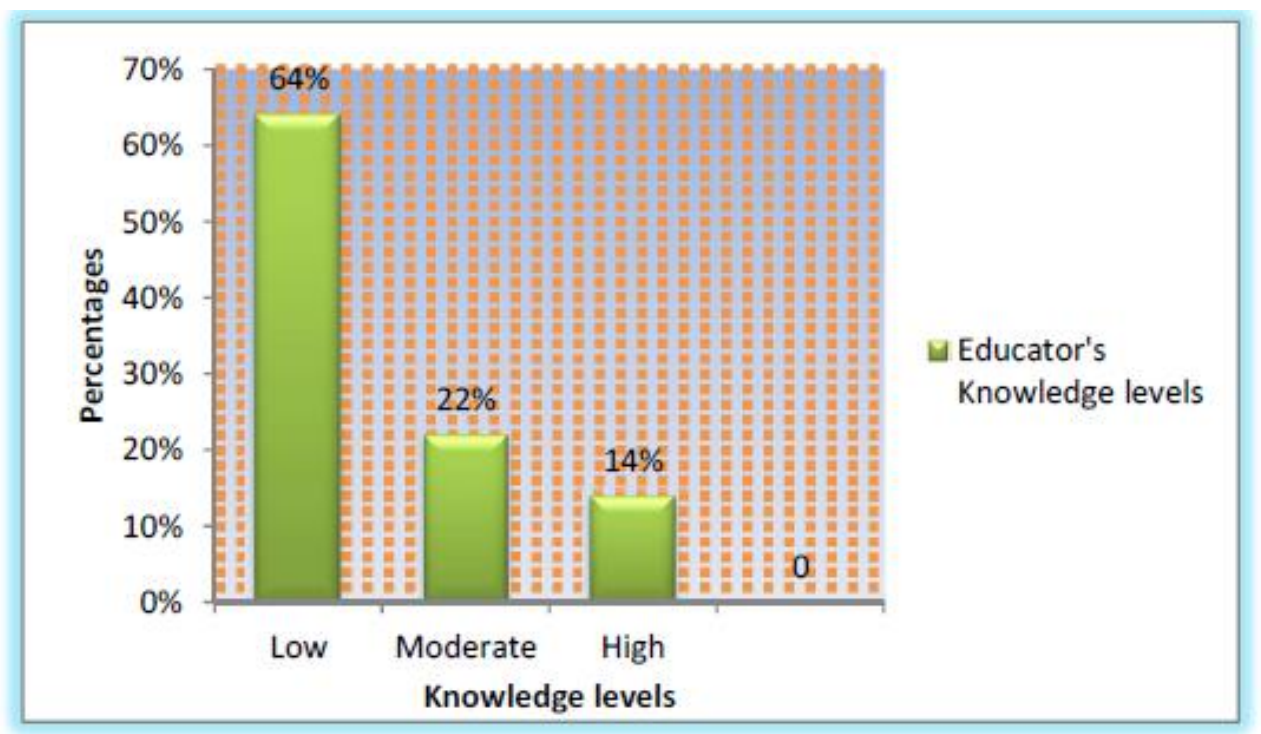

Figure 3. Nurse educators' knowledge levels on bloom's cognitive levels $(n=63)$ 
DOI: $10.21522 /$ TIJNR.2015.03.02.Art008

ISSN: $2520-3126$

Figure 3 shows that majority, 64\% of nurse educators had low know on Bloom's cognitive levels

Use of cognitive levels of educational objectives when preparing test items by nurse educators

The second specific objective of this study was to determine the levels of cognitive domain assessed in examination papers. To achieve this objective, nurse educators were asked a number of questions to find out whether they used cognitive levels of educational objectives when preparing test items for examinations. The responses were recorded as shown in figure 4

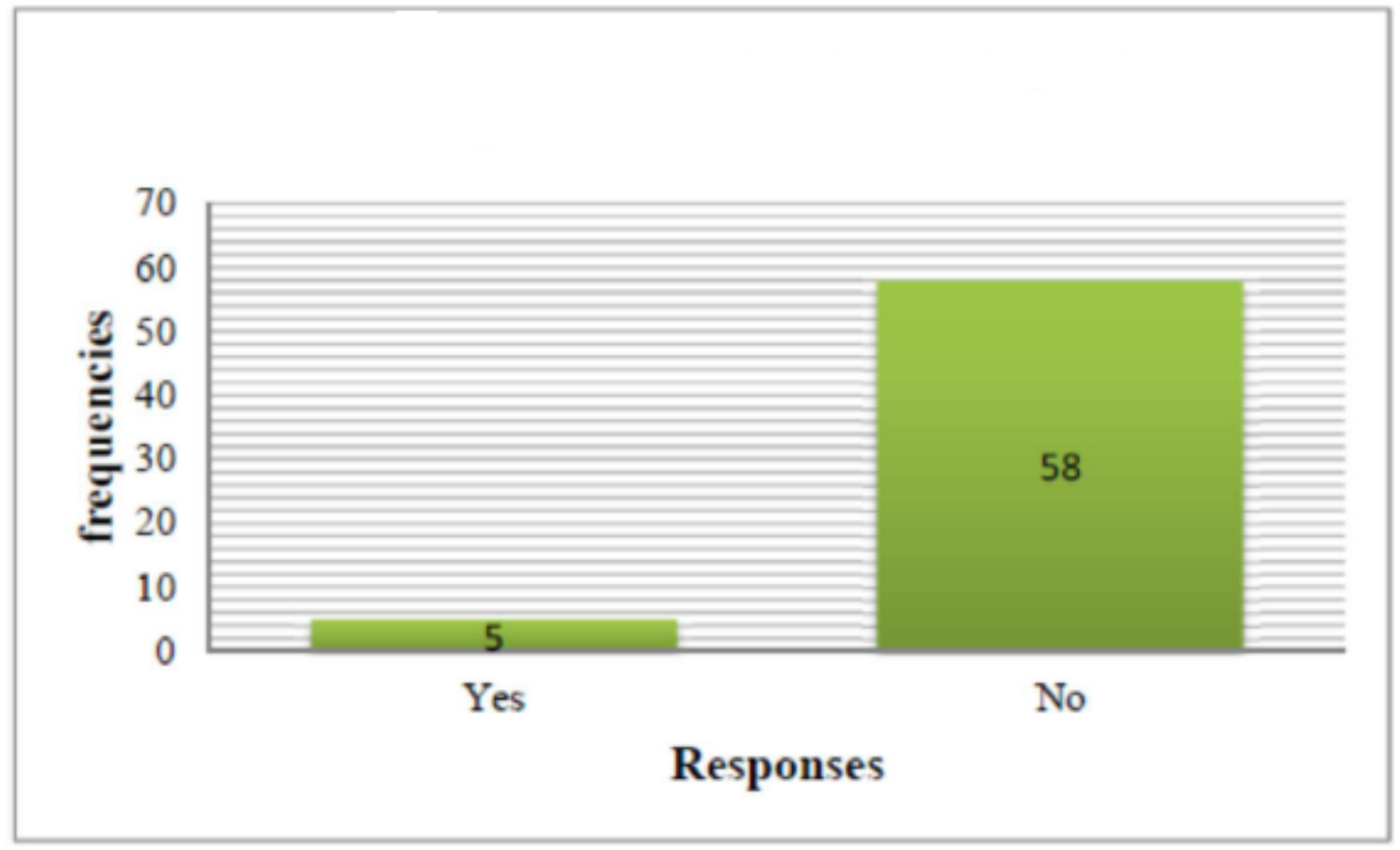

Figure 4. Following cognitive levels when setting examinations $(n=63)$

Figure 4 above indicates that $5(8 \%)$ of the respondents mentioned that they always followed the Bloom's hierarchy of cognitive levels of educational objectives when setting examinations whereas majority, 58 (92\%) stated that they did not.

\section{Use of standardized guidelines when preparing test items by nurse educators}

The analysis also gleaned information on whether nurse educators followed any standardized assessment guidelines when setting examination questions (preparing test items). The results are indicated in figure 5 . 


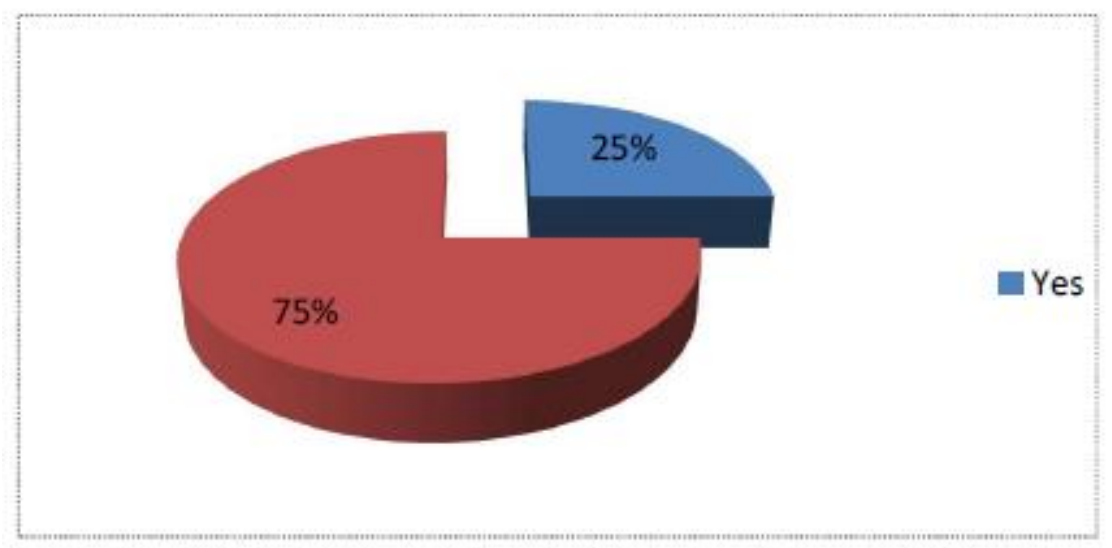

Figure 5. Following standardized assessment guidelines when setting examinations $(n=63)$

Based on data presented in Figure 5 above, 16 (25\%) of the respondents agreed that they used standardised guidelines for classroom assessment when setting examinations while the majority 47 (75\%) stated that they did not follow any standardised guidelines when setting examinations.

With regard to standardized guidelines, the study also gathered information on peer reviewing (moderation) of test items before they were administered to students. Nurse educators' responses are presented in the figure below.

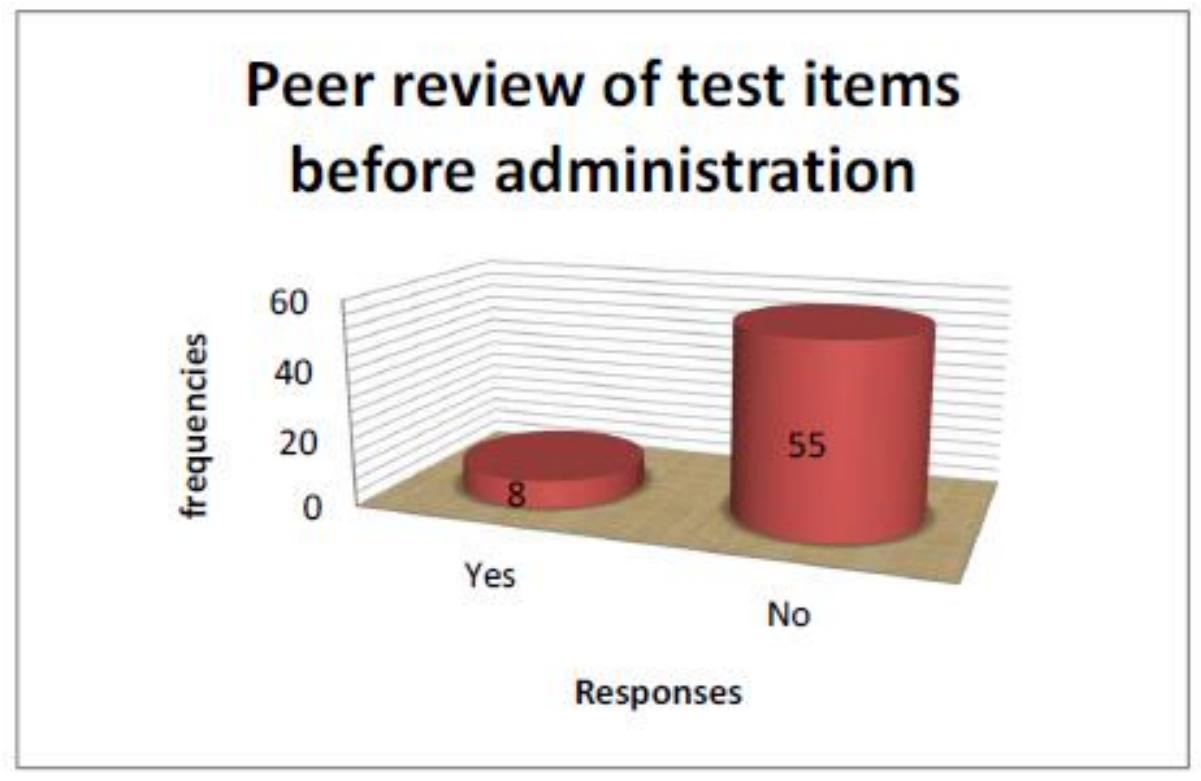

Figure 6. Peer review of test items before administration to students $(n=63)$

According to Figure 6 above, $8(13 \%)$ of the respondents agreed that a team(s)/committee peer reviewed the test items before being administered to the students, whereas majority, $55(87 \%)$ disagreed that they did not have their test papers peer reviewed before being administered to students.

Furthermore, the study acquired the responses nurse educators gave on the availability of a blue print in nursing schools. The findings indicated that only $4(6 \%)$ of the respondents had a blue print (table of specification) which act as a guide on how many questions to set in each cognitive level where as the rest $59(94 \%)$ of the respondents affirmed that they did not have any blueprint. Figure 7 gives a picture of the results. 
DOI: $10.21522 /$ TIJNR.2015.03.02.Art008

ISSN: $2520-3126$

\section{Have Blue print which act as guide}

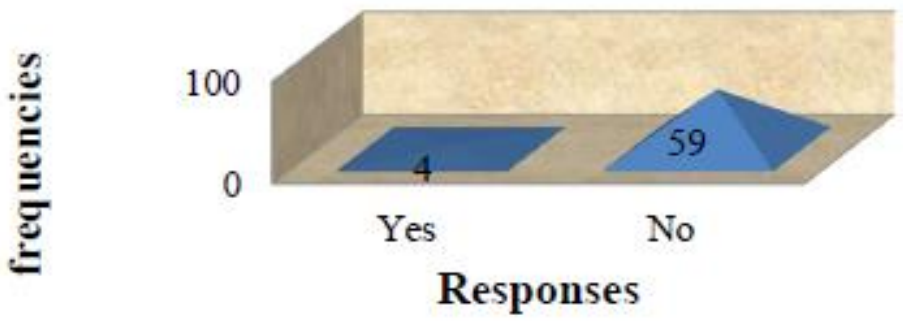

Figure 7. Have blue print which acts as a guide on number of questions to set in each cognitive level $(\mathrm{n}=63)$

\section{Discussion}

Knowledge of Bloom's taxonomy is believed to be useful for educators to ask questions at various levels (Brown, 2001; Mkandawire, 2013; Cook, 2013). De young (2009) affirms that basic knowledge of Bloom's taxonomy would help educators to build an informational data base at lower level first before proceeding to higher levels of cognitive domain during teaching and assessments.

The findings in this study revealed that only $41 \%$ of the respondents defined Blooms taxonomy correctly whereas more than half (59\%) of the respondents did not know what Bloom's Taxonomy is. Bloom's Taxonomy is a tool used to classify learning objectives and to assess students' abilities (Krathwohl, 2002; Ferris and Azizi, 2005). This clearly demonstrates that less than the average number of nurse educators who participated in the study know what Bloom's taxonomy is. However, when an inquiry into the words that should be used to classify test questions in the lowest level of cognitive domain was made, $65 \%$ of the nurse educators gave a correct response whereas the rest $(35 \%)$ got it wrong. This could be the reason why a greater percentage of questions $(95 \%)$ were observed at lower order level compared to (5\%) at higher order in all the reviewed past question papers. Sithole (2011) argues that continuous usage of questions in the lowest cognitive domain serves no purpose in nursing since the nurse is expected to apply a scientific method in nursing in order to function as an independent practitioner.

Athanassiou, et al., (2003); Clauss and Geedey (2010); Cook, (2013); Agbedia and Ogbe (2014) affirms that it is important to know the cognitive levels of educational objectives as they are necessary for learning since they are classified in order of the complexity of the thought process involved. Surprisingly, the findings of this study revealed that a few (19\%) of the respondents knew the cognitive levels of educational objectives that promote critical thinking in students which are Application and Analysis as shown in the answer key.

Majority $(81 \%)$ did not know them. These results are similar to the findings in the study by Mkandawire (2013) who observed that teachers had no knowledge of cognitive levels that promote critical thinking. Studies by Garekwe (2010); Mkandawire (2013) ; Agbedia and Ogbe (2014) noted that knowledge and usage of cognitive levels that promote critical thinking facilitate the development of students' thinking ability, decision making and problem solving. This would have an impact on their performance and prepare them to be vigilant when caring for clients thereafter.

From the analysis of responses of nurse educators, it is interesting to note that only $8 \%$ of the respondents affirmed that they followed cognitive levels when setting examinations. A larger percentage (92\%) of the respondents mentioned that they did not follow Bloom's hierarchy of cognitive levels. The findings from the analyzed past examination question papers equaled the results above. The analysis revealed that questions were not set in application, analysis and evaluation levels of cognitive domain thus knowledge/recall and comprehension questions dominated. Mkandawire (2013) reported similar 
results and recommended that educators should be encouraged to follow cognitive levels of educational objectives during classroom assessments. Surprisingly, the greater percentage of the respondents (92\%) felt that following the cognitive level tool was important in nursing education while $(8 \%)$ of the respondents indicated that it was not important. Masters et al., (2001); Clauss and Geedey, (2010); Cook, (2013) observes that following taxonomies during assessments is important. However, factors such as shortages of nurse educators and time affect the adherence to taxonomies thereby hindering quality in assessments.

The study further excavated more pitfalls related to non-peer reviewing of test items. An investigation conducted on past examination papers showed that some of the questions prepared were unrelated to the program objectives. This was observed in mock and intermediate examinations of exiting students (finalists). A classic example of such parallel questioning includes matching of individual names with respective positions at the provincial health office. Such type of questioning not only has the potential to flair the percentage for general knowledge/recall questions in an assessment but also stands at crossroads in the promotion of higher order thinking among students. Garekwe (2010) and Reichert (2011) argues that repetition of questions in examination papers is associated to difficulties in the construction of own test items coupled with limited time to develop them. From this study, it is clear that most nurse educators prepared and administered test items to students without having a second person to look at them. This has serious implications in that tests may be of low quality and biased towards only one cognitive level of the Bloom's taxonomy.

Use of blue prints can effectively guide nurse educators to spread questions across cognitive levels of educational objectives. This view is supported by De Young (2009); Reichert (2011); Cook (2013). These scholars recommended the use of blue prints (table of specifications) as a guide on how many questions to set in each cognitive level. Contrary to this view, the findings in this study showed that very few $(6 \%)$ nurse educators had a blueprint for test items across the cognitive levels in their institutions while the majority (94\%) did not have. Additionally, the findings in this study revealed that only $3 \%$ of the respondents confirmed that they often times used the blue print whereas $5 \%$ said that they used the blueprint but not often. The majority (92\%) of the respondents either did not use the blue print or did not even respond to the question. It may be alleged that those who did not respond to the question did not know what a blue print is. This implies that examinations are mostly set without such a guide and as such there may not be a clear balance on the number of questions set in each cognitive level. The above findings from the questionnaires were complemented with the analysis done from the question papers. The analysis indicated a greater percentage (88.5\%) of the set questions at basic knowledge (recall) level. This was followed by comprehension, $(6.4 \%)$ while the smaller percentages were observed at synthesis level with (4.2\%), analysis accounting for (0.5\%), application level, $(0.3 \%)$ and evaluation level at $(0.1 \%)$ respectively.

It was clear from the findings that an immense percentage of questions were prepared at the lower cognitive level than the higher cognitive level which promote critical thinking. The resounding negative implication is that the graduating nurses go in the ward to practice armed with a low thinking baby mind who entirely depends on the external orders from the clinicians.

No wonder, scholars such as Scheffer and Rubenfeld (2000); Agbedia and Ogbe (2014) observe that in the practical world of clinical nursing, critical thinking is the ability of nurses to see patients' needs and respond appropriately, beyond or in spite of the physicians' orders.

A critical thinker, said the scholars, goes beyond being a robot machine who simply does as he or she is told. Critical thinking is thus a crucial professional skill which goes hand in hand with clinical reasoning and clinical reflection (Sithole, 2011). The findings of this study match the results of the studies conducted by Mkandawire (2013), Reichert (2011), Garekwe (2010). These scholars observed that educators do not use a blue print to balance questions according to cognitive levels.

Continuing Professional Development (CPD) is a process by which educators keep up-to-date with knowledge and improve their skills in assessment techniques (Tarrant et al., 2006). 
DOI: $10.21522 /$ TIJNR.2015.03.02.Art008

ISSN: $2520-3126$

De young (2009) asserts that professional development meetings and other organized in-service programs are designed to foster the growth of educators that can be used for their further development. However, the findings of this study revealed that only $10 \%$ of nurse educators indicated that their departments conducted continuous professional development meetings on assessment techniques while the majority $(90 \%)$ did not (Figure 22). This is glairing evidence that CPD meetings were not conducted on a large scale in nursing schools. It is also highly probable that nurse educators who might have had participated in the CPD meetings did not share knowledge with other nurse educators on assessment techniques including the use of taxonomies. This was evidenced from the past examination papers analyzed in this study. Ultimately the standard of assessment was terribly compromised because in the final year of training, it is keenly expected that nursing students are assessed by appealing to questions and test items that promote higher order thinking.

Mkandawire (2013) notes that CPD is crucial because it enables educators to progress and develop their professional self, as well as remaining current with their skills and competencies. However, in his study also, $85 \%$ of teachers indicated that their departments did not conduct Continuing Professional Development meetings on classroom questioning.

Makandawire's findings are essentially a homologous to the findings of the studies by Tarrant et al., (2006); Masters et al., (2001); Clifton and Shriner (2010).

\section{Use taxonomies in asking questions either through tests, assignments or during lessons by nurse educators}

Curriculum designers and educators are expected to use the taxonomic model of teaching/ learning in their work. Commenting on the importance of using taxonomies, Kim et al., (2012) states that it is an ideal practice for educators to use guides when setting tests, assignments and examinations to ensure compliance to educational standards at all levels. The essence is to analyze and formulate questions according to cognitive levels. This is because the hierarchical levels of student learning can be used to determine the extent to which educators emphasize both lower and higher order thinking behaviours (Kim et al., 2012).

The findings of this study however, indicated that $46 \%$ of the respondents followed Bloom's Taxonomy in asking questions either through tests, assignments or during lessons while $54 \%$ did not. It is very clear from this finding that tests, examinations and assignments are usually set without any guide.

A similar observation was noted from the analyzed examination question papers that a colossal number of questions (74\%) were constructed using verbs which made students to only recall previously learned information. Recall type of questioning does not stimulate higher order thinking among students.

Mkandawire (2013); Kanter (2013); Kim et al., (2012); Krathwohl (2002) assert that, although it is now customary to write educational objectives as outcomes, lack of a systematic framework (Bloom's taxonomy) means that quality is not evident, or verifiable, and there could be a mismatch between the stated (intended) outcomes and the actual behavior of students.

It is therefore crucially important that nurse educators use Bloom's taxonomy when assessing students. However, studies by Reichert (2011) and Allen (2008) revealed that some factors like faculty shortages, lack of knowledge on Bloom's taxonomy, student population and time pose a big problem in the usage of Bloom's taxonomy in nursing education. The findings of this study also indicated that factors such as lack of time, knowledge on Bloom's taxonomy, inadequate orientation to test item preparation, large student numbers, poor attitude towards Bloom's taxonomy usage, no standard assessment guidelines, shortage of teachers and heavy workload affects use of the Blooms taxonomy when preparing test items in nursing. The study further indicated that majority of the respondents $92 \%$ strongly agreed that factors which affected nurse educators' usage of Bloom's taxonomy in questioning also affected performance of student nurses. On the other hand, $8 \%$ of the respondents argued that these factors did not affect student nurses' performance. 
Higher order thinking among students can be achieved if test items are spread across the cognitive levels. In this study, all (100\%) of the respondents indicated that asking questions at different levels of cognitive domain helps student nurses/learners to have critical thinking skills in nursing. The findings match the study results by Mkandawire (2013); Garekwe (2010); Boikhutso (2010); Kim (1996) who observed that a mixture of questions at various levels of the taxonomy during instruction and assessments promote critical thinking and induce different levels of student learning. Reichert (2011) and Garekwe (2010) further highlighted the advantage of having papers with mixed questions.

The two scholars indicated that low ability students performed better on knowledge/recall questions while high ability students performed better on application level questions. It is for this reason that, Kim (1996) affirms that the hierarchical levels of student learning can be used to determine the extent to which educators emphasize both lower and higher order thinking behaviours.

Surprisingly, application, analysis and evaluation levels remained at $0 \%$ throughout the years in some of the reviewed examination question papers (2011 to 2013) in this study. Krathwohl (2002); Garekwe (2010); Kim et al., (2012); Mkandawire (2013); Agbedia and Ogbe (2014) describes these levels as higher order levels in the cognitive hierarchy necessary for critical thinking. This clearly shows that the schools may produce students that will have problems with application, evaluation and analysis related issues during their nursing practice. These results are in line with findings by Zheng et al., (2008); Garekwe (2010) and Mkandawire (2013). One may link the higher number of questions which were asked at knowledge level (91\% and $92 \%)$ to a problem of construction of questions.

Having a P-value of 0.001 clearly affirms that the relationship between ability to identify Bloom's hierarchy of cognitive levels of educational objectives that promote critical thinking in students and use of Bloom's hierarchy of cognitive levels of educational objectives is statistically significant.

Any serious intervention to improve the use of Bloom's hierarchy of cognitive levels of educational objectives should consider methods that will increase knowledge in this particular important dimension.

\section{Conclusion and Recommendations}

This study revealed that a greater percentage (64\%) of nurse educators had low knowledge on Bloom's hierarchy of cognitive levels of educational objectives. Despite low knowledge on Bloom's hierarchy of cognitive levels of educational objectives, majority, $90 \%$ of nurse educators affirmed that Continuing Professional Development meetings on assessment techniques were not conducted in the schools of nursing. Based on these findings, the author recommends that Continuing Professional Development meetings, workshops and seminars on questioning techniques should be developed and made mandatory for all academic staff in all the schools of nursing. This will improve quality in nursing education and keep all nurse educators abreast with the current information on questioning techniques and on Bloom's hierarchy of cognitive levels of educational objectives.

\section{References}

[1].Affiliated Health Training Institutions (2004). Assessment standards for semesterised and non semesterised programs. Gaborone, Botswana.

[2].Agbedia, C and Ogbe, J. (2014). Critical thinking; issues in nursing education and practice. International Journal of Advanced Nursing Studies, 3 (1) 13 - 17. http://www.sciencepubco.com/index.php/IJANS accessed on 06/03/14 at 11: 14 hours.

[3].Allen, L. (2008). The Nursing shortage continues as faculty shortage grows. Nursing Economics, 26 (1) 35 - 40. http://www.ncbi.nlm.nih.gov/pubmed/18389840. accessed on 9/3/14 at 09:30 hours.

[4].American Nurses Association. (2001). Code of ethics for nurses with interpretive statements. Washington, DC. American Nurses Publishing Company. http://www.vcuhealth.org. Accessed on 9/3/14 at 10:01 hours.

[5].Anderson, L. W, David R. and Krathwohl, D. R., et al (Eds.). (2001). A Taxonomy for Learning, Teaching, and Assessing: A Revision of Bloom's Taxonomy of Educational Objectives. Allyn \& Bacon. Boston, MA (Pearson Education Group). Http://www.odu.edu/educ/roverbau/Bloom/bloom's taxonomy.htm accessed on 12/02/14 at 15 hours. 
DOI: $10.21522 /$ TIJNR.2015.03.02.Art008

ISSN: $2520-3126$

[6].Athanassiou, N. McNett, J.M and Harvey, C. (2003). Critical thinking in the management classroom: Bloom's Taxonomy as a learning tool. Journal of Management Education, 27(5) 533 - 55. http://eric.ed.gov/?id=EJ675756 accessed on 10/04/14 at 14:30 hours.

[7].Ayvaci, H.S and Turkdogan, A. (2010). Analysing "Science and Technology Course exam questions" according to Revised Bloom's Taxonomy. Turkish Science Education, 7 (1) 13 - 25. http://ebookily.net/doc/res-351-finalexam. accessed on 28/01/14 at 14:50 hours.

[8].Azer, S. A. (2006). Assessment in a problem based learning course: Twelve tips for constructing multiple choice questions that test student's cognitive skills. Biochem.Mol.Biol.Educ., $\quad 31(6) \quad 428$ - 434. http://onlinelibrary.wiley.com accessed on 14/03/14.

[9].Bailey, L.R. (2011). Standardized procedure guidelines. Retrieved from http://www.rn.ca.gov/regulations/title16.shtml\#1470. accessed on 11/5/15 at 17:21 hours.

[10]. Bandaranayake, R. (2008). Setting and maintaining standards in multiple choice examinations. AMEE guide No. 37, medical teacher, 30 (9) 836 - 845. http://www.ncbi.nlm.nih.gov/pubmed/19117221. accessed on 9/3/14 at 11:30 hours.

[11]. Beekman, L. (2000). Problem solving and decision making strategies skills: A co - curriculum teaching thinking skills for nursing students. South Africa: Van Schaiki.

[12]. Blanchette, J. (2001). Journal of Distance Education. Royal Roads University, Victoria, BC. http://www.cade.athabascau.calvo116.2/blanchette.html. accessed on 9/3/14 at 16:05 hours.

[13]. Bloom, B. S. (1956). Taxonomy of Educational Objectives: The classification of educational objectives. New York. David McKay. http://www.officeport.com/edu/bloom.htm. accessed on 03/3/14 at 08:20 hours

[14]. Boikhutso, K. (2010). The theory into practice dilemma: lesson planning challenges facing Botswana student teachers. http://imp.sapub.com/content/13/3/205 accessed on 24/02/2014 at 20:54 hours.

[15]. Brady, A. M. (2005). Assessment of learning with multiple choice questions, 5 (4) 238 - 42. Journal for Nurse Education and Practice. http://www.ncbi.nlm.nih.gov/pubmed/10938205. accessed on 10/04/14 at 15:06 hours.

[16]. Bradley, M. et al (2007). Ask and you will receive: How question types influences quantity and quality of online discussions. British Journal of Educational Technology, 39, 888-900.

[17]. Brown, G. (2001). Assessment: A Guide for lecturers. http://78.158.56.101/achive/palatine/files/980.pdf accessed on 14/03/14 at 07: 55 hours.

[18]. Bumen, N. T. (2007). Effects of the original versus revised Bloom's Taxonomy on lesson planning skills: a Turkish study among pre-service teachers. Review of Education, 53, $439-455$.

[19]. Burns, N and Grove, S. K. (2009). The Practice of Nursing Research: Appraisal, Synthesis, and Generation of Evidence. 6th edition, Saunders Elsevier.

[20]. Clauss, J and Geedey, K. (2010). Knowledge Surveys: Students ability to self - assess, 10(2) 14 - 24. Journal of the scholarship of Teaching and Learning. http://dmc.augustana.edu/ks/Accessed on 21/04/14 at 06:30 hours.

[21]. Clifton, S and Schriner, C. (2010). Assessing the quality of multiple choice test items. Nurse educator, 35(1) 12 - 16. http://www.ncbi.nlm.nih.gov/pubmed/20010262. accessed on 9/3/14 at 15:05 hours.

[22]. Considine, J. Bott, M. and Thomas, S (2005). Design, format, validity and reliability of multiple choice questions for use in nursing research and education. Collegian, 12 (08) 19 - 24. http://www.academia.edu/737711/Design,format,validity Accessed on 9/3/14 at 14 hours.

[23]. Cook, J. (2013). How can a teacher use Bloom's taxonomy in the classroom? Retrieved June 26, 2014 at 19:49 hours from http://www.ehow.com/way-5809221

[24]. De Young, S (2009). Teaching Strategies for Nurse Educators. 2nd edition, New Jersey: Prentice Hall.

[25]. Downing, S. (2005). The effects of violating standard item writing principles on tests and students: The consequences of using flawed test items on achievement examinations in medical education, 10 (2) $133-143$. http://www.ncbi.nlm.nih.gov/pubmed/16078098. accessed on 9/3/14 at 17:10 hours.

[26]. Eber, P.A and Parker, T.S (2007). Assessing student learning: applying Bloom's Taxonomy. Human Service Education, 27(1) 45 - 53. http://www.lesn.appstate.edu/olson/RES5560/course-components/student-work. accessed on $13 / 03 / 14$ at 20:08 hours.

[27]. Edwards, S (2003). Critical thinking at bedside: a practical perspective. British Journal of Nursing, 12(19) 


\section{Texila International Journal of Nursing}

Volume 3, Issue 2, Dec 2017

1142-1149. http://www.britishjournalofnursing accessed on 9/3/2014 at 22:15 hours.

[28]. Ellis, K (1993). Teacher questioning behaviour and student learning: What research says to teachers? Paper presented at the 64th annual meeting of the Western States Communication Association, Albuquerque. http://eric.ed.gov/?id=ED359572 accessed on 10/3.2014 at 20:31 hours.

[29]. Ferris, L.J. and Azizi, S.M. (2005). A psychomotor Skills Extension to Bloom's Taxonomy of Education Objectives for Engineering Education. University of South Australia, Mawson Lakes, 5095, Australia: Putney Publishing.

[30]. Fesler - Birch, D.M (2005). Critical thinking and practical outcomes. A review. Nursing outlook, 53(2) 59 65.

[31]. Garekwe, M (2010). Analysis of cognitive levels of examination questions set in the Bachelor of Nursing Programme at the University of KwaZulu-Natal. Masters dissertation in Nursing Education. http://hdl.handle.net/10413/244 accessed on 25/2/2014 at 20:49 hours.

[32]. General Nursing Council of Zambia (2005): The Nursing Regulatory Framework. Lusaka, Zambia.

[33]. Goodman, B (2011). The sociological imagination, provocative pedagogy and scholarship: re-valuing thinking and writing in nurse education. Nurse Education Today. http://www.ncbi.nih.gov/pubmed/21496975. accessed on 13/04/14 at 21: 26 hours.

[34]. Haladyna, T.M., Downing, S.M., and Rodriguez, M.C (2002). A review of multiple - choice item writing guidelines for classroom assessment. Applied measurement in education, 15(3) 309-334. Http://download.springer.com/.../pdf/10.1007\%2Fs12630-011-9467-9 accessed on 14/07/2014 at 09:13 hours.

[35]. Hard, J (2010). Creating tests that assess higher order thinking skills. http://www.cfcc.edu/SACS/QEP/testshigher-thinking.ppsx accessed on 10/04/14 at 14:47 hours.

[36]. Jozefowicz, R. Koeppen, B. Case, S. Galbraith, R. Swanson, D. Glew, R (2002). The effects of violating standard item writing principles on tests and students: the consequences of using flawed test items on achievement examinations in medical education, 77(2) $156-161$

[37]. Kantar, L. D (2013). Assessment and instruction to promote higher order thinking in nursing students. http://www.ncbi.nlm.nih.gov/pubmed/24035312 accessed on 31/03/14 at 14:44 hours.

[38]. Kastberg, S.E (2003). Using Bloom's Taxonomy as a framework for classroom assessment. The mathematics teacher, 96(6) 402 - 405. http://www.ipcsit.com/vol136/005-ICIIM2012-M0017 accessed on 25/03/2014 at 16:11 hours.

[39]. Kim, S. Phillip, W.R. Pinsky, L. Brock, D. Phillips, K. and Keary, J (1996). A conceptual framework for developing teaching cases. A review and synthesis of the literature across disciplines. Journal of Medical Education, 40(9) $867-876$. http://onlinelibrary.wiley.com accessed on 09/03/14 at 01:14 hours.

[40]. Kim, M. Patel, R. Uchizono, J, Beck, L (2012). Incorporation of Bloom's Taxonomy into multiple - choice examination questions for a pharmacotherapeutics course. American Journal of Pharmaceutical Education, 76(6) 14. http://www.ncbi.nlm.nih.gov/pubmed/22919090. accessed on 28/01/2014 at 15:16 hours.

[41]. Krejcie R. V., And Morgan D. W., (1970): Determining Sample Size for Research Activities. Educational and Psychological Measurement. Published formula for determining sample size. ... The relationship between sample size and total population illustrated in Figure 1. Accessed on 6/05/2014 from http://home.kku.ac.th/sompong/guest_speaker/KrejcieandMorgan_article.pdf.

[42]. Knapp, R. (2014). Continuing Nursing Competency. Http://thenetstudyguide.com accessed on 14/03/14 at 13 : 15 hours.

[43]. Krathwohl, D. R (2002). A revision of Bloom's Taxonomy: An overview. Theory into practice, 41(4) 212 218. http://www.jstor.org/stable/1477405. accessed on 14/03/14 at 07:30 hours.

[44]. Krau, (2011). Creating educational objectives for patient education using the new Bloom's Taxonomy, 46(3) $299-312$. http://dx.doi.org/10.1016/j.cnur accessed on 14/03/14 at 14:50 hours.

[45]. Masters, J. Hulsmeyer, B. Pike, M. Leichty, K. Miller, M. and Verst, A (2001). Assessment of MCQ in selected test banks accompanying text books used in nursing education. Journal of nursing education, 40(1) $25-32$. http://www.ncbi.nlm.nih/gov/pubmed/11198906. accessed on 10/3/14 at 08:00 hours.

[46]. Ministry of Health (2006 to 2011) National Health strategic Plan, Lusaka, Zambia. 
DOI: 10.21522 /TIJNR.2015.03.02.Art008

ISSN: $2520-3126$

[47]. Mkandawire, C. (2013). Teachers Questioning techniques in Mathematics at Grade 11 level: The case of four selected secondary schools in Petauke District. Masters dissertation in Education. University of Zambia.

[48]. Moreno.R., Martinez, R., and Muniz, J (2006). New guidelines for developing multiple - choice items. Methodology, 2(2) 65 - 72. http://www.psycontent.com/index/X1817H71H93018T6.pdf accessed on 11/4/14 at 9:26 hours.

[49]. Morrison, S. and Walsh Free, K. (2001). Writing Multiple Choice test items that promote and measure critical thinking. Journal of Nursing Education, 40(1) 17-24. http://www.researchgate.net/publication/12/3208/. Accessed on 9/3/2014 at 19:30 hours.

[50]. Msidi. E.J., (2010): The General Nursing Council of Zambia: Registered Critical Care Nursing Curriculum. Zero Draft, Lusaka.

[51]. Mukarugwiza, F. (2003). Analysis of the cognitive level of basic nursing examinations in Rwanda. Durban, South Africa.

[52]. National League for Nursing. (2005). Core competencies of Nurse Educators. Retrieved from http://www.nln.org/profdev/corecompetencies.pdf

[53]. Nicholl, M. and Tracey, C. (2007). Questioning: A tool in the nurse educators' kit; 7, 285 - 295. Journal for Nurse Education in Practice. http://gamenuig.files.wordpress.com accessed on 20/09/2015 at 20:41 hours.

[54]. Nkonde (2014). Chilenje patient dies on the queue. http://www.postzambia.com accessed on 20/03/14 at 04:34 hours.

[55]. O’Neill, G. (2010). Overview of curriculum models program design. UCD Teaching and Learning Resources. http://www.ucd.ie/teaching accessed on 13/03/14 at 19:50 hours.

[56]. Palmer, E. and Devitt, P. (2007). Assessment of higher order cognitive skills in undergraduate education: modified essay or multiple choice questions? Research paper, medical education, 49 (7) 7 - 4. http://www.biomedcentral.com accessed on 03/03/14 at 09:30 hours.

[57]. Pardue, S.F. (1987). Decision - making skills and critical thinking ability amongst associate degree, diploma, baccalaureate and masters - prepared nurses. Journal of Nursing Education, 26 (9) 354 - 361. http://www.ncbi.nlm.nih.gov/pubmed/2830374. accessed on 13/03/14 at 18: 06 hours.

[58]. Phillips, N. and Duke, M. (2001). The questioning skills clinical teachers and preceptors: A comparative study. Journal of Advanced Nursing, 33 (4) 523 - 532. Available at academic search premier database. Accessed on $02 / 03 / 14$.

[59]. Polit, D. F. and Beck, C. T. (2008). Generating and Assessing Evidence for Nursing Practice, 8th edition, Lippincott, Philadelphia.

[60]. Polit. D.F and Hungler. B. (2001): Nursing Research, Principles and methods,

Lippincott, Philadelphia.

[61]. Profetto - Mcgrath, J. Smith, K. Day, R. and Yonge, O. (2008). The questioning skills of tutors and students in a context based baccalaureate nursing program. Nursing Education Today, 24(5) 363 - 372.

[62]. Reichert, T.G. (2011). Assessing The Use of High Quality Multiple Choice Exam Questions in Undergraduate Nursing Education: Are Educators Making the Grade? Masters of Arts in Nursing Thesis. St. Catherine University. http://Sophia.stkate.edu/cgi/viewcontent. accessed on 14/03/14 at 07:15 hours.

[63]. Russel, A. Comello, R. Wright, D (2007). Journal of Education and Human Development, 1(1) $1934-7200$. http://www.scientificjournals.org/journals2007/articles/1025.htm

[64]. Scheffer, B and Rubenfeld, M (2000). A consensus statement on critical thinking in nursing. Journal of Nursing Education, 39(8) $352-60$.

[65]. Sellappah, S. Hussey, T. Blackmore, A. and McMurray, a (1999). The use of questioning strategies by clinical $\begin{array}{lllllll}\text { teachers. Journal of } & \text { Advanced } & \text { Nursing, } & 28(1) & 142 & - & 149 .\end{array}$ http://ahn.mnsu.edu/nursing/facultyformsandinfo/clinicalquestioning.pdf accessed on 13/03/14 at 19:43 hours.

[66]. Sithole, P. C. (2011). 'An exploration of teaching strategies utilised in the facilitation of learning for first level students in general nursing science'. University of Pretoria, South Africa. http:/hdl.handle.net/2263/24801. accessed on $14 / 03 / 14$ at $07: 18$ hours.

[67]. Tarrant, M. Knierim, A. Hayes and Ware, J (2006). The frequency of item writing flaws in multiple choice 


\section{Texila International Journal of Nursing \\ Volume 3, Issue 2, Dec 2017}

questions used in high stakes nursing assessments. Nurse Education Today, 26(8) $662-671$.

[68]. Tarrant, M. and Ware, J. (2008). Impact of item - writing flaws in multiple choice questions on student achievement in high - stakes nursing assessments. Journal of Medical Education, 42(2) 198 - 206. http://www.ncbi.nlm.nlh.gov/pubmed/18230093. accessed on 09/03/14 at 20:40 hours.

[69]. Titler, M. Dochterman, J. Kim, T. Kanak, M. Shever, L. Picone, D.M. Everett, L. Budreau, G. (2007). Cost of care for seniors hospitalized for hip fracture and related procedures. Nursing Outlook, 55(1), 5-14

[70]. Trochim, W. M. (2002). The Research Methods Knowledge Base, 2nd Edition. Available online at: http://trochim.human.comell.edulkb/index.htm.

[71]. Van derHorst, H. and McDonald, R. (2003). Outcome - based Education. Theory and Practice: 2nd edition. South Africa. Kagiso Publishers.

[72]. Zheng, A.Y. Lawhorn, J.K. Lumley and Freeman, S. (2008). Education forum: Application of Bloom's Taxonomy debunks the "MCAT Myth". Science, 319, 414 - 415. http:/www.ncbi.nlm.nih.gov/pubmed/18218880. 


\title{
Sickle Cell Disease in Pregnancy: Active Nursing Management
}

\author{
Article by Anisley Fabars-Johnson \\ BSN, Texila American University, Saint Kitts and Nevis \\ E-mail: anisley30@yahoo.com
}

\begin{abstract}
Sickle cell disease is considered as a major complication and risk factor for perinatal morbidity Imortality. Literature document that most pregnancies complicated by sickle cell are likely to result in live birth, but the consequences of influence of the disease for the pregnancy/newborn remains a significant concern for health care providers worldwide. According to the bibliography obstetrical-fetal risks are due to the metabolic demands, hypercoagulable state, and vascular stasis associated with pregnancy characterized normally for blood cells to be able to carry oxygen to the growing fetus. With sickle cell anemia, the abnormal red blood cells and anaemic characteristics of the disease physiopathology may result in lower amounts of oxygen going to the developing baby with negative outcome for the future newborn.

Research review studies agreed that access of the pregnant client to a multidisciplinary care team knowledgeable about sickle cell disease and high-risk obstetrics can significantly decrease fetomaternal morbidity and mortality. Example: decreases in spontaneous miscarriage, in perinatal death rates and lowered incidence of preterm labour. Active prenatal management include: education; genetic counselling and prenatal diagnosis for couples at risk; improving nutritional status; vaccination for disease prevention, and early detection of bacterial infection.

Objective of this study was to explore active nursing management of the pregnant women with sickle cell disease, including education, treatment and nursing intervention.

Method: use of English Literature review current through: Jun 2017, Data were searched using MEDLINE, EMBASE, PUBMED and COCHRANE Systematic Reviews.
\end{abstract}

Keywords: Sickle Cell Disease, complication, feto-maternal risk, active nursing management.

\section{Introduction}

Sickle cell disease (also called sickle cell anemia) is an inherited blood disorder that affects red blood cells. People at risk for inheriting the gene for sickle cell, are descended from people who are or were originally from Africa or parts of India and the Mediterranean. Population mobility has spread the sickle cell gene through Europe, Asia, Americas and the Caribbean. It means that millions of people have Sickle Cell Disease worldwide. They are either carriers of or have the sickle cell trait. Carriers are usually asymptomatic and have a low percentage of sickle hemoglobin (HbS). Two parents who are carriers can both pass on the sickle cell trait to their offspring, resulting in SCD. There is a $50 \%$ chance with each pregnancy for the child of two sickle cell carriers to be born with the sickle cell trait, and there is a $25 \%$ chance for the child to be born with SCD.

The disease has been declared by WHO (2006) as a major world health problem. The sickle cell gene mutation causes the body to produce abnormal haemoglobin. In sickle cell disease, the haemoglobin clumps together, causing red blood cells to become stiff and develop a C-shaped ("sickle") form. These red blood cells can block blood vessels, reducing blood flow, which limit adequate oxygenation to many parts of the body. This contributes to the severe pain experienced as a sickle cell crisis and both shortterm and long-term organ damage. The disease also makes patients more susceptible to infections as the spleen may be damage decreasing the individual ability to fight infection. 
DOI: 10.21522 /TIJNR.2015.03.02.Art009

ISSN: $2520-3126$

For some pregnant women, a less percentage of studies show no change in their disease during pregnancy, while others may have a worsening of the disease, resulting from or in many cases as the pregnancy accelerates sickle cell complications surface.

\section{Risks to the woman}

Sickle cell disease is associated with:

- Increased incidence of perinatal mortality

- Premature labour

- More acute painful crises during pregnancy

- Increase in spontaneous miscarriage

- Recurrent antenatal hospitalisation

- Maternal mortality

- Delivery by caesarean section

- Infections (especially urinary tract infection) during pregnancy

- Thromboembolic events

- Ante partum haemorrhage

- Increased risk of pre-eclampsia

- Pregnancy-induced hypertension

- Postpartum infection

- Increased numbers of cases with acute chest syndrome

- Increases the risk of blood transfusion reactions

- Increased incidences of thromboembolism and pulmonary infarct, which are usually fatal

- Heart enlargement and heart failure from anemia

- Vision problems.

\section{Risks to the baby}

Sickle cell disease is associated with fetal complications such as:

- Premature birth

- Fetal growth restriction or IUGR (intrauterine growth retardation)

- Increase the likelihood of fetal distress

- Chance of their baby being affected by Sickle cell disease

- Birth defects

- Low weight babies

- Stillbirths.

- Newborn death

- Newborn with Severe anemia.

- Neonatal jaundice.

\section{Nursing interventions}

Goals of active nursing intervention related to management of sickle cell disease in pregnancy.

- Improve obstetric and neonatal outcomes.

- Give emotional support and measures to alleviate symptoms associated with disease manifestations.

- Enhance patient knowledge for better understanding and cooperation.

- Minimize complications

- Comprise a multidisciplinary approach.

- Promote and maintain a safe environment during pregnancy, labor, delivery, and the postpartum period.

- Enhanced patient sense of self-esteem and power. 
- Active Nursing interventions for pregnant patient with sickle cell anemia should start at the client first antenatal visit.

- Early and regular prenatal care allows healthcare provider to keep a close monitoring on the disease condition and on the health of developing baby.

- Antenatal care should be provided by a multidisciplinary team including an obstetrician and midwife with experience of high-risk antenatal care and a haematologist with an interest in Sickle cell disease condition.

- A head to toe assessment should be performed at each visit to discard signs of worsening anemia, joints swelling, appropriate fundal high according to gestational age.

- Assess for fetal movement and normal fetal heart rate.

- Assess for any sign and symptoms of infection.

- Antenatal education is a significant resource in increasing knowledge for the pregnant client, her partner and family involve, about the disease process, with beneficial results for a healthy pregnancy and baby.

The nurse must teach the patient about situations that can precipitate a sickle cell crisis and steps to help prevent or diminish such crises example:

- Keep warm.

- Maintain adequate hydration.

- Avoid stressful situations.

- Educate patient on the importance of maintain a healthy diet.

- Encourage patient to take folic acid, vitamins and iron supplements.

- Enhance good patient-nurse communication and encourage patient to report any changes.

- Educate patient to maintain proper hygiene to avoid infections.

Studies have also demonstrated an increase in the incidence of urinary tract infection and asymptomatic bacteraemia so is recommended a urinalysis to be performed at each antenatal visit and midstream urine should be sent for culture and sensitivity monthly. Blood pressure and weight should be checked at each visit to monitor for signs of preeclampsia.

\section{Ultrasound scanning during pregnancy}

Serial growth scans allow early detection of fetal growth restriction and hence aid appropriate timing of delivery to reduce perinatal mortality and morbidity

- Women should be offered a viability scan at 7-9 weeks of gestation.

- Women should be offered the routine first-trimester scan (11-14 weeks of gestation) and a detailed

- Anomaly scans at 20 weeks of gestation.

- serial fetal biometry

- Growth and amniotic fluid monitoring scans every 4 weeks from 24 weeks of gestation.

- 32 weeks and advance, growth and well-being scans.

\section{This includes}

- Nonstress tests: measure fetal heart rate

- Biophysical profile tests: monitor fetal movements, muscle tone, and breathing movements, etc.

- Doppler sonography: monitor blood flow from the placenta to the fetus.

\section{Nursing intervention should focus on}

- Managing Pain

- Preventing and Managing Infection

- Promoting Coping Skills

- Monitoring and Managing Potential Complications

- Promoting Home and Community Based Care

- Medications 
DOI: $10.21522 /$ TIJNR.2015.03.02.Art009

ISSN: $2520-3126$

\section{This includes}

- Daily folic acid and prophylactic antibiotics (if not contraindicated).

- Drugs that are unsafe in pregnancy should be stopped.

- Iron supplementation should be given only if there is laboratory evidence of iron deficiency.

- Low-dose aspirin $75 \mathrm{mg}$ once daily from 12 weeks of gestation in an effort to reduce the risk of developing pre-eclampsia.

- Prophylactic low-molecular-weight heparin during antenatal hospital admissions. For the associate risk with risk of venous thromboembolism.

\section{Managing pain}

Sickle cell disease (SCD) is associated with chronic haemolysis and painful episodes, during pregnancy, SCD may become more severe, and pain episodes may happen more often; usually happen in the bones, joins, abdominal organs. They can last a few hours, few days, or last for weeks. Sickle cell painful crisis is the number one cause of recurrent hospitalization. It must be treated with medications that are safe to use during pregnancy.

Women admitted with sickle cell crisis should be looked after by the multidisciplinary team, involving obstetricians, midwives, haematologists and anaesthetists. A detail assessment should be rapidly carried out to rule out medical complications requiring intervention such as ACS, sepsis or dehydration.

- Dehydration and electrolyte imbalance caused by vomiting, diarrhoea or pyrexia should by corrected with the administration of intravenous fluid.

- Initial investigations should include full blood count, reticulocyte count and renal function. Other investigations will depend on the clinical scenario but may include blood cultures, chest X-ray, urine culture and liver function tests.

- Oxygen therapy may be required if baseline less than $95 \%$ for supplementary therapy and to prevent fatal hypoxia. Sickle cell disease can lead to severe placental damage which decreases the transfer of blood rich in oxygen and nutrient to the fetus.

The World Health Organization analgesic ladder should be used, starting with paracetamol for mild pain; NSAIDs can be used for mild to moderate pain between 12 and 28 weeks of gestation. Weak opioids such as co-dydramol, co-codamol or dihydrocodeine can be used for moderate pain, and stronger opiates such as morphine can be used for severe pain. Morphine or diamorphine can be given by the oral, subcutaneous, intramuscular or intravenous route depending on the woman's preference and local expertise. Parenteral opiates can be given by intermittent bolus or patient-controlled administration systems.

Pethidine should be avoided because of the risk of toxicity and pethidine-associated seizures in patients with SCD. While women are receiving parenteral opiates, they should be nursed in an area where they can undergo hourly observations. Assessments of pain score, sedation score and oxygen saturation should be performed. Opiate morphine constricts the blood vessels in the placenta and so may harmful to the fetus. Nurses must monitor continuo fetal activity to rule out fetal distress. And provision of social, physical and psychological support to alleviate symptoms associated with chronic pain.

According to the literature review sickle cell pain crisis on third trimester are more likely lasts for a longer time or until after delivery. Which required a longer stay in hospital, in most cases until the baby is born.

- The nurse must monitor patient for sings of worsening condition:

- A fever higher than $101^{\circ} \mathrm{F}$

- Difficulty breathing

- Chest pain

- Abdominal oedema

- A severe headache 
- A sudden feeling of weakness

- Seizures

- Sudden vision loss

\section{Blood transfusion during pregnancy}

A systematic cohort review indicated that there is insufficient evidence to draw conclusions about the role of prophylactic transfusion in pregnancy to decrease the incidence of maternal painful crises. Routine prophylactic transfusion is not recommended during pregnancy for women with SCD. If acute exchange transfusion is required for the treatment of a sickle complication, it may be appropriate to continue the transfusion regimen for the remainder of the pregnancy. Risks associated with transfusion, include alloimmunisation (the formation of antibodies to red cell antigens), delayed transfusion reactions, transmission of infection and iron overload.

\section{Blood transfusion therapy should be given only}

1. To compensate for anemia with symptoms of impending cardiac failure

2. To provide a prophylactic "top-up" transfusion before a caesarean section

3. Emergency transfusion for acute anemia $(<5 \mathrm{~g} / \mathrm{dL}$ hemoglobin)

4. Twin pregnancy

5. Previous history of perinatal mortality

6. Septicaemia,

7. Acute renal failure

8. Acute chest syndrome

9. A recent neurologic event, hypoxemia,

Randomized studies have shown that many patients, when closely monitored, had well-tolerated anemia, regardless of the level of hemoglobin, and that many were able to complete their pregnancy successfully without transfusion, regardless of the route of delivery.

\section{Recommendations}

\section{Preconception care}

- Amplify the role of family planning and health promotion in the communities to provide education to all women in childbearing age about Sickle cell disease effect- outcome in pregnancy. And the importance of have the haemoglobinopathy status of their partner before becoming pregnant.

- Promote counselling about reproductive options, planning and contraceptive choice.

- Advice the couple to assist genetic counselling.

- Folic acid (5 mg) should be given once daily both preconceptual and throughout pregnancy.

\section{Antenatal care}

- Identify the client as a high risk and refer couple to high risk pregnancy clinic.

- Remit patient to a high - risk clinic to be evaluate by a multidisciplinary team including an obstetrician and midwife with experience of high-risk antenatal care and a haematologist with an interest in SC.

- Promote screening programme to ensure that screening tests are offered by $8-10$ weeks of pregnancy by Primary care or maternity services.

- To monitor and prevent worsening of the condition.

- Iron supplementation should be given only if there is laboratory evidence of iron deficiency.

- Referring to type of delivery is important to maintain proper temperature on delivery room to avoid hypothermia, acidosis and hypoxemia. And to prevent vaso-occlusion and joint pain

- Care could be improved by more specialist centres and specialist nurses or midwives. 
DOI: $10.21522 /$ TIJNR.2015.03.02.Art009

ISSN: $2520-3126$

- Guidelines need to be created for all healthcare professionals to improve management of these women during pregnancy.

- Refer to genetic counselling and promote partner screening testing to determine presence of HbS.

\section{Conclusion}

The detail of appropriate prenatal care and perinatal management for these patients is still a matter for debate in developed countries. However nowadays outcomes have improved significant for pregnant women with Sickle Cell Disease and newborns thanks to medical/obstetric advancement and earlyvigilant nursing care, with a good chance of having a safe and healthy pregnancy. Different studies agreed for the need of a dedicated multidisciplinary health care for pregnant women and newborn with SCD for crucial improvement of the disease condition and prevention of short/long term complications. Optimal management during pregnancy should be directed to education/counselling about healthy diet, prenatal vitamins, folic acid supplements and B vitamins, prevention of dehydration, also avoidance of precipitants such as a cold environment and excessive exercise, that can trigger pain crises, and to prevent chronic organ damage, and optimization of fetal health with the goal of minimizing early maternal mortality.

\section{References}

[1]. Eugene Oteng-Ntim, Daveena Meeks, Paul T Seed, Louise Webster, Jo Howard, Pat Doyle, and Lucy C Chappell. Adverse maternal and perinatal outcomes in pregnant women with sickle cell disease: systematic review and meta-analysis. Blood, March 2015 DOI: 10.1182/blood-2014-11-607317

[2]. Goldsmith JC, Bonham VL, Joiner CH, et al. framing the research agenda for sickle cell trait: building on the current understanding of clinical events and their potential implications. Am J Hematol 2012; 87:340.

[3]. NHLBI. Evidence-Based Management of Sickle Cell Disease: Expert Panel Report, 2014. p.24. http://www.nhlbi.nih.gov/guidelines (Accessed on August 11, 2014).

[4]. Oteng-Ntim E, Meeks D, Seed PT, Webster L, Howard J, Doyle P, Chappell LC. Adverse maternal and perinatal outcomes in pregnant women with sickle cell disease: systematic review and meta-analysis. Blood. 2015; 125(21):3316-25. [PubMed]

[5]. Oteng-Ntim E, Ayesha B, Knight M, Howard J. Pregnancy outcome in patients with sickle cell disease in the UK--a national cohort study comparing sickle cell anaemia (HbSS) with HbSC disease. Br J Haematol 2015; 169:129.

[6]. Pintova S, Cohen HW, Billet HH. Sickle cell trait: is there an increased VTE risk in pregnancy and the postpartum? PLoS One 2013; 8:e64141.

[7]. Royal College of Obstetricians and Gynaecologists Green-top. Guideline Management of sickle cell disease in pregnancy. RCOG. 2011; 61:1-20.

[8]. Souza J.P., Cecatti J.G., Fagundes A., Morais S.S., Villar J., Carroli G.A. Maternal near miss and maternal death in the World Health Organization's 2005 global survey on maternal and perinatal health. Bull World Health Org. 2010; 88:113-119. [PubMed].

[9]. Yawn BP, Buchanan GR, Afenyi-Annan AN, et al. Management of sickle cell disease: summary of the 2014 evidence-based report by expert panel members. JAMA 2014; 312:1033. 


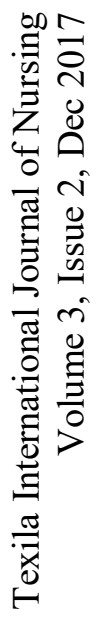

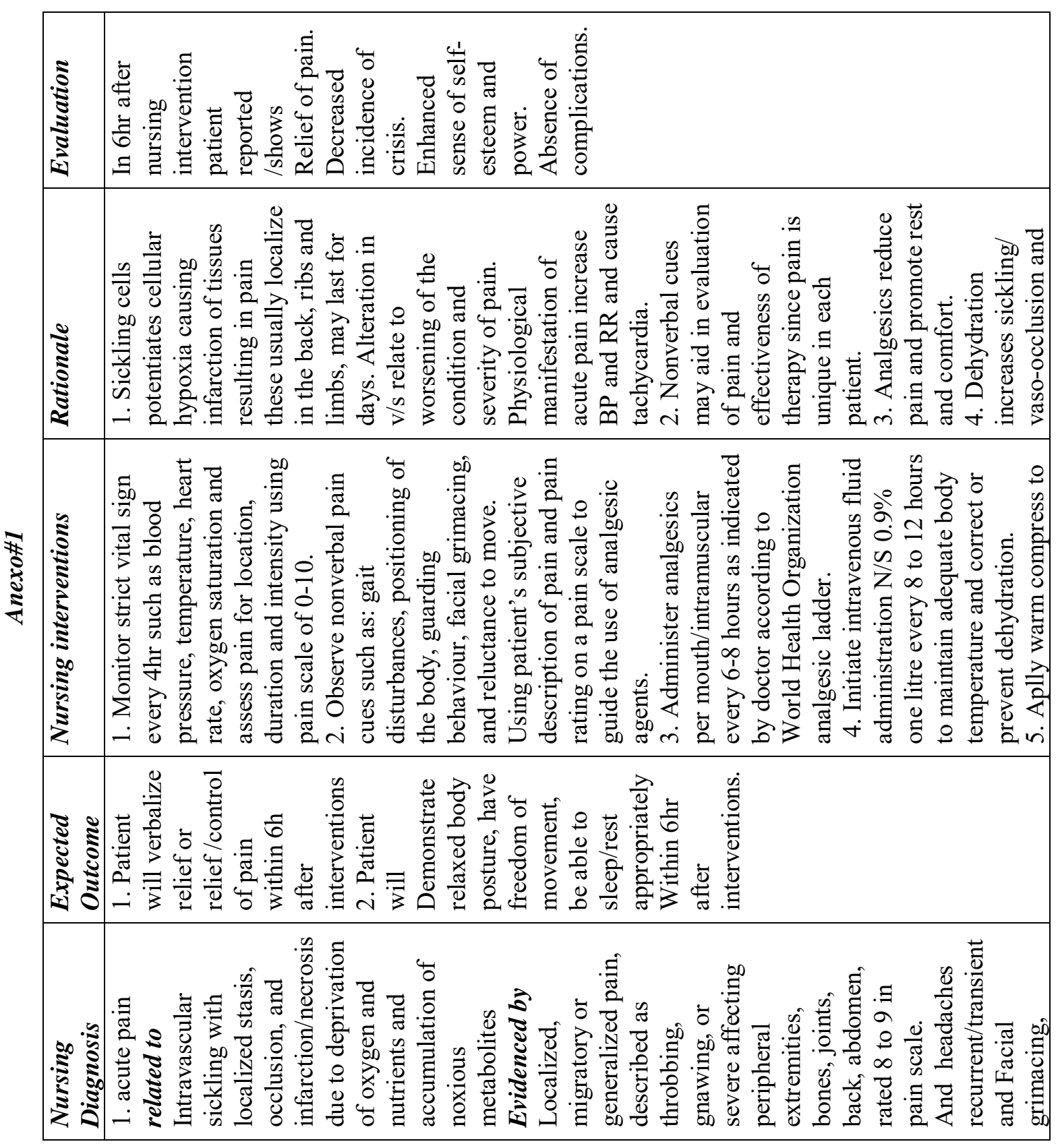




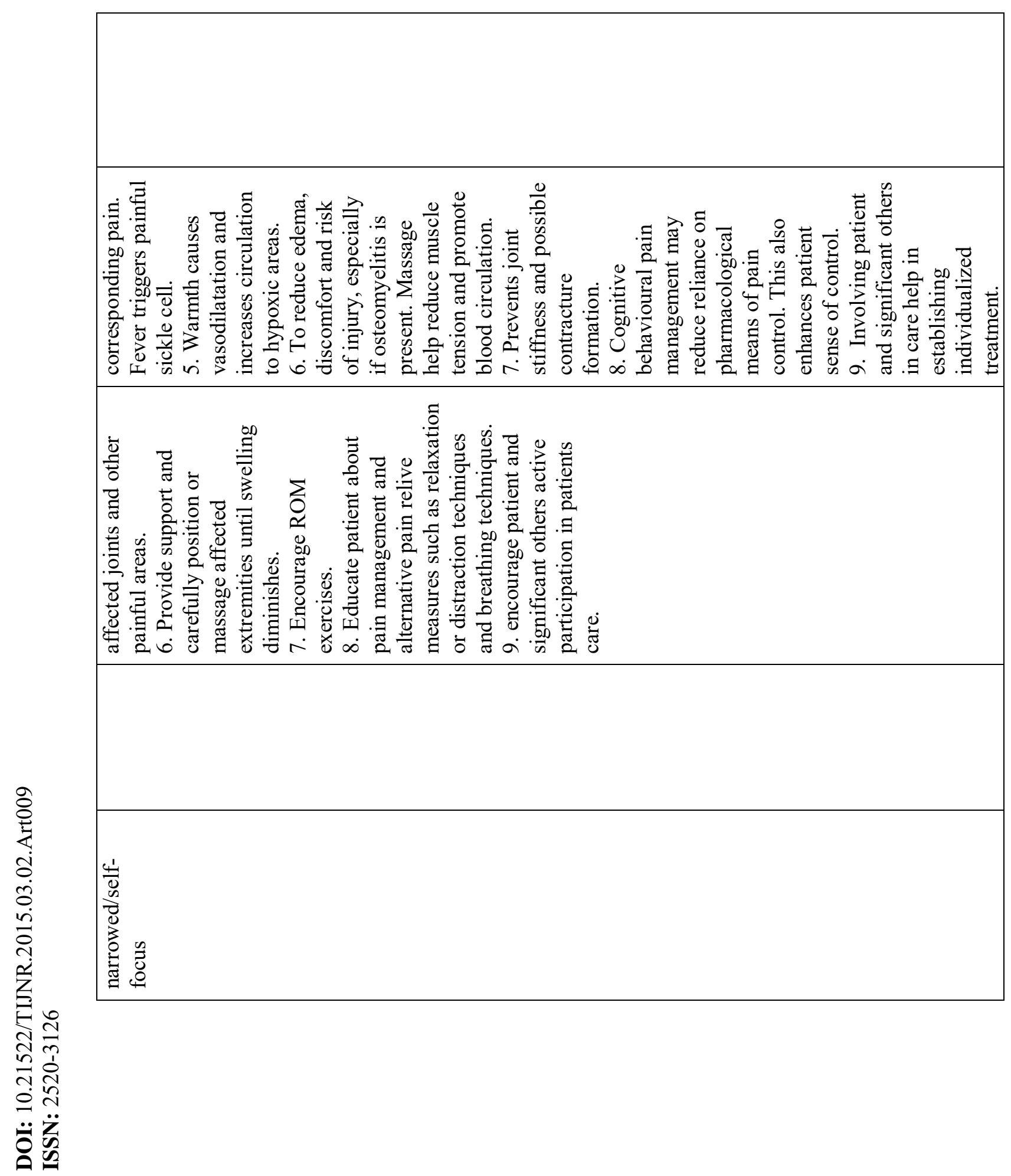




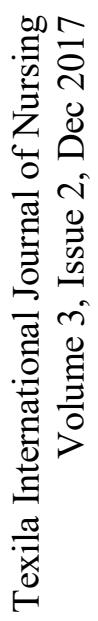

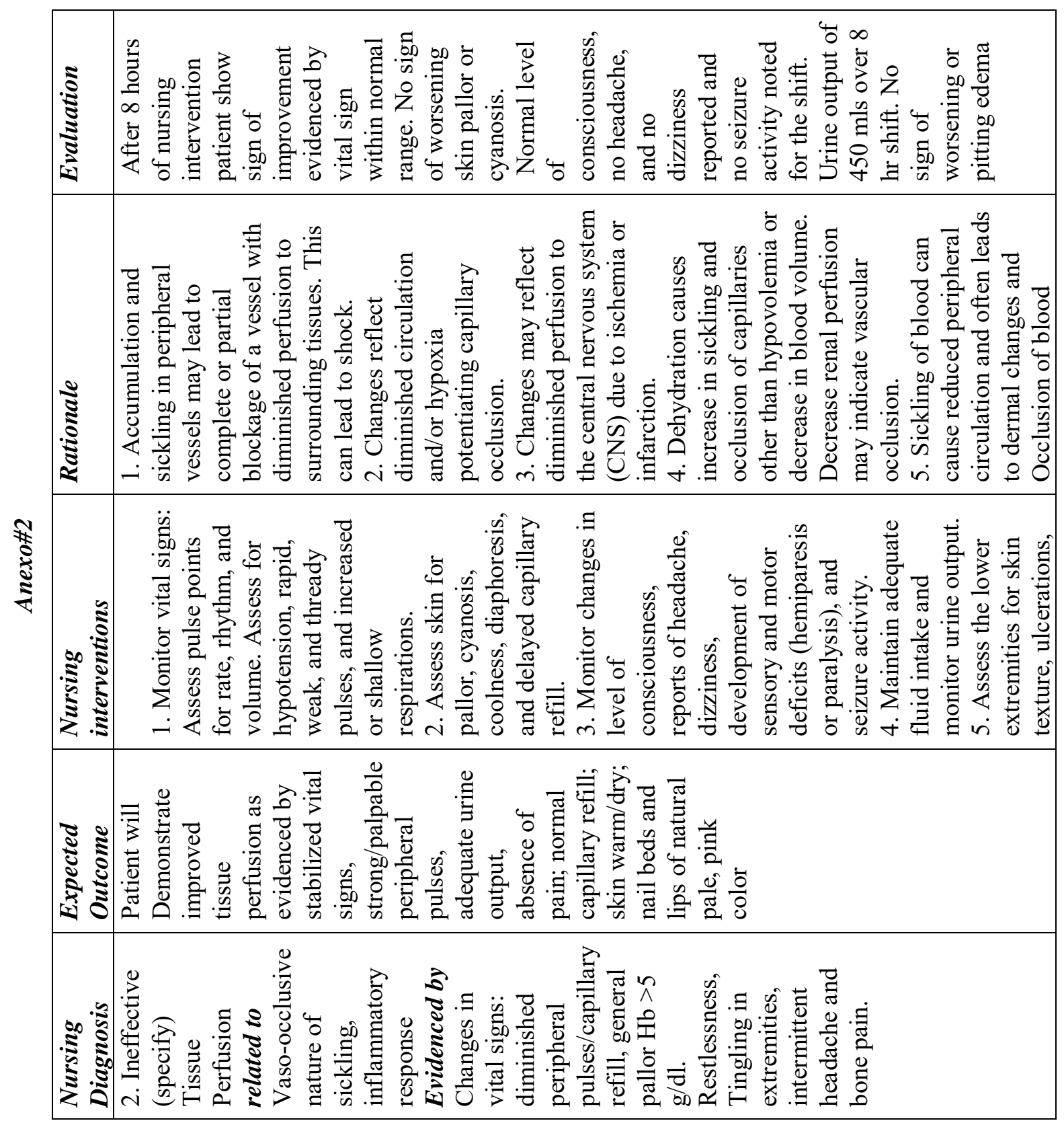




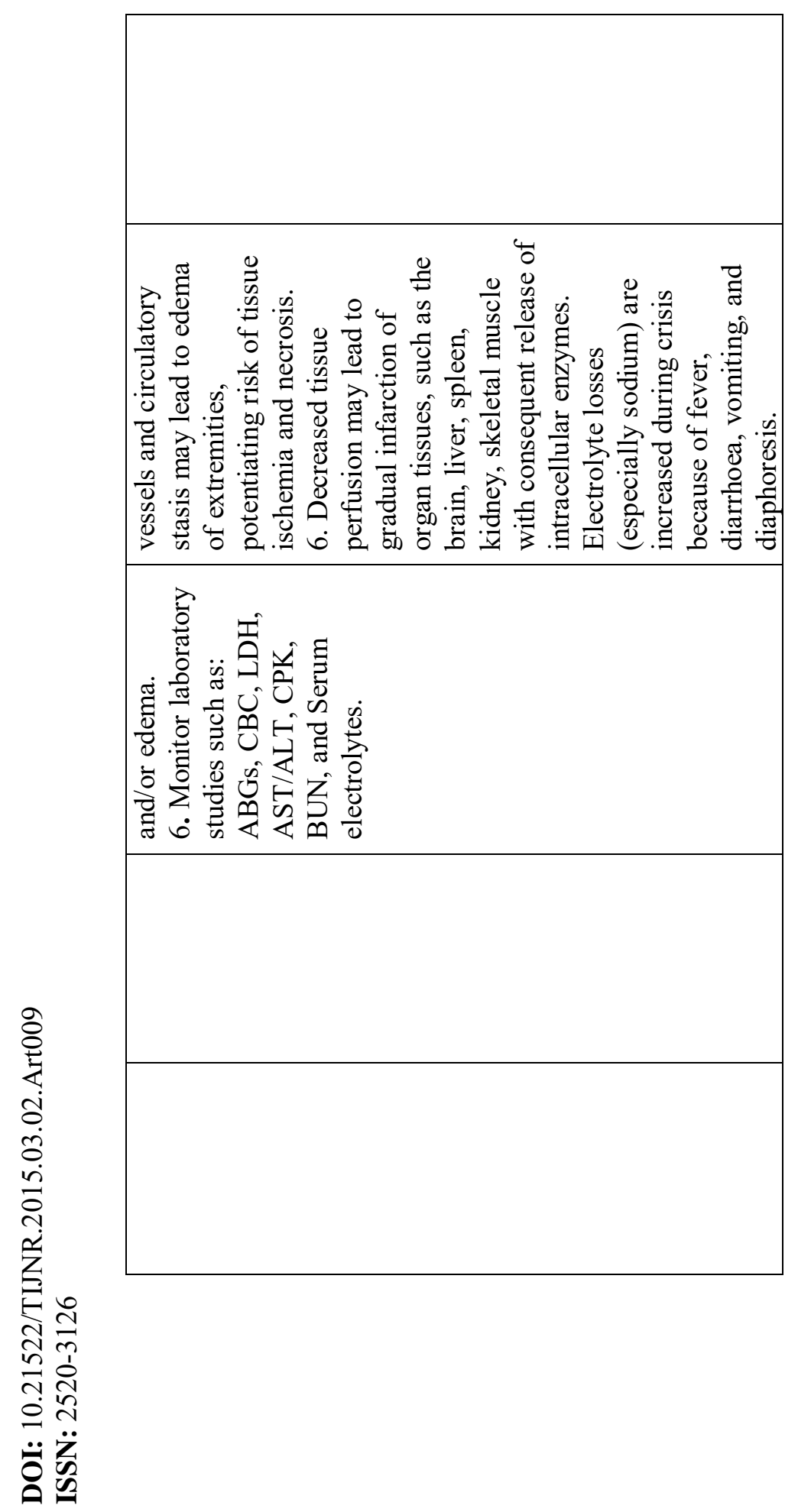




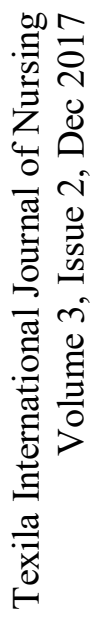

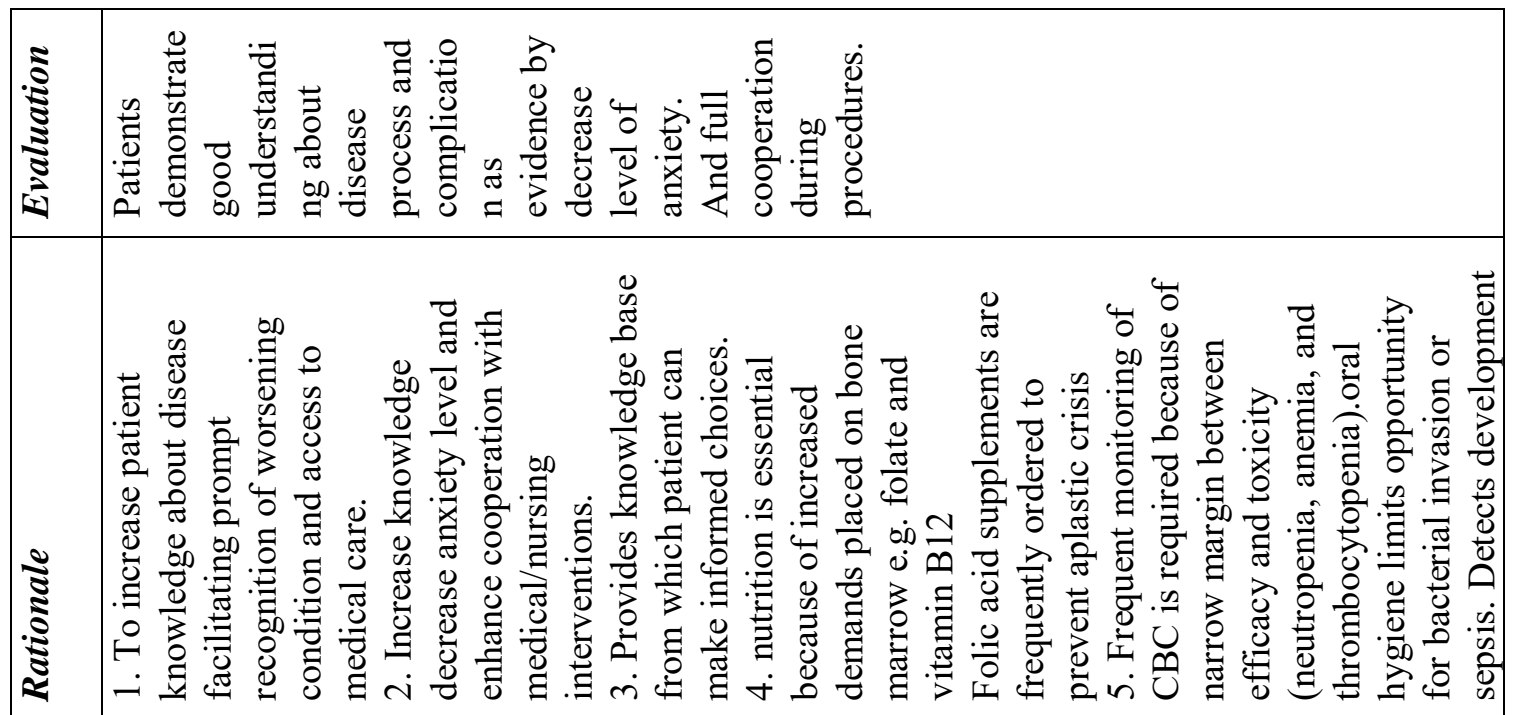

.

苛芯

î

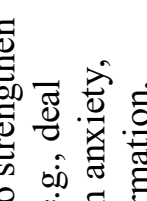

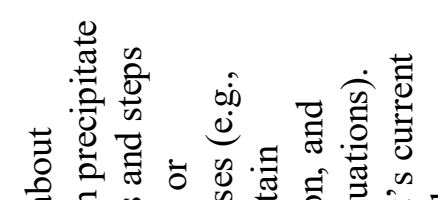

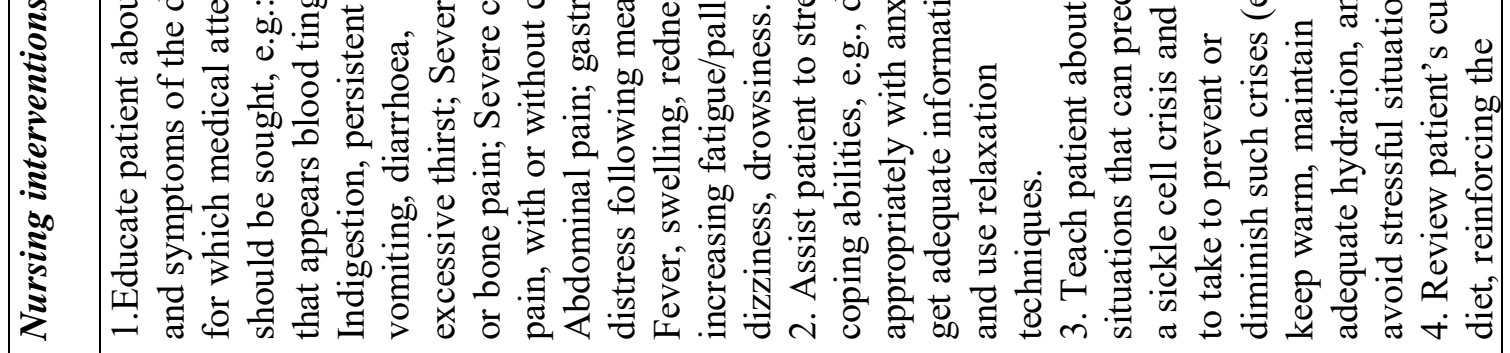

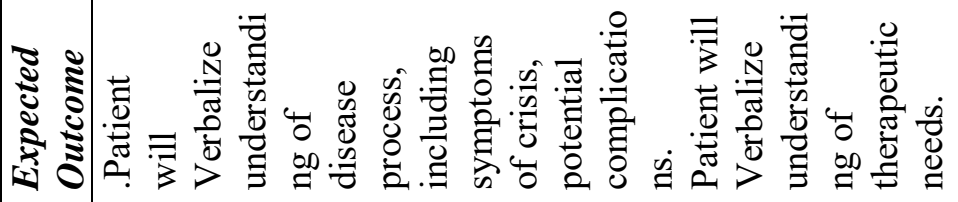

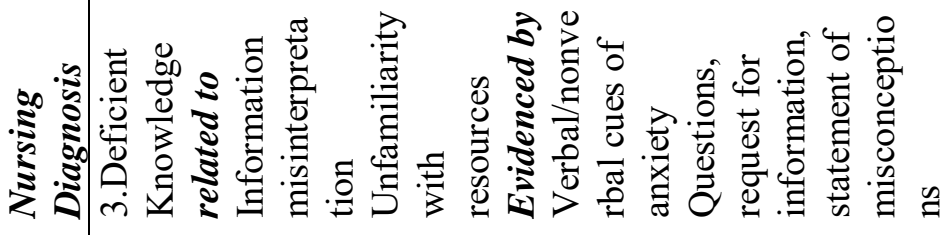




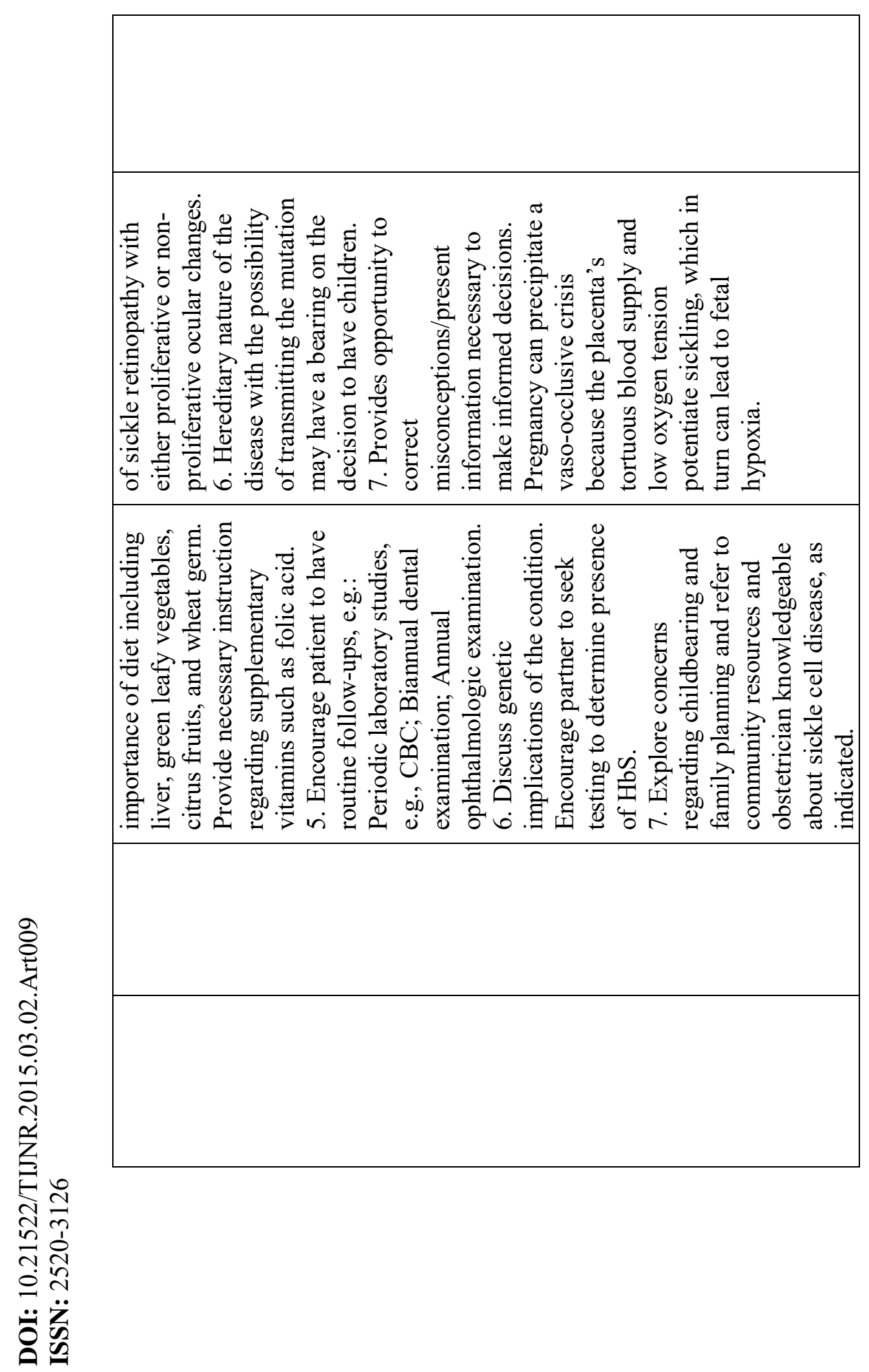




\title{
Effects of Shortage of Nurses at St. Dominic's Mission Hospital, Ndola, Zambia
}

\author{
Article by Elizabeth Njovu \\ Nursing, Texila American University \\ E-mail: njovulisa@yahoo.com
}

\begin{abstract}
The shortage of nurses is a problem that is common everywhere in the world. Nurses form the largest number in the healthcare system and play a significant role in providing direct patient care. Considering the importance of the role of nurses in the healthcare system, it is important to investigate how nursing shortage affects the quality of patient care, nurses' job satisfaction and their work stress. Zambia is not an exception to this scourge, most hospitals face this challenge of nursing shortage. One such Hospital is St. Dominic's Mission Hospital located in the outskirts of Ndola.

There is a confirmed positive relationship between nurse shortage and workload. There is also a significant positive relationship between workload and the quality of patient care. Furthermore, a negative relationship was observed between workload and the quality of patient care. In addition, this study calculates the mean effect of emotional intelligence of these factors, and a significant correlation is found between emotional intelligence and workload as well as work stress. It can be said that in Zambia, nursing shortage Influences the workload of the employee, finally affecting the quality of patient care. In addition, the study recognized the capability of nurses to manage their emotions as well as emotions of others, which has increased their tolerance to control psychological stress in performing their duty. This study confirms that nurse's emotional intelligence act as a partial moderating variable for job outcomes of nurses.

Background: The shortage of nursing staff is a great challenge worldwide, it affects many nations in the world. With this shortage, patients are suffering because the healthcare workforce is not prepared to deal with their health needs. In each country, the shortage of nurses is as a result of a number of factors that ultimately cause a decrease in the quality of health care given. However, little is known about the global causes of a shrinking professional nurse workforce.

Main objective: To assess the effects that shortage of nurses has on the care of patients and on the few nurses providing care at St. Dominic's Mission Hospital, Zambia.

Method: A cross-sectional study was conducted to assess and identify the effects of the shortage of nurses on care of the patient as well as on the few nurses providing care. Data was collected using the self-structured questionnaire with closed and open ended questions. Purposeful sample of 20 nurses participated.

Results: 20 nurses participated: 15 females and 5males; aged between 21 to 50 years. Majority (90\%) diploma Holders and are registered nurses. Findings reveal that (100\%) are aware of the shortage of nurses at the Hospital, (89\%) feel the impact of the shortage of nurses has on them. (70\%) indicated that shortage of nurses compromises the quality of patients care, 55\% of the participants had knowledge on the nurse-patient ratio for the general medical ward while $45 \%$ did not. $20 \%$ indicated that poor Human resource planning by administration has caused the shortage, while $75 \%$ indicated unrevised staff establishment and 5\% indicated that migration of nurses is the reason for nurse shortage at the hospital. $100 \%$ expressed that shortage of staff makes them stressed and work long hours.

Conclusion and recommendation: the participants' are very much aware of the shortage of nurses not only at St. Dominic's Mission Hospital but in other health care facility as well; they are determined to continue doing the best for the patients despite the shortage. It is therefore recommended that the
\end{abstract}


DOI: $10.21522 / \mathrm{TIJNR} .2015 .03 .02 . A r t 010$

ISSN: $2520-3126$

administration at St. Dominic's Mission Hospital should urgently lobby for more nursing staff from the Ministry of Health.

Keywords: shortage, effects, nurses, compromised care, quality care, stressful environment, St. Dominic Mission Hospital.

\section{Introduction}

In every healthcare system nurses are the heart of the care of the patients and their shortage is very complex. The Shortage of nurses has an adverse impact on the health care systems around the world (Oulton, 2006). Kimball and O' Nell, 2002 defined the Nursing Shortage as a disproportion of supply and demand for nurses attributed to demographics, qualifications, availability and willingness to the work). However, Toh et al., 2012, described nursing shortage $\mathrm{i}$ as the inadequate number of nurses is to provide quality nursing care. Nurses in developed countries with distinctly healthcare systems have reported the same compromised quality of health care. The high spread nursing shortage and nurses' high turnover is a global issue ("The Global Shortage of Registered Nurses", 2013). The Shortage of Nurses in many hospitals and their impact, particularly on the compromised quality of care, has become common phenomenon. According to Douglas (2010), he suggested that administrators in the health care institutions need to collaborate to develop a workable and lasting solution for safe staffing.

Purpose and significance of the research: This research has been conducted to assess effects of shortage of nurses on the care of the patients and on the few nurses that provide care to the patients at St. Dominic's Mission Hospital.

When staff nurses are not adequate, the result is that quality nursing care is compromised and nurse burnout and stress is evident. The importance of this research has added to evidence based researches on effects of shortage of nurses on the patient care and the few nurses working. Findings are beneficial to both patients and the Human resource planners in planning for adequate Nursing Professionals, in improving quality nursing care and preventing stress and burnout of nurses. In the research done in March 2004 by the Agency for Healthcare Research and Quality on the impact that nursing shortage has on the patient outcomes, the study shows that hospitals with lower nurse staffing levels and fewer registered nurses tend to have higher rates of poor patient outcomes, nurse burnout and stress. This research was a reminder to the Human resource planners that for the quality patient care, adequate nurses need to be deployed in the hospitals and health care institutions in order to reduce on nurse burnout and nursing workload. According to Hurst (2002) he identified several criteria available to define whether the level and number of nurse staffing are enough to address the needs of patients and nurse staff herself. Some of the criteria identified includes: nurse's level of education, number of hospital beds, Size of the word, status of patients acute or chronic, the time required for individual nursing interventions and bed occupancy. Duffield et al., 2009 described Nursing workload as being influenced by the time spend by patients on wards. However a many studies on nursing workload and patient safety uses nurse-patient ratio as the measure of nursing workload.

Problem to be solved: The shortage of nurses in the health institutions has remain the major challenge and problem in most countries especially in developing countries, exposing the few nurses that are working to work long hours under very difficult and stressful conditions, are fatigued and have less job satisfaction. Nurse shortage, has contributed to the compromised care of patient. The nurse shortage mainly has been caused by few nurses being deployed by the Ministry of Health, unrevised establishment in most health facilities, nurse migration in search for greener pastures, fewer nurses being trained because of fewer nursing schools and the increased disease pattern that demand more nursing care. According to the World Health Organization almost 4.3 million of shortage of nurses globally was estimated. Nurses are the heart of the health care institution and the quality of patients care depends on them.

Existing solution to the problem: The most effective solution in addressing the problem of nursing shortage is through retention and recruitment which remains the most important ways to achieve a long- 
term solution to the nursing shortage. Recruitment should be done in a more attractive way to make nursing professional appealing especially to younger people. The work environment for nurses should be redesigned in order to achieve job satisfaction. The other way to reduce the shortage of nurses and especially at St. Dominic's Mission Hospital is for the Hospital administrator through the Ministry of Health to revise the staff establishment which has remained the same for a long time even after the growing number of the population accessing services at the hospital. At St. Dominic's Mission Hospital, the administrator through Churches Health Association of Zambia (CHAZ) has taken initiative to train the community volunteers to do the basic nursing care on the patients to reduce the work load on the nurses. The community volunteers are able to do bed making, dump dusting, bathing and feeding of patients. According to the Mach 30, 2013 America Magazine entitled, Nurse Recruitment, Nursing Careers, it stated that without adequate number of nurses in the health care institutions, patient care and safety is compromised and while nurses themselves become overwhelmed, distressed, and dissatisfied. The patient-nurse ratios at St. Dominc's Mission Hospital and in many health facilities in Zambia has been so high (1:20). Many based evidence and efforts to reduce the shortage of nurses have been implemented by the hospital administrator. Different researchers have done different studies to find potential and lasting solutions for the nursing shortage as they examine its causes. Their researches findings give hope to maintain and improve the healthy environment that promotes safe, quality nursing care and initiates a professional avenue that is desirable by nurses. (Zurmehly, J. 2008)

\section{Background}

The Zambian Government has put in place a national health care syste, to service its's population of about 13 Million. The government's commitment to the objective of improving the quality of life of all Zambians has been demonstrated through its effort to improve health care delivery by reforming the Public Health Sector through the Health Reforms. In 1991, the Zambian government articulated radical health policy reforms characterized by a move from a strongly centralized health system in which the central structures provided support and national; guidance to the peripheral structures (CBoH 1991). These Health Reforms established government's commitment to improve the health of the population by progress towards achieving targets that were set. The Ministry of Health states that careful human resources is necessary in order to meet the health needs of the population (CBOH 1991).

The human resources in the Ministry of Health mainly comprise health proffesionals. Nurses comprise about $75 \%$ of all health care proffessionals in the health care system in the country (General Nursing Council of Zambia, 2004). This menas that Nurses who are the majority in the health care delivery system implement most of the health care programmes.

The Zambian health system has two (2) categories of nurses, namely the Registered Nurses and the enrolled Nurses. The levels of training differentiate the two (2) categories. The Enrolled Nurses undergo a two year (2) training programme and graduate with a Certificate. The Registered Nurses undergo a three (3) year training programme and graduate with a Diploma. They can then specialize locally in Registered Midwifery, Operating theatre Nursing and Mental Health Nursing (General Nursing Council of Zambia, 2004). The University of Zambia and many other private universities offers a Bachelor of Science degree programme for Registered Nurses who upon graduation are skilled to become researchers, educators, administrators, clinical specialists etc.

The Ministry of Health (2005) states that Zambia has around 10,000 nurses in practice as against a population of more than 10 millon, leaving a ratio of about 1 nurse to 1,000 . With the increase in population, the Ministry of Health articulated the ratio to be 0.8 nurse to 1,000 . The ratio is in adequate to meet the health needs of the Zambian population. For some years it has been noted that most of our nurses are leaving the country for greener pastures in foreign countries. There are many reasons for the attrition of nurses in general and at St. Dominic's mission Hospital in particular. It is widelt believed that Britain, South Africa, USA and Australia are currently large drawers of Zambian nurses, who are well trained but 
DOI: 10.21522 /TIJNR.2015.03.02.Art010

ISSN: $2520-3126$

unable to make ends meet working at home. In 2004, it was noted that 2000 nurses in the UK General Nurses Council Register are Zambians, (Post News paper 2004).

St. Dominic's mission Hospital where the Study was conducted is a mission Hospital in the outskirts of Ndola. It has a bed capacity of 100 with a catchment area population of 15, 000(Table 1). According to the records, the establishment is supposed to have over 30 nurses but currently there are only about 16 nurses, leaving a balanc of about 14 , as shown in Figure 2. This has led to a situation where one nurse attends to a lot more patients.

Table 1. St. Dominic's mission hospital population

\begin{tabular}{|l|l|l|}
\hline \multicolumn{3}{|l|}{ ST. Dominic's Mission Hospital Population } \\
\hline Category & & YEAR 2017 \\
\hline Children under one year & $\%$ & 15,000 \\
\hline Children under five years & 15.5252 & 529 \\
\hline Children 5-14 years & 27.125 & 4,069 \\
\hline Children 0-15 years & 42.804 & 6,421 \\
\hline Women 15-45 years & 25.029 & 3,754 \\
\hline All adults 15 years + & 57.196 & 8,579 \\
\hline Total Male all ages & 49.531 & 7,430 \\
\hline Total Females all ages & 50.469 & 7,570 \\
\hline Total District Population & 100 & 15,000 \\
\hline
\end{tabular}

\section{NURSES}

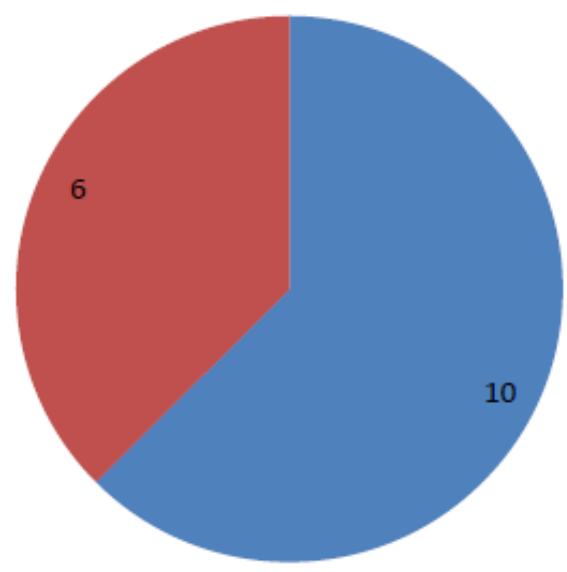

Figure 1.1. Number of nurses according to their positions 
Table 1.2

\begin{tabular}{|l|l|l|l|}
\hline Position & Establishment & Actual & Variance \\
\hline Registered Nurses & 12 & 10 & 2 \\
\hline Enrolled Nurses & 18 & 6 & 12 \\
\hline
\end{tabular}

For Sustained change and assurance of an adequate supply of nurses, solutions must be developed in several areas these include: staff retention methods that is improving the conditions of service and giving incentives, staff replacement by recruiting the conditions of service and also staff development through training, workshops, and improved image of nurses, hence this strudy needs to be carried out in order to identify the factors associated with the acute shortage of nurses at St. Dominic's Mission Hospital.

Study limitations: Study participants were only nurses; excluded other professionals and support staff. This could result in missing other key and rich information on effects of nursing shortage at St. Dominic's Mission Hospital.

Because of limited time and the busy schedule during data collection period, some missing responses in the questionnaire could not be followed up; hence important information could have been missed, to make the report richer

\section{Method used}

The research was conducted in May/June 2017. Data was collected at one point in time which was appropriate due to limited time and inadequate resources for the whole research. Collected data gave information of the effects of shortage of nurses on the care of the patient. Findings would assist administrators who do budgeting and planning for Human resource in identifying effects that nursing shortage has on the care of the patients while they plan and budget for nurse recruitment and make it a priority.

Purposive sampling, a type of non-probability sampling, which is extremely useful was used to obtain the information from nurses working at St. Dominic's Mission Hospital.

Self-administered structured questionnaire of both open and closed ended questions was used for Data collection. Questionnaires were hand delivered to 20 nurses and then hand collected, for confidentiality's sake; quality data verification was done. Collected Data consisted of Primary and secondary; primary data included; social demographic, respondents' characteristics of age and sex, marital status, and number of years in service which helped in assessing effects of shortage of nursing on the care of patients while secondary data consisted of the main topic of the research.

Strengths of data collection method: The self-structured questionnaire was given to the respondents once only and all respondent work at the same hospital, which made it cheaper and less time consuming. The respondent were eager to participate because the topic affects them and they have experience the effects of nurse shortage.

Limitations during data collection period: The distribution of the questionnaire was limited to nursing staff only and all of them working at the same hospital, this could have lead to some missing information and values to add to the richness of the research.

\section{Results}

20 nurses participated: 15 females and 5males; aged between 21 to 50 years. Majority (90\%) diploma Holders and are registered nurses. Findings reveal that (100\%) are aware of the shortage of nurses at the Hospital, (89\%) feel the impact of the shortage of nurses has on them. (70\%) indicated that shortage of nurses compromises the quality of patients care, $30 \%$ indicated that nursing shortage has caused the poor patient outcome, $55 \%$ of the participants had knowledge on the nurse-patient ratio for the general medical ward while $45 \%$ did not. $20 \%$ indicated that poor Human resource planning by administration has caused the shortage, while $75 \%$ indicated unrevised staff establishment and $5 \%$ indicated that migration of nurses is the reason for nursing shortage at the hospital. $100 \%$ expressed that shortage of staff makes them 
DOI: $10.21522 / \mathrm{TIJNR} .2015 .03 .02 . A r t 010$

ISSN: $2520-3126$

stressed and work long hours. $90 \%$ indicated 1:35 as the nurse patient ratio of the medical ward at St. Dominic's mission hospital while $10 \%$ did not know the ratio. $100 \%$ of the participants recommended that the hospital establishment for nurses be revised and the Ministry of Health to deploy more nurses.

\section{Discussion}

Social demographic characteristics of study participants: 20 total number of study participants all of them nurses. Their age ranged from 21 to 50 years, majority were $21-35$ years. $55 \%$ of the study participants were married, reason being that, at this time they had completed their diploma course, as reflected by high number $90 \%$ of diploma holders and mostly as registered nurses $60 \%$; having worked between 1-5 years.

Participants' general information about effects of nursing shortage on patient care: Findings revealed that most participants are aware of the nursing shortage; they have experiences the effects this has on the patient as well as on themselves

Concerning the causes of nursing shortage the participants were able to elaborate at least 3 causes each. Mostly participants talked amongst themselves how the nursing shortage affects their work and quality of nursing care. Therefore, results shows adequate participants' general knowledge on nursing shortage, however there was need to update themselves on the standard nurse patient ratio $\mathrm{s}$ for different departments.

Without a sufficient number of nurses, patient care and safety may become compromised, while nurses themselves may be overwhelmed, distressed, and dissatisfied. High nurse-patient ratios has shown to that nurses are frustrated and experience job burnout, which is linked to higher turnover.

\section{Knowledge of participants towards nursing shortage}

Specific objectives on participants' nursing shortage knowledge level were: finding out whether the nursing levels were adequate, what effects nursing shortage has on the patient as well as the nurse. General knowledge on the nurse/patient ratio, causes of nursing shortage and what would be proper recommendations to the hospital administrator.

The findings indicated that most participants had adequate knowledge on all the aspects of the research objectives. Figure 3 illustrates the major effects of the shortage of nurses according to the respondents.

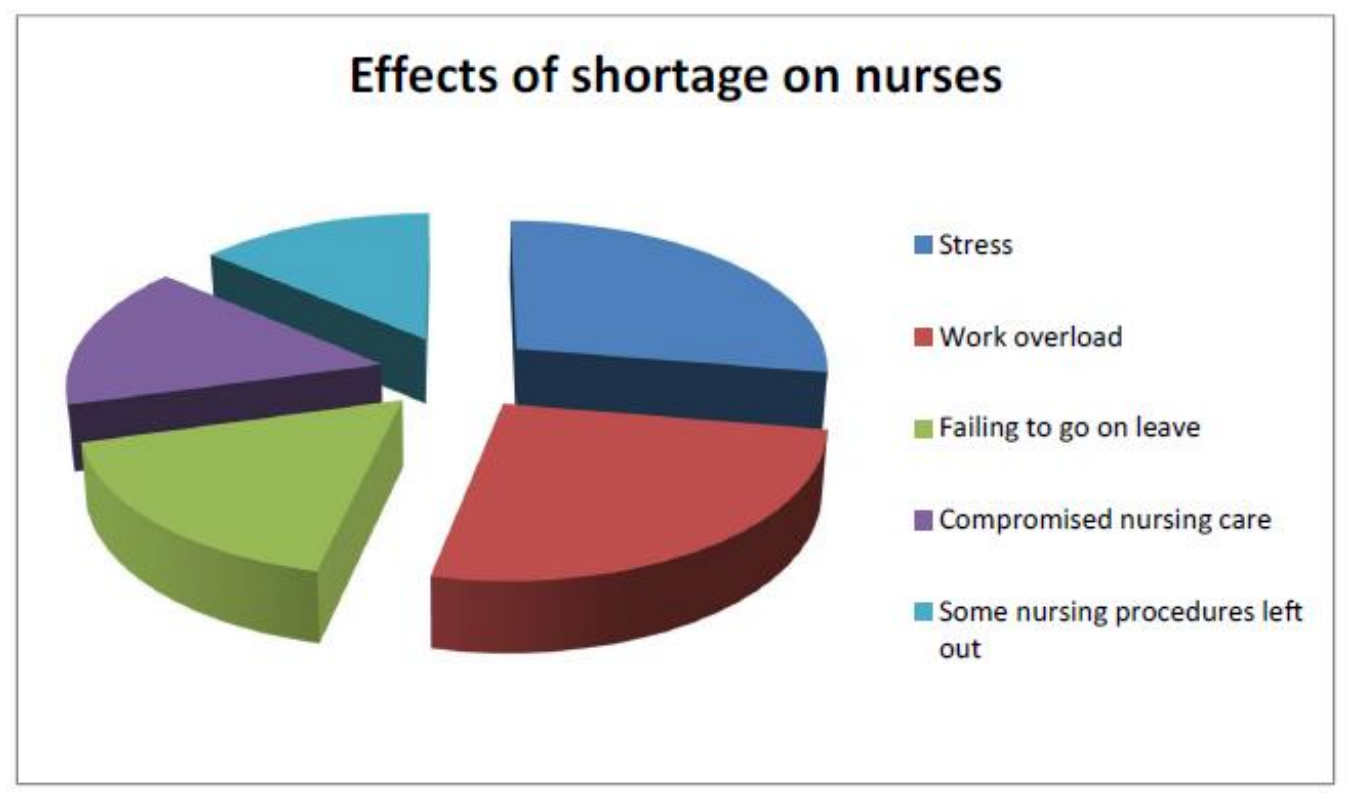

Figure 2. Major effects of shortage of nurses 


\section{Conceptual framework and variables}

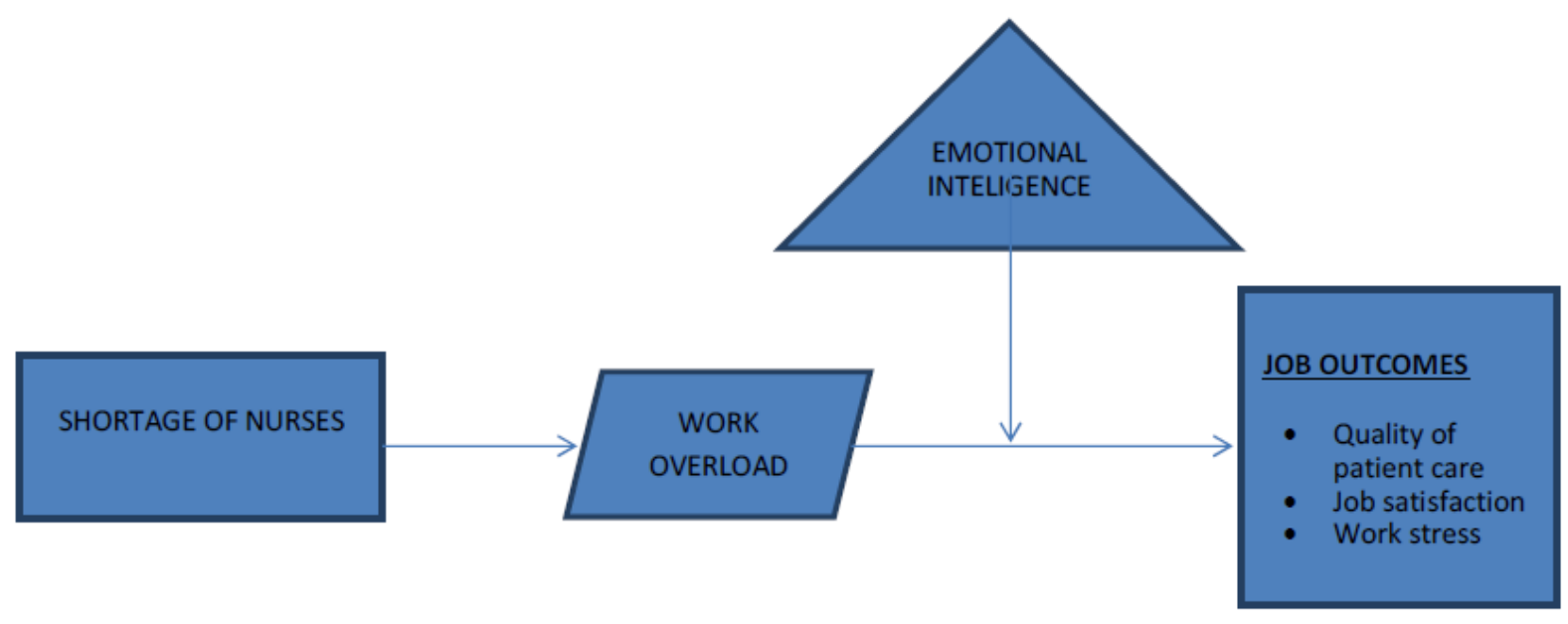

Figure 2.1. Conceptual framework

The following conceptual framework was developed to identify the relationships, if any, and the Impact among the related variables of the research. The following operational definitions of the study variables were developed and used in this study.

Table 2.2. Operational definitions of the variables

\begin{tabular}{|l|l|}
\hline Variable & Definition \\
\hline Nurses' Shortage & $\begin{array}{l}\text { The number of nurses is not enough to provide high quality of care as } \\
\text { compared to the professional standard }\end{array}$ \\
\hline $\begin{array}{l}\text { Quality of Patient } \\
\text { Care }\end{array}$ & $\begin{array}{l}\text { Delivering healthcare that fulfills the expressed or implied } \\
\text { requirements of a patient }\end{array}$ \\
\hline Job Satisfaction & $\begin{array}{l}\text { The degree to which individual feel positive or negative about their } \\
\text { jobs }\end{array}$ \\
\hline Work Stress & $\begin{array}{l}\text { The response people may experience when presented with work } \\
\text { demands and pressures that are not matched to their knowledge and } \\
\text { abilities and which challenge their ability to cope }\end{array}$ \\
\hline $\begin{array}{l}\text { Emotional } \\
\text { Intelligence }\end{array}$ & $\begin{array}{l}\text { The ability or skill of an individual to understand and influence the } \\
\text { emotions within themselves and those around them. }\end{array}$ \\
\hline
\end{tabular}

Source: Researchers based on literature survey.

Based on the above conceptual framework, the following hypotheses were developed.

- There is a positive relationship between shortage of nurses and workload.

- There is a negative relationship between workload and quality of patient care.

- There is a negative relationship between workload and nurses' job satisfaction.

- There is a positive relationship between workload and work stress. 
DOI: $10.21522 / \mathrm{TIJNR} .2015 .03 .02 . A r t 010$

ISSN: $2520-3126$

Table 2.3. Self developed scales to measure the variables of the study

\begin{tabular}{|l|l|}
\hline VARIABLE & INDICATORS \\
\hline Workload & $\begin{array}{l}\text { Shift Duration } \\
\text { Overtime (Mandatory and Voluntary) } \\
\text { Busyness of the Ward } \\
\text { Floating to Nursing Units }\end{array}$ \\
\hline $\begin{array}{l}\text { Quality of Patient } \\
\text { Care }\end{array}$ & $\begin{array}{l}\text { Communicating with Nurse } \\
\text { Respect for patient values } \\
\text { Showing attention to the patient } \\
\text { Nurses' Competence }\end{array}$ \\
\hline Job Satisfaction & $\begin{array}{l}\text { Nature of the work } \\
\text { Work environment } \\
\text { Interpersonal relations } \\
\text { Career advancement }\end{array}$ \\
\hline Work Stress & $\begin{array}{l}\text { Nature of the work } \\
\text { Dealing with the staff } \\
\text { Work environment } \\
\text { Required knowledge and skills }\end{array}$ \\
\hline $\begin{array}{l}\text { Emotional } \\
\text { Intelligence }\end{array}$ & $\begin{array}{l}\text { Ability to work under pressure } \\
\text { Ability to manage stress } \\
\text { Ability to Control Own Impulses } \\
\text { Adaptation to Environment } \\
\text { Problem Solving Skills }\end{array}$ \\
\hline
\end{tabular}

\section{Workload}

Nursing workload is mainly influenced by the shortage of nurses and the number of patients staying in the ward. In Zambian healthcare setting, a nursing ward is where a large number of patients requiring care and lack of resources to provide care with inadequate number of nurses.

Nurses are midst of the system that requires them to work hard. Normally, hospital wards are overcrowded with large number of patients, bystanders and healthcare staff. It looks very busy, a chaotic and demanding environment for nurses to work in. Comparing large patient numbers do not increase the number of nurses and the roster remains the same. Therefore, the study results showed that the considerable number of nurses continued their duty to next shift. Some nurses indicated that their duty shift was often extended within the last month. This situation led nurses to do more overtime to make up minimum nurse workforce numbers. Considering the overtime done by nurses, they have done more voluntary overtime hours compared to the mandatory overtime. The increased workload of nurses leads to high possibility in nursing errors and delays. It was evident in this study that, increased workload has influenced both tasks delayed and tasks not completed. The working situation in the ward at St. Dominic's Mission Hospital highlighted that the nurses have limited time to interact with their patients. Because of the routine nursing tasks like medication, injections, referrals, blood transfusion that nurses have to undertake, they have not enough time to talk with patients. The significant number of nurses reported that they have less time available to deliver care, because they have to complete non-patient activities such as maintaining ward statistics, dietary, nursing administration, and housekeeping during the shift.

The study reveals that the several wards and units at the hospital have a steady increase in workload. 


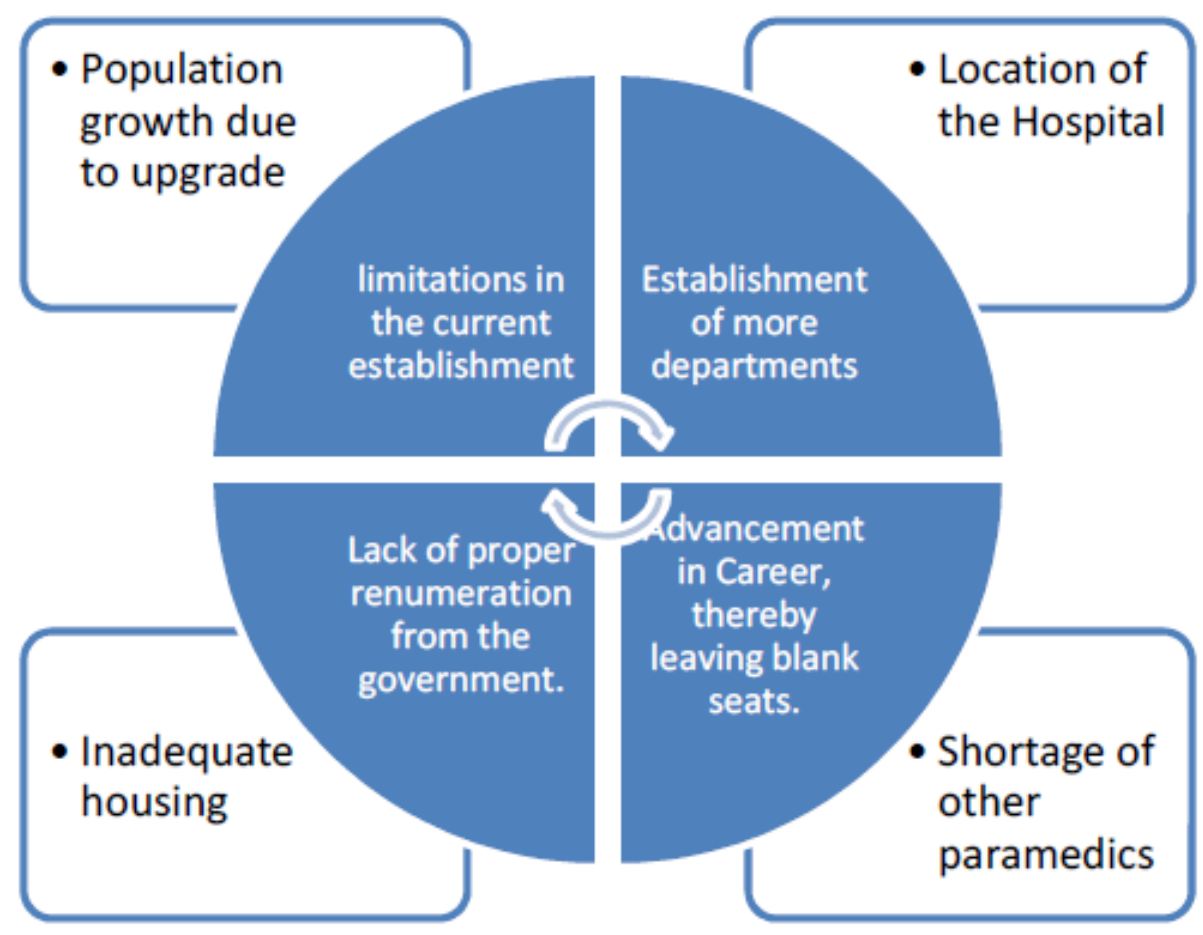

Figure 3. Causes of the shortage of nurses at st. dominic's mission hospital

The figure above illustrates the causes of the shortage of nurses at St. Dominic's Mission Hospital according to the staff who participated in the research via a questionnaire. The responses were varied but similar. The mast recurring cause was the shortage of adequate staff in other departments thereby forcing nurses to work in other fields other than what they were trained in. For example, some nurses work in the Pharmacy, focusing all their attention there due to lack of man power. The Hospital was recently upgraded to its current status as it used to be a health center; this has attracted more people and increased the population. Figure 3.1 illustrates the change in the workload of nurses now with the Hospital status as compared to when it used to be a health center. Due to lack of proper remuneration from the government, some nurses are changing careers thereby leaving a gap. The hospital is $25 \mathrm{~km}$ away from Ndola town center, this could be another reason why nurses are not motivated enough to transfer there. 
DOI: 10.21522 /TIJNR.2015.03.02.Art010

ISSN: $2520-3126$

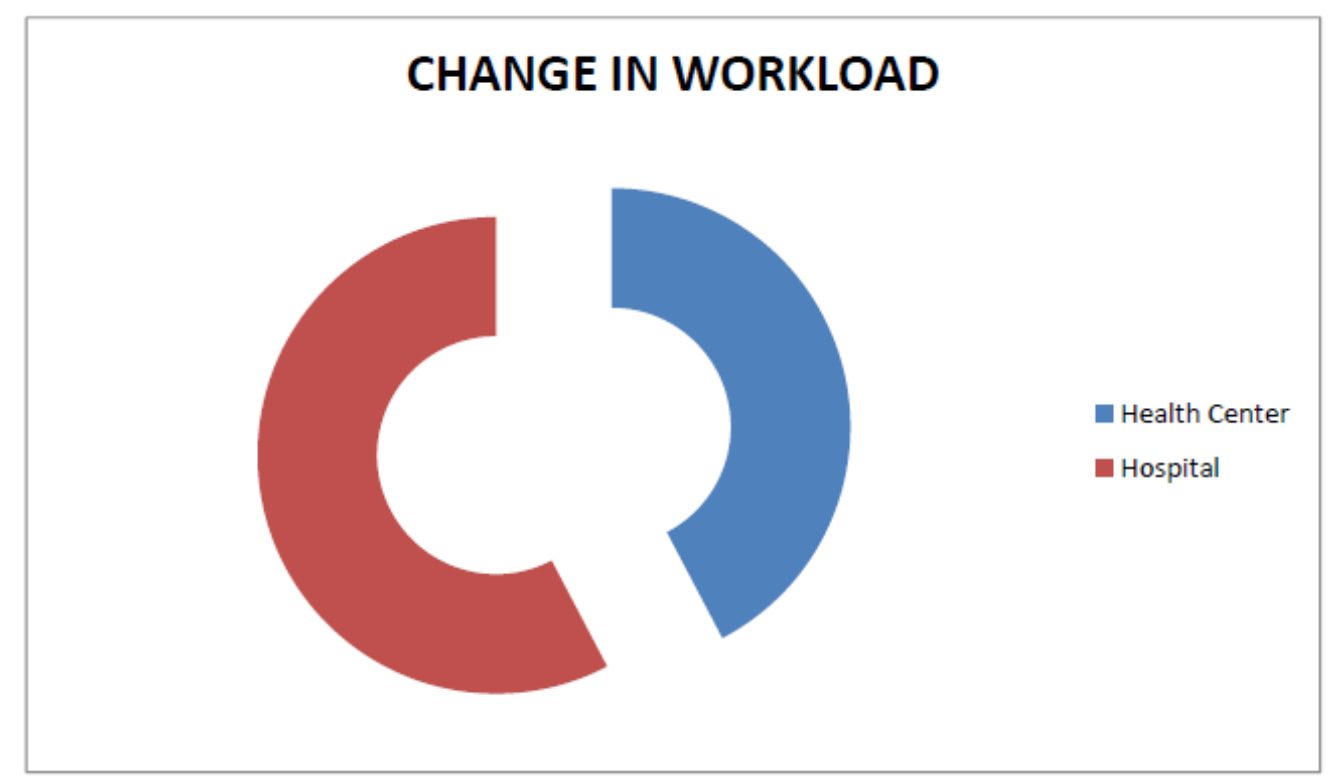

Figure 3.1. Change from health center to hospital effect on nurses's workload.

\section{Strategies for addressing the nursing shortage}

\section{There should be congruence between the different strategies}

Of course there will be various assertions and different estimations around nursing shortages and the extent of that shortage. But in evaluation of the policy initiatives in place to address the identified shortages, one does not expect there to be large discrepancies.

\section{Recruiting the future workforce}

Many experts recognize the need to increase funding for nursing education, directed toward nursing faculty as well as students. Subsidized training is seen as one way to increase the number of nurses. In addition, experts point to a need for changes in nursing training to better prepare the existing workforce to respond to changes in health care delivery. As options to strengthen nursing care, experts suggest training in gerontology, technology and information systems, clinical management, and variations in care delivery, as well as opportunities for further training for nurses at all stages in their careers.

Another way to address the nursing shortage would be to devote resources toward increasing Nurses' wages. This approach could affect recruitment as well as retention of nurses already in the workforce. Experts also suggest a need to improve the image of nursing. Strategies range from encouraging nurses to communicate more frequently about positive aspects of nursing to launching professional advertising campaigns promoting the profession.

\section{Retaining nurses in the workforce}

Strategies to improve nurses' retention are needed. Policies that improve the hospital's work environment are one set of important considerations. Another aspect of improving the work environment involves reorganizing nursing care to reduce paperwork and alter the types of work performed by nurses in order to increase the proportion of nursing time spent on patient care.

Redesigning the workplace in accord with ergonomic standards may become increasingly important to prevent injuries as the average age of the nurses' workforce increases.

Involving nurses in designing staffing and overtime policies also may result in higher satisfaction among nurses and better patient care. Unions representing nurses promote policies that reduce nurse workloads by increasing staffing to legislatively mandated nurse-to-patient ratios. Not all nurses or health 
professionals agree that mandated ratios are the most effective approach. Some suggest that nurse staffper-patient levels are best determined collaboratively with RNs at the hospital level.

It is also highly recommended that the Ministry of health assign more paramedics such as Pharmacy technicians to the hospital so that nurses are not forced to focus in other departments and there is equality in terms of man power.

The research findings reveal that nurses are consistently working long over stretched shifts due to staff shortage. This study reveals the nurse's workload directly influences to the quality of patient care. However, it does not influence significantly to the level of satisfaction and level of stress. The administration needs to customize their strategies for the recruitment and retention of nurses. The strategies should take into consideration the specific work settings that are experiencing negative nursing outcomes (poor patient care). The strategies should also aim to train that help nurses better manage their emotions.

A hospital is a group of healthcare professionals (primary care physicians, specialists and nurses) that work together as a team to coordinate care for patients. Nurses are mainly responsible for managing patients' health and providing care. They are set to play integral roles that include acting as care coordinators, communicators and quality improvement while providing care for patients. As a solution for nursing shortage prevailing in the country, health organizations can be reassigned the roles played by nurses only for patient-centered care. Nurses deployed for other services than direct patient care such as receptions and health education can be replaced with some other qualified personals. Many nurses are concerned that these substitutions could improve the quality of patient care. It is recommended that stress management training should be provided especially for nursing staff. The staff in management positions should emphasize the importance of interactions among nursing staff and between nurses and patients. The performance of emotional work was associated with fewer negative effects and with more positive psychological and social wellbeing for hospital nurses. Therefore the performance of emotional work should be considered to be a valuable coping strategy to be encouraged by hospital management.

\section{Conclusion}

Even absent nurse shortages, it would be costly for hospitals and long-term care providers to

Increase nurse staffing. Yet, recent evidence suggests that more nurses lead to better patient outcomes. Projected long-term shortages will create still greater cost and quality challenges. Without increased payments from public or private purchasers, health care institutions will most likely have to make tradeoffs between investing in staffing and pursuing other quality-improvement efforts. Little information is available to inform such decisions, which are likely to become more pressing in future years.

\section{References}

[1]. Bleich, M. R. (2011). IOM report, the future of nursing: Leading change, advancing health: Milestones and challenges in expanding nursing science. Research in Nursing \& Health.

[2]. Buerhaus, P. (1997). What is the harm in imposing mandatory hospital nurse staffing regulations? Nursing Economics.

[3]. Carayon, P., \& Gurses, A. (2005). Nursing workload and patient safety in intensive care units: a human factors engineering evaluation of the literature. Intensive critical Care Nursing.

[4]. Duffield, C., O’Braien, L., Diers, D., Aisbett, C., Aisbett, \& Homer, C. K. (2009). Nursing Workload and Staffing: Impact on Patients and Staff. University of Technology Sidney.

[5]. Greenglass, E. R., Burke, R. J., \& Moore, K. A. (2003). Reactions to increased workload: effects on professional efficacy of nurses. Apply Psycholog y: An International Review.

[6]. Kimball, B., \& O’Neil, E. (2002). Healthcare's Human Crisis.

[7]. Oulton, J. A. (2006). The Global Nursing Shortage: An Overview of Issues and Actions Policy Politics Nursing Practice. 
DOI: $10.21522 /$ TIJNR.2015.03.02.Art010

ISSN: $2520-3126$

[8]. The Global Shortage of Registered Nurses: An Overview of Issues and Actions. (2013). Retrieved June 2, 2014, from http://www.icn.ch/publications/the-global-shortage-ofregistered-nurses-an-overview-of-issues-andactions/.

[9]. Toh, S. G., Ang, E., \& Devi, M. K. (2012). Systematic review on the relationship between the nursing shortage and job satisfaction, stress and burnout levels among nurses in oncology/hematology settings. International Journal of Evidence-Based Healthcare.

[10]. Weydt, A. P. (2009). Defining, analyzing, and quantifying work complexity. Creative Nursing. 


\title{
Consequences of Teenage Pregnancy
}

\author{
Article by Catherine Malethola Lebina \\ MSN, Texila American University, Lesotho \\ E-mail: catherine.lebina@gmail.com
}

\begin{abstract}
Teenage pregnancy remains a challenge requiring urgent resolution the world over (United Nations Population Fund, 2013). In 2014 the World Health Organization reported that 11\% of all births were due to women aged 15- 19 years (World Health Organization, 2014). Approximately 95\% of teenage pregnancies occur in developing countries with 36.4 million women becoming mothers before age 18 (United Nations Population Fund, 2013) (Mkwananzi and Odimegwu).

All teen pregnancies are dangerous because every teen lacks the skills that are needs to handle oodles of stress that pregnancy brings along. All teen pregnancies are dangerous because every teen lacks the skills that are needs to handle oodles of stress that pregnancy brings along(Social Dynamics of Adolescent Fertility in Sub-Saharan Africa).

Main objective: The key objective of this formative research study was to compare the response got from the target audience (youth aged 15-19 years) at St Charles catchment area and St Peter H/C catchment area on the challenges they are facing with after conceiving at an early stage of life. The study also seek to find out number of teenagers delivered at the facility with or without complications.

Method: The study was quantitative descriptive cross sectional where the emphasis is on comparing groups. The study aimed to identify the relation of responses from the respondents. Data on teenage pregnancy were compiled for 2 facilities namely; St Charles Hospital and St Peter Health Centre

Results: A sample of 35 questionnaires distributed at St Charles Hospital, returned 33. St. Peter H/C (25) questionnaires were distributed to the youth who came for health services. 24 were returned of which all of them were returned. For St Charles hospital, 13.64\% were those 15 and 19 years, $22.73 \%$ were between 16-17 years, 27\% were 18 years at the time of delivery of first kids. At St Peter $\mathrm{H} / \mathrm{C}$, $23.81 \%$ were 15 years, $14.29 \%$ were at 16 and 17 years, $19 \%$ were $18 y e a r s$, and $28.57 \%$ were 19 years old when they gave birth to their first kids.

Conclusion: The results clearly indicate that teenage pregnancy occurs equally to married and unmarried females. The difference is one to make both parameters equal. $27 \%$ of the respondents gave birth at the age of 18 years. At the remote areas, teenage pregnancy is more prominent as the study shows that $23.81 \%$ had their first kids at the age of 15 from the catchment area of St Peter Health Centre.

Teenage or adolescent pregnancy is noted as a major public health and demographic problem with medical, psychological, social and demographic implications. (Shaw and McKay; 1942).
\end{abstract}

Keywords: Teenager, Pregnancy, challenges, unplanned marriage.

\section{Background}

St Charles Hospital known is a Catholic Mission situated in the North Eastern Country side of BothaBothe district in Lesotho $27 \mathrm{~km}$ away from the town. It is at the foothill of the mountain. It serves the population of approximately 14,200 residents in 30 villages. It serves 4 outreaches on monthly basis and supervises 5 health centers. The study focuses on the past year 2016.

\section{Introduction}

Teenage pregnancy remains a challenge requiring urgent resolution the world over (United Nations Population Fund, 2013). In 2014 the World Health Organization reported that $11 \%$ of all births were due to women aged 15- 19 years (World Health Organization, 2014). Sub-Saharan Africa had the highest prevalence of teenage pregnancy in the world in 2013 (United Nations Population Fund, 2013). 
The majority of countries with teenage pregnancy levels above $30 \%$ occur in sub-Saharan Africa (Loaiza \& Liang, 2013).Despite huge investments and refinement of these policies: Teenage pregnancy continues to reach crisis proportions in most African countries (UNFPA, 2010).

In Lesotho, $19 \%$ of women age 15-19 have begun childbearing: $15 \%$ have given birth, and an additional $4 \%$ are pregnant with their first child. Trends shows that teenage childbearing has held steady over the last decade. The proportion of teenagers who have a child or who are pregnant was $20 \%$ in 2004 and 2009 compared with 19\% in 2014("Lesotho 2014 Demographic and Health Survey BOPHELO MINISTRY OF HEALTH")

In addition, teenage pregnancy has huge global policy inferences. Much has been written about sexual education. Little if any research has been conducted on learner pregnancy as a hurdle toward the achievement of MDGs and EFA goals(Ramulumo and Pitsoe).

\section{Statement of the problem}

Despite scaling up of school health services, there are still teenage pregnancy occurring at schools leading to drop out of school. This gives an impression that health education provided is not approached in a manner that behavioural is observed to the scholars.

\section{Justification of the study}

The study aims at helping Ministry of Health to be aware of the consequences of teenage pregnancy which bring complications to the growing teenager. Dropping out of school and raining the child also have a negative impact on the welfare of the teenager.

\section{Aim of the study}

To identify the major consequences of teenage pregnancy.

\section{Literature review}

The 2014 World Health Statistics indicate that the average global birth rate among 15 to 19 year olds is 49 per 1000 girls. Country rates range from 1 to 299 births per 1000 girls, with the highest rates in sub-Saharan Africa. Adolescent pregnancy remains a major contributor to maternal and child mortality, and to the cycle of ill-health and poverty.("WHO | Adolescent Pregnancy").

In Lesotho, 19\% of women age 15-19 have begun childbearing: $15 \%$ have given birth, and an additional $4 \%$ are pregnant with their first child Teenagers in rural areas are more likely to begin childbearing than their urban peers: $23 \%$ of rural teenagers have had a live birth or are pregnant, compared with $12 \%$ of urban teenagers("Lesotho 2014 Demographic and Health Survey BOPHELO MINISTRY OF HEALTH").

Because of the time and energy that raising children require, which interferes with the time and energy required to study and attend classes, women who bear a child during the school years often leave before they can complete their schooling(Childbearing, Hofferth, and Hayes).

Teen mothers are more likely to experience posttraumatic stress disorder (PTSD) than other teenage women, as well("Effects of Teenage Pregnancy: Mental Health").

Similarly, teenagers from the poorest households are more likely to have begun childbearing (26 percent) than teenagers from the wealthiest households (10 percent). The proportion of teenagers who have begun childbearing has not changed since the 2008-09 KDHS("Kenya 2014 Demographic and Health Survey").

According to a latest report released on December 30, 2015, some 18 African countries appear on a United Nations (UN) list of 20 countries with the highest teenage pregnancies in the world("Africa: Teen Pregnancies Haunt Africa - allAfrica.com").

Among the 21 countries with complete statistics, the pregnancy rate among 15- to 19-year olds was the highest in the United States (57 pregnancies per 1,000 females) and the lowest rate was in Switzerland (8)(Sedgh et al.).

There may be a feeling of bitterness or sadness when pregnant teens watch their peers engage in normal teenage activities which they are unable to participate in the responsibility of assuming the role of a parent at such a young age may take a toll on the emotional health of many teen mothers("Consequences of Teenage Pregnancy - Teenage Pregnancy Center"). 
Teenage pregnancy is one of modern society's evils and is a rather alarming situation. Most countries, developed, and underdeveloped, consider teenage pregnancy a social stigma. And, it can have devastating effects on the teen's social life. The negativity, the social alienation, and the financial distress can wreak havoc in anyone's life, let alone that of a teen, who isn't yet mature or strong enough to face the world.("11 Negative Side Effects Of Teenage Pregnancy On Society").

As Gustafsson and Worku (2007:2) observe, there is a high rate of teenage childbearing in South Africa. The United States, Turkey and Brazil have similar levels of around thousands of women giving birth during their teenage years. This suggests that teenage pregnancy is a global social problem which affects both developing and developed countries(Ramulumo and Pitsoe).

\section{Methodology}

\section{Study design}

The study was quantitative descriptive cross sectional where the emphasis was on comparing groups. The study aimed to identify the relationship of responses from the respondents. Data on teenage pregnancy were compiled from 2 facilities namely; St Charles Hospital and St Peter Health Centre. The sample was drawn from a defined population from the delivery records for the past year 2016, $1^{\text {st }}$ January to $31^{\text {st }}$ December. Odds ratios were used to evaluate the age and parity. 26 records St Charles hospital retrieved and used, 28 records from St Peter's Health centre.

The questionnaire was also developed and administered to individuals who were considered to have had teenage pregnancy at their first pregnancy. The questionnaire was distributed evenly to the health center. There were 65 questionnaires distributed. St Charles Hospital area (40) and returned 31(77.5\% and 2 spoiled. The St. Peters health center they were 25 and returned 25(100\%) and 3 considered spoiled.

\section{Study site}

The study was conducted at St Charles Hospital situated at Botha-Bothe district within Likila Community Council, $27 \mathrm{~km}$ away from town, with the prevalence rate of $18.6 \%$ of teenage pregnancy as per 2015 mini study conducted. St Peter H/C, situated at Nqoe Community Council, still in BothaBothe district, $30 \mathrm{~km}$ away from town with prevalence rate of $20.2 \%$. The two places were accessible to the researcher. For both facilities, delivery records and questionnaires were distributed to the participants.

\section{Target population}

Teenagers from 15-19 years of age who access services at St Charles Hospital and St Peter H/C who got pregnant either for the first time or many a time participated in a study.

\section{Sample size}

A quantitative method used as a data analysis where odds ratios was a preferred method of choice. 54 charts/ records from both facilities and 58 questionnaires were used.

\section{Data analysis}

The records were retrieved in the hospital and sister health center (clinic) for the year 2016, therefore the table below presents findings within the hospital records vs Health centre results. At the age 16 only $10.7 \%$ delivered their first babies during the period under reviewed, none from the hospital. In both facilities at the age of 17 greater number of teens delivered $30.76 \%$ from the hospital and $32.14 \%$ at the $\mathrm{H} / \mathrm{C}$. Between the age of $18-1925 \%$ of them delivered at the $\mathrm{H} / \mathrm{C}$ and $30.76 \%$ at the hospital.

\section{6 hospital records}

Table 1. 2016 St. Peters health center (clinic)

\begin{tabular}{|l|l|l|}
\hline Ages & Normal vertex delivery & Caesarean section \\
\hline 15 & 0 & 0 \\
\hline 16 & 0 & 0 \\
\hline 17 & $8(30.76 \%)$ & 0 \\
\hline
\end{tabular}


DOI: $10.21522 /$ TIJNR.2015.03.02.Art011

ISSN: $2520-3126$

\begin{tabular}{|l|l|l|}
\hline 18 & $7(26.92 \%)$ & $3(11.53 \%)$ \\
\hline 19 & $8(30.76 \%)$ & 0 \\
\hline TOTALS & $\mathbf{2 3}$ & $\mathbf{3}$ \\
\hline GRAND TOTAL 26 &
\end{tabular}

Table 2.

\begin{tabular}{|l|l|l|}
\hline Ages & Normal vertex delivery & Caesarean section \\
\hline 16 & $3(10.7 \%)$ & $1(3.56 \%)$ \\
\hline 17 & $9(32.14 \%)$ & 0 \\
\hline 18 & $7(25 \%)$ & 0 \\
\hline 19 & $7(25 \%)$ & $1(3.56 \%)$ \\
\hline TOTALS & $\mathbf{2 6}$ & $\mathbf{2}$ \\
\hline GRAND TOTAL 28 & \\
\hline
\end{tabular}

Apart from the hospital and $\mathrm{H} / \mathrm{C}$ records illustrated above, the questionnaire was developed and administered to individuals who were considered to have had teenage pregnancy at their first pregnancy. The questionnaire was distributed evenly to the health center. 35 were distributed at St Charles Hospital and 33 were returned. 25 were distributed to St. Peters health center and all returned.

Table 3 below shows the comparison of findings on marital status of each respondent during the time of giving birth.

Table 3. Marital status

\begin{tabular}{|l|l|l|}
\hline Status & St Charles Hospital & St Peter H/C \\
\hline Married & 17 & 20 \\
\hline Single & 16 & 5 \\
\hline
\end{tabular}

Table 3 clearly indicates that at St Charles Hospital teenage pregnancy occurs equally to married and unmarried females. The difference is one to make both parameters equal as compared to the health centre.

\section{Years of delivery}

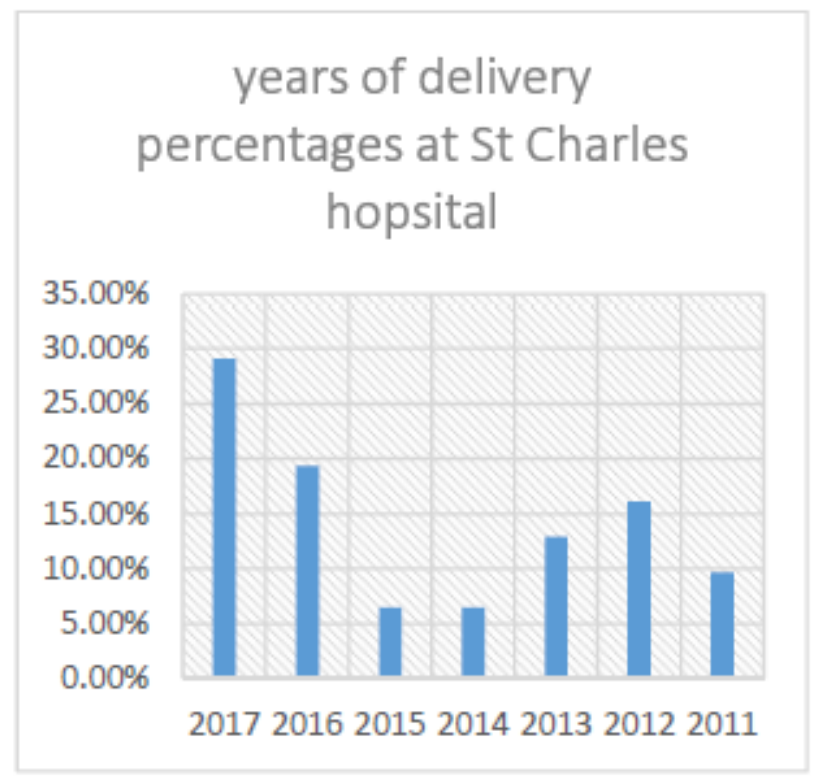

Figure 1.0 


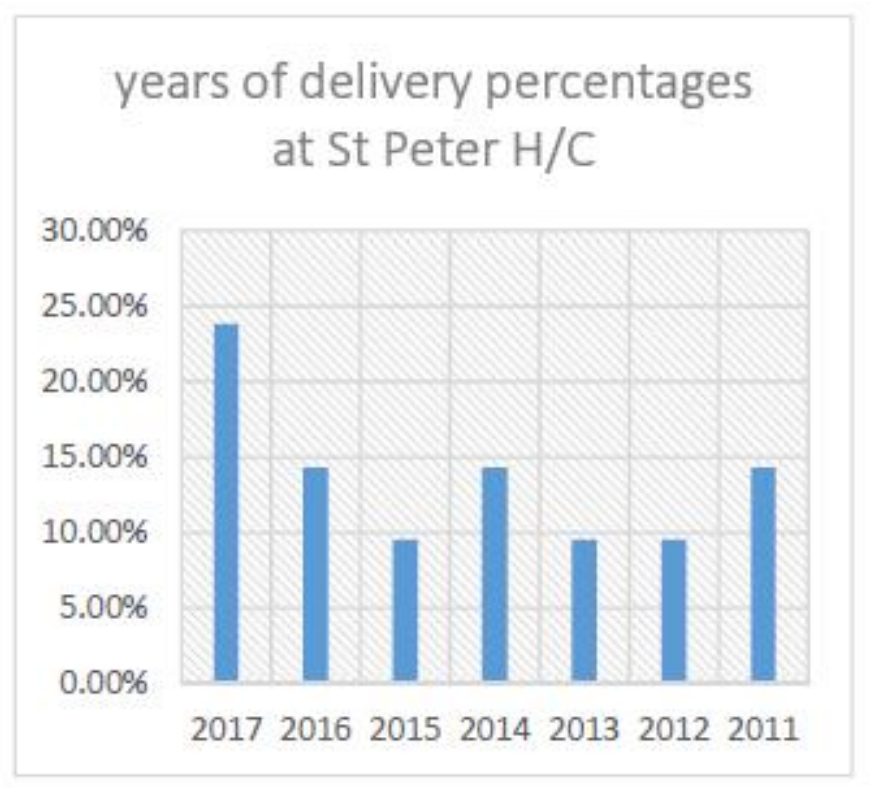

Figure 1.1

Figure 1.0 and 1.1 above display seven consecutive years in which study looked at in both health facilities as to see the trend of teenage pregnancy. This period was selected orderly without any absolute reason. However, though the study pays a focus on 2016, there is an alarming results of 2017 which seems to have increased in 6 months, indicating that by end of the year, drastic figures will be shown.

Figure 1.2 and 1.3 below show age trend at the time of delivery amongst teenage pregnancies. For St Charles hospital, $13.64 \%$ were those 15 and 19 years, $22.73 \%$ were between $16-17$ years, $27 \%$ were 18 years at the time of delivery of first kids. At St Peter H/C, 23.81\% were 15 years, $14.29 \%$ were at 16 and 17 years, $19 \%$ were 18 years, and $28.57 \%$ were 19 years old when they gave birth to their first kids.

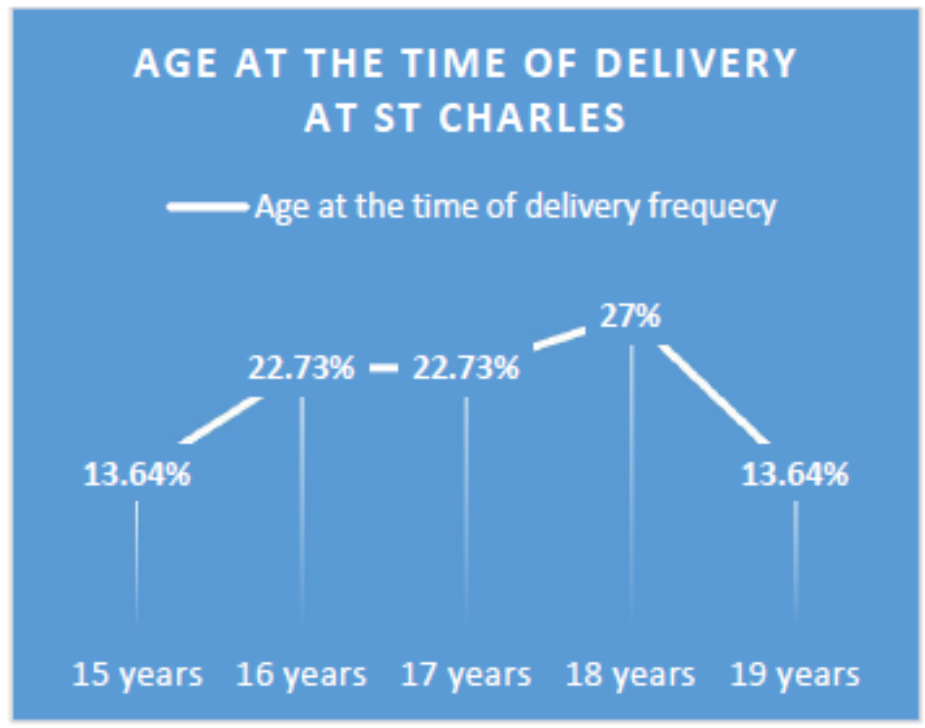

Figure 1.2 
DOI: $10.21522 /$ TIJNR.2015.03.02.Art011

ISSN: $2520-3126$

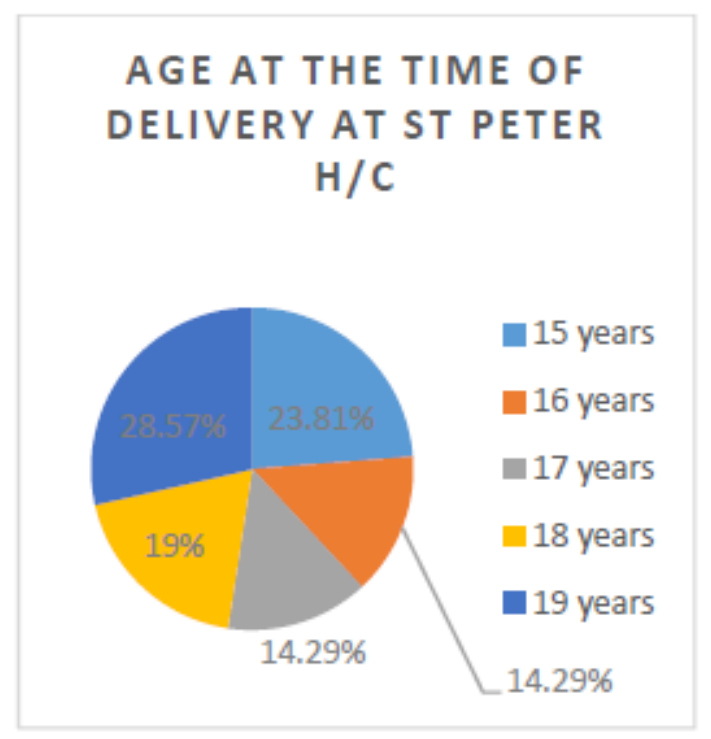

Figure 1.3

The questionnaire went on asking respondents on how many kids do they have at the moment. Table 4 below tabulates the findings and clearly indicates that $42.86 \%$ had babies for the first time at $\mathrm{St}$ Charles whereas, $48 \%$ were from St Peter H/C. Number of kids respondents have St Charles Hospital St Peter H/C.

Table 4. The place of delivery and a birth attendant were looked at by the study, therefore the findings were as follows

\begin{tabular}{|l|l|l|l|l|l|}
\hline $\begin{array}{l}\text { Respondents } \\
\text { category }\end{array}$ & $\begin{array}{l}\text { Number } \\
\text { of kids }\end{array}$ & Frequency & $\begin{array}{l}\text { Respondents } \\
\text { category }\end{array}$ & $\begin{array}{l}\text { Number of } \\
\text { kids }\end{array}$ & Frequency \\
\hline A & 1 & 15 & A & 1 & 12 \\
\hline B & 2 & 10 & B & 2 & 7 \\
\hline C & 3 & 6 & C & 3 & 5 \\
\hline D & 4 & 2 & D & 4 & 1 \\
\hline
\end{tabular}

Delivery place and birth attendants

\section{St charles hospital}

Table 5. $90.9 \%$ of the respondents indicated clearly that they delivered at the hospital though none delivered at the health centre vs $9.09 \%$ who conducted home delivery

\begin{tabular}{|l|l|l|l|l|}
\hline $\begin{array}{l}\text { Place of } \\
\text { birth }\end{array}$ & $\begin{array}{l}\text { Number of } \\
\text { women }\end{array}$ & Birth attendants \\
\hline & & Doctors & Nurses & TBA \\
\cline { 2 - 5 } Home & 3 & 0 & 0 & $\mathbf{3}$ \\
\hline Clinic & 0 & 0 & 0 & 0 \\
\hline Hospital & 30 & $\mathbf{3}$ & $\mathbf{3 0}$ & $\mathbf{0}$ \\
\hline
\end{tabular}

\section{St peter $\mathbf{H} / \mathbf{C}$}

Table 6.

\begin{tabular}{|l|l|l|l|l|}
\hline $\begin{array}{l}\text { Place of } \\
\text { birth }\end{array}$ & $\begin{array}{l}\text { Number of } \\
\text { women }\end{array}$ & Birth attendants \\
\hline \multirow{3}{*}{ Home } & 3 & Doctors & Nurses & TBA \\
\hline Clinic & 0 & 0 & 0 & 3 \\
\hline Hospital & 22 & 0 & 0 & 0 \\
\hline
\end{tabular}


The table above shows that none of them delivered at the health center. It further shows that $88 \%$ of the teenagers delivered at the facility and $12 \%$ delivered at home assisted by traditional birth attendants.

\section{Challenges during pregnancy}

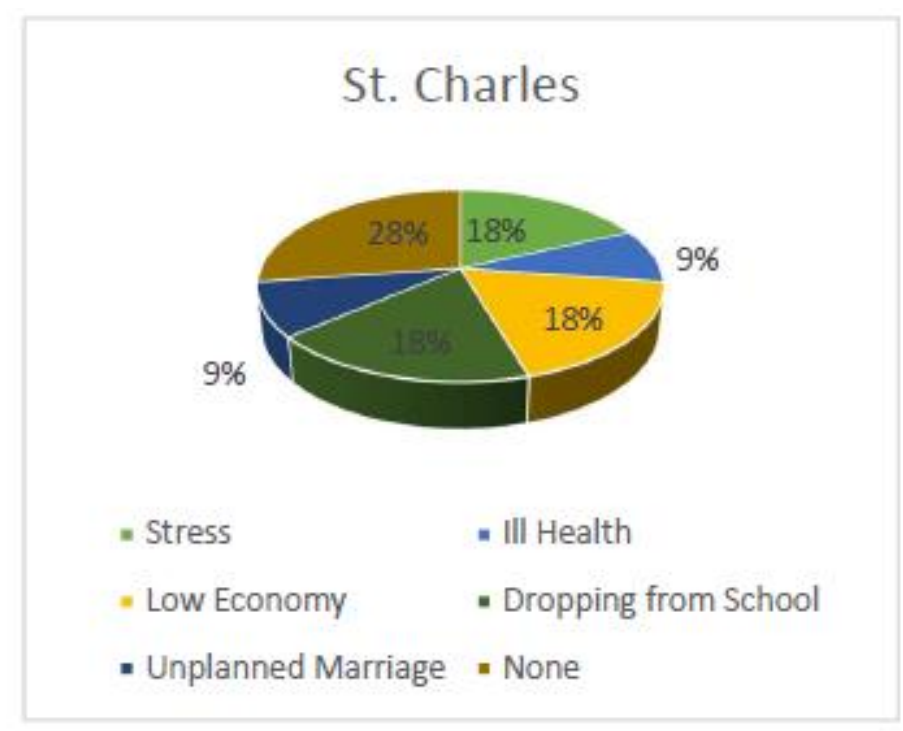

Figure 1.4

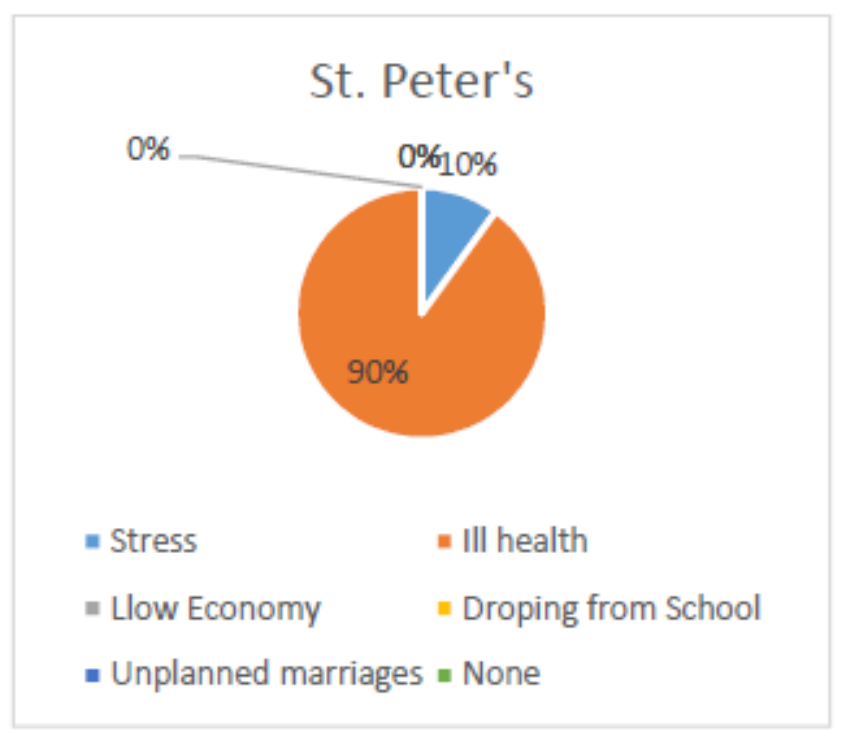

Figure 1.5

As shown in fig 1.4 and 1.5 challenges during pregnancy average of $41 \%$ did not encounter any problems during this time. However, However, St Charles Hospital shows that $18 \%$ dropped out of school, $11.43 \%$ suffered stress, $5.71 \%$ it was unplanned pregnancy. For St Peter's H/C, $90 \%$ became ill and $4.55 \%$ dropped out of school and $10 \%$ suffered stress. It is therefore, noted that dropping out of school is applicable to both areas which hampers with normal development of the teenager. 
DOI: $10.21522 / \mathrm{TIJNR} .2015 .03 .02 . A r t 011$

ISSN: $2520-3126$

Challenges to teenagers during labour and delivery

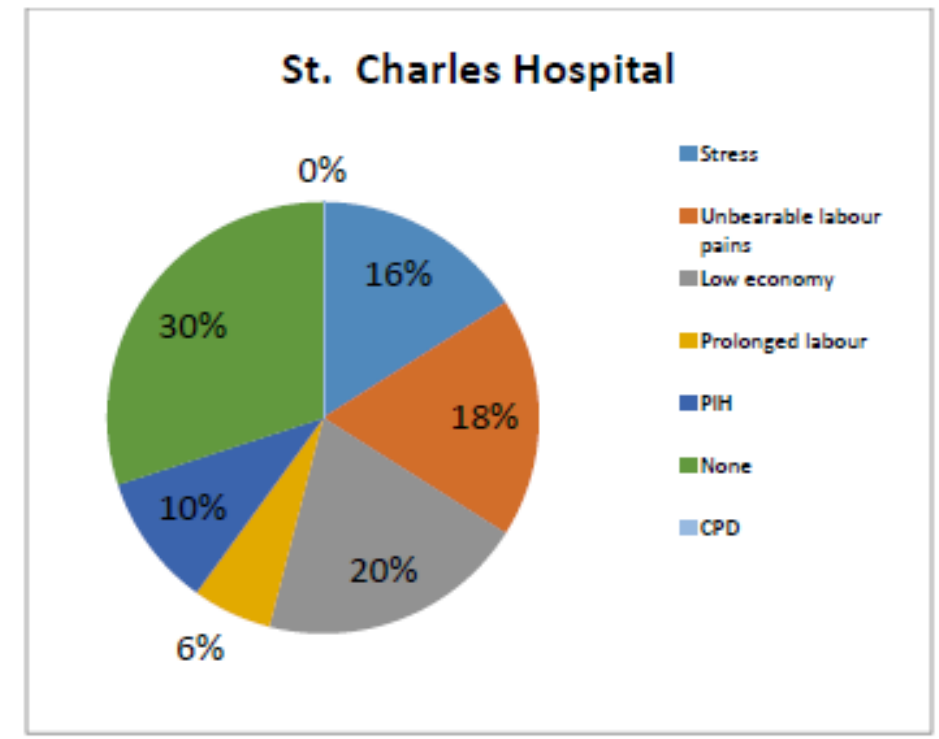

Figure 1.6

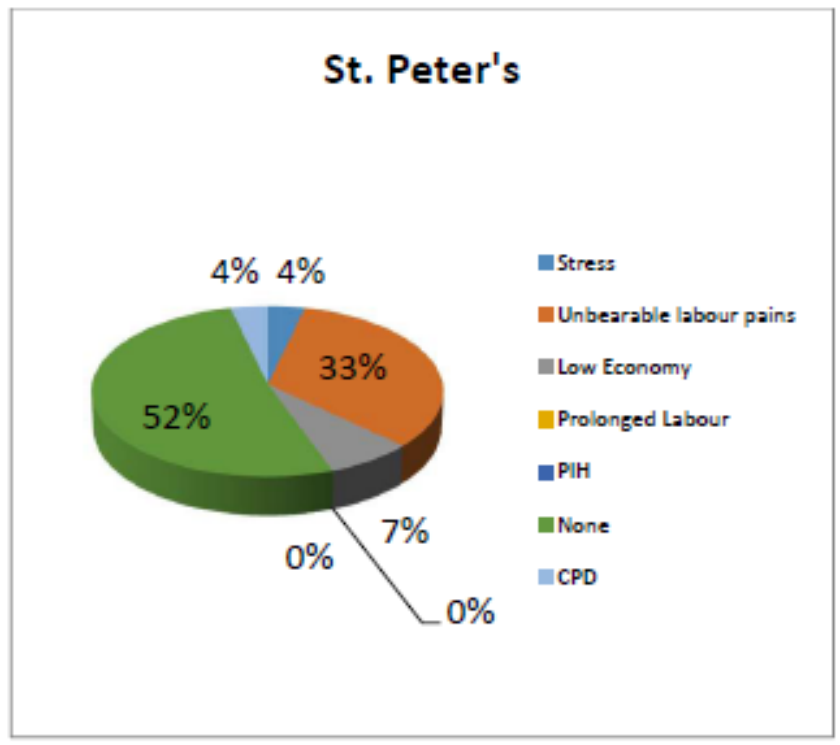

Figure 1.7

The pies above shows that an average of 30\% did not encounter any challenge during labour and delivery at St Charles and 52\% from St Peter H/C. However, some experienced unbearable labour pains at average of $25.5 \%$. Majority (16\%) of them at St Charles experienced stress and $10 \%$ suffered Pregnancy Induced Hypertension. Minority at St Peter had the above ill health. 


\section{Challenges at 6 weeks}
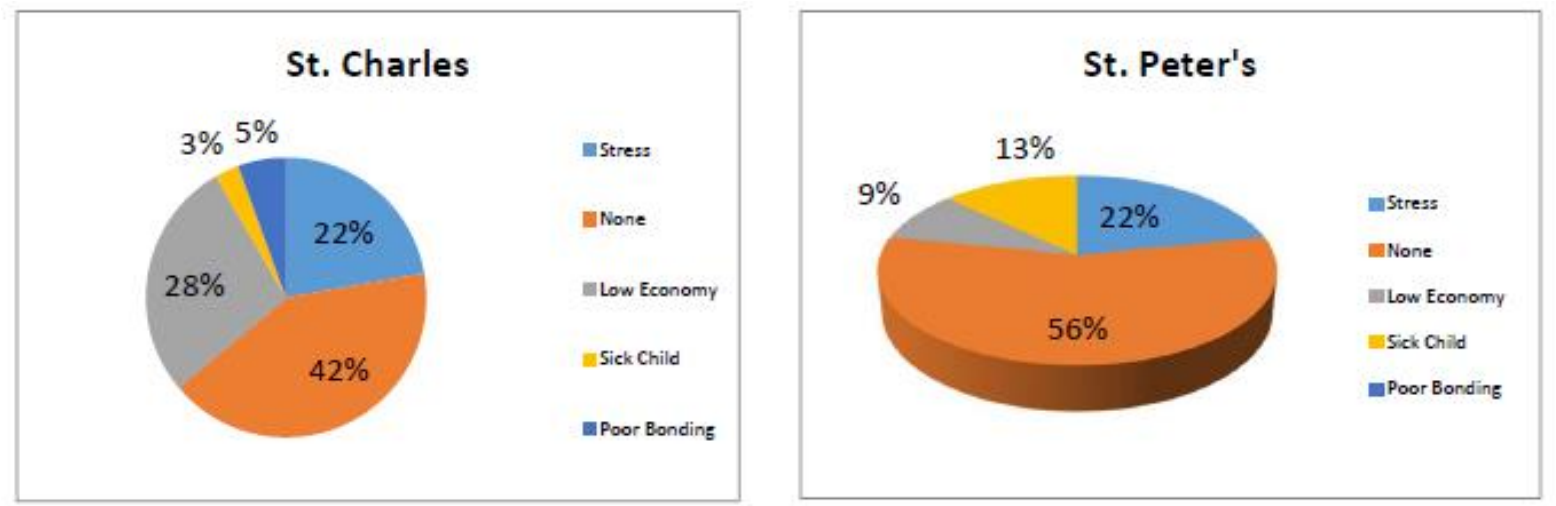

At 6 weeks, no much of the challenges were experienced. However, stress seems to be leading of $22 \%$ on both sites. Low economy also contributed at $28 \%$ from St Charles hospital and $9 \%$ at St Peter $\mathrm{H} / \mathrm{C}$.

\section{Challenges of raising the under 5 child}
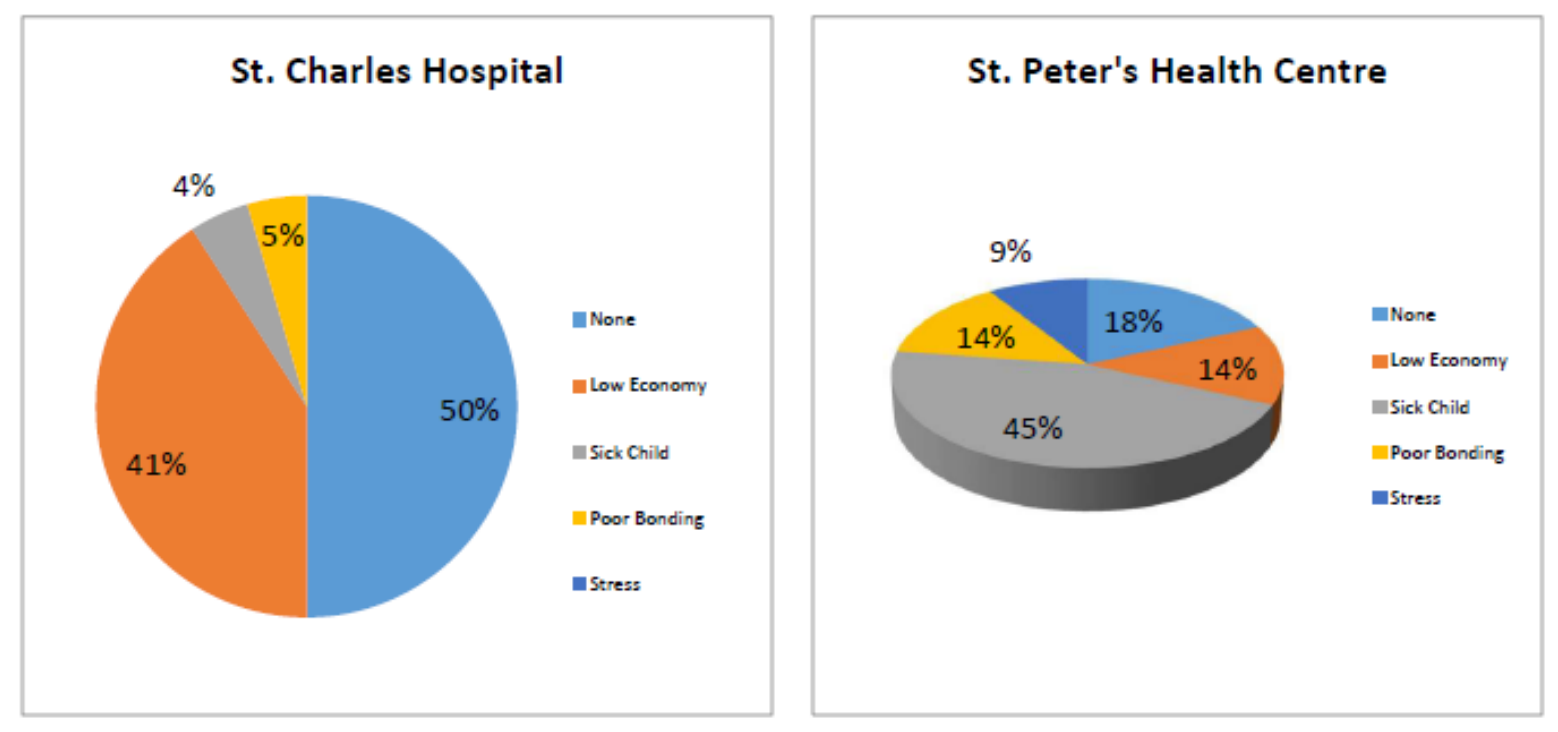

Respondents at St Peter H/C indicates that $45 \%$ of teenage mothers struggled with sick child. Poor bonding and low economy share the same results of 14\% and $41 \%$ from St Charles Hospital.

\section{Conclusion}

The results clearly indicate that teenage pregnancy occurs equally to married and unmarried females. The difference is one to make both parameters equal. $27 \%$ of the respondents gave birth at the age of 18 years. . At the remote areas, teenage pregnancy is more prominent as the study shows that $23.81 \%$ had their first kids at the age of 15 from the catchment area of St Peter Health Centre

Teenage or adolescent pregnancy is noted as a major public health and demographic problem with medical, psychological, social and demographic implications. While different theories have been tested in existing studies, the theory of social disorganisation has not been applied in investigating teenage pregnancy. The social disorganisation theory is an example of an ecological framework and posits that crime is not randomly distributed, but occurs more frequently in 'bad' neighbourhoods than in 'good' neighbourhoods (Shaw and McKay; 1942).

Many teenage mothers do not complete their high school education and this may affect their selfesteem. Due to the many concerns associated with teenage pregnancy, a large number of teens turn to alcohol and drugs. Some teen mothers may feel stigmatized by their families or ignored by their friends. There may be a feeling of bitterness or sadness when pregnant teens watch their peers engage in normal 
DOI: $10.21522 /$ TIJNR.2015.03.02.Art011

ISSN: $2520-3126$

teenage activities which they are unable to participate in("Consequences of Teenage Pregnancy Teenage Pregnancy Center").

\section{Limitations}

The study was conducted on two settings being records and use of questionnaire at the semi-rural area only. There is a need to revise the questionnaire and ensure that it is very simple and straight to the point.

\section{Recommendations}

- There is a need to conduct a study on a larger scale including both rural and urban people for proper comparisons.

- Engagement of all stakeholders to handle this global issue

- Revival of Adolescent health corners is crucial

\section{References}

[1]. "11 Negative Side Effects of Teenage Pregnancy on Society." N.p., n.d. Web. 26 Aug. 2017.

[2]. “Africa: Teen Pregnancies Haunt Africa - allAfrica.com.” N.p., n.d. Web. 1 June 2017.

[3]. Childbearing, National Research Council (US) Panel on Adolescent Pregnancy and, Sandra L. Hofferth, and Cheryl D. Hayes.

[4]. CM kwananzi, Sibusiso, and Clifford Odimegwu. "Teen Pregnancy in Sub-Saharan Africa." n. pag. Web. 1 June 2017.

[5]. "Consequences of Teenage Pregnancy - Teenage Pregnancy Center." N.p., n.d. Web. 26 Aug. 2017. ---. N.p., n.d. Web. 29 Aug. 2017.

[6]. "Effects of Teenage Pregnancy: Mental Health.” N.p., n.d. Web. 24 Aug. 2017.

[7]. "Kenya 2014 Demographic and Health Survey." n. pag. Web. 24 Aug. 2017.

[8]. "Lesotho 2014 Demographic and Health Survey BOPHELO MINISTRY OF HEALTH." n. pag. Web. 24 Aug. 2017.

[9]. Ramulumo, Mashudu R., and Victor J. Pitsoe. "Teenage Pregnancy in South African Schools: Challenges, Trends and Policy Issues." Mediterranean Journal of Social Sciences (2013): n. pag. Web. 27 Aug. 2017.

[10]. "SOCIAL AND ECONOMIC CONSEQUENCES OF TEENAGE CHILDBEARING." (1987): n. pag. Web. 24 Aug. 2017.

[11]. Sedgh, Gilda et al. "Adolescent Pregnancy, Birth, and Abortion Rates across Countries: Levels and Recent Trends." The Journal of adolescent health : official publication of the Society for Adolescent Medicine 56.2 (2015): 223-30. Web. 1 June 2017.

[12]. Social Dynamics of Adolescent Fertility in Sub-Saharan Africa. Washington, D.C.: National Academies Press, 1993. Web. 24 Aug. 2017.

[13]. “WHO | Adolescent Pregnancy.” WHO (2016): n. pag. Web. 1 June 2017. 


\title{
Factors Affecting the Utilization of Family Planning among Women Attending Selected Health Centers in Ile Ife, Osun State, Nigeria
}

\author{
Article by Agunbiade Funmilayo B \\ $R N, R M, C E R T$. in Family Planning, CRNA, BSN \\ Assistant Director of Nursing Services, Department of Anaesthesia, Obafemi Awolowo \\ University Teaching Hospitals Complex, Ile-Ife, Nigeria \\ E-mail: abolanle@texilaconnect.com
}

\begin{abstract}
Many unintended pregnancies and illegal abortions contributes significantly to the high mortality rate in Nigeria, which signifies the unmet needs for family planning among women of reproductive age, which could be affected by myriads of factors. Hence, this study assesses factors influencing the utilization of family planning methods among women attending selected health centers in Ile Ife. Osun State. Nigeria.

Findings showed that more than two-third (68.6\%) had ever used a family planning method. Meanwhile, about two-third (60.4\%) were currently using a family planning method, while $39.6 \%$ were not using any method. Majority (26.3\%) rated condom as the most effective method of contraception. Factors identified as militating against the utilization of contraceptive use were; fear of side effects (80.2\%), personal dislike (71.7\%), opposition of spouse (63.5\%) and unwelcoming attitude of health workers (61.1\%) and non-effectiveness of family planning services (54.3\%). Hypothesis testing revealed a strong relationship between fear of side effects and utilization of family planning services $\left(X^{2}=\right.$ 26.091, $d f=1$ and $p=0.001$ at 0.05 significant value). However, there is no significant relationship between spouse opposition and utilization of family planning services $\left(X^{2}=1.171, d f=1, p=0.279\right.$ at 0.05 significant value).

In conclusion, although a good number of the respondents were using a family planning method, some of them were not still using it. Hence, the need for health care provider to educate based on isolated factors such as side effects, preference, spousal opposition that influence contraceptive use among women of child bearing age.
\end{abstract}

Keywords: Factors influencing contraceptive use among Lori Ashford, Donna Clifton, and Toshiko Kaneda, The World's Youth 2006.

\section{Introduction}

It has been estimated that two-thirds of all unintended pregnancies in developing countries occur among women and adolescents who do not use contraceptives (Mbizvo \& Zaidi, 2010). In 2014, it was reported that two hundred and twenty-five million women in developing regions had an unmet need for modern contraception (Singh, Darroch and Ashford, 2014). (Of this total, 160 million were using no method and 65 million were using a traditional method.) The total changed little over the past decade, mainly because increases in contraceptive use have barely kept up with growing populations and rising desire for smaller families. The health implications of such a large unmet need are profound. Every year, an estimated 74 million unintended pregnancies occur in developing regions, the great majority of which are among women using no contraception or a traditional method. Should the need for modern contraception be met among those who were supposed to be using it but not using it, fifty-two millions of these pregnancies not planned could be averted, thereby preventing the deaths of 70,000 women from pregnancy-related causes (Singh, et al, 2014). In Nigeria, the contraceptive prevalence rate has remained low (Olugbenga-Bello, Abodurin and Adeomi, 2011). Meanwhile, literature shows that reduced contraceptive usage is associated with high maternal mortality indices, and Nigeria records one of the highest ratio, with maternal mortality ratio of 545 deaths per 100,000 live births (Nigeria Demographic and Health Survey, 2008). Igbodekwe, Oladimeji, Oladimeji, Adeoye, Akpa \& Lawson (2014) in a review of use of contraceptives using a nationally representative data in the 2008 National 
Demographic and Health Survey, found that the overall rate for current contraceptive use was $13.2 \%$, while the rate for modern methods was $9.4 \%$.

Family planning could nip to the bud up to one-third maternal deaths by allowing women to delay motherhood, space births, avoid unintended pregnancies and abortions, and stop child bearing when they have reached their desired family size (Lori, Donna and Toshiko (2006). Contraception is the use of various devices, drugs, agents, sexual practices or surgical procedures to prevent pregnancy (WHO, 2011). They are usually referred to as birth control methods (WHO, 2011). By helping women prevent unintended pregnancies, programs can reduce unwanted births and unsafe abortions, and improve maternal and child health (Singh, Darroch and Ashford, 2014). These gains can also contribute to other development objectives, such as curbing poverty and slowing population growth (Canning and Schultz, 2012). Enabling women to act on their pregnancy preferences has become a high priority on the global development agenda. Not long past strategies have called for improving the unmet need for modern contraception, which arises when women want to avoid a pregnancy but are using no method or a traditional one. The most prominent of these initiatives is Family Planning 2020, a global partnership launched in 2012 that aims to add 120 million new users of modern contraceptives in the world's 69 poorest countries by 2020 (Family Planning Summit, 2012).

Several factors play an important role in the use of contraceptives among women of childbearing age. The identification of these factors is crucial to the planning and implementation of suitable family planning programmers (Kabir, Saha, Oliveras and Gazi, 2013). Many studies in Sub-Sahara Africa show that there are many factors that inhibit the use of modern contraceptives among adolescents. These barriers include poor knowledge of contraceptive, fears and rumours about side effect, and unsupportive or negative influences of partners and family members (Williamson, Parkes, Wight, Petticrew and Hart, 2009). Family members put pressure on adolescents, especially female adolescents to give birth because they are not sure whether she would be fertile after using contraceptives. Others also reject contraceptives for religious reasons (Williamson et al, 2009). The use of contraceptives by teenagers has also been found to be a factors of socio-economic status, knowledge about contraceptives, attitudes about issues related to contraceptives, residential area, educational status, counseling received about contraceptives, attitudes of the contraceptive providers, and cultural values, beliefs and norms (Kanku and Mash, 2010).

In 2012, more than one-third of women in the United States who were not using a contraceptive method when they had an unintended pregnancy said it was because they did not think they could get pregnant (Mosher, Jones and Abma, 2012). It was the most common reason the women gave for not using contraception, and there was no significant variation in the proportions of women who cited this reason by age, marital status or income. Concern about side effects and health risks appears somewhat less common among sexually active never married women than among married women. Concern about side effects is also high among married women in Ghana, and studies there have shown that many educated, urban women avoid hormonal methods (Machiyama and Cleland, 2014). A promising study in Kenya showed that improvements in the quality of care were positively associated with modern contraceptive use, particularly among young and less educated women (Tumlinson, Okigbo and Speizer, 2015).

Studies in the Philippines among adolescents also show poverty, lack of knowledge on contraceptives and having infrequent sex as reasons for contraceptive non-use (Gipson, Hirz and Avila, 2011). Religion has also been a barrier to contraceptive use for decades where children are regarded as gifts or blessings from God (Gipson et al., 2011). This is found mostly among the Catholics and Muslims who see contraceptive use as a license for illicit or extra marital sexual behavior or indiscriminate sexual behavior (Gipson et al., 2011). Studies in Africa have inquired into the healthcare providers' attitude towards providing contraceptives for unmarried adolescents and reports reveal that many providers have negative attitudes. For instance, a Ugandan study reported that most of the providers had negative attitudes towards the provision of contraceptives for young people and were not prepared or were hesitant to give young people contraceptives (Ahanonu, 2013). As such, they imposed non-evidence based age restrictions and consent requirements (Ahanonu, 2013). A major reason reported to be responsible for the resistance of service providers to provide contraceptive services to 
adolescents is the belief that it promotes sexual promiscuity and that by restricting access to services, they were protecting both the client and the society (Ahanonu, 2013).

\section{Objectives}

The main objectives of this study were to;

1. To assess the level of utilization of family planning methods among women attending selected health centres in Ile- Ife, Osun State, Nigeria.

2 To identify factors affecting the use of family planning methods among respondents.

\section{Methodology}

The design was descriptive analytical survey as it helped the researcher to describe and analyze respondents' view statistically. This research was carried out among women of child bearing age attending three various selected health centers in Ile-Ife; Aderemi Health Centre, Enuwa Health Centre, and Eleyele Comprehensive Health Centre, Ile-Ife. Multistage sampling was used to select 293 participants; at the first level, 3 health centers were purposively selected. At the second level, proportionate sampling was done based on clinic attendance of each health center, and lastly, incidental sampling method was used to select 293 respondents from all the clinics; Eleyele (107), Enuwa (96) and Aderemi (90), which formed the sample size.

The data was collected using a self-structured questionnaire which contained questions drawn in open ended and close ended forms. The questionnaire has three sections with section $\mathbf{A}$ exploring the socio-demographic characteristics of the samples, section B exploring the attitude and perception of women about family planning and section $\mathbf{C}$ exploring the factors affecting women's choice in utilizing family planning services.

The data collection was a face-to-face distribution of questionnaires to the respondents by hand. The questionnaires were also translated into Yoruba language putting into consideration some respondents who could not read or write in English. Informed consent was gained from all the respondents as they were briefed on the research topics and given opportunity to decide if to participate in the study or not, and all the information on the questionnaires issued were treated with strict confidentiality. The data collected was analyzed using a descriptive (frequency tables) and inferential statistics (correlations), graphs and Statistical Package for Social Sciences (SPSS) as statistical tools.

\section{Results}

Demographic Profile of the of Respondents $(n=293)$

\begin{tabular}{|l|l|l|l|}
\hline Demographic Variables & Frequency & Percent \\
\hline Age of the respondents & $15-24$ & 75 & 25.6 \\
\cline { 2 - 4 } & $25-34$ & 158 & 53.9 \\
\cline { 2 - 4 } & $35-44$ & 40 & 13.7 \\
\cline { 2 - 4 } & $45-54$ & 20 & 6.8 \\
\hline \multirow{4}{*}{$\begin{array}{l}\text { Religion of the } \\
\text { respondents }\end{array}$} & Christianity & 215 & 73.4 \\
\hline Marital status & Islam & 78 & 26.6 \\
\hline \multirow{4}{*}{ Residence } & Single & 60 & 20.5 \\
\cline { 2 - 4 } & Married & 224 & 76.5 \\
\cline { 2 - 4 } & Divorced & 9 & 3.1 \\
\hline \multirow{3}{*}{ Educational level } & Urban & 234 & 79.5 \\
\cline { 2 - 4 } & Rural & 60 & 20.5 \\
\hline \multirow{2}{*}{$\begin{array}{l}\text { Partners Educational } \\
\text { Level }\end{array}$} & Secondary & 56 & 19.1 \\
\cline { 2 - 4 } & Tertiary & 237 & 80.9 \\
\cline { 2 - 4 } & Secondary & 39 & 13.3 \\
\cline { 2 - 4 } & Tertiary & 227 & 77.5 \\
\cline { 2 - 4 } Occupation & No Partner & 27 & 9.2 \\
\hline
\end{tabular}


DOI: $10.21522 /$ TIJNR.2015.03.02.Art012

ISSN: $2520-3126$

\begin{tabular}{|l|l|l|l|}
\hline \multirow{5}{*}{ Family Setting } & Student & 108 & 36.9 \\
\cline { 2 - 4 } & Self Employed & 79 & 27 \\
\cline { 2 - 4 } & Civil Service & 87 & 29.7 \\
\hline Ideal Number of Children & Monogamous & 238 & 81.2 \\
\cline { 2 - 4 } & Polygamous & 55 & 18.8 \\
\cline { 2 - 4 } & Two & 89 & 30.4 \\
\cline { 2 - 4 } Children & Three & 75 & 25.6 \\
\cline { 2 - 4 } & Four & 129 & 44 \\
\hline \multirow{5}{*}{ Sex Composition } & No child at all & 29 & 9.9 \\
\cline { 2 - 4 } & One & 28 & 9.6 \\
\cline { 2 - 4 } & Two & 111 & 37.9 \\
\cline { 2 - 4 } & Three & 86 & 29.4 \\
\cline { 2 - 4 } & Four & 30 & 10.2 \\
\cline { 2 - 4 } & Five and above & 9 & 3.1 \\
\hline & No child & 29 & 9.9 \\
\cline { 2 - 4 } & $\begin{array}{l}\text { Same number of } \\
\text { male and Female }\end{array}$ & 72 & 24.6 \\
\cline { 2 - 4 } & Female $>$ Male & 48 & 16.4 \\
\cline { 2 - 4 } & Male $>$ Female & 47 & 16 \\
\cline { 2 - 4 } & No Female & 49 & 16.7 \\
\cline { 2 - 4 } & No Male & 48 & 16.4 \\
\hline
\end{tabular}

Table 1 above showed $53.9 \%$ of the respondents were aged $25-34$, about $73.4 \%$ were Christians, $79.5 \%$ resides in urban setting, $20.5 \%$ were single, while 76.5 were married, majority $(80.9 \%)$ of them and their spouses $(77.5 \%)$ attended tertiary institution, larger percentage $(56.7 \%)$ were employed and $36.9 \%$ were students. The table also revealed that majority of the respondents was from monogamous setting; the ideal number of children by majority of the respondents was four.

Table 2. Contraceptive use among respondents

\begin{tabular}{|l|l|l|l|}
\hline Variables & Yes (\%) & No (\%) & Total (\%) \\
\hline Ever use contraceptive before & $201(68.6 \%)$ & $92(31.4 \%)$ & $293(100 \%)$ \\
\hline $\begin{array}{l}\text { Do you use any family } \\
\text { planning presently? }\end{array}$ & $177(60.4 \%)$ & $116(39.6 \%)$ & $293(100 \%)$ \\
\hline
\end{tabular}

In table 2, more than two-third (68.6\%) of the respondents have used contraceptive before. Majority $(60.4 \%)$ were using contraceptive presently, while $39.6 \%$ were not using it.

Table 3. Distribution of respondents based on their rating of the effectiveness of family planning methods

\begin{tabular}{|l|l|l|}
\hline Family Planning Methods & Frequency & Percent \\
\hline Pills & 9 & 3.1 \\
\hline Injectables & 38 & 13.0 \\
\hline Condoms & 77 & 26.3 \\
\hline Sterilization & 9 & 3.1 \\
\hline Periodic abstinence & 12 & 4.1 \\
\hline Withdrawal & 19 & 6.5 \\
\hline More than one methods & 11 & 3.8 \\
\hline Not using any method & 116 & 39.6 \\
\hline No response & 2 & $0.7 \%$ \\
\hline Total & 293 & 100.0 \\
\hline & &
\end{tabular}


The table above showed that more than a quarter of the respondents $(26.3 \%)$ rated condom as the most effective, followed by injectables, which was $13 \%$. However, $39.6 \%$ of the respondents could not rate the effectiveness of the contraceptive methods as they were not using any method at all.

Table 4: Distribution of respondents based on factors reducing their choices and utilization of family planning services

\begin{tabular}{|l|l|l|}
\hline Variables & Yes & No \\
\hline Fear of side effects (bleeding, headaches etc.) & $235(80.2 \%)$ & $58(19.8 \%)$ \\
\hline Personal Dislike & $210(71.7 \%)$ & $83(28.3 \%)$ \\
\hline Opposition of Spouse & $186(63.5 \%)$ & $107(36.5 \%)$ \\
\hline $\begin{array}{l}\text { Unwelcoming attitude of Health Care } \\
\text { Providers }\end{array}$ & $179(61.1 \%)$ & $\begin{array}{l}114 \\
(38.9 \%)\end{array}$ \\
\hline Non- effectiveness of Family Planning & $159(54.3 \%)$ & $134(45.7 \%)$ \\
\hline Reduces Coital Satisfaction & $146(49.8 \%)$ & $147(50.2 \%)$ \\
\hline Not having/ Infrequent Sex & $130(44.4 \%)$ & $163(55.6 \%)$ \\
\hline $\begin{array}{l}\text { Lack of Knowledge of family planning } \\
\text { services }\end{array}$ & $124(42.3 \%)$ & $169(57.7 \%)$ \\
\hline Non-availability of Family Planning Methods & $115(39.2 \%)$ & $178(60.8 \%)$ \\
\hline Religious Prohibition & $109(37.2 \%)$ & $184(62.8 \%)$ \\
\hline Distance to Service Provider & $103(35.2 \%)$ & $\begin{array}{l}190 \\
(64.8 \%)\end{array}$ \\
\hline Need for Female Children & $68(23.2 \%)$ & $225(76.8 \%)$ \\
\hline Cost too much & $58(19.8 \%)$ & $\begin{array}{l}235 \\
(80.2 \%)\end{array}$ \\
\hline Need for Male Children & $57(19.5 \%)$ & $\begin{array}{l}236 \\
(80.5 \%)\end{array}$ \\
\hline
\end{tabular}

Ranked most of the factors reducing the utilization of family planning services were: fear of side effects $(80.2 \%)$, personal dislike $(71.7 \%)$, and opposition of spouse $(63.5 \%)$, negative attitude of health workers $(61.1 \%)$ and non-effectiveness of family planning services $(54.3 \%)$.

Table 5. Association between fear of side effects and utilization of family planning services

\begin{tabular}{|c|c|c|c|c|c|c|c|}
\hline & & \multicolumn{3}{|c|}{$\begin{array}{l}\text { Fear of side effects } \\
\text { (bleeding, headaches, } \\
\text { cessation of menses) }\end{array}$} & \multirow[t]{2}{*}{$\mathrm{X}^{2}$} & \multirow[t]{2}{*}{$\begin{array}{l}\text { D } \\
\text { f }\end{array}$} & \multirow[t]{2}{*}{$\mathbf{P}$} \\
\hline & & No & Yes & Total & & & \\
\hline \multirow{3}{*}{$\begin{array}{l}\text { Do you use any family } \\
\text { planning presently? }\end{array}$} & No & 40 & 76 & 116 & \multirow[t]{3}{*}{26.091} & \multirow[t]{3}{*}{1} & \multirow[t]{3}{*}{.001} \\
\hline & Yes & 18 & 159 & 177 & & & \\
\hline & Total & 58 & 235 & 293 & & & \\
\hline
\end{tabular}

Using Pearson chi square, $\mathrm{X}^{2}=26.09, \mathrm{P}=0.001$, which is less than $0.05 \mathrm{Sig}$. value. There is a significant relationship between fear of side effects of family planning methods and utilization of family planning services. 
DOI: $10.21522 /$ TIJNR.2015.03.02.Art012

ISSN: $2520-3126$

Table 6. Association between spouse opposition and utilization of family planning services

\begin{tabular}{|c|c|c|c|c|c|c|c|}
\hline & & \multicolumn{3}{|c|}{ Opposition of the spouse } & \multirow[t]{2}{*}{$\mathbf{X}^{2}$} & \multirow[t]{2}{*}{ Df } & \multirow[t]{2}{*}{$\mathbf{P}$} \\
\hline & & No & Yes & Total & & & \\
\hline \multirow{3}{*}{$\begin{array}{l}\text { Do you use any family } \\
\text { planning presently? }\end{array}$} & No & 38 & 78 & 116 & \multirow[t]{2}{*}{1.171} & \multirow[t]{2}{*}{1} & \multirow[t]{2}{*}{0.279} \\
\hline & Yes & 69 & 108 & 177 & & & \\
\hline & Total & 107 & 186 & 293 & & & \\
\hline
\end{tabular}

Using Pearson chi square, $\mathrm{X}^{2}=1.17, \mathrm{P}=0.279$, which is greater than $0.05 \mathrm{Sig}$. value. There is no significant relationship between spouse opposition to family planning methods and utilization of family planning services" was accepted.

\section{Discussion of findings}

This study assessed the factors influencing the utilization of family planning methods among women attending selected health centers in Ile-Ife. 293 respondents partook in the study. The sociodemographic characteristics showed a little over half (53.9\%) of the respondents were aged 25-34, majority were Christians, married, had tertiary education, and from monogamous setting; the ideal number of children for larger percentage (44\%) of the respondents was four.

This study assessed the level of utilization of contraception among respondents. The result showed that more than two-third of the respondents $(68.6 \%)$ had ever used contraceptive before, while majority $(60.4 \%)$ were still using contraception presently. Meanwhile, significant number $(39.6 \%)$ was still not using contraception. This is in contrast with Olugbenga-Bello, et al (2011) who reported that contraceptive use remained low. It is also at variance with Igbodekwe, et al, (2014). In a review of use of contraceptives using a nationally representative data in the 2008 National Demographic and Health Survey, the overall rate for current contraceptive use was $13.2 \%$, while the rate for modern methods was $9.4 \%$.

On the factors reducing contraceptive choices among respondents, majority $(80.2 \%)$ agreed that fear of side effect prevented them from utilizing family planning services. This supports Machiyama and Cleland (2014), they submitted that concern about side effects and health risks appear somewhat a strong factor affecting contraceptive use. Also, majority (63.5\%) agreed that spouse opposition reduced their choice of family planning, which supports the view of Olaitan (2009) that "the woman's husband is one of many socially significant actors who might discourage or oppose a woman who wishes to use contraception. Larger percentage (71.7\%) had personal dislike for family planning. Majority $(61.1 \%)$ also saw unwelcoming attitude of the family planning providers as reducing their choices. This validates the findings of Ahanonu (2013) in Uganda that most of the providers had negative attitudes towards the provision of contraceptives for young people and were not prepared or were hesitant to give young people contraceptives.

The study found the association between fear of side effects and utilization of family planning services using chi square. The result showed a significant relationship between fear of side effects and utilization of family planning services $(\mathrm{P}=0.001)$, this further corroborates the findings of (Machiyama and Cleland, 2014). The study assessed the association of spouse opposition and utilization of family planning using chi square. Therefore, there is no significant relationship between spouse opposition and respondents' utilization of family planning $(\mathrm{P}=0.279)$.

\section{Summary}

The study examined factors affecting the utilization of family planning among women attending selected health centers in Ile-Ife, Osun State, Nigeria. . The findings and recommendations should serve to improve the use of family planning by women of child bearing age, the role of the family planning providers, spouse involvement in family planning and government in making essential provisions for women's health promotion and their families to support the millennium development goal, support safe motherhood and accelerate the country's progress towards reducing poverty. 


\section{Conclusion}

In this study, it was observed while majority were using contraception, significant number of women of child bearing age is ambivalent about using contraception, reasons not far-fetched from fear of side effect and spouse opposition. Therefore, the need to further intensify efforts to create awareness on benefits of family planning and reaching out to the society by the health care providers in achieving the millennium development goals should be redressed.

\section{Implications for nursing practice}

The findings from this study implicate the need for nurses and family planning providers to include information that would educate couples on their family planning choices, reproductive behavior, relationship, and decision-making.

Secondly, family planning provider and nurses need to consider those variables tested when designing intervention programs for modifying couples attitudes towards family planning choices.

Finally, all those in the helping professions should design programs for couples on the social and economic benefit on couple's decision-making on family planning choices.

\section{Recommendations}

Having studied the factors influencing the utilization of family planning among women in selected health centers in Ile-Ife, Osun State, Nigeria, the following recommendations were made:

1. Health care providers especially nurses should educate women based on isolated factors affecting contraceptive use, such as side effects, preference, and spousal opposition.

2. Societies and communities should give a couple of advice to their neighbors on the importance of family planning in order to promote healthy living.

3. Religious leaders should encourage their followers on the needs for family planning choice as related to their holy book. Information from such people aids wider acceptance.

4. Community leaders should discourage the habit of not having family planning choice in their cultural norms because person's cultural and social environment influence decisions on family planning.

5. Federal Government should build Reproductive Health Centers, where family planning education would be given to couples on the choice of family planning for both educated and non-educated couples.

6. Family planning service providers should educate the couples on the effectiveness of family planning choice and benefits as these ensure acceptance and utilization.

7. Every couple should be discouraged about the thought of health risk of family planning choice.

\section{References}

[1].Ahanonu, E. L. (2013). Attitudes of Healthcare Providers towards Providing Contraceptives for Unmarried Adolescents in Ibadan, Nigeria. Journal of Family and Reproductive Health Vol. 8, No. 1,

[2].Canning, D. and Schultz, T.P. (2012). The economic consequences of reproductive health and family planning, Lancet, 380(9837):165-171.

[3].Family Planning Summit - July 2012,

http://www.who.int/workforcealliance/media/events/2012/LondonSummitonFamilyPlanningOverview.pdf.

[4].Gipson, J. D., Hirz, A. E., \& Avila, J. L. (2011). Perceptions and practices of illegal abortion among urban young adults in the Philippines: a qualitative study. Studies in family planning, 42(4), 261-272.

[5].Igbodekwe, F.C., Oladimeji, O., Oladimeji, K.E., Adeoye, I.A., Akpa, O.M., \& Lawson, L. (2014). Utilisation of Modern Contraceptive among Women of Childbearing Age in Resource Constraint Setting: Evidence from 2008 National Demographic and Health Survey in Nigeria. Journal of Health Science, 4(3): 72-78.

[6].Kabir, H., Saha, N. C., Oliveras, E. and Gazi, R. (2013). "Association of programmatic factors with low contraceptive prevalence rates in a rural area of Bangladesh," Reproductive Health, vol. 10(31), 2013.

[7].Kanku, T., \& Mash, R. (2010). Attitudes, perceptions and understanding amongst teenagers regarding teenage pregnancy, sexuality and contraception in Taung. South African Family Practic, 52(6).

[8].Lori Ashford, Donna Clifton, and Toshiko Kaneda, The World's Youth 2006 (Washington, DC: Population Reference Bureau, 2006). 
DOI: $10.21522 /$ TIJNR.2015.03.02.Art012

ISSN: $2520-3126$

[9].Machiyama, K. and Cleland, J. (2014). Unmet need for family planning in Ghana: the shifting contributions of lack of access and attitudinal resistance, Studies in Family Planning, 45(2):203-226.

[10]. Mbizvo, M. T., \& Zaidi, S. (2010). Addressing critical gaps in achieving universal access to sexual and reproductive health (SRH): the case for improving adolescent SRH, preventing unsafe abortion, and enhancing linkages between SRH and HIV interventions. International Journal of Gynecology \& Obstetrics, 110, S3-S6.

[11]. Mosher, W.D., Jones, J., and Abma, J.C., (2012). Intended and unintended birth in the Unites States: 19822010, National Health Statistics Report No. 55, Hyattsville, and MD: National Center for Health Statistics, 2012.

[12]. Nigeria Demographic and Health Survey (2008). National Population Commission and ICF micro, Calverton, MD 0705, USA 2008.

[13]. Olugbenga-Bello, A. I., Abodunrin, O. L., and Adeomi, A. A. (2011). "Contraceptive Practices among Women in Rural Communities in South-Western Nigeria," Global Journal of Medical research Vol. 11(2), 2011.

[14]. Singh, S., Darroch, J.E. and Ashford, L.S., (2014). Adding It Up: The Costs and Benefits of Investing in Sexual and Reproductive Health 2014, New York: Guttmacher Institute.

[15]. Tumlinson, K., Okigbo, C.C., \& Speizer, I.S., (2015). Quality of care and contraceptive use in urban Kenya, International Perspectives on Sexual and Reproductive Health, 2015, 41(2):69-79.

[16]. Williamson, L. M., Parkes, A., Wight, D., Petticrew, M., \& Hart, G. J. (2009). Limits to modern contraceptive use among young women in developing countries: a systematic review of qualitative research. Reprod Health, 6(3), 1-12. 


\title{
Role of Husband's Age in Percentage of Eggs that get Fertilized in Invitro Fertilization Cycle
}

\author{
Article by Monisayo Olayemi Komolafe ${ }^{1}$, Komolafe Johnson Olusanmi ${ }^{2}$ \\ ${ }^{1}$ Lautech Teaching Hospital, Osogbo \\ ${ }^{2}$ Department of Obstetrics \& Gynaecology \\ Lautech Teaching Hospital, Osogbo \\ E-mail: monisayokomolafe@gmail.com ${ }^{1}$,komosayo@gmail.com²
}

\begin{abstract}
Background: Female age is a known independent index in determining outcome of fertility treatment with ovulatory and fertility potentials declining rapidly after age 35 however it an assumed fact that men are capable of spermatogenic activity beyond age 60 with world oldest father procreating at age 97. (Myers, 1972)

Objectives: Determine if age affected semen concentration and motility of male partners undergoing invitro fertilization.

Determine if age of male partners had influence on percentage of oocytes that are fertilized following invitro fertilization cycles.

Method: A descriptive retrospective review of data of IVF cycles performed between July 2015 and June 2017. Inclusion criteria was that age of oocytes producer must be less than 36, post sperm wash count of at least 10million per milliliters and 15\% active motile sperm. Exclusion criteria were female age of oocyte producer more than 35, incomplete relevant data.

Results: One hundred and twenty cycles met inclusion criteria. Mean husband age was 45.70 ( \pm 7.07$)$. Mean percentage oocyte fertilized among the group was $51.95 \%( \pm 29.85 \%)$. Mean percentage of oocytes fertilized among husband equal to or less than 50 was $54.21 \%$ ( $\pm 28.87 \%)$ while mean percentage of oocytes fertilized among husband age 51 and above was $45.20 \%$ ( \pm 32.20$)$, the observed difference being statistically significant $\left(p=0.0000 ; X^{2}=90.133\right)$.

Conclusion: There is a significant drop in ability of men above 50years to fertilize oocytes compared to men below 51 years of age during invitro fertilization cycles.
\end{abstract}

Keywords: In-vitro Fertilization, Intra uterine insemination.

\section{Abbreviation}

BNSc Bachelors Degree Nursing Science

IUI Intra uterine insemination

IVF In-vitro fertilization

O\&G Obstetrics and Gynecolog

\section{Introduction}

Infertility is a major problem in our culture and society at large. Infertile couple are seen as abnormal, unfortunate and most of the time the woman is seen as the cause of delay in child bearing while the man is always seen as free of all abnormality hence does not even present themselves for evaluation in the fertility centers of our hospital units.

It has also been observed in our society that academic and economic pursuit's leads to late marriage which has been documented to affect the females. In couples younger than age 30 who are generally healthy, $20 \%$ to $37 \%$ are able to conceive in the first 3 months (American Society for Reproductive 
DOI: $10.21522 / \mathrm{TIJNR} .2015 .03 .02 . A r t 013$

ISSN: $2520-3126$

Medicine, 2012), but males are believed to be fertile throughout their life time. Therefore, this study wants to investigate if there is any significance in fertilization rate in relation to paternal age.

It has been established that one in every six couple is infertile.

Infertility is defined clinically in women and men who cannot achieve pregnancy after 1 year of having intercourse without using birth control, and in women who have two or more failed pregnancies. Studies suggest that after 1 year of having unprotected sex, $15 \%$ of couples are unable to conceive, and after 2 years, $10 \%$ of couples still have not had a successful pregnancy. (Practice Committee of the American Society for Reproductive Medicine in collaboration with the Society for Reproductive Endocrinology and Infertility, 2008), (Male Infertility Best Practice Policy Committee of the American Urological Association and Practice Committee of the American Society of Reproductive Medicine, 2006).

For conception to take place a man's sperm must combine with the woman's egg. Sperm are made and stored in the testicles, which are ejaculated by the penis to deliver sperm to the female reproductive tract during sexual intercourse.

External genital organs: Penis-The penis is the male intromittent organ. It has a long shaft and an enlarged bulbous-shaped tip called the glans penis, (https://prezi.com/i0z5miveenwg/human-malereproductive-system/ Oct 1, 2013) which supports and is protected by the foreskin. When the male becomes sexually aroused, the penis becomes erect and ready for sexual activity. Erection occurs because sinuses within the erectile tissue of the penis become filled with blood. The arteries of the penis are dilated while the veins are compressed so that blood flows into the erectile cartilage under pressure. (https://en.wikipedia.org/wiki/Male_reproductive_system) The penis is supplied by the pudendal artery.

Scrotum-The scrotum is a pouch-like structure that hangs behind the penis. It holds and protects the testicles. It also contains numerous nerves and blood vessels. During times of lower temperatures, the Cremaster muscle (https://hyattractions.wordpress.com/2012/11/.. ./male-and-female-reproductivesystem, 2012) contracts and pulls the scrotum closer to the body, while the Dartos muscle gives it a wrinkled appearance; when the temperature increases, the Cremaster and Dartos muscles relax to bring down the scrotum away from the body and remove the wrinkles respectively.

The scrotum remains connected with the abdomen or pelvic cavity by the inguinal canal. (https://hyattractions.wordpress.com/2012/11/.../male-and-female-reproductive-system ， 2012) (The spermatic cord, formed from spermatic artery, vein and nerve bound together with connective tissue passes into the testis through inguinal canal.)

Epididymis-The epididymis, a whitish mass of tightly coiled tubes cupped against the testicles, (https://en.wikipedia.org/wiki/Male_reproductive_system) acts as a maturation and storage for sperm before they pass into the vas deferens, that carry sperm to the ampullary gland and prostatic ducts.

Vas deferens-The vas deferens, also known as the sperm duct, is a thin tube approximately 30 centimetres $(0.98 \mathrm{ft})$ long that starts from the epididymis to the pelvic cavity. It carries the spermatozoa from the epididymis to ejaculatory duct.

To conceive a child, a man's sperm must combine with a woman's egg. The testicles make and store sperm, which are ejaculated by the penis to deliver sperm to the female reproductive tract during sexual intercourse. The most common issues that lead to infertility in men are problems that affect how the testicles work. Other problems are hormone imbalances or blockages in the male reproductive organs. In about $50 \%$ of cases, the cause of male infertility cannot be determined. (Jose-Miller, 2007)

A complete lack of sperm occurs in about $10 \%$ to $15 \%$ of men who are infertile. (American Urological Association, 2008). A hormone imbalance or blockage of sperm movement can cause a lack of sperm. In some cases of infertility, (samadiroboticsfoundation.org/what-is-male-infertility/ Nov 18, 2016) a man produces less sperm than normal. The most common cause of this condition is varicocele, an enlarged vein in the testicle. (Damilola F, 2015) Varicocele is present in about 40\% of men with infertility problems. (American Urological Association, 2008)

Sperm specimen should be collected by masturbation and the ejaculate produced into a sterile glass that has been checked for sperm toxicity. As soon as the seminal plasma has liquefied, the specimen 
should be analyzed according to the WHO guidelines and prepared for sperm isolation. Sperm can be prepared by Simple Washing and Dilution. Repeat centrifugation, usually two or three times in total, is often used to ensure removal of contaminating seminal plasma. The centrifugation is usually performed at 200-300 g and it should certainly be performed at centrifugal forces less than $800 \mathrm{~g}$ (Jeulin C, 1982).

\section{Research design}

A descriptive retrospective review of data of IVF cycles performed between July 2015 and June 2017. Inclusion criteria was that age of oocytes producer must be less than 36, post sperm wash count of at least 10 million per milliliters and $15 \%$ active motile sperm. Exclusion criteria were female age of oocyte producer more than 35 , incomplete relevant data.

\section{Research population}

A total of three hundred and five cycles were recorded. All the respective folders were retrieved in batches and parameters retrieved with predetermined data sheet. Inclusion criteria included age of the woman who had oocyte retrieval must be less than 36years, the semen parameters after sperm washing preparatory for invitro fertilization must be at least ten million per milliliter with at least $15 \%$ of them actively and progressively motile. All cases with incomplete data for example age of husband not indicated or percentage motility of the sperm after sperm preparation omitted were all excluded from analysis.

\section{Research setting}

A private fertility specialist hospital 'Ayomide Womens' health IVF centre and fertility hospital. The hospital is located in Osogbo the state capital of Osun state. This hospital major mainly in various aspects of fertility care and investigations.

The hospital has three main theatres first occupying the ground floor of the hospital is the laparoscopy and hysteroscopy theatre where closed surgeries and diagnostic laparoscopy is carried out.

The second theatre is the IVF theatre where follicular aspiration is done for IVF treatments. Attached to the IVF theatre is the andrology laboratory where the embryologist work on the aspirated eggs and semen preparation is carried. The third theatre is where various obstetrics and gynecological open surgeries such as caesarian section, myomectomy, subtotal abdominal hysterectomy, Total abdominal hysterectomy, vaginal hysterectomy, adhesiolysis for intrauterine and pelvic adhesion.

Other investigations and procedures includes Hormonal assay, follicular tracking, abdominal and transvaginal scans, intra uterine insemination-IUI. Ante natal care is rendered to pregnant women on Mondays while Gynecological clinics holds on Wednesdays and Fridays of every week.

The hospital is covered by a consultant Obstetrician and gynecologist who is also a fertility specialist.

Other doctors are an O\&G consultant, a senior medical officer and two medical officers. The hospital has six Registered Nurses and midwives, three with BNSc.

The hospital has five private rooms, four bedded post natal ward, four bedded post embryo transfer ward, a labour ward, one neonatal ward with two phototherapy kits. All resuscitative measures such as multi parameter monitor, 100percent oxygen, suctioning machine etc., are always available to meet clients need. The hospital has recorded several successful IVF pregnancies with deliveries of live infants

The hospital has two certified embryologist and two trainees. There are four ward orderlies and two security men

\section{Research sampling and sampling technique}

Convenience sampling of all IVF cases done that met inclusion criteria of the 305 listed cases were one hundred and twenty. 
DOI: $10.21522 / \mathrm{TIJNR} .2015 .03 .02 . A r t 013$

ISSN: $2520-3126$

\section{Method of data collection}

The list and embryology data sheets of invitro fertilization cycles conducted from $1^{\text {st }}$ of July 2015 to $30^{\text {th }}$ day of June 2017 was retrieved from the director of embryology laboratory. A total of three hundred and five cycles were recorded. All the respective folders were retrieved in batches and parameters retrieved with predetermined data sheet. Inclusion criteria included age of the woman who had oocyte retrieval must be less than 36years, the semen parameters after sperm washing preparatory for invitro fertilization must be at least ten million per milliliter with at least $15 \%$ of them actively and progressively motile. All cases with incomplete data for example age of husband not indicated or percentage motility of the sperm after sperm preparation omitted were all excluded from analysis. Total number that met inclusion criteria of the 305 listed cases were one hundred and twenty. Semen analysis is done in the facility using world health organization criteria (WHO)

\section{Method of data analysis}

The retrieved data were entered into SPSS version 17.0. The data was sorted by age in ascending order, age of husband variable was recoded into different variable of age group less than 40years, age 41-45, 4650, 51-55 and above 55 years. Descriptive analysis was subsequently carried out yielding frequencies, mean, and standard deviations of numerical data. Cross tabulations of percentage oocyte fertilized against that of age groupings were then done with determination of level significance of observed difference using chi square.

\section{Ethical consideration}

Permission to use stored data for the purpose of this research work was gotten by a formal request to the ethical review unit of the hospital which gave her consent.

\section{Result}

A total of one hundred and twenty cycles met the inclusion criteria set for this study out of the three hundred and five cycles conducted during the two year period. The mean age of husband in this study is $45.70( \pm 7.07)$. Almost fifty percentage of the male partners were in the fourth decade (Table 1a) with three quarters of them aged below 51years (Table 1b). The age range was from minimum of 33 to maximum of 64years. Mean semen count post sperm washing preparatory for invitro fertilization among the studied male partners was one hundred and twenty million per milliliter $\left(120 \times 10^{6} / \mathrm{ml} \pm 97.91\right)$ while mean sperm motility among reviewed cases was $44.67 \% \pm 16.87$ and mean oocyte production among the women reviewed was $9.9 \pm 3.87$.

Mean percentage oocyte fertilization in this review was $51.95 \%( \pm 29.85)$ with zero fertilization in fifteen $(12.5 \%)$ of cases reviewed while hundred percent fertilization was seen in only three of the cases $(2.5 \%)$. When the age groupings were cross tabulated against percentage oocyte fertilized, increasing age was found to be inversely proportionally related percentage egg fertilized especially after age of 50 years. The observed difference among the age groupings were found to be statistically significant (Table $2 \& 3$ ).

\section{Discussion}

Semen Parameters and age: Mean semen concentration among the studied male partners was 120 million per milliliter. The value appears high compared to average expected value for post semen wash count to perform intrauterine insemination (IUI) or invitro fertilization which is put at 10 million per milliliter(Ok E.K, 2013). This is not unexpected as men with semen adjuged not to meet minimum WHO semen parameters of semen concentration of 15 million per milliliter (Morshedi M, 2010) were excluded to remove confounding factors that may affect ability to fertilize oocytes apart from husband age.

Semen concentration showed a direct proportional increase with increasing age and this became distinctly noticeable in men over 55 years, this is in keeping with findings of Brahem et al (Brahem S, $\underline{2011)}$ and (Andolz, 1999) compared to others who recorded no change or minimal decrease in sperm 
concentration) (Auger J,1995) (Schwartz D,1983). Andolz et al in a study of study of 20,411 men found a statistically significant increase in concentration of $0.7 \%$ per year of age amounting to an increase in concentration of $14 \%$ over a 20 -year period.

Mean semen motility among reviewed men in this study was $44.67 \%$. This also as expected by the design of this study is expected to be above the minimum motility of $15 \%$ progressively motile sperm for IUI or IVF (Michelmann H.W, 1995) therapy. Sperm motility in relation to advancing age in this review showed inverse relationship. This agrees with general consistent findings of reduction in motility with advancing age in many studies (Wu Y, 2015), (Harris I.D, 2011), (Auger J, 1995).

\section{Oocytes fertilization and age}

Mean oocyte fertilization in this review was $51.95 \%$ with zero fertilization in fifteen $(12.5 \%)$ of cases reviewed. Mean oocyte fertilization of $54.21 \%$ found among male partners who are 50years or less dropped to $45.21 \%$ among those who are 51years or over. Yixuan et al concluded that fertilization rates of oocytes is not altered by paternal age. (Sloter E, 2006). There is paucity of papers looking at effects of paternal age on fertilization as most papers invariably puts advanced maternal age as main cause of failure of fertilization. This study with is suggesting that there may be a role for paternal age in determination of oocytes fertilization.

\section{Recommendation}

More studies to explore role of paternal age in occyte fertilization to be conducted. Men like women folks need to attend to reproductive challenges early.

\section{Conclusion}

There is a significant drop in ability of men above 50years to fertilize oocytes compared to men below 51years of age during invitro fertilization cycles.

\section{Figures and tables}

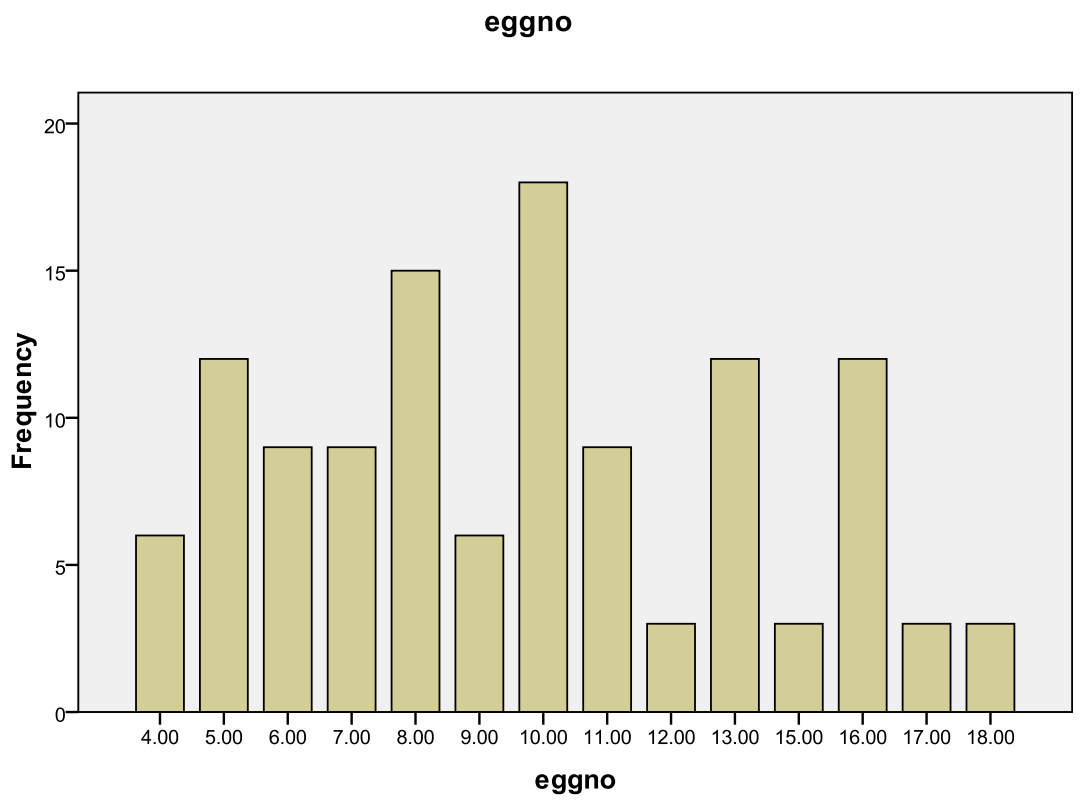

Figure 1. Distribution of oocytes retrieved from female population of the study 
DOI: $10.21522 / \mathrm{TIJNR} .2015 .03 .02 . A r t 013$

ISSN: $2520-3126$

Table 1. Age distribution of male partners of studied IVF cycles

$1 \mathrm{~A}$.

\begin{tabular}{|l|l|l|}
\hline S/no & Age groups & Frequency $(\%)$ \\
\hline 1 & $\leq 40$ & $33(27.5)$ \\
\hline 2 & $41-45$ & $39(32.5)$ \\
\hline 3 & $46-50$ & $18(15)$ \\
\hline 4 & $51-55$ & $21(17.5)$ \\
\hline 5 & $\geq 56$ & $09(7.5)$ \\
\hline
\end{tabular}

$1 B$.

\begin{tabular}{|l|l|l|}
\hline S/no & Age groups & Frequency $(\%)$ \\
\hline 1 & $\leq 50$ & $90(75)$ \\
\hline 2 & $\geq 51$ & $30(25)$ \\
\hline
\end{tabular}

Table 2. Percentage oocyte fertilization and age groupings

2.

\begin{tabular}{|l|lll|}
\hline S/NO & Age groups & $\begin{array}{l}\text { Percentage oocyte } \\
\text { fertilized (\%) }\end{array}$ & $\mathrm{X}^{2}=90.133$ \\
\cline { 1 - 1 } 1 & $\leq 50$ & 54.21 & $\mathrm{P}=0.0000$ \\
\cline { 1 - 1 } 2 & $\geq 51$ & $45.21 \%$ & \\
\hline
\end{tabular}

3.

\begin{tabular}{|l|l|l|l|}
\hline S/no & Age groups & $\begin{array}{l}\text { Percentage oocyte } \\
\text { fertilized (\%) }\end{array}$ & \multirow{2}{*}{$\mathrm{X}=85.405$} \\
\cline { 1 - 1 } & $\leq 40$ & 54.94 & $\mathrm{P}=000$ \\
\cline { 1 - 1 } 2 & $41-45$ & 49.98 & \\
\cline { 1 - 1 } 3 & $46-50$ & 62.02 & \\
\cline { 1 - 1 } 5 & $21-55$ & 46.19 & \\
\hline
\end{tabular}

Table 4. Mean post semen wash sperm concentration among age groupings undergoing IVF cycle

\begin{tabular}{|c|c|c|c|}
\hline S/no & Age groups & $\begin{array}{l}\text { Mean semen concentration } \\
\left(\mathrm{x} 10^{6} / \mathrm{ml}\right)\end{array}$ & \multirow{6}{*}{$\begin{array}{l}X^{2}= \\
413.132 \\
P=0.000\end{array}$} \\
\hline 1 & \multirow{5}{*}{$\begin{array}{l}\leq 40 \\
41-45 \\
46-50 \\
51-55 \\
\geq 56\end{array}$} & \multirow{5}{*}{$\begin{array}{l}117.54( \pm 91.49) \\
113.15( \pm 73.88) \\
128.15( \pm 111.85) \\
128.50( \pm 111.58) \\
266.67( \pm 145.14) \\
\end{array}$} & \\
\hline 2 & & & \\
\hline 3 & & & \\
\hline 4 & & & \\
\hline 5 & & & \\
\hline
\end{tabular}

Table 5. Mean post semen wash sperm motility among age groupings undergoing IVF cycle

\begin{tabular}{|l|l|l|l|}
\hline S/no & Age groups & Mean semen motility $(\%)$ & $\mathrm{X}^{2}=249.684$ \\
\cline { 1 - 1 } 1 & $\leq 40$ & $47.27( \pm 20.12)$ & $\mathrm{P}=0.000$ \\
\cline { 1 - 1 } & $41-45$ & $49.46( \pm 12.61)$ & \\
\cline { 1 - 1 }$-56-50$ & $41.17( \pm 18.97)$ & \\
\cline { 1 - 1 } 5 & $21-55$ & $41.17( \pm 18.97)$ & \\
\hline
\end{tabular}




\section{References}

[1]. American Urological Association (2008). A basic guide to male infertility: how to find out what's wrong. Retrieved June 11, 2012.

[2]. American Society for Reproductive Medicine. (2012). Optimizing natural fertility. Retrieved June 11, 2012, from

http://www.asrm.org/uploadedFiles/ASRM_Content/News_and_Publications/Practice_Guidelines/committee_Opini ons/optimizing_natural_fertility(2).pdf https://hyattractions.wordpress.com/2012/11/.../male-and -femalereproductive-system...Nov 12, 2012

[3]. Andolz P, Bielsa MA, Vila J. Evolution of semen quality in North-eastern Spain: a study in 22,759 infertile men over a 36 year period. Hum Reprod. 1999; 14:731-735.

[4]. Auger J, Kunstmann JM, Czyglik F, Jouannet P. Decline in semen quality among fertile men in Paris during the past 20 years. N Engl J Med. 1995; 332:281-285.

[5]. Brahem S, Mehdi M, Elghezal H, Saad H. The effects of male aging on semen quality, sperm DNA fragmentation and chromosomal abnormalities in an infertile population. J Assist Reprod Genet. 2011 May; 28(5): $425-432$.

[6]. Harris I.D, Fronczak C, Roth L, Meacham R.B. Fertility and the Aging Male. Rev Urol. 2011; 13(4): e184 e190.

[7]. Jeulin C, Serres C, Jouannet P. The effects of centrifugation, various synthetic media and temperature on the motility and vitality of human spermatozoa. Reprod Nutr Dev 1982; 22:81.

[8]. Jose-Miller, A. B., Boyden J. W., \& Frey, K. A. (2007). Infertility. American Family Physician, 75, 849-856.

[9]. Male Infertility Best Practice Policy Committee of the American Urological Association \& Practice Committee of the American Society of Reproductive Medicine. (2006).Report on optimal evaluation of the infertile male. Fertility and Sterility, 86, S202-S209.

[10]. Michelmann H.W. Minimal criteria of sperm quality for insemination and IVF therapy. Int J Androl. 1995 Dec; 18 Suppl 2:81-7.

[11]. Morshedi M. New 2010 WHO Standards (5th Edition) for the Evaluation of Human Semen. WHO semen analysis review. https://www.aab.org/images/aab/pdf/2014/CRBPPT14/WHO.pdf Ok E. K, Doğan O.E, Okyay R.E, Gülekli B. The effect of post-wash total progressive motile sperm count and semen volume on pregnancy outcomes in intrauterine insemination cycles: a retrospective study. J Turk Ger Gynecol Assoc. 2013; 14(3): 142-145.

[12]. Practice Committee of the American Society for Reproductive Medicine in collaboration with the Society for Reproductive Endocrinology and Infertility. (2008). Optimizing natural fertility. Fertility and Sterility, 90(5, suppl), S1-S6.

https://en.wikipedia.org/wiki/Male_reproductive_system (https://prezi.com/i0z5miveenwg/human-malereproductive-system/ Oct 1, 2013).

[13]. Schwartz D, Mayaux MJ, Spira A, et al. Semen characteristics as a function of age in 833 fertile men. Fertil Steril. 1983; 39:530-535.

[14]. Sloter E, Schmid TE, Marchetti F, et al. Quantitative effects of male age on sperm motion. Hum Reprod. 2006; 21:2868-2875.

[15]. Wu Y, Kang X, Zheng H, Liu H, Liu J. Effect of Paternal Age on Reproductive Outcomes of In Vitro Fertilization. PLoS One. 2015; 10(9): e0135734.

www.post-nigeria.com/common-causes-of-infertility-in-men-by- damilola-faleke/May 20, 2015. 


\title{
A Comparative Study to Determine the Knowledge and use of Breast Self- Examination Technic among Female Student Nurses at St. Lukes School of Nursing, Rufunsa. Zambia
}

\author{
Article by Toddy Sinkamba \\ Nursing, Texila American University, Zambia \\ E-mail: toddkedsink@gmail.com
}

\begin{abstract}
Breast cancer is the second common cancer after cancer of the cervix in women in Zambia. Although screening methods for breast cancer such as mammography has been shown to reduce mortality from breast cancer in developing countries where it is commonly used, the World Health Organisation (WHO) does not recommend it for use in developing countries because of it has cost implications. Instead, WHO recommends an alternative screening method called Breast Self-Examination for all women in the reproductive age group (15-49). The purpose of the study was to compare breast cancer knowledge, attitude and use of Breast Self-Examination among female student nurses in the reproductive age group (15-49). The study site was St. lukes nursing school Rufunsa district of the Lusaka province in Zambia. A total of 50 female student nurses participated in the study.
\end{abstract}

Keywords: Breast cancer, Breast Self-Examination practice, Breast cancer knowledge, student nurses in year $2 \& 3$, Mammography.

\section{Introduction}

\section{Background information}

Breast cancer is one of the leading causes of death among middle-aged women and it is becoming a major public health problem developing countries including Zambia. The incidence rate of breast cancer has increased by $27 \%$ in blacks and $10 \%$ in whites over the past 30 years (Price 1992). It usually develops in women over 50 years but this trend has changed in the recent past as breast cancer is now being detected in pre-menopausal women. (Mukupo, 2006). At cancer diseases hospital, just the first quarter of 2017,37 cases were attended to at outpatient department compared to 21 during the same period in 2016 showing a $57 \%$ increase. (CDH, 2017).

The case detection and prevalence of breast cancer has continued to rise in Zambia, for instance, the incidence of breast cancer at the Cancer Diseases Hospital (CDH) increased from 21 in the first quarter of 2016 to 37 in 2007 (PIM, REPORT 2017). Data also showed that the disease was common in women aged 50 and above but now breast cancer is being recorded in women less than twenty years old. In 2002, 3 women less than 14 years were diagnosed with breast cancer and the incidence of those aged between 15 to 34 has risen from 13 in 2003 to 19 in 2003 (Mukupo, 2006).

It was noted that the above cases were just a minimal representation of breast cancer cases. There was still a problem of poor record keeping in the health institutions in the country. (mukupo 2006).

It was also reported that most women sought medical help in the late stage of disease. This could have been attributed to in adequate knowledge on the condition and non-utilisation of BSE as a screening tool by women.

Dorsey (2001) defines BSE as a method whereby a woman examines her breasts regularly and at specific intervals. According to Berkow (1997) the woman herself examines the breasts monthly one to two days after menstruation when the breasts are not tender or swollen. The monthly date of one's birthday or the first day of the month are common choices for many women. Available evidence showed that the sensitivity of BSE ranged from 60-65\% (Bailey 
2000; Humphrey 2002). BSE is a cost-effective self-care action, which when performed correctly can detect tumours of $2 \mathrm{~cm}$ or less, does not require specialised personnel or equipment as it can be performed at home by the individual in about 10 minutes (Bell 1997).

\section{Review of relevant literature}

Studies from around the world had shown that the incidence of breast cancer was rising both in developed and developing nations and that was common in menopausal women but this trend had changed in recent years (Bird 1992; Persson 1995). This change could have been as a result of changes in lifestyles especially in African women (Amir 1998). In the past women had started child bearing early, they reproduced many children and breast fed them for longer periods. In countries south of the Sahara, breast cancer was the second most common malignancy in women. In Uganda, the incidence was 16.4\% (Akhtar 1993) and in Tanzania breast cancer represented $8.1 \%$ of all female cancers with peak prevalence in the group 35-44 years (Zarubara 1999). Identified risk factors for breast cancer included early menache, nulliparity, late menopause, diet, physical exercise and hormonal factors (Amir 1994).

In addition, studies had shown that alcohol intake was associated with breast cancer and the risk increased slightly in women who consumed even one alcoholic drink daily but the risk doubled among women taking three drinks daily (Amir 1998; Dorsay 2001). Smeltzer (2000) had also suggested that smoking increased the risk of breast cancer and that the earlier women begun to smoke, the higher the risk.

\section{Objectives of the study}

\section{General}

To compare the knowledge, attitude /practice of BSE amongst student nurses and distinguish variation or association among the study variables

\section{Specific}

- To assess the knowledge of breast cancer and BSE among student nurses.

- To compare the knowledge of breast cancer and BSE among students in year $2 \& 3$.

- To assess the attitude/practice of students' nurses towards BSE

- To make recommendations to the General Nursing Council of Zambia

\section{Variables under study}

- Knowledge

- Attitude/ Practice

\section{Research methodology}

The study was conducted at St. lukes school of nursing-Mpanshya. The study design was exploratory and comparative in nature. Permission to conduct the study was obtained from the research ethics committee of the Institution and the General Nursing Council of Zambia authorities and informed consent was gotten from the individual students who participated in the study. The study units were female student nurses aged 16-49 years who were in year $2 \&$ 3. A total of 50 female student nurses participated in the study. The study adopted a systemic random sampling technique, using a sampling frame of intakes which has a total of 175 student population (nominal register, 2017).

The data-collecting instrument was a 28 -item semi structured interview schedule developed by the researcher. Face to face interviews were also conducted by the researcher. Each respondent was interviewed independently.

The research instrument comprised of three sections. Section a included elicited information on socio-demographic characteristics of the respondents. Section B was designed to obtain information on student's breast cancer knowledge. Section C elicited information on respondents' Breast Self -Examination altitude and practices. The instrument was pre-tested in order to assess validity and precision. After data collection, raw data was edited for 
completeness and consistency categorised and coded. EPI Info statistical package was used to analyse data. Excel spread sheet analysis was as well utilised to determine the association between variables.

\section{Research results}

The results are presented in tables and figures. A total of 50 respondents were interviewed. All the respondents were student nurses in year $2 \& 3$. Fifty-eight percent (58\%) of the respondents were from year 3 and $42 \%$ were from year 2 . The median age for year 2 students was 21 years and 23 for year 3 students. $70 \%$ of year 2 and $30 \%$ of year 3 students were married. Majority of the year 2 students (52\%) had one to five children, $2 \%$ had more than 5 children and $46 \%$ had never had child (Table 1 ).

With respect to educational attainment, $100 \%$ of year $2 \& 3$ had post-secondary education

As reflected in table 1, $19 \%$ of year 2 and $33 \%$ year 3 students were Catholics, $5 \%$ of year 2 students and $16 \%$ of year 3 belonged to United Church of Zambia and Pentecostal assemblies were $16 \%$ from year 2 and $11 \%$ were from year 3 . The rest of the respondents $60 \%$ from year 2 and $40 \%$ from year 3 belonged to other churches.

Table 1. Socio-demographic characteristics of respondents

\begin{tabular}{|l|l|l|}
\hline $\begin{array}{l}\text { Socio demographic } \\
\text { characteristics }\end{array}$ & Year 2 n=21 & Year 3 n = 29 \\
\hline Year of study & $42 \%$ & $58 \%$ \\
Median age & 21 & 23 \\
Marital Status & $70 \%$ & $30 \%$ \\
married & $46 \%$ & $69 \%$ \\
Parity & $52 \%$ & $27 \%$ \\
Never had a Child & $2 \%$ & $4 \%$ \\
$1-5$ & $100 \%$ & $100 \%$ \\
$>5$ & $0 \%$ & $0 \%$ \\
Educational Attainment & $0 \%$ & $0 \%$ \\
Post-secondary & $19 \%$ & $33 \%$ \\
Secondary & $5 \%$ & $16 \%$ \\
Primary Education & $16 \%$ & $11 \%$ \\
Religious Affiliation & $60 \%$ & $40 \%$ \\
Catholics & & \\
United Church of Zambia & \multicolumn{2}{|l}{} \\
Pentecostal assemblies & \multicolumn{2}{|l}{} \\
Others & & \\
\hline
\end{tabular}

As regards knowledge about breast cancer, $58 \%$ of year 3 students had knowledge while $82 \%$ of year 2 students had no knowledge. Significant differences in knowledge were observed between the two (P0.000). Year 3 students were more knowledgeable about breast cancer than year 2 students (Figure $1)$. 
DOI: $10.21522 /$ TIJNR.2015.03.02.Art014

ISSN: $2520-3126$

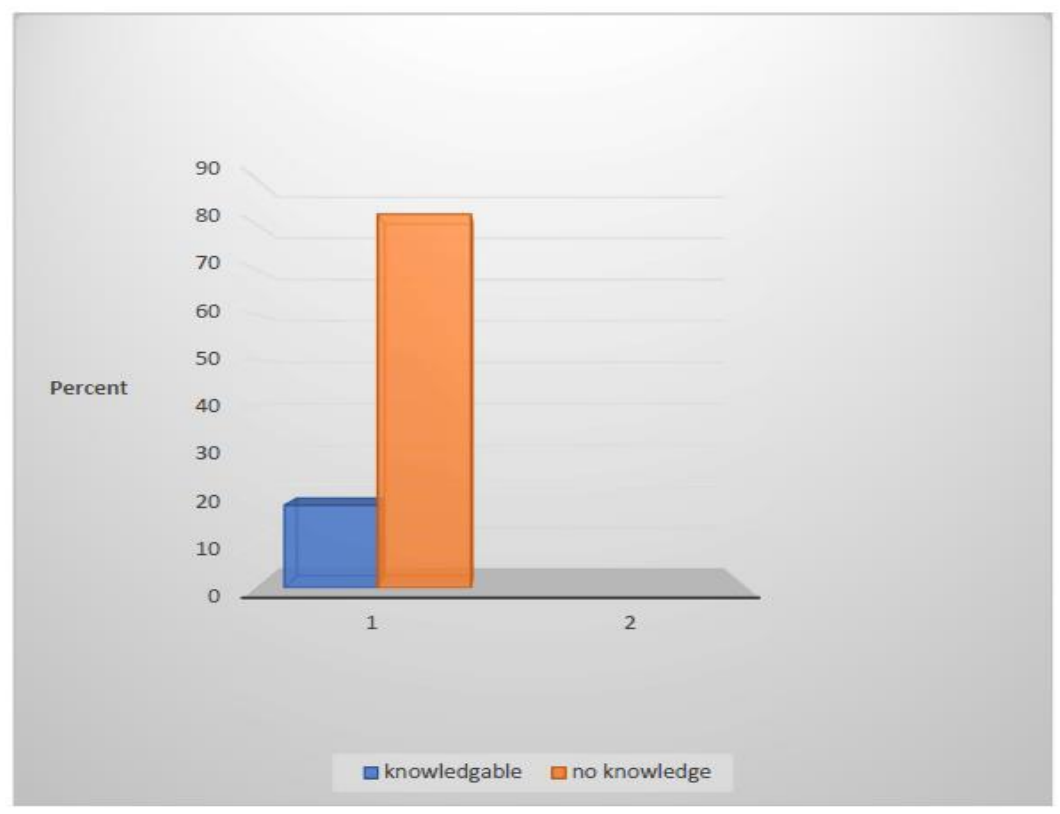

Figure 1. Breast cancer knowledge among students in year 2 and year 3 intakes

Figure 2 . Show that $95 \%$ of year 3 students and $95 \%$ of year 2 students did not practice Breast SelfExamination. No significant differences were observed in BSE practice between year 3 and year 2 students (P 0.928).

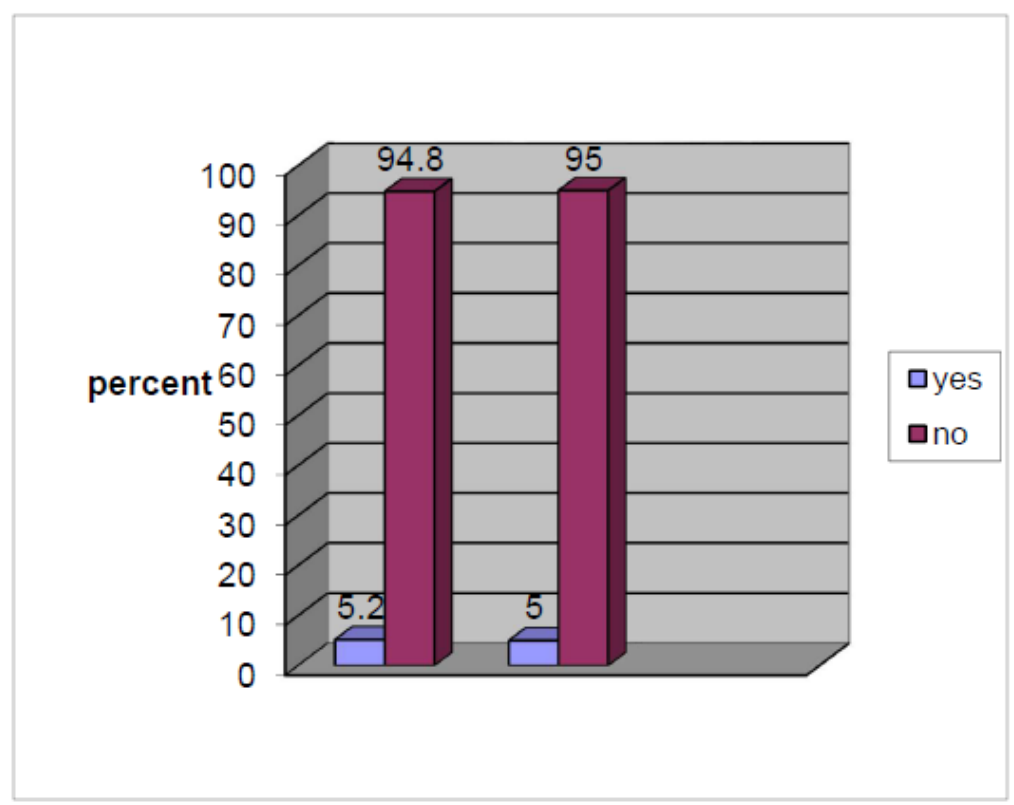

Figure 2. BSE practice among year 2 and year 3 students

The reasons given by both year 2 and year 3 students for not practicing breast self- examination were lack of knowledge on how to do the examination $\left(2^{\text {nd }}\right.$ year , $88 \%, 3^{\text {rd }}$ year $89 \%$, ) did not think it was important $\left(2^{\text {nd }}\right.$ year $7 \%, 4$ (four) $3^{\text {rd }}$ year $\%$ ), did not perceive themselves to be at risk $\left(2^{\text {nd }}\right.$ year $0 \%, 3^{\text {rd }}$ year $0 \%$ ), I forget ( $2 \%$ year $3,0 \%$ year 2 ) (Table 2 ). 
Table 2. Reasons for not practising BSE

\begin{tabular}{|l|l|l|}
\hline $\begin{array}{l}\text { Reasons for Non- } \\
\text { Practice of BSE }\end{array}$ & Year 3 n=21 & $\begin{array}{l}\text { Year } 2 \\
\mathrm{n}=29\end{array}$ \\
\hline Lack of knowledge & $89 \%$ & $88 \%$ \\
\hline $\begin{array}{l}\text { Did not think it's } \\
\text { important }\end{array}$ & $4 \%$ & $7 \%$ \\
\hline I forget & $2 \%$ & - \\
\hline
\end{tabular}

\section{Discussion of research findings}

In this study, the aspects of knowledge that were assessed included the definition, predisposing factors, signs and symptoms, treatment and prevention of breast cancer. The study revealed that both the $2^{\text {nd }}$ years and $3^{\text {rd }}$ year student's breast cancer knowledge levels were generally low. This could be attributed to lack of content in the nursing curricula as well as educational programs on breast cancer by curriculum developers and implementers and other concerned stakeholders and this has limited access to accurate information by students. In adequate knowledge on breast cancer could have led to students not practicing Breast Self- Examination (Leslie 2003; Macdonald 1999; Nzarubara 1999; Price 1992; Sadler 2001). A similar result was obtained in an American and Zambia study where women's knowledge levels about breast cancer were low (Leslie 2003, Mukupo 2006). Students need to know the dangers of breast cancer so that they can effectively pass on the knowledge and skill to mothers whose information could be communicated to women during antenatal, postnatal clinics visits and through electronic and print media. It is quite clear that education on breast cancer could promote early diagnosis of the condition and women would see the need to do breast self-examination.

The results however showed significant differences in breast cancer knowledge between year 2 and year 3 students ( $\mathrm{P}$ 0.000). Knowledge level was higher in year 3 students compared to year 2 counterparts. The differences in knowledge levels could due to easy access to information and level of training by year 3 students than their colleagues.

Many students in both year 2 and year 3 intakes did not practice breast self- examination. This could be attributed to lack of specific information about breast self- examination as a screening tool. According to Steinberger (1994) and Ko (2000), knowledge of breast cancer and provision of screening guidelines is related to high screening rates. The major reasons cited by the students for not practicing Breast Self- Examination included lack of knowledge and skill on how to perform breast selfexamination, they did not think it was important to examine themselves, and that they did not perceive themselves to be at risk. Barton (1999) and Budden (1995) also found that many women in America gave similar reasons for not practicing Breast Self-Examination. Mukupo 2006, also found similar reasons.

\section{Conclusion}

The findings showed that a large percentage of year 2 students had no knowledge about breast cancer than year 3 students. A significant difference in knowledge levels on breast cancer was observed between the two intakes. Students in year 3 intake had more knowledge on breast cancer than their counterparts in $2^{\text {nd }}$ year. Breast Self-Examination practice was poor in both intakes. They mutually did not practice Breast Self- Examination.

\section{Recommendations}

Based on the research results the following recommendations were made:

- The General nursing council of Zambia should review the content on breast cancer in the curriculum and incorporate the tutors and peer educators as master trainers on the dangers of breast cancer and breast self -examination so that they are equip student nurses that will in turn educate communities on the dangers of breast cancer and breast self- examination.

- The Government should develop a policy on breast screening. Breast Self- Examination should be recommended as the best method of screening for cancer of breast in Zambia.

- Educational programs on breast cancer and Breast Self-Examination should be conducted on electronic and print media by Ministry of Health 
DOI: $10.21522 /$ TIJNR.2015.03.02.Art014

ISSN: $2520-3126$

- The Ministry of Health and other concerned stakeholders should develop teaching manuals and other teaching aids for use by health providers so that there is consistency and uniformity in the information given to women.

- Breast cancer and breast self-examination should be incorporated in the Zambian school curricular so that girls in schools are sensitised at an early age.

- A more rigours study to be conducted on the topic in order to shed more light on the subject matter.

\section{References}

[1].Abdel-Fattah, M., et al, (2000). Breast self-examination practice and its impact on breast cancer diagnosis in Alexandria, Egypt. Eastern Mediterranean Health Journal. Volume 4. No. 2. PP 34-40.

[2].Akhtar, S.S., et al, (1993). Cancer in Libya- A Retrospective Study 1981-1985. African Journal of Medicine and Medical Sciences. Vol .22. No 1, PP 17-

[3].American Cancer Society (1999). Cancer Related Check- Ups; Atlanta G.A.

[4].Amir, H., et al, (1994). A Comparative Study of Carcinoma Of The breast in African Population; East African Journal, Volume 71. No. 4, PP 215-218

[5].Amir, J.T., et al, (1998). Breast Cancer and Risk Factors in an African Population: A Case Referent Study. East Africa Medical Journal. Volume 75. No. 5, PP 268-270.

[6].Anim, J.T., (1993). Breast cancer in Sub Sahara African Women. African Journal of Medicine and Medical Sciences. No 1. PP 5-10

[7].Attai, A.K., et al, (1997). Effects of Educational Film on Health Belief Model and Breast Self-Examination practice. Eastern Mediterranean Health Journal. Volume 3. No. 3. PP 435-443.

[8].Bailey, K., (2000). The Nurse's Role in Promoting Breast Awareness. Nursing Standards. Vol.14. No. 30. PP 34-36.

[9].Bell, R., et al, (1997). The Impact of Wellness: Guide on Hispanic Women's Well Being. Related Mediating Role of Enculturation; Health Education and Behaviour; Volume 24. No. 3. PP 326-343.

[10]. Berkow, R., (1997). The Merck Manual of Medical Information. Merck Research Laboratories. Whitehouse Station. New Jersey. PP 796, 1096-1107.

[11]. Budden, L., (1995). Young Women's Breast Self-Examination and Practice. Journal of Community Health Nursing. Vol. 12. No. 1, PP23-32.

[12]. Cancer Diseases Hospital, (2017) PIM. Report. $1^{\text {st }}$ quarter 2017, Lusaka, Zambia

[13]. Cancer Registry, (2003). Cancer Annual Report. University Teaching Hospital. Lusaka. PP 1-30 Care. Mosby Company. Chicago.

[14]. Central Stastical Office, (2002-2003). Demographic and Health Survey Report. Lusaka. PP 29-45

[15]. Central Statistical Office, (2003). Zambia 2000 Census of Population and Housing Summary Report. Lusaka. PP 28-35

[16]. Champion, V.L., (1995). Results of a Nurse-delivered intervention on Proficiency and Nodule detection with breast self-examination. Oncology Nursing Forum. Vol.22. No 5. PP 819-824.

[17]. Chee, H.L, et al., (2003). Factors Related to the Practice of BSE and Pap smear Screening among Malaysian Women Workers in the Selected Electronics Factories. BMC Women's Health. Vol. 3. PP3.

[18]. Dorsay, R.H., et al., (2001) Breast Self-Examination. Improving Competence and Frequency in a Classroom Setting. American Journal of Public Health. Vol. 78. No. 5, PP520-522

[19]. Epstein, S. S., et al (1998). The Breast Cancer Prevention Program. Macmillan, New York, 1998.

[20]. Epstein, S. S., et al (2001). Dangers and Unreliability of Mammography: Breast Examination is a Safe, Effective and Practical Alternative. International Journal of Health Sciences. vol.31 No. 3 PP 605-615

[21]. Gastrin, G., et al. (1994). Incidence and mortality from Breast cancer in the Mama program for Breast Screening in Finland, 1973-1983, No 73. pp 2168-2174.

[22]. Gotzsche, P. C. et al (2000). Is screening for breast cancer with mammography justifiable? Lancet 355: 129134.

[23]. Government Republic of Zambia, (2000). National Gender Policy Report .Lusaka. PP 38-49.

[24]. Harkness, G.A. et al (1996). Medical surgical Nursing. Total Patient

[25]. Heitkemper, L.C., (1996). Medical Surgical Nursing: Assessment and Management of Clinical Problems. Mosby Company. Chicago. PP 1548-1549. 
[26]. Hill, D. et al, (1988) Self-examination of the Breast: Is it Beneficial? Meta-Analysis of Studies Investigating BSE and the Extent of Disease in Patients with Breast Cancer. British Medical Journal. PP 271-297.

[27]. Janda, M., et al, (2000). Australian Women's Attitude towards and Knowledge of Breast self-examination. Journal of Cancer Education. Volume 15. No. 2. PP 91-94.

[28]. Janda, M., et al, (2000). Australian Women's Attitude towards and Knowledge of Breast self-examination. Journal of Cancer Education. Volume 15. No. 2. PP 91-94.

[29]. Kartz, L., et al, (1981). The Epidemiological Review of Breast Cancer in Israel. Israel Journal of Medical Sciences. Vol 19. No 9, PP 810-815.

[30]. Kartz, L., et al, (1981). The Epidemiological Review of Breast Cancer in Israel. Israel Journal of Medical Sciences. Vol 19. No 9, PP 810-815.

[31]. Knobf, T.M., (1990). Early-Stage Breast Cancer. The Options. American Journal of Nursing. PP 28-29.

[32]. Knobf, T.M., (1990). Early-Stage Breast Cancer. The Options. American Journal of Nursing. PP 28-29.

[33]. Ko, C., et al, (2000). Fillipina American Women's breast cancer knowledge, attitude and screening behaviour. BMC Public Health. Volume 3. PP 27

[34]. Ko, C., et al, (2000). Fillipina American Women's breast cancer knowledge, attitude and screening behaviour. BMC Public Health. Volume 3. PP 27

[35]. Leight, S. B., et al, (2000). The effect of structured training on breast self- examination search behaviors as measured using biomedical instrumentation. Nursing Research. Vol. 49 No 5.pp 283- 289.

[36]. Leight, S. B., et al, (2000). The effect of structured training on breast self- examination search behaviors as measured using biomedical instrumentation. Nursing Research. Vol. 49 No 5.pp 283- 289.

[37]. Leslie, N.S., et al, (2003). Knowledge, Attitude, Practice Surrounding Breast Cancer Screening in Educated Appalachian Women. Oncology Nursing Forum. Vol. 30. No. 4. PP659-667.

[38]. Leslie, N.S., et al, (2003). Knowledge, Attitude, Practice Surrounding Breast Cancer Screening in Educated Appalachian Women. Oncology Nursing Forum. Vol. 30. No. 4. PP659-667.

[39]. Lewis, S.M., et al, (1996) Medical surgical Nursing. Assessment and Management of Clinical Problems.

C.V. Mosby. Chicago.

[40]. Lewis, S.M., et al, (1996) Medical surgical Nursing. Assessment and Management of Clinical Problems.

C.V. Mosby. Chicago.

[41]. Mahajan, B., (997). Methods in Biostatstics for Medical Students and Researchers. Medical Publishers. Calcutta. PP 97-98

[42]. McDonald, P. A., et al, (1999). Perceptions and knowledge of Breast Cancer among African-American women residing in Public Housing, Ethnic Dis. Vol. 9. No 1. PP81-93.

[43]. McMahon, E., et al., (1993). Diseases. Causes and Complications. Assessment Findings. Nursing Diagnoses and Interventions. Patient Teaching and Current Therapy. Springhouse. Pennsylvania. PP 276-278.

[44]. Meissner, H.I., (1992). How Resources of Health Information Relate to Knowledge and Use of Cancer Screening Exams. Journal of Community Health. Vol. 17. No. 3, PP 153-165.

[45]. Mukupo, (2006) SBE, RURAL \& URBAN WOMEN, LUSAKA ZAMBIA.

[46]. Nzarubara, R.G., (1999). Control of breast Cancer Using Health Education. East African Journal of community Medicine. Vol. 76. No. 12, PP 661-663.

[47]. Orem, D., (1999). Nursing Concepts of Practice. Mosby Co. St. Louis.

[48]. Orzturic, M., et al, (1999). The practice of BSE among women in Gullistan District of Isparta. Eastern Journal of Medicine. Vol. 4. No. 2 PP 47-50.

[49]. Park, K., (2002). Park's Textbook of Preventive and Social Medicine. M/s Banarsidas Bhanot Publishers. Jabalpur. PP 291-292

[50]. Patistea, E., et al, (1992). Breast self-Examination: Knowledge and behaviour of Greek female health care Professionals Working in Primary Health Care Centres. Cancer Nursing. Vol. 15. No. 6. PP 415-442.

[51]. Patton, Q. M., (1990). Qualitative Evaluation and Research Methods. Sage Publication International. London.

[52]. Peragallo, N.P., et al, (1998). Breast Care among Latino Immigrant Women in the United States. Health Care for Women International. Vol. 19. PP 101-108.

[53]. Peragallo, N.P., et al, (2000). Acculturation and Breast Self-Examination among Immigrant Latin Women in the USA. International Council Review. Vol. 47. No. 1. PP 38-45. 
DOI: $10.21522 /$ TIJNR.2015.03.02.Art014

ISSN: $2520-3126$

[54]. Persson, K., et al, (1995). Breast Self-Examination among Swedish Women: A survey of Frequency, Knowledge and Attitudes. Journal of Cancer Education. Vol.10. No3. PP 163-167

[55]. Polit, D., (1995). Nursing Research. Principles and Methods. J.B. Lippincott Company. Philadelphia [56]. Polit, D., et al (1999). Nursing Research. Principles and Methods. J. B. Lippincott Company. Philadelphia. [57]. Powel, E., et al, (1987). The Diagnosis and Detection of Breast Disease. Mosby Co. Chicago. PP 71-75

[58]. Price, J.H., (1992). Urban Black Women's Perceptions of Breast Cancer and Mammography. Journal of Community Medicine. Vol. 17. No. 4, PP 191-203.

[59]. Quinn, F.M., (1997). The Principles and Practice of Nurse Education. Stanley Thornes Publishers Ltd. London.

[60]. Sadler, G.R., et al (2001). Korean Women; Breast Cancer Knowledge, Attitude and Behaviours. BMC Public Health. Vol. 1. No. 7. PP1471-2458.

[61]. Sample. (n.d.). The American Heritage ${ }^{\circledR}$ New Dictionary of Cultural Literacy, Third Edition. Retrieved June 4, 2017 from Dictionary.com website http://www.dictionary.com/browse/sample

[62]. Smeltzer, C.S., et al, (2000). Textbook of Medical Surgical Nursing. Philadelphia. Toronto. PP 1268-1268

[63]. Smigel, K. (1993). Perception of risk heightens stress of breast cancer. Journal of National. Cancer Institute. Vol. 85. No 7. PP 525- 526

[64]. Steinberger, C., (1994). Breast Self-Examination: How Nurses can influence Performance. Medical Surgical Nursing. Vol. 3. No.5.PP 367-371

[65]. Utilisation and Associated Factors. American Journal of Public Health. Vol.79. No. 11. PP1499-1501.

[66]. Van Loon, J.M., et al, (1994). Socio economic Status and Breast Cancer Incidence: A Prospective Cohort Study. International Journal of Epidemiology. Vol. 23.No 5. PP 899-905.

[67]. Virobiof, D.A., et al, (2001). Cancer Incidence in South Africa. Journal of Clinical Oncology. Vol. 19. (18 Supplement) PP 1255-1275.

[68]. Worden, J. K., et al, (1990). A community-wide program in breast self-examination. Preventive Medicine. Vol. 19. PP 254- 269.

[69]. Zapka, J.K., et al, (1989). Breast Cancer Screening by Mammography.

[70]. Zapka, J.K., et al, (1992). Changes in Mammography Use: Economic, Need and Service Factors. American Journal of Public Health. Vol. 82. No. 10, PP 1345-1355. 


\title{
Challenges Faced by Healthcare Providers in Providing Services to Key Population at Risks of HIV in Ethiopia
}

\author{
Article by Nebiyu Lera Alaro \\ Nursing, Texila American University, Guyana \\ E-mail:nebiyulera@gmail.com
}

\begin{abstract}
As one of the main goals of the Partnership Framework (PF) between the Government of Ethiopia $(G o E)$ and the U.S. Government (USG), Ethiopia has set a national target of reducing new HIV infections by $50 \%$ by the end of 2014 (National Target). Funded by the USG, the PF provides a five-year joint strategic plan (2010-2014) for cooperation to support Ethiopia's national HIV/AIDS response (PEPFAR, 2010). Ethiopia has an estimated adult prevalence of $1.5 \%$ and about a million people living with HIV/AIDS (PLWHA) (ECSA \& IFC, 2012), among countries most affected by the epidemic. The International Labor Organization (ILO) projection for 2015 indicates that as much as 8.5\% of the Ethiopian labor force loss will be due to HIV/AIDS deaths (World Learning, 2012). On the other hand, since the PF took effect, USG funding to the program has been in constant decline. Moreover, the PF does not fully take into account context and development barriers due to the prevailing social, political, economic and development policies in the country. Participation of the private sector, independent civil societies and media in the development process has been severely curtailed. Contextual factors have been seriously challenging the prevention of mother-to-child transmissions (PMTCT) efforts. Furthermore, the country lacks a comprehensive strategy to fully address the issue of most-at-risk population (MARP) as drivers of the HIV epidemic; and the HIVIAIDS response excludes Men who have sex with Men (MSM), a "significant unacknowledged" but fast growing transmission route of HIV (Tadele, 2008). Drawing from literature review and practicum experience in Ethiopia, this paper examines the feasibility of Ethiopia's National Target. The main problem in the HIVIAIDS discourse in Ethiopia appears to be behavioral change, but not lack of knowledge. In addition, contrary to the widespread public belief that homosexuality is not Ethiopian, there exists a flourishing underground male-sex trade in Addis Ababa.
\end{abstract}

\section{Acronyms}

$\begin{array}{ll}\text { AIDS } & : \text { Acquired Immune Deficiency Syndrome } \\ \text { ARC/NARC } & \text { : National AIDS Resource Center } \\ \text { ART } & : \text { Antiretroviral Therapy } \\ \text { ARV } & \text { : Antiretroviral } \\ \text { CBO } & : \text { Community Based Organization } \\ \text { CCFDRE4 } & : \text { Criminal Code of the Federal Democratic Republic of Ethiopia } 2004 \\ \text { CDC } & : \text { Centers for Disease Control and Prevention } \\ \text { CSW } & \text { : Commercial Sex Workers } \\ \text { CSAE } & : \text { Central Statistical Agency of Ethiopia } \\ \text { CSOs } & \text { : Civil Society Organizations } \\ \text { DFID } & \text { : Department for International Development (UK) } \\ \text { EDHS } & : \text { Ethiopia Demographic and Health Survey } \\ \text { EIFDAA } & : \text { Ethiopian Interfaith Forum for Development Dialogue and Action } \\ \text { EPRDF } & : \text { Ethiopian People's Revolutionary Democratic Front (The Ruling }\end{array}$


DOI: $10.21522 /$ TIJNR.2015.03.02.Art015

ISSN: $2520-3126$

\begin{tabular}{|c|c|}
\hline & Party) \\
\hline FDRE & : Federal Democratic Republic of Ethiopia \\
\hline FGM & : Female Genital Mutilation \\
\hline FHAPCO & : Federal HIV/AIDS Prevention and Control Office (Ethiopia) \\
\hline FMOH & : Federal Ministry of Health (Ethiopia) \\
\hline FSW & : Female Sex Workers \\
\hline GAMET & : Global HIV/AIDS M\&E Team (World Bank) \\
\hline GDP & : Gross Domestic Product \\
\hline Global Fund & : Global Fund to Fight AIDS, Tuberculosis and Malaria \\
\hline GNP & : Gross National Product \\
\hline GoE & : Government of Ethiopia \\
\hline GTP & : Growth and Transformation Plan (Ethiopia) \\
\hline HCT & : HIV Counseling and Testing \\
\hline $\mathrm{HCT}$ & \\
\hline Guideline & : FHAPCO Guidelines for HIV Counseling and Testing \\
\hline HDI & : UN Human Development Index \\
\hline HEP & : Health Extension Program \\
\hline HIV & : Human Immunodeficiency Virus \\
\hline HIV-EMR & : HIV Electronic Medical Record \\
\hline HRW & : Human Rights Watch \\
\hline IDA & : International Development Program (World Bank) \\
\hline ILO & : International Labor Organization \\
\hline IRA & : Informal Rapid Assessment \\
\hline KII & : Key Informant Interview \\
\hline LGBT & : Lesbian, Gay, Bisexual and Transgendered \\
\hline MARP & : Most-at-Risk Population \\
\hline MDGs & : Millennium Development Goals \\
\hline MHS & : Mandatory HIV Screening \\
\hline MSM & : Men who have sex with Men \\
\hline MSP & : Multiple Sexual Partner \\
\hline MTCT & : Mother-to-Child Transmission \\
\hline MULU II & : MULU II Workplace HIV Prevention Program (Ethiopia) \\
\hline MULU & \\
\hline Prevention & : MULU Prevention Program for At-risk Populations (Ethiopia) \\
\hline NAC & : National AIDS Council (Ethiopia) \\
\hline & Ethiopia's National Target of Reducing New HIV Infections by $50 \%$ \\
\hline & National Target by the end of 2014 \\
\hline $\mathrm{NEP}+$ & : Network of Networks of HIV Positives in Ethiopia \\
\hline NGOs & : Nongovernmental Organizations \\
\hline ODA & : Official Development Assistance (OECD) \\
\hline OECD & : Organization for Economic Co-operation and Development \\
\hline OVC & : Orphans and Vulnerable Children \\
\hline PEPFAR & : U.S. President's Emergency Plan For AIDS Relief \\
\hline PFs & : Partnership Frameworks \\
\hline PITC & : Provider-initiated HIV Testing and Counseling \\
\hline PLWHA & : People Living with HIV/AIDS \\
\hline
\end{tabular}




$\begin{array}{ll}\text { PMTCT } & \text { : Prevention of Mother-to-Child Transmission } \\ \text { PSI } & \text { : Population Services International } \\ & \text { : Strategic Plan for Intensifying Multisectoral HIV/AIDS Response } \\ \text { in Ethiopia I (2004-2008) } & \text { : Strategic Plan for Intensifying Multisectoral HIV/AIDS Response } \\ & \text { in Ethiopia II (2010/11 - 2014/15) } \\ \text { SPM II } & : \text { Sexually Transmitted Infections } \\ \text { STI } & : \text { Joint United Nations Programme on HIV/AIDS } \\ \text { UNAIDS } & : \text { UN Development Assistance Framework in Ethiopia } \\ \text { UNDAF } & : \text { United Nations Population Fund } \\ \text { UNFPA } & : \text { United States Agency for International Development } \\ \text { USAID } & : \text { United States Government } \\ \text { USG } & : \text { Client-initiated, or Voluntary Counseling and Testing } \\ \text { VCT } & : \text { World Health Organization }\end{array}$

\section{Introduction and background}

This paper examines GoE's response to the HIV/AIDS threat, and the feasibility of the National Target. Moreover, the paper looks into existing and emerging development challenges to Ethiopia's national HIV/AIDS response, and explores the following questions:

1. What are the challenges for the GoE to incorporate the emerging and highly vulnerable MSM community into the national HIV/AIDS response?

2. What are the factors that might help GoE to succeed in meeting the National Target?

3. How is the GoE planning to promote host country ownership in terms of the HIV/AIDS response?

In order to answer the above research questions, I examined historical, social, and prevailing political and development challenges of Ethiopia. The next four sections provide an overview of country context and background of HIV/AIDS in Ethiopia. Drawing from primary and secondary literature review including the assessment of GoE HIV/AIDS publications and legal documents, PRs and donor profiles, and practicum experience in Ethiopia, subsequent sections investigate responses to the HIV/AIDS threat, and describe the ongoing challenges to the sustainability of the national HIV/AIDS response.

\section{Country overview}

Ethiopia, one of the world's oldest civilizations and home to ancient orthodox Christian rites and traditions, is the second-most populous country in sub-Saharan Africa. Recent CIA estimates put Ethiopia's population at over 90 million. Landlocked in the Horn of Africa, Ethiopia shares a border with the Sudan, Eritrea, Djibouti, Somalia, Kenya and South Sudan. With a total surface area of approximately 1.1 million square kilometers, an area slightly less than twice the size of the U.S. state of Texas, Ethiopia's topography ranges from 4,533 meter peak above sea level to a low land of 125 meters below sea level (CIA, 2013).

Although surveillance indicates a steady decline in HIV prevalence in Ethiopia, there are still close to a million PLWHA, one of the highest to care for and treat in East Africa, placing substantial demand on already strained resources. HIV/AIDS is also characterized as a mixed epidemic across geographic areas and population groups in the country. Transmission is primarily driven by MARP, and small towns close to large-scale development zones are considered hot spots, forming a bridge for the extension of new infections into rural areas. According to the 2011 Ethiopia Demographic and Health Survey (EDHS), the total HIV prevalence in the country is 1.5 with marked difference along gender lines: $1.9 \%$ for women ${ }^{2}$ and $1.0 \%$ for men, and an urban prevalence of 4.2 and rural 0.6 (0.8 for men and 0.5 for women) (ECSA \& IFC, 2012, p. 13). HIV prevalence also varies by region; for example, in Gambela region HIV prevalence is $6.5 \%$, compared with $0.9 \%$ in the SNNP region (ECSA \& IFC, 2012, p. 13). Nonetheless, 
DOI: $10.21522 / \mathrm{TIJNR} .2015 .03 .02 . A r t 015$

ISSN: $2520-3126$

consistent with the reports, knowledge of HIV/AIDS among the population has progressively increased since 2004.

\section{Political context}

For much of its history, Ethiopia was ruled by a monarchy in a centralized system of government. The current ruling party, the Ethiopian People's Revolutionary Democratic Front (EPRDF) came to power in 1991 overthrowing the brutal Communist regime that deposed the last Emperor in 1974. Since taking power, the EPRDF has led an ambitious political and economic reform, and undertook a peaceful transition of power following the death of Prime Minister Meles Zenawi.

On the other hand, after the disputed 2005 election wherein hundreds of people were killed, much democratic ground has been lost; opposition groups were divided and crushed; and the size and control of the ruling party increased immensely (USAID, 2012, p. 8). In fact, it was evident from the 2010 Parliamentary election (EPRDF "won" $99.6 \%$ of the seats) that the political landscape in Ethiopia remains uneven.

\section{Development challenges}

Ethiopia is faced with plethora of development challenges including: sustaining the progress made in recent years toward the MDGs, addressing the causes of poverty among its population, sustaining the large scale donor support, using aid effectively, improving governance and empowering local authorities, and for the government to become more accountable to its citizens (World Bank, 2013a). According to USAID Ethiopia, ten to fifteen percent of the Ethiopian population remains chronically food insecure, $82 \%$ dependent on subsistence agriculture, and the country has one of Africa's highest rural and overall population growth rates $(2012$, p. 3$)$.

\section{HIV/AIDS background in ethiopia}

HIV/AIDS remains one of the key development challenges in Ethiopia. Analysis by the World Health Organization (WHO) showed that HIV/AIDS has led to a seven-year loss in life expectancy, close to a million orphans, and the loss of productivity and income at workplace with severe effects on households and communities across Ethiopia (WHO, 2005, p. 2).

The first evidence of HIV infection in Ethiopia was documented in 1984, and the first two AIDS cases were reported to the Ministry of Health (MOH) in 1986 (FT \& Zewdie, 1998, p. 139-145). HIV-1 subtype $\mathrm{C}$, which mainly spreads through unprotected heterosexual intercourse, remains the predominant strain in the country (FHAPCO, 2012, p. 12).

Since the mid-1980s, HIV has been spreading in both urban and rural areas of Ethiopia. For instance, in 2003, Ethiopia had an estimated 950,000 to 2.3 million PLWHA, among the highest number in one country in the world (WHO, 2005, p. 1). Consequently, by the end of 2003, the national prevalence was $4.4 \%$, and an estimated 120, 000 people died and 720, 000 children younger than 17 had been orphaned by the epidemic (WHO, 2005, p. 1).

\section{Literature, documents and donor profile review}

\section{GoE response to the HIV/AIDS epidemic}

According to a joint GoE and World Bank analysis: Since the outbreak of the epidemic in 1985 into the late 1990s, HIV/AIDS intervention in Ethiopia was inadequate in scale; it was largely ineffective in implementation; it lacked sufficient stakeholder involvement in planning and implementation particularly at regional and community level; it was poorly coordinated across sectors and among service providers; and it received relatively low priority within government, society in general, and the international community, with a resultant low level of allocated financial and human resources. (FHAPCO \& GAMET, 2008, p. 77).

However, since the late 1990s, the response to the epidemic has been a coordinated Collective effort of 
GoE, multilateral and bilateral donors, national and international non-Governmental organizations (NGOs). In 1998, GoE adopted HIV/AIDS policy that outlined Strategies for HIV prevention, care and support. In 2000, the National AIDS Council (NAC) was established to oversee the implementation of federal and regional HIV/AIDS responses.

Recognizing the seriousness of the epidemic and its multi-faceted impact, NAC declared HIV/AIDS a national emergency. In 2001, a Strategic Framework for the National Response to HIV/AIDS was adopted, and priority intervention areas such as condom distribution, Voluntary Counseling and Testing (VCT), STI and PMTCT were identified. The framework was Multispectral and engaged public and private sectors, local and international NGOs, and civil Society, faith and community-based organizations. In 2002, the Federal HIV/AIDS Prevention and Control Office (FHAPCO) was established with mandates to coordinate and lead implementation of the national HIV/AIDS policy.

While the federal HAPCO coordinated national and regional level responses to the HIV/AIDS threat, regional HAPCOs galvanized interventions at zonal, district and neighborhood levels. Making PMTCT, treatment and care strategic priorities, the federal HAPCO established HIV/AIDS resource centers and introduced the health extension program (HEP), a community-based approach for addressing health and HIV/AIDS issues. HEPs train female health extension workers and assign them at rural health posts to provide outreach services to households. For instance, since the implementation of SPM I (between 2004 - 2008), the deployment of over 30,000 health extension workers in rural posts across the country helped start public conversation about HIV/AIDS, expanded HIV/AIDS service facilities, increased utilization of HIV/AIDS services, and created social transformation. In fact, evaluation of the SPM I implementation has shown remarkable progress in expanding access to HIV services and scaling-up response capacity. Key to the success of the scale-up was the building of leadership capacity in the health sector, involvement of civil societies and the community, and engagement of bilateral and multilateral partners in the process of planning, implementation, monitoring and evaluation.

As a result of the implementation of multispectral approach to HIV/AIDS response, between 2001 and 2006, GoE claims the following successes:

- An increased level of awareness and positive trends in behavioral change

- An increased demand for VCT

- An increasing trend in condom distribution and utilization

- Integration and expansion of VCT

- Initiation of PMTCT and AVR services

- Positive trends in openness, and reduction of stigma and discrimination

- Encouraging trends in involvement of PLWHA in the response

\section{The international community response}

Ethiopia has been one of the major international aid recipient countries in the world in recent years. For instance, in 2006, net Official Development Assistance (ODA) to Ethiopia amounted to US\$1.94 billion, the 7th largest among development aid receiving developing countries (Alemu, 2009).

GoE's major development partners for the national HIV/AIDS response include the Global Fund to Fight AIDS, Tuberculosis and Malaria (Global Fund), Presidential Emergency Programme for AIDS Relief (PEPFAR), the World Bank (up to 2011), UN Development Assistance Framework (UNDAF) and the HIV Governance Pooled Fund. The national HIV/AIDS response aims at attaining universal access to HIV prevention, care and treatment; and improving the health system in Ethiopia (FHAPCO, 2012, p. 4447).

\section{The global fund}

The Global Fund is the major source of funds for the national multispectral HIV/AIDS response in Ethiopia. The Global Fund resources are channeled through the Federal Ministry of Health (FMOH), FHAPCO, Network of Networks of HIV Positives in Ethiopia (NEP+) and Ethiopian Interfaith Forum for 
DOI: $10.21522 / \mathrm{TIJNR} .2015 .03 .02 . A r t 015$

ISSN: $2520-3126$

Development Dialogue and Action (EIFDAA). From 2003-2013, Ethiopia has received US\$803, 728,322 from Global Fund; and 270,000 people are on ART as a result of the support (Global Fund, 2013). U.S. is the largest single contributor of the Global Fund, and Ethiopia received more funding from Global Fund than any other country in the last decade (Glassman, 2012). However, PEPFAR's contribution to Global Fund that peaked in 2010 has decreased by 50\% in 2012; and a further funding cut is likely given the recent trend of decreasing funds and the challenging budget environment in the U.S. (Glassman, 2012).

\section{PEPFAR}

USG provides extensive support for the national HIV/AIDS response. Funds are mainly channeled through PEPFAR, the US Agency for International Development (USAID), and the Centres for Disease Control and Prevention (CDC).

PEPFAR is a USG initiative to help save the lives of those affected by HIV/AIDS, and the largest component of the President's Global Health Initiative. PEPFAR - Ethiopia is one of the largest recipients of PEPFAR, and its projects are implemented through USAID, CDC, the Department of Defense, Peace Corps and the Department of State Refugee Bureau. From the fiscal years 2004 - 2011, Ethiopia has received close to US\$1.8 billion in PEPFAR funding to fight HIV/AIDS (PEPFAR, 2010).

- 237,400 individuals receiving ART

- $1,156,900$ HIV-positive individuals received care and support (including TB/HIV)

- 493,200 OVCs received support

- 815,100 pregnant women with known HIV status received services

- 10,300 HIV-positive pregnant women received ART for PMTCT

- 5,580,100 individuals received HCT services

- 3,174 estimated infant HIV infections averted

Due to changing HIV/AIDS epidemiological trends in Ethiopia (e.g., the lowering of prevalence) and improved efficiency, in 2013, PEPFAR Ethiopia experienced 79\% reduction.

\section{USAID}

USAID Ethiopia provides technical and financial support for HIV prevention programs with particular focus on MARPs, PMTCT and Workplace HIV intervention. It also supports care and ART programs for PLWHA and OVCs, health extension programs, and invests on capacity building to buttress the shift to host country ownership. USAID Ethiopia works to improve the private sector engagement in HCT, ART and TB/HIV services provision as well (USAID, 2013c).

\section{The CDC global aids program}

The CDC Global AIDS Program provides extensive technical expertise in areas of blood safety, antiretroviral treatment services, laboratory infrastructure, and providing strategic information. CDC works in cooperation with 23 other implementing partners including U.S. based universities (e.g., Universities of Washington, Columbia and Johns Hopkins), and other local and international partners. For instance, in partnership with the Ethiopian Health and Employees of large scale development zones, e.g., commercial farms with 500 or more employees.

\section{The world bank}

The World Bank has provided US\$30 million from 2007 - 2011 to scale-up HIV preventive services for the youth and MARP, to sustain access to care and support for PLHIV and OVCs, and to strengthen institutional capacity across sectoral ministries. The World Bank project was closed in September 2011 (FHAPCO, 2012, p. 44).

\section{UNDAF}

UN agencies (such as WHO, UNICEF, UNAIDS, UNDP) and GoE jointly formulated UNDAF as a 
strategic planning instrument to guide and appropriate contributions for Ethiopia. From January 2007 December 2011, UNDAF programs supported humanitarian responses, recovery and food security, basic social services and human resources, HIV/AIDS, good governance, and enhanced economic growth. In 2010/11, UNDAF invested US\$30 million on HIV/AIDS (FHAPCO, 2012, p. 44-45).

\section{HIV governance pooled fund}

The HIV Governance Pooled Fund was established in 2008 by a number of international organizations including the Irish Aid, Italian Cooperation, United Nations Population Fund (UNFPA), and the UK Department for International Development (DFID) (FHAPCO, 2012, p. 46-47). The fund focuses on improving governance of the HIV/AIDS response through ensuring accountability, improving capacity and promoting responsiveness among implementing institutions such as the FHAPCO. Between 2008 2010, DFID contributed UK£2 million to the pooled fund (DFID, 2012). DFID is not part of the Pooled Fund anymore.

\section{The origin of the national target}

On October 27, 2010, the GoE-USG Partnership Framework was signed for HIV/AIDS Prevention and Control in Ethiopia. The framework illustrates the leadership of GoE in addressing the HIV epidemic that is mainly driven by MARP.

\section{Challenges to the national target}

\section{HCT shortfalls}

Studies have shown that lack of infrastructure including comprehensive HIV counseling and testing guidelines and information and communication systems, is considered a barrier to successful HIV/AIDS response and treatment. According to the FHAPCO Guidelines for HIV Counseling and Testing (HCT Guideline), there are three types of HIV testing in Ethiopia.

\section{The PMTCT challenge}

MTCT is one of the two major routes of HIV transmission in Ethiopia. According to a qualitative study published in June 2012, MTCT of HIV accounts for more than $90 \%$ of pediatrics AIDS in Ethiopia (Adedimeji et al., 2012, p. 2). Despite marked improvements in HIV/AIDS service delivery and implementation of PMTCT services, the number of pregnant women accessing the services remains very low. For example, since the goal of universal access was established in 2007, in one southern region, less than 7,000 HIV positive pregnant women received ART, representing about 19\% of the annual targets; and at national level, only $8 \%$ of eligible HIV positive pregnant women were on ART in 2012 (Adedimeji et al., 2012, p. 2,4).

\section{MARP as drivers of the HIV epidemic}

HAPCO defines MARP as “... a group within a community with an elevated risk for HIV, often because group members engage in some form of high risk [sexual] behaviour; in some cases the behaviors or HIV serostatus of their sex partner may place them at risk" $(2012$, p. 14). MARP include female sex workers (FSWs), young girls engaged in transactional and cross- generational sex, uniformed forces, long distance drivers, discordant couples (one partner is infected and the other is not), refugees, and migrant laborers or cross-border and mobile populations. Recent studies indicate that MSM in Ethiopia are fast emerging as MARP (Morris \& Brundage, 2012, p. 4; Tadele, 2010; Gebreyesus \& Mariam, 2009; Tadele, 2008).

\section{Country ownership assessment of the HIV/AIDS response}

Foreign aid has played a pivotal role in Ethiopia's development effort in the last few decades. According to Getnet Alemu, following a regime change in 1991 and with the implementation of World 
DOI: $10.21522 / \mathrm{TIJNR} .2015 .03 .02 . A r t 015$

ISSN: $2520-3126$

Bank's structural adjustment program in 1992/93 in particular, Ethiopia received a significant amount of foreign aid (2009).

Ethiopia's HIV/AIDS response is mostly donor-assisted. For instance, in 2004/05, from the estimated US\$ 208.7 million needed to support the scaling-up of ART to reach the treatment target of 100000 by the end of 2005, Ethiopia contributed only $21 \%$. The remaining $79 \%$ was covered by foreign funding (WHO, 2005). Similarly, in 2007/08, according to National Health

Accounts Survey, Ethiopia's national HIV/AIDS expenditure was US\$248,000,114, accounting for more than $20 \%$ of the total health sector spending (the largest spending on a specific disease in the country). While $84 \%$ of the total expenditure came from external sources, GoE contributed

$11 \%$; citizen's out of pocket expenditures for HIV diagnosis treatment and care accounted for 3.5\%; and other sources such as the private sector and local NGOs accounted for $1 \%$ of the total expenditure (FHAPCO, 2012; Glassman, 2012).

\section{Impact of the denial, stigmatization and criminalization of homosexuality}

In this paper, I use the phrase MSM and homosexuality interchangeably. In some cultures where the society strongly promotes marriage, MSM may not regard themselves as "homosexual" or "bisexual," and could be married to a woman, so that they might avoid living under cloud of suspicion (Tadele, 2008, p. 1).

The Ethiopian public at large still holds the myth that homosexuality is alien to the country. Moreover, homosexuality is not only considered a sin but also a criminal offense. The perception of homosexuality both as a criminal offence and sin might have stemmed from the fact that state and religion in Ethiopia have always been inseparable from the monarchical dynasties of the last two thousand years to the current government. For instance, Article 629 and 630 of the Criminal Code of Ethiopia (as amended after 48 years in 2005), prohibit:

"Homosexual Acts" between same-sexes with a penalty of one year to ten years' "simple imprisonment." The general aggravation to the crime include taking unfair advantage of the material or mental distress of another or of the authority one exercises over another by virtue of one's position; and when the offender "makes a profession of such activities

\section{Methodology}

To examine the national HIV/AIDS response, and gain further insight into HIV transmission routes in Ethiopia, I studied various GoE HIV/AIDS publications and bilateral PF documents, donor profiles and carried out extensive literature review that is captured in various sections of this paper.

Moreover, during my practicum in Ethiopia, the MULU II team designed an informal rapid assessment (IRA) to collect information on health, HIV risks and behaviors, and HIV services provided at MULU worksites ${ }^{4}$. I took no part in designing the IRA. The IRA was divided into three parts: Key Informant Interview (KII): 19 semi-structured qualitative interview questionnaires, designed to collect HIV/AIDS related information and challenges from worksite management, and regional and zonal HAPCO personnel Quantitative IRA: 72 interview questionnaires for worksite employees including daily-laborers, technical and support staff

C. Biomedical assessment (solely carried out by PSI personnel assessment used semi-structured KII guides to explore the overall situation of health, HIV risk factors and behaviors within and around worksites. Five key informants were purposely selected and interviewed from each worksite using the semi-structured interview guide.

The World Learning Ethiopia Monitoring and Evaluation department did the initial analysis. For the purposes of this paper, I summarized the findings as follows:

- In general, HIV/AIDS knowledge appears to be universal in the country.

- Economic depravity (e.g., low wage), gender inequality and low literacy primarily drive women daily-laborers into sex for extra income. 
- Alcohol and khat (a mildly narcotic plant) abuse among the youth, crowded living space in camps, nature of farm work (men and women working side by side for long hours in bushy areas) and nature of factory work (e.g., late night shifts) made women vulnerable to sex abuse and unprotected sex.

- The presence of multiple large-scale development projects, and institutions such as federal prison, military camp and tourist sites around towns and communities attract large number of mobile labor force, visitors, bars, commercial sex workers (CSW) thereby increasing vulnerability to HIV/AIDS.

- The misconception that women working in leather factories could be infertile made unprotected sex inevitable to young women (the society highly values family life).

- HIV/AIDS related light duty assignments, and frequent absenteeism and sick leaves have led to a reduced productivity, and incurred large medical bills on companies.

- The most mentioned at-risk population were female daily-laborers.

In terms of HIV/AIDS prevention and awareness activities, not much has been done in the last 12 months preceding the IRA (some respondents associated it with availability of ART.

\section{Conclusion and recommendations}

\section{Conclusion}

Coordinated and targeted HIV Prevention strategies such as the MULU HIV Prevention, certainly contribute to the success of the National Target. The MULU HIV Prevention initiative uses a collaborative approach and engages citizens, the private sector, government agencies and international development organizations to tackle the epidemic. On the other hand, although MTCT is the second major transmission route of HIV in Ethiopia, low PMTCT coverage has been a consistent challenge for the government. GoE needs to bring aboard grass-roots CBOs, CSOs and the private sector to untangle contextual and structural matters that hamper the PMTCT efforts. Yet, the new CSO and "anti-terror" legislations render weak support for the roles played by independent CSOs and media. Moreover, ongoing and drastic funding cuts by the Global Fund and PEPFAR threaten the success of the national HIV/AIDS response and the feasibility of the National Target.

Contrary to the widespread public belief that homosexuality is not Ethiopian, scholarship indicates that not only the practice of homosexuality did exist in the country but also a flourishing underground malesex trade. This, in fact, warrants attention for the prevention of HIV/AIDS among the MSM and the general public. The main problem, in the HIV/AIDS discourse in Ethiopia appears to be not a lack of knowledge about HIV, but a lack of accountability and willingness among citizens in acting on what they know. Conversely, among the MSM community, a lack of knowledge and misperceptions about HIV transmissions appear to be the case. In general, there is persisting misconception among the MSM community that sex between men is less risky than sex between a man and a woman. This has alarming implications because the reverse is true when unprotected sex is involved. Though it is evident that HIV/AIDS knowledge by itself is not enough to bring about behavioral change among the population, interventions aimed at preventing the spread of HIV from the general public could benefit from an approach that addresses the MSM community. In addition, even though legal and societal resistances further complicate the HIV prevention efforts among the MSM, considering the scale of the practice and vulnerability of the MSM, discussion on the issue is long overdue.

\section{Recommendations}

- The GoE needs to ease legal and funding restrictions on independent CSOs and the media, create an enabling environment for private sector investment and research, and encourage and reward innovative approaches that help educate and address the issue of lack of accountability and behavioral change among citizens.

- To examine the relationship between GoE and independent CSOs, I used Coston's model and 
DOI: $10.21522 / \mathrm{TIJNR} .2015 .03 .02 . A r t 015$

ISSN: $2520-3126$

typology of government-NGO partnership framework (1998). In fact, the relation between $\mathrm{CSOs/NGOs}$ and GoE is both repressive and of rivalry. It is repressive because the operating environment for independent CSOs and media in the country is very restrictive; and it is rivalry and obstructive because GoE sought to control independent CSOs and media through. Stringent regulations. This sore relationship must be changed to competitive one, where both GoE and CSOs can be attentive to the HIV/AIDS threat, and focus on ownership of the development process (Coston, 1998, p. 358-382).

- Expand the operational scope of the Global Fund, PEPFAR, USAID and HIV Governance Pooled Fund and other NGOs to work directly with the private sector, CSOs, and grass-roots and community based organizations.

- As an agency of social justice, GoE should outlaw hate crimes, discriminatory healthcare practices, and solicit citizens' participation in designing MARP, PMTCT and MSM targeted intervention plans to contain the HIV epidemic.

\section{Acknowledgment}

Many thanks to the World Learning MULU HIV Prevention team for their care, friendship and generosity in Ethiopia, and to Alemayehu Kassaye and Daniel Damtew for the help with housing, sharing literature and all the good times in Addis Ababa.

\section{References}

[1].Adedimeji, A., Abboud, N., Merdekios, B., \& Shiferaw, M. (2012). A Qualitative Study of Barriers to Effectiveness of Interventions to Prevent Mother-to-Child Transmission of HIV in Arba Minch, Ethiopia. International Journal of Population Research, 2012, 7. Retrieved July 20, 2013, from doi:10.1155/2012/532154

[2].Aderaw, M. (2012, August). Perspectives on Life and Health: A qualitative study among same-sex attracted men in Addis Ababa, Ethiopia. Retrieved July 31, 2013, from

https://www.duo.uio.no/bitstream/handle/10852/34244/Mekonnen.pdf?sequence=1

[3].Alemu, G. (2009). A Case Study of Aid Effectiveness in Ethiopia. The Brookings Institution. Retrieved July 18, 2013, from http://www.brookings.edu/research/papers/2009/04/ethiopia-aid-alemu CIA. (2013, July). The World Factbook: Ethiopia. Central Intelligence Agency. Retrieved July 27, 2013, from

https://www.cia.gov/library/publications/the-world-factbook/geos/et.html

[4].Coston, J. M. (1998). A Model and Typology of Government-NGO Relationships. Nonprofit and Voluntary Sector Quarterly, 27(3), 358-382.

[5].DFID. (2012). HIV/AIDS Governance Pooled Fund: Ethiopia. UK Aid. Retrieved July 29, 2013, from http://projects.dfid.gov.uk/project.aspx?Project=200202

[6].ECSA, \& IFC. (2012). 2011 Ethiopia Demographic and Health Survey: Key Findings. Retrieved August 8, 2013, from http://www.measuredhs.com/pubs/pdf/SR191/SR191.pdf

[7].FDRE. The Criminal Code of the Federal Democratic Republic of Ethiopia 2004 (2005). Retrieved July 10, 2013, from http://www.ilo.org/dyn/natlex/docs/ELECTRONIC/70993/75092/F1429731028/ETH709 93.pdf

[8].FHAPCO. (2004, December). Strategic Plan for Intensifying Multisectoral HIV/AIDS Response in Ethiopia I (2004 - 2008). FMOH. Retrieved August 7, 2013, from

http://www.moh.gov.et/English/Resources/Documents/HIVStrategicPlan.pdf

[9].FHAPCO. (2007a). Guidelines for HIV Counseling and Testing in Ethiopia. FMOH. Retrieved Augusts 7, 2013, from

http://www.ilo.org/wcmsp5/groups/public/ed_protect/protrav/ilo_aids/documents/legaldocument/wcms_125384.pdf [10]. FHAPCO. (2007b). Comprehensive HIV Counseling and Testing: Intervention Protocol (Components, Tasks and Scripts).

[11]. FHAPCO. (2010, February). Strategic Plan for Intensifying Multisectoral HIV/AIDS Response in Ethiopia II (2010/11 - 2014/15). FMOH. Retrieved August 7, 2013, from

http://www.ilo.org/wcmsp5/groups/public/ed_protect/protrav/ilo_aids/documents/legaldocument/wcms_175221.pdf 
Texila International Journal of Nursing Volume 3, Issue 2, Dec 2017

[12]. FHAPCO. (2012). Ethiopia: Country Progress Report on HIV/AIDS Response, 2012. Federal Democratic Republic of Ethiopia. Retrieved May 7, 2013, from

http://www.unaids.org/en/dataanalysis/knowyourresponse/countryprogressreports/2012countries/GAP\%20Report\% 202012.pdf

[13]. FHAPCO, \& GAMET. (2008). HIV/AIDS in Ethiopia - An Epidemiological Synthesis. Retrieved July 20, 2013, from

http://siteresources.worldbank.org/INTHIVAIDS/Resources/375798-1103037153392/EthiopiaSynthesisFinal.pdf

[14]. FT, L., \& Zewdie, A. S. (1998). Acquired Immunodeficiency Syndrome: Seven Cases in an Addis Ababa Hospital. Ethiopian Medical Journal, 3, 139 - 145. 


\title{
Perception of Patients about Cardiovascular Disease (CVD) and Effect of Communication by Physician and the Assisting Registered Nurse to Enhance Assessment of Risk and Bridge a Gap of Accurate Perception of their Risk of CVD
}

\author{
Article by Anette Marina Rodrigues \\ Nursing, Texila American University, India \\ E-mail: arodrigues@texilaconnect.com
}

\begin{abstract}
This paper validates the level of perception of patients about Cardiovascular Disease (CVD) and effect of communication by Physician and the assisting Registered Nurse to enhance risk assessment and bridge a gap of accurate perception of their risk of CVD.

Design and Procedure-A Non-experimental Descriptive study of patients visit to Out Patient Department for Physician Consultation. Non- Random selection of patients with complaints of chest pain visit from October 2016 to March 2017 over a period of 6 months. Assessment of Vital Parameters of 60 patients, Male-57 and Female 3, within age group of 30 to 40 years and ECG graphs readings were done for all. Information is collected from Health Information System Portal.

Result-Communication and providing positive thought on seriousness, to prevent CVD over the future years, among 60 patients with complaints of chest pain was a challenging aspect. $(n=15)$ were newly diagnosed with Hypertension, $(n=10)$ were follow up patients with Hypertension and Diabetes Mellitus), and $(n=25)$ were referred to Cardiologist with appointment fixed for further management and $(n=10)$ ECG was normal significant of gastric pain.

The Physician did initial assessment and significant symptoms on history of illness on all 60 patients. $(n=44)$ were advised on appropriate diet and reduction of weight by balanced diet and exercise. $(n=30)$ were advised on follow up among them $(n=25)$ had visited the physician as follow-up. $(n=10)$ Obese were referred to dietician with appointment fixed, and assisting nurse gave advice to $(n=50)$.

Conclusion-Patient's perception on CVD suggests $(n=50)$ were ignorant about risk of CVD and $(n=10)$ had known about risk of CVD. The trustful patient relation and communication by the treating Physician and health education by Registered Nurse has direct and positive effect on outcome of the research. Patients were enthusiastic to gain more knowledge on Modifiable risk factors. The attitude and behavior of patients were significant and positive with revisit and follow up visits.
\end{abstract}

Keywords: Perception, Cardiovascular Disease, Communication, Health Information System, Health education, follow up visit.

\section{Introduction}

\section{Purposes}

1) Identify patient's perception of cardiovascular risk.

2) Effective communication by treating Physician and Registered Nurse to bridge a gap.

3) Positive outcome of changing Modifiable Risk factors.

\section{Problem}

Cardiovascular Disease is the leading cause of death and disability worldwide. $80 \%$ of Acute Myocardial Infarction (Ref1) can be attributed to just five Modifiable Risk factors like Smoking, Dyslipidemia, Hypertension, Diabetes Mellitus and Obesity which are also implicated in the increased risk of Stroke. 
DOI: $10.21522 / \mathrm{TIJNR} .2015 .03 .02 . A r t 016$

ISSN: $2520-3126$

\section{Existing solution}

Once the risk has been assessed treatment options are established. Statin Therapy, BP lowering medications, Antiplatelet Medications, Smoking Cessation and Diet and Exercise. Mass media and Mobile apps give lot of exercise schedule plans, diet modification and weight loss programs. But with one to one interaction with the General Practitioner or Physician will help the patient to clear the negative perceptions and change existing Modifiable Risk factors.

\section{Achievements}

Patient's perception of Cardiovascular risk shows their attitude and behavior is changed with the details in the figures of patients revisit to Physician and with follow up cases for further investigation, medications, dietary modifications and advanced cardiology visit.

Effective communication by treating Physician and Registered Nurse to bridge a gap of positive outcome of changing Modifiable Risk factors. This is evident in initial visit and follow up visit.

\section{Methods}

\section{Description of setting}

Observations of patients visit to General practitioner and Physician.

Demographic Data/ History Collection.

Secondary data Collection of patient health record via Electronic health records.

High risk score calculator for 10 years.

\section{Population}

Total of 1200 patients of different age groups had visited the facility in six months for various specialists out of them 350 visited the Physician. Patients with symptoms of chest pain, sample size 60 patients (Male and Female) age group of 30 to 40 years had visited facility from October 2016 to March 2017 were the target.

\section{Variables}

\section{Exclusive criteria}

Patient with CVD, on treatment and surgery

\section{Inclusive criteria}

Age group 30-40 years

Symptoms of chest pain (Unknown Origin)

Known History of Hypertension and Diabetic Mellitus.

\section{Research approach}

The Physician has done detailed Physical Assessment and filled GHA form to identify the reason for symptoms like chest pain in 60 patient was taken on all patients. Blood Investigations like Serum Cholesterol, HDL Levels was done in few patients suspecting CVD. Patients with signs of palpitation, Sinus Tachycardia and Bradycardia of unknown and known origin were referred to Cardiologist. The Physician has explained about Modifiable Risk Factors like control Blood Pressure, Diabetes Mellitus, reduction and stopping of Cigarette smoking, overweight management and patients with increased BMI were given Dietician reference and advice for follow up. The assisting Registered Nurse has also advised on weight reduction, dietary control, exercise, intake of balanced diet and consume regular medications for Hypertension and Diabetes Mellitus as prescribed and follow up. 


\section{Research design}

All participants within age group of 30 to 40 years were the target out of 350 patients visit to Physician for various symptoms like Hypertension, Diabetic Mellitus, 60 patients with complaints of chest pain in 6 months were the target for the research. The knowledge, attitude and behavior related to risk of CVD is assessed during the triage and initial and follow up assessment by Registered Nurse and Physician. All the details are compiled and noted in Electronic Health Record.

Anthropometric and Demographics study including Age, Nationality, BMI, education level was identified on the participants by Receptionist with OPD registration, RN with Anthropometric measurements and vital parameters recording

Observation method was used to assess the type, location and severity of chest pain; non-biased random selection with assessment of their knowledge, new diagnosis management, follow up treatment, referral to Cardiology and Dietician was done by treating doctor.

Cardiovascular risk score is calculated to identify risk in next 10 years which is not a part of Electronic Health Record.

\section{Variables with measuring devices}

Continuous Variable, Bio physiological Measurement like Blood Pressure, Pulse, Blood Sugar, Serum Cholesterol Levels and HDL Levels were compared with initial assessment and follow up depending on the symptoms and ECG findings.

\section{Setting of the study}

The study is done in Out Patient Department of NMC Medical Center with 5 General Practitioners, 1 Physician and 10 Specialists. The patients were directed to Physician with internal referral from GP Doctor according to Insurance Coverage and direct reference to Physician (Internal Medicine) with Insurance coverage and cash bases too.

\section{Result}

1) Patient's perception of cardiovascular risk was assessed before the visit to physician, during triage and after visit to physician, while providing health education to patient and family.

2) Effective communication by treating Physician and Registered Nurse to bridge a gap was done during the triage, consultation and after care of patient.

3) Positive outcome of changing Modifiable Risk factors is with graphic representation of patient revisit to the physician and dietician. Cardiovascular risk score is calculated to identify risk in next 10 years

\section{Discussion}

Patients perception on CVD suggests $(n=50)$ were ignorant about their health status initially and knowledge about risk of CVD and $(n=10)$ had known about risk of CVD. The trustful patient relation and communication by the treating Physician and Registered Nurse has direct and positive effect on outcome of the research Patients were enthusiastic to gain more knowledge on Modifiable risk factors. The attitude and behavior of patients were significant and positive with follow up visits and regular intake of medications. Similar study was done by Ruth Webster; Perceptions of risk: understanding cardiovascular disease (Ref 1) with need to educate the patient.

Cardiovascular risk score is calculated to identify risk in next 10 years Health. Out of 33 patients with blood values of Cholesterol and HDL, 21 patients have 0 to 10\% risk, 6 patients have 10 to $20 \%$ risk and 6 patients have 20 to $30 \%$ risk of CVD. (Ref 3 ). 
DOI: $10.21522 / \mathrm{TIJNR} .2015 .03 .02 . A r t 016$

ISSN: $2520-3126$

\section{Additional findings}

Routine General Health checkup must be advised to all persons in younger age groups of 25 to 45 . This will help to identify the initial risks and future risks of CVD.

The Health Information system (Electronic data recording) need to be advanced with High risk score calculator inbuilt to have wider and effective communication with the details of patient health outcomes instantaneously so that patient would have quick results and guidance to take appropriate steps to avoid risk of CVD.

\section{General take home message}

Each Individual is responsible for his/her own health. Balance of health and lifestyle modification need to be maintained in order to live without any disease. Physical and Mental wellbeing are both necessary to remain healthy. Regular General Checkup in younger age groups would definitely avoid future CVD Risk and Vascular Disorders like Hypertension and Endocrine Disorder like Diabetic Mellitus.

\section{Conclusion}

Patients perception on CVD suggests $(n=50)$ were ignorant about their health status initially and knowledge about risk of CVD and $(n=10)$ had known about risk of CVD. The trustful patient, physician communication by the treating Physician and Registered Nurse has direct and positive effect on outcome of the research Patients were enthusiastic to gain more knowledge on Modifiable risk factors. The attitude and behavior of patients were significant and positive with follow up visits. Cardiovascular risk score is calculated to identify risk in next 10 years Health Risk for CVD which is very significant.

\section{Figures and tables}

Table 1. Comparison-before/after scores

\begin{tabular}{|l|l|l|}
\hline Personal Data & Risk factors & Value in percentage \\
\hline Age Group & $30-40$ yrs. & 60 patients \\
\hline Sex & Male-(n=57) Female-(n=3) & \\
\hline \multirow{5}{*}{ Nationality } & Indian-30, Pakistan-14 & \\
\cline { 2 - 3 } & $\begin{array}{l}\text { Bangladesh-9, Sudhanese- } \\
3\end{array}$ & \\
\cline { 2 - 3 } & Ethiopian-1, Comeron-1 & \\
\cline { 2 - 3 } & Jordan-1, Indonesian-1 & \\
\hline \multirow{5}{*}{ Weight } & $50-70 \mathrm{Kg}(\mathrm{n}=9)$ & $15 \%$ \\
\hline & $71-90 \mathrm{Kg}(\mathrm{n}=35)$ & $58 \%$ \\
\hline & $91-110 \mathrm{Kg}(\mathrm{n}=15)$ & $25 \%$ \\
\hline & $111-130 \mathrm{Kg}(\mathrm{n}=1)$ & $1.6 \%$ \\
\hline & $140-160 \mathrm{Kg}(\mathrm{n}=1)$ & $1.6 \%$ \\
\hline \multirow{5}{*}{ BMI } & $20-24.9=(\mathrm{n}=18)$ & $30 \%$ \\
\hline & $25-29.9=(\mathrm{n}=20)$ & $33.3 \%$ \\
\hline & $30-40=(\mathrm{n}=22)$ & $37 \%$ \\
\hline
\end{tabular}




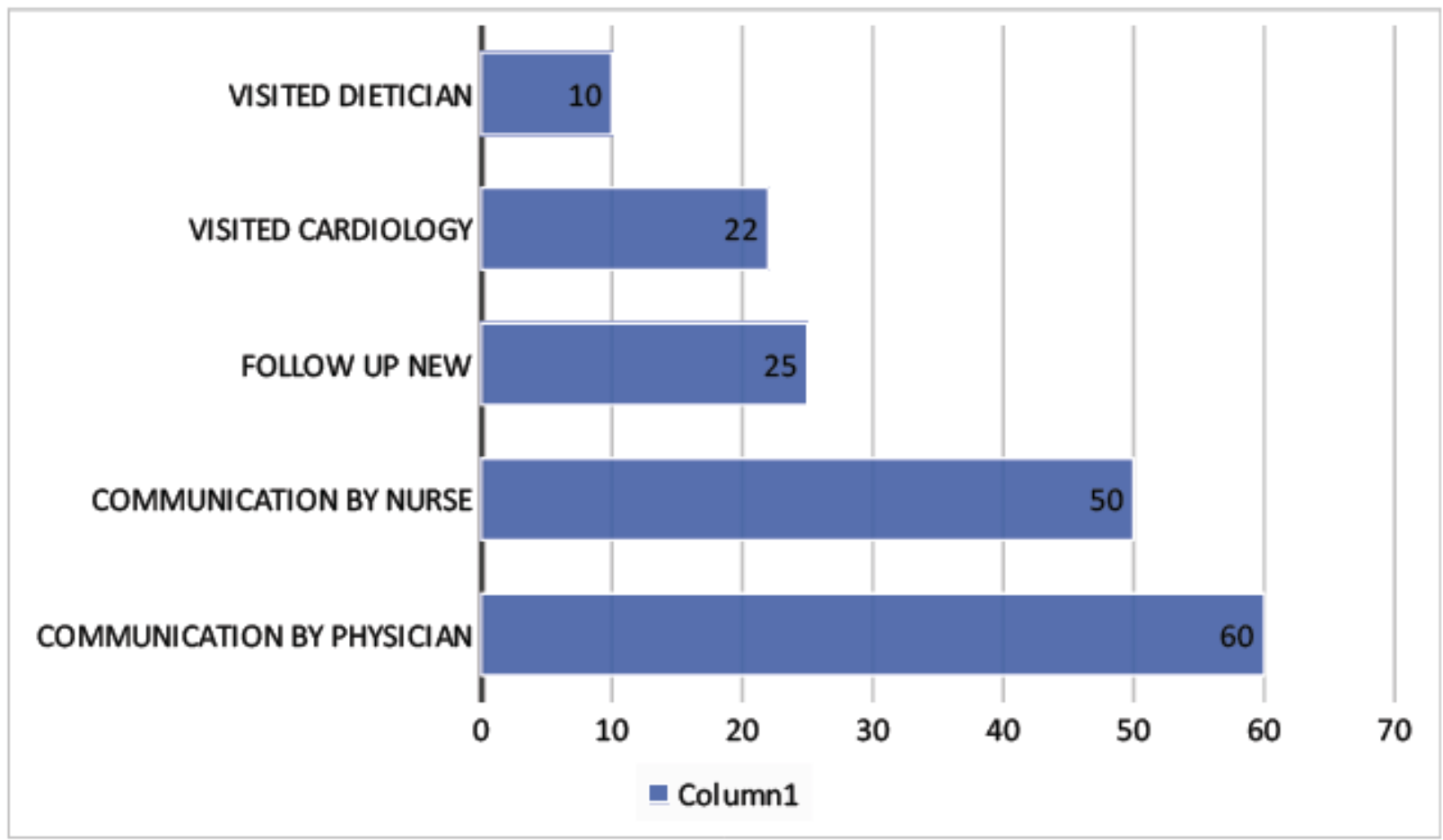

Figure 1. Physician assessment

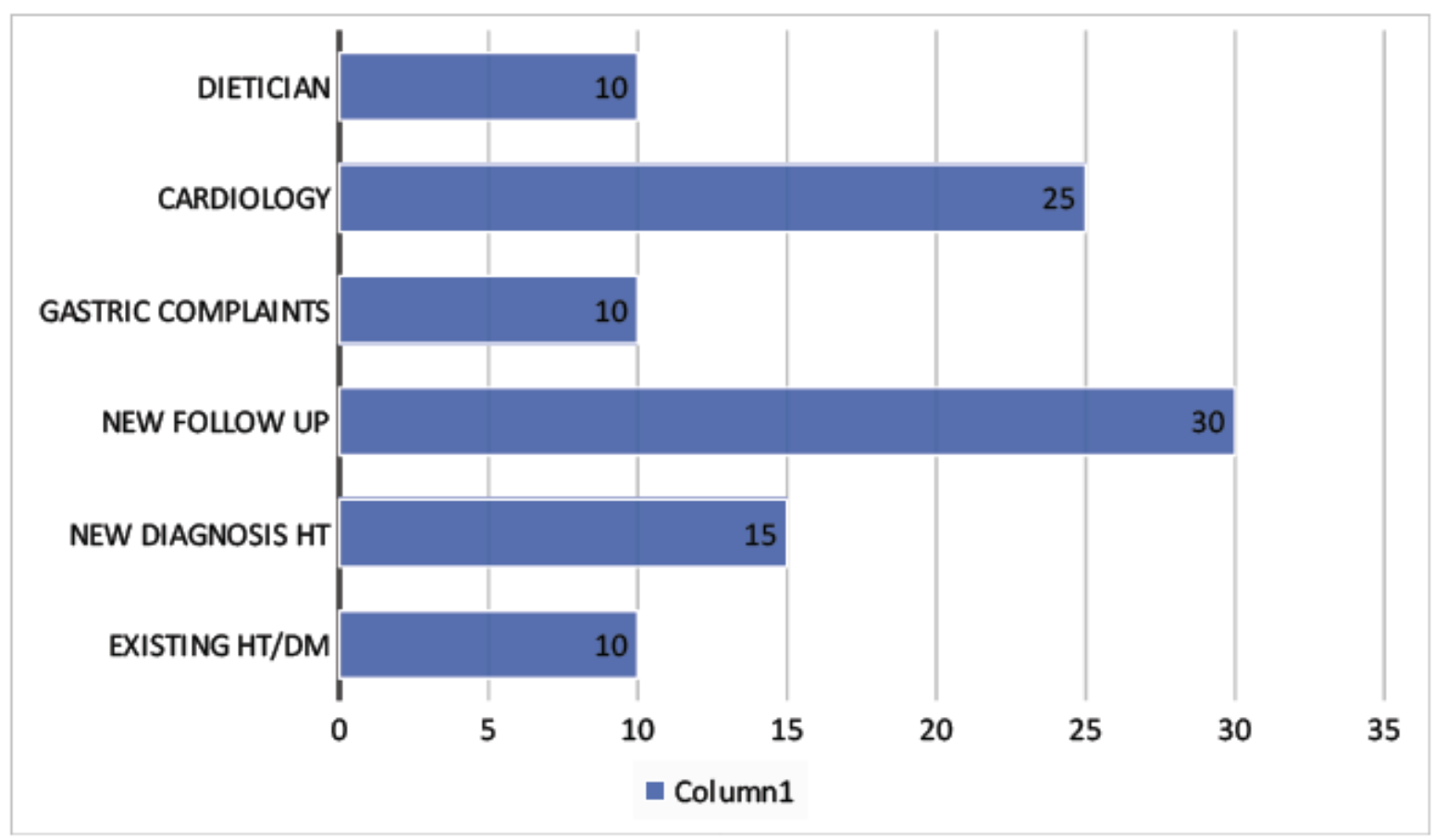

Figure 2. Follow up 
DOI: $10.21522 / \mathrm{TIJNR} .2015 .03 .02 . A r t 016$

ISSN: $2520-3126$

Calculator: Cardiovascula $\times$ Secure | https://www.uptodate.com/contents/calculator-cardiovascular-risk-assessment-10-year-men-patient-education
Calculator: Cardiovascular risk assessment (10-year, men: Patient education)
The content on the UpToDate website is not intended nor recommended as a substitute for medical advice, diagnosis, or treatment. Always seek the advice of your own physician or other qualified health care professional regarding any medical
questions or conditions. The use of this website is governed by the UDTODate Terms of Use $\Theta 2017$ UpToDate, Inc.

Calculator: Cardiovascular risk assessment (10-year, men: Patient education)

\begin{tabular}{|c|c|c|c|}
\hline \multicolumn{4}{|c|}{ Input: } \\
\hline Age & & $\mathrm{yr}$ & v \\
\hline Systolic blood pressure & & $\mathrm{mmHg}$ & v \\
\hline Total cholesterol & & $\mathrm{mg} / \mathrm{dL}$ & v \\
\hline HDL cholesterol & & $\mathrm{mg} / \mathrm{dL}$ & $\checkmark$ \\
\hline On blood pressure medication & No & & \\
\hline Cigarette smoker & No & & V \\
\hline Diabetes present & No & & $\checkmark$ \\
\hline
\end{tabular}

Notes

- This calculator may be applied to men who have had no prior history of cardiovascular disease.

- A person with cardiovascular disease is someone who has (now or in the past) blocked coronary arteries, a heart attack, a stroke or blocked carotid arteries, peripheral arterial disease (blocked arteries to the legs), or heart failure.

- Systolic blood pressure is the top number (eg, 120 if blood pressure is $120 / 80$ )

Cardiovascular risk calculator (Part 1) (Ref 3)

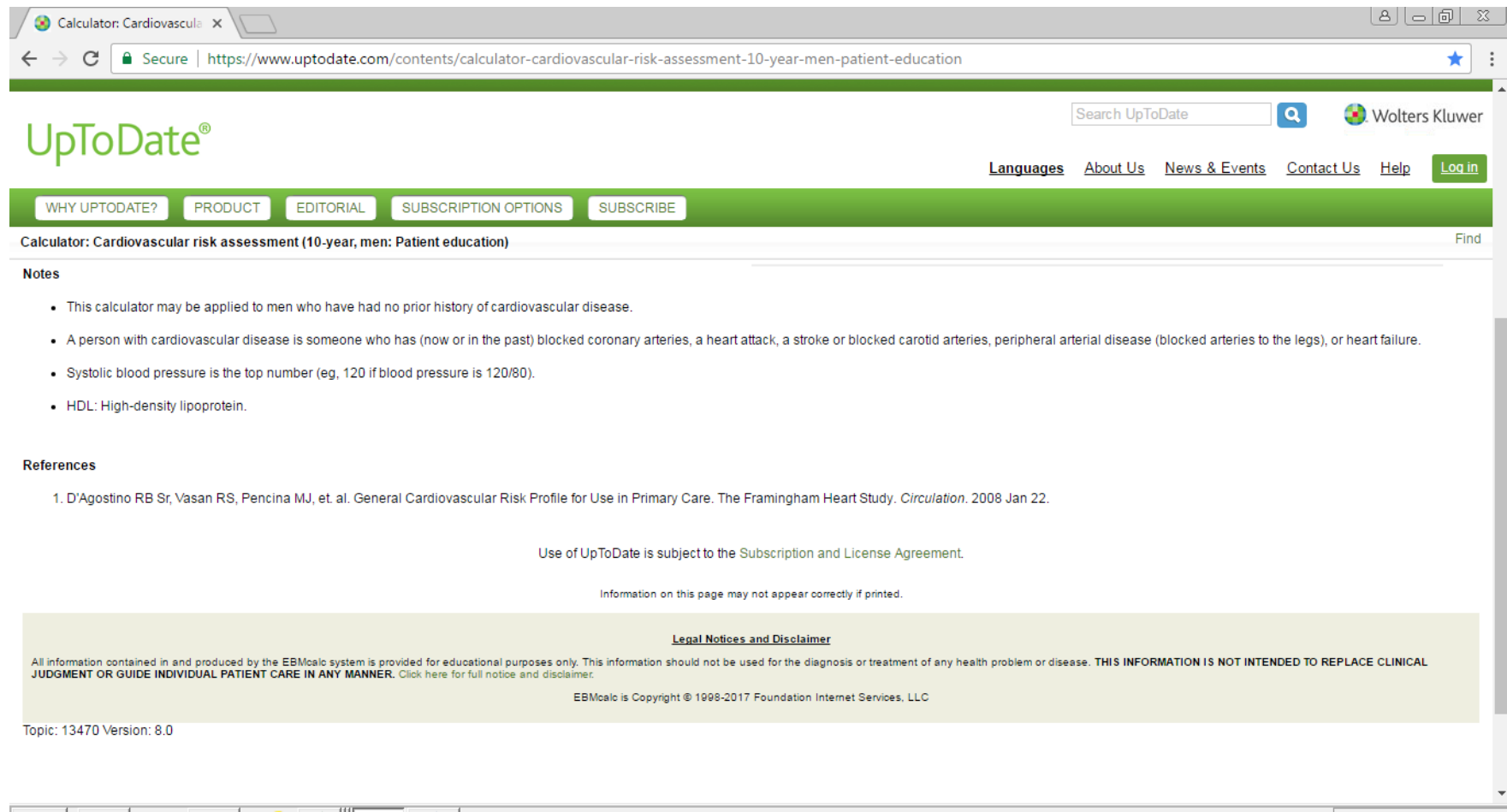

Cardiovascular risk calculator (Part2) 


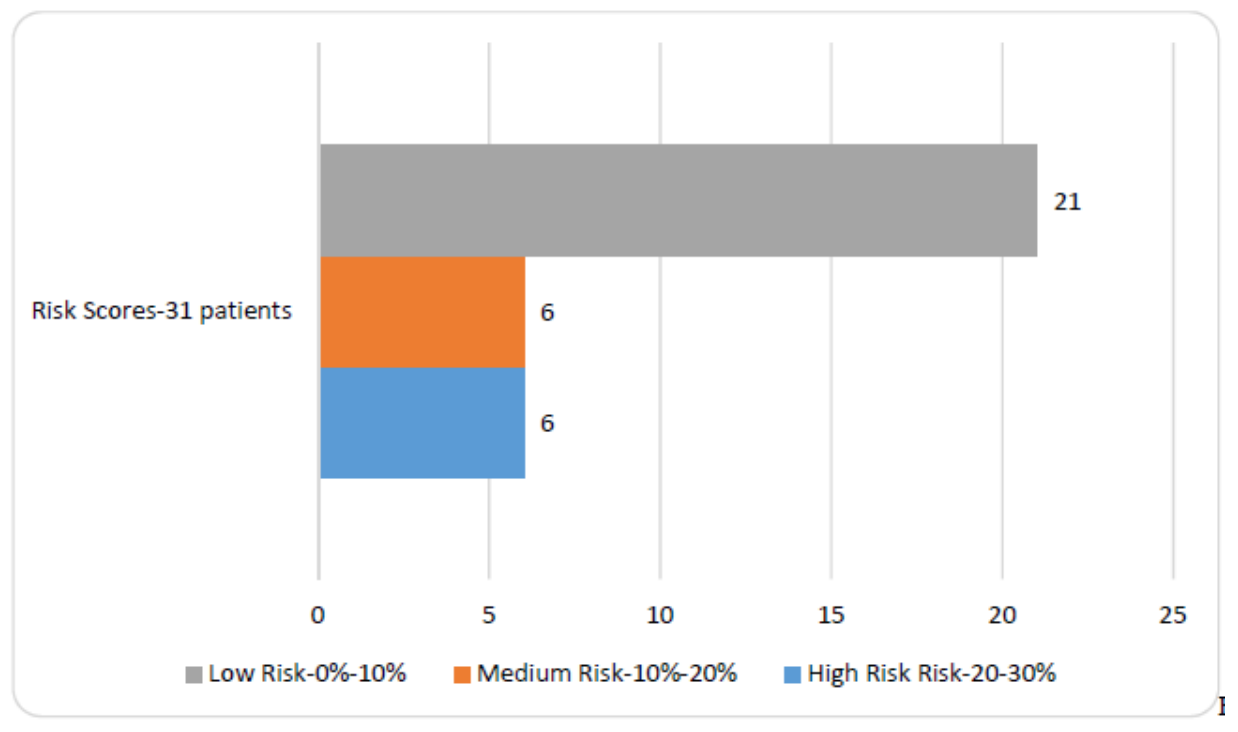

\section{Acknowledgement}

High risk score calculator results

I thank my facility, NMC Medical Centre, Alwadi for giving me an opportunity to do the Primary Research.

I thank the Physician and staff nurses, Registered Nurses for assisting me in doing the research and providing health education to the patients.

I thank the patients who are part of this project.

\section{References}

[1].Peterson JA; One theoretical framework for cardiovascular disease prevention in women; Journal of Cardiovascular Nursing. 2012 Jul-Aug; 27(4):295-302. doi: 10.1097/JCN.0b013e31822072fc.

[2].Ruth Webster; Perceptions of risk: understanding cardiovascular disease; Dove Press Journal; 2010 Webster and Heely, publisher and licensee Dove Medical Press Ltd; Published 4 September. https://www.ncbi.nlm.nih.gov/pmc/articles/PMC3270917/.

[3].https://www.uptodate.com/contents/calculator-cardio vascular-risk-assessment-10-year-men-patient-education. 


\title{
Perception of Reflective Journaling during Clinical Posting among Nursing Students
}

\author{
Article by Musah K. Toyin ${ }^{1}$, Philip A. Ojo ${ }^{2}$, Okueso Grace Ogba ${ }^{3}$ \\ ${ }^{l}$ Department of Community Health Science, School of Allied Health and Environmental \\ Science, College of Pure and Applied Sciences, Kwara State University, Malete, Nigeria \\ ${ }^{2}$ School of Nursing, University College Hospital, Ibadan, Oyo State, Nigeria \\ ${ }^{3}$ School of Nursing Science, Department of Maternal \& Child Health, Babcock University, \\ Ilishan-Remo, Ogun State, Nigeria \\ E-mail: khadijat.musah@kwasu.edu.ng ${ }^{1}$ or musahtoyin1@gmail.com ${ }^{1}$, \\ philocomet@yahoo.com ${ }^{2}$,graceokueso@gmail.com ${ }^{3}$
}

\begin{abstract}
The aim of the study was to find out about perception of reflective journaling among undergraduate nursing students in Babcock University, Ilisha-Remo, Ogun State, Nigeria. The objectives were to determine the students' perception of reflective journaling and the perceived meaning of reflective journal writing. This study utilized a descriptive research design. Data was collected through self-administered questionnaire. Population of 130 students in 400 and 500 levels were used. Results of the reliability test, using Cronbach's alpha of all the constructs measuring the perception and the explanatory variables were well above the recommended minimum of 0.70. Results revealed that, a significantly higher proportion of the participants have positive perception towards reflective journaling in the undergraduate nursing program in Babcock University. The mean score of perception of reflective journaling was 1.93205. Most of the students were able to correlate theory with practice (96.2\%) with the mean of 1.9615. Data evidences also revealed that, the status of perceived meaning of reflective journaling of nursing students' clinical learning and practice is high. This inference is evident in the fact that overall criterion weighted mean score (1.805147) is greater than the average Likert scale of 1.5.
\end{abstract}

Keywords: Critical thinking, Journaling, Perception, Reflective writing, Nursing Students

\section{Introduction}

Reflection, as defined by Reed, ${ }^{[1]}$ is a process of reviewing an experience of practice in order to describe, analyze, evaluate and to inform learning about practice. It involves opening one's practice for others to examine and require courage and open-mindedness as well as to take on board and act on-criticism ${ }^{[2]}$. There is also the element of critical theory where there is an assumption that reflection will involve a changed perspective, action, experimentation reviews and learning through one's experience. Reflection and reflective practice are terms that have become very familiar to contemporary nursing practice in the United Kingdom and other advanced countries ${ }^{[3]}$ but currently, the same concept is gradually evolving in nursing practice in Nigeria ${ }^{[4]}$ According to Burton ${ }^{[5]}$, reflection and reflective practices are terms that can engender a whole spectrum of reactions, ranging from positive enthusiasm to feelings of gross ambiguity and consternation. Reflection provides an excellent way for students to analyze care and increase their abilities to make clinical judgments. Reflective journaling therefore, is a strategy used often in clinical education to gain insight into students' critical thinking and professional development.

\section{Reflective journaling and reflective writing}

A reflective journal is a way of thinking in a critical and analytical way about a particular work in progress ${ }^{[6]}$. It shows how different aspects of the work interconnect. Reflective writing on the other hand is evidence of looking back at an event, idea, object, experience, process and so on. It involves analyzing and commenting on the object or process from different points of view using contemporary ideas and theories exploring and explaining the importance or relevance of the object or process, 
considering things that went wrong as well as successes, saying what the object, process or means to and saying how learning will influence the way we work ${ }^{[7]}$. According to Babcock University (BU) curriculum for the training of nursing students, the process of reflective journal writing was introduced to generic students from 200level and at 300level to direct entry nursing students respectively. The students are to journal on special posting areas during medical-surgical and Community Health posting. This is so because, reflection facilitates the integration of theory and practice and makes nurses critical thinkers and doers. This explains why the present study was designed to find out about the perception of reflective journaling during clinical posting among nursing students in BU. The objectives were to determine nursing students' perception of reflective journaling and to also find out the perceived meaning of reflective journal by the students.

\section{Literature review}

\section{Types of reflection}

Journals can be used to reflect on a range of issues and situations from numerous viewpoints and perspectives. RMIT (2006) ${ }^{[8]}$ lists six types of reflections.

Observations - at this stage, a student would write about what they actually saw or their viewpoint on a particular event.

Questions - upon reflection, the student could ask the question on what s/he has reflected upon.

Speculations-after thinking about the situation, the student could reflect.

Self-awareness - at this point a student may place himself or herself in the situation by considering the ramifications.

Integration of theory and ideas - by reflecting on theories or ideas about cultural norms, the student has connected the experience with what he or she has learned.

Critique - this is where the student may self-reflect on or "critique" the situation.

\section{The reflection cycle}

Reflecting is a cyclical process, where recording ones thoughts (reflecting) "leads to improvement and/or insight" ${ }^{\text {"[8] }}$. Improvement could mean progress, development, growth, maturity, enhancement, or any number of words which could imply change. In education, we want students to change for the better, to grow while learning and to mature into knowledgeable adults and the same thing is applicable during clinical posting. Recording what has happened, reflecting on processes and analyzing to improve deeper learning all can lead to new dimensions of students' inner selves. RMTI $(2006)^{[8]}$ described four cyclical process of reflection: Reflect (Think); Analyze (Explain and gain insight); New action; Record (What). Various cycle of reflective exist, what is common in most of them is the ability to evaluate and analyze an event. For the purpose of this study, only Gibb's Cycle of reflection is reviewed.

\section{Gibb's reflective cycle}

Model as cited by Dye, $\left(2011^{[9]}\right.$ acknowledges that personal feelings influence the situation and how one has begun to reflect on it. It builds on Boud's model by breaking down reflection into evaluation of the events and analysis and there is a clear link between the learning that has happened from the experience and future practice. Instead, other theorists have broken down the cycle into further stages, an example of which is Gibb's reflective cycle ${ }^{[10]}$. 

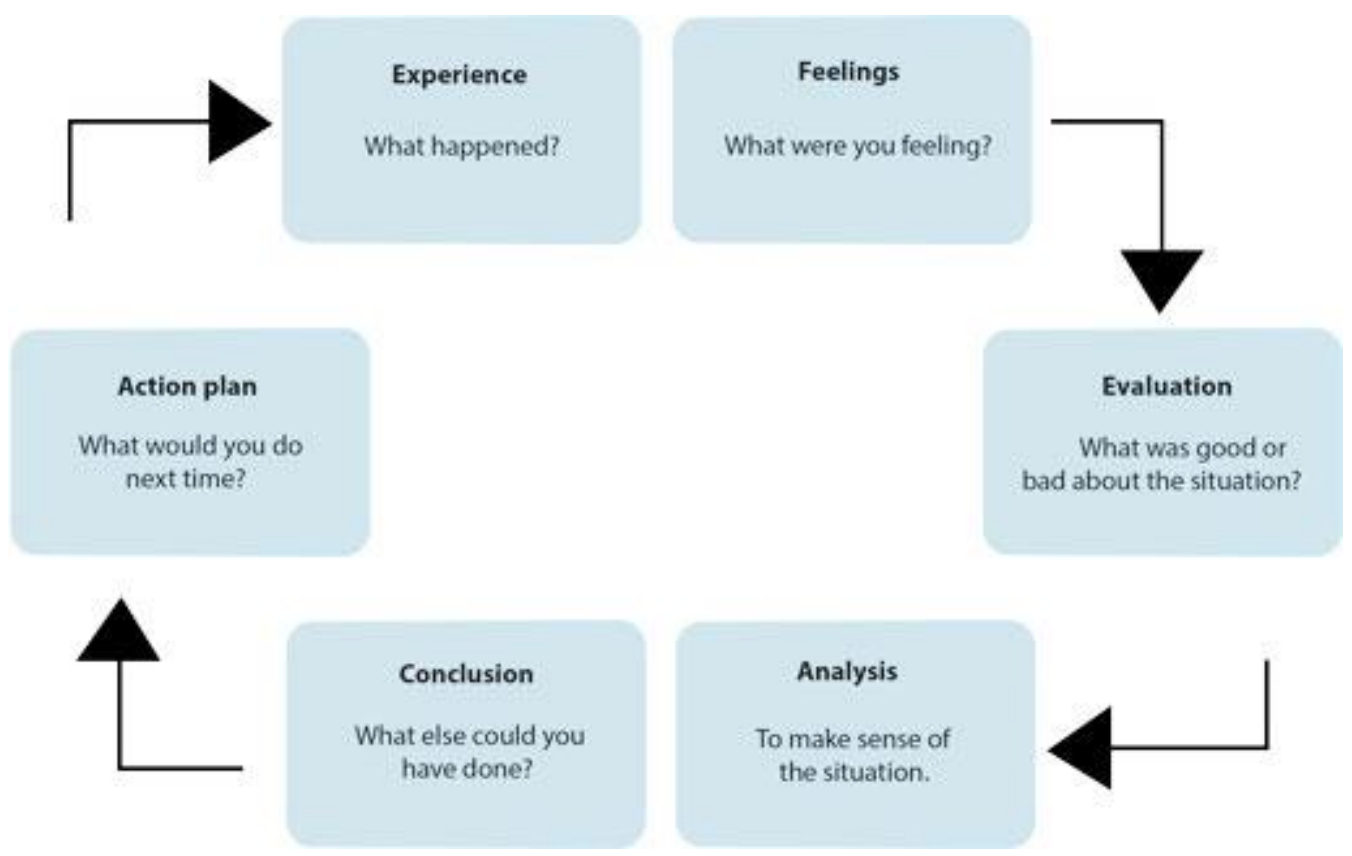

Figure 1. Gibb's reflective cycle (adapted from dye, 2011)

\section{Elements of the gibbs' reflective cycle}

Mantzoukas and Jasper ${ }^{[1]}$ explained that, Gibbs' model of reflection consists of six distinct steps namely: the description of what happened; the practitioner's feelings during the experience; the evaluation of what was good and bad about the experience; the analysis or sense making of the situation; the conclusions and potential alternatives in dealing with the situation, and; the action.

Stage 1: Description of the event-At this stage, the nursing student must describe in detail the event being reflected on. McMillan-Coddington and Weyers ${ }^{[12]}$ suggested that, powers of observation and ability to record the situation and associated events will be utilized. This includes responding to questions such as where she/he was; who else was there; why was he/she there; what was he/she doing; what were other people doing; what was the context of the event; what happened; what was his/her part in this; what parts did the other people play; what was the result. Bulman and Schutz ${ }^{[13]}$ however concluded that no judgments must be made at this stage, only a simple description. The students must be encouraged therefore, to tell their own stories in their own voice.

Stage 2: Feelings-At this stage, the student must try to recall and explore the reactions and emotions that were going on inside his/her mind, explaining why this event sticks in his/her mind? The following must be included: how he/she was feeling when the event started; what he/she was thinking about at the time; how did it make he/she feel; how did other people make he/she feel; how did he/she feel about the outcome of the event; what he/she thinks about it now ${ }^{[13]}$.

Stage 3: Evaluation- The student tries to evaluate or make a judgment about what has happened. Consider what was good about the experience and what was bad about the experience or what didn't go so well ${ }^{[13]}$.

Stage 4: Analysis-At this stage, the student must break the event down into its component parts so they can be explored separately. He/she may need to ask more detailed questions about the answers to the last stage. These must be included: what went well; what did he/she do well; what did others do well; what went wrong or did not turn out the way it should have; in what way did he/she or others contribute to this. Similarities and/or differences of his/her feelings compared to others can be described ${ }^{[13]}$.

Stage 5- Conclusion At this stage the issue is explored from different angles. In addition, the student must have a lot of information to base his/her judgment. It is here that he/she is likely to develop insight into his/her own and other people's behavior in terms of how they contributed to the outcome of the event ${ }^{[13]}$. The emphasis therefore, is on learning from an experience. During this stage the student should ask him/herself what s/he could have done differently. The student can make 
general or specific conclusions regarding the event ${ }^{[13]}$ and this indicates insight and maturity of the student.

Stage 6: Action Plan- During this stage, the student should think forward. Faced with the same event again what would he/she plan and do differently or would s/he be likely to do the same? This becomes very personal as the student decides on future encounters and own actions regarding same event/experience ${ }^{[13]}$.

\section{Methods}

\section{Study design}

A descriptive survey research design was adopted for the study to determine the participants' perception and perceived meaning of reflective journaling.

\section{Location and period of study}

The study was carried out between January to June, 2017 in Babcock University. Babcock University is a private Christian co-educational Nigerian University owned and operated by the Seventh-day Adventist Church in Nigeria. The University is located equidistant between Ibadan and Lagos ${ }^{[14]}$. It is a part of the Seventh-day Adventist education system, the world's second largest Christian school system ${ }^{[15]}$. The Nursing Science Department started in 1999 when Babcock University was established as the Health Sciences Department which ran two programs; Nursing Science and Public Health Education. The following Departments are under school of Nursing as contained in Student handbook, 2015-2017- Adult Health, Comunity Health, Marternal \& Child Health and Mental/Psychiartric Health.

\section{Sample size and sampling techniques}

Participants were drawn purposively from 400 and 500 level students in the School of Nursing, BU. The minimum sample size was determined using the Evan Morris sample size formula for small population ${ }^{[16]}$. A total sample size of 178 was used which includes margin for non-response. However, only 130 questionnaires were retrieved in good condition, sorted, coded and analyzed. Only students who have undergone clinical posting on Journaling met the inclusion criteria.

\section{Ethical clearance and informed consent}

The study protocol, the associated informed consent forms, and study-related documents such as participation, education and recruitment materials were all submitted to Babcock University Health Research Ethics Committee (BUHREC) for review. The study was conducted in full compliance with the protocol. There was close coordination between the researchers and BUHREC to track study progress. Every effort was made to protect participants' privacy and confidentiality.

\section{Instrument and data collection}

Interviewer administered questionnaire was used to collect data from the participants. The questionnaire captured socio-demographic characteristics like sex, age, mode of admission and level of study. Questionnaire on perception contained items such as 'I am able to correlate theory with practice', 'I am involved in critical thinking before journaling', 'I am able to redefine experiences and problems'. Some of the items on perceived meaning of journaling are: 'A journal is an instrument for practicing writing and thinking'; 'It is a mere listing of events', 'It is a personal record of life', 'It is a tool for documenting and accompanying students' actions.

\section{Data analysis}

The analysis of the data from the survey/questionnaire was performed using the SPSS 22.0 Descriptive statistics such as frequencies, simple percentage, mean and standard deviation tables were used to describe the data based on the objectives. 


\section{Results}

Table 1 reveals the results on perception of reflective journaling. To establish the status, the average modified Likert rating scale below was adopted.

Criterion Scoring of perception of Journaling as- 1.45= Lowperception;1.5-1.95= High Perception. The detailed result is given below.

Table 1. Perception of reflective journaling $\mathrm{N}=130$

Criterion Scoring of Perception of Journaling: $\mathrm{Yes}=2, \mathrm{No}=1$

\begin{tabular}{|c|c|c|c|c|}
\hline Items & Yes & No & Mean & Std. Deviation \\
\hline $\begin{array}{l}\text { I am able to correlate } \\
\text { theory with practice }\end{array}$ & $125(96.2)$ & $5(3.8)$ & 1.9615 & .19305 \\
\hline $\begin{array}{l}\text { My problem solving skill } \\
\text { have improved }\end{array}$ & $124(95.4)$ & $6(4.6)$ & 1.9538 & .21063 \\
\hline $\begin{array}{l}\text { I am able to redefine } \\
\text { experiences and } \\
\text { problems }\end{array}$ & $123(94.6)$ & $7(5.4)$ & 1.9462 & .22659 \\
\hline $\begin{array}{l}\text { I am able to make } \\
\text { proactive decisions and } \\
\text { take on the spot } \\
\text { corrective actions }\end{array}$ & $113(86.9)$ & $17(13.1)$ & 1.8692 & .33845 \\
\hline $\begin{array}{l}\text { I am able to use past } \\
\text { experiences to prevent } \\
\text { future occurrences }\end{array}$ & $124(95.4)$ & $6(4.6)$ & 1.9538 & .21063 \\
\hline $\begin{array}{l}\text { I am involved in critical } \\
\text { thinking before } \\
\text { journaling }\end{array}$ & 121(93.1) & $9(6.9)$ & 1.9308 & .25483 \\
\hline
\end{tabular}

Only 130 students participated fully and filled the questionnaire correctly in the study area out of 178 and the overall findings have shown a high perception towards reflective journal writing in the undergraduate nursing program in BU. The mean score of perception of reflective journaling was 1.93205. Most of the students were able to correlate theory with practice $(96.2 \%)$ with the mean of 1.9615. Of the 130 participants, only (4.6\%) said their problem solving skills did not improve. However, $(86.9 \%)$ of them were able to make proactive decisions and took on the spot corrective actions while journaling. The highest proportion, (95.4\%) of the respondents had been able to use past experiences to prevent future occurrences with mean score of 1.9538. Majority of the participants (93.1\%) said they were involved in critical thinking before journaling during clinical posting.

Table 2 reveals the results on perceived meaning of reflective journaling. To establish the status, the average modified Likert rating scale below was also adopted.

Criterion Scoring of Perceived Meaning of Journaling was- 1.45 = Low Perceived Meaning; 1.5 $1.95=$ High Perceived Meaning. 
DOI: $10.21522 /$ TIJNR.2015.03.02.Art017

ISSN: $2520-3126$

Table 2. Perceived meaning of journaling

\begin{tabular}{|c|c|c|c|c|c|}
\hline Options & No (1) & $\begin{array}{l}\text { Yes } \\
\text { (2) }\end{array}$ & \multirow[t]{2}{*}{ Mean } & \multirow[t]{2}{*}{ SD } & \multirow[t]{2}{*}{ Remark } \\
\hline Items & \multicolumn{2}{|c|}{ Frequency } & & & \\
\hline $\begin{array}{l}\text { A journal is an instrument } \\
\text { for practicing writing and } \\
\text { thinking }\end{array}$ & 120 & 10 & 1.923077 & 0.2675002 & $\begin{array}{l}\text { High Meaning } \\
\text { Perceived }\end{array}$ \\
\hline $\begin{array}{l}\text { It is a personal record of } \\
\text { your educational experience } \\
\text { in class }\end{array}$ & 103 & 27 & 1.792308 & 0.4072246 & $\begin{array}{l}\text { High Meaning } \\
\text { Perceived }\end{array}$ \\
\hline It is a mere listing of events & 44 & 86 & 1.338462 & 0.4750169 & $\begin{array}{l}\text { Low Meaning } \\
\text { Perceived }\end{array}$ \\
\hline It is a personal records of life & 77 & 53 & 1.407692 & 0.4933064 & $\begin{array}{l}\text { Low Meaning } \\
\text { Perceived }\end{array}$ \\
\hline $\begin{array}{l}\text { It is a tool for documenting } \\
\text { and accompanying students' } \\
\text { actions }\end{array}$ & 94 & 36 & 1.723077 & 0.449209 & $\begin{array}{l}\text { High Meaning } \\
\text { Perceived }\end{array}$ \\
\hline Total & & & 8.184616 & 2.092257 & \\
\hline
\end{tabular}

Criterion Mean Score: 8.184616

Criterion SD Score: 2.092257

Data evidences in table 2 revealed that the status of perceived meaning of reflective journaling of nursing students' clinical learning and practice is high. This inference is evident in the fact that overall criterion weighted mean score (1.805147) is greater than average Likert scale of 1.5.In terms of item by item analysis 'A journal is an instrument for practicing writing and thinking 'with mean and standard deviation criterions scores 1.923077 and 0.2675002 ranks highest based on the mean score rating. This is followed by 'It is a tool for documenting and accompanying' (mean = 1.723077); 'It is a personal records of life' (mean = 1.592308); 'It is a personal record of your educational experience in class' $($ mean $=1.407692)$; and 'It is a mere listing of events' $($ mean $=1.338462)$.

\section{Discussion}

The objectives of this study were to determine the nursing students' perception of reflective journaling on clinical posting and to also find out their perceived meaning of reflective journaling. The discussion presented here followed the sequence of the stated objective.

\section{Perception of reflective journaling}

The study revealed that a significantly higher proportion of the participants showed a high perception towards reflective journal writing in the undergraduate nursing program in BU. The participants were able to correlate theory with practice, made proactive decisions and took on the spot proactive actions. Participants also affirmed their problem solving skills have improved and confirmed that, reflective writing was useful to them. This finding corroborates the results in a similar study conducted by Mahlanze ${ }^{[17]}$ among undergraduate nursing students at the Durban University of Technology. The author evaluated the use of guided reflective journals by assessing perception and the levels of reflection of the undergraduate nursing students during clinical learning and practice ${ }^{[17]}$ It was reported in her study that the participants generally expressed writing of reflective journals as a valuable tool in professional, personal development as well as clinical learning ${ }^{[17]}$. Similarly, the current study also support the findings from Henter and Indreica ${ }^{[18]}$ on reflective journal writing as a metacognitive tool among freshmen in University of Brasov, Romania ${ }^{[18]}$. In a reflective writing, students record their thoughts on the level of awareness involved in their cognitive labor and comment on their learning decisions ${ }^{[18,19,20]}$. 


\section{Perceived meaning of journaling}

The study showed that participants understood the perceived meaning of journaling to a reasonable extent. Data evidences in table 2 revealed that the status of perceived meaning of reflective journaling of nursing students' clinical learning and practice is high. This inference is evident in the fact that overall criterion weighted mean score (1.805147) is greater than average likert scale of 1.5. However, in terms of item by item analysis a higher proportion of the respondents said a reflective journal is an instrument for documenting and accompanying personal record of life and is a mere listing of events. This notion was wrong as only diary fall in this category. Spring ${ }^{[21]}$ had earlier differentiated between journal and diary.

\section{Conclusion/ recommendation}

This study concludes that students perceive reflective journaling as a useful tool for problem solving approach in nursing profession. Through a reflective journal, one can explore the ways of using learning strategies consciously and adapting the learning process to the concrete situations during clinical postings. Levels of reflection and development of reflective journaling or writing should therefore be greatly enhanced if reflective practice among clinical nurses must be achieved. To that effect, Olson and Johnson ${ }^{[22]}$ emphasize writing journals should become a weekly routine among students in order to meet its purpose, along with a descriptive feedback offered each time by the teacher ${ }^{[22]}$.

\section{References}

[1]. Bulman C., and Schutz S. 2008. Reflective practice in nursing. (4th edition. USA: Blackwell Publishing Ltd) Adventist News Network, 2009. Commentary Opinion, 2015.

[2]. Boud D., Using Journal writing to enhance reflective practice, New directions for adult and continuing education, 90, 2001, 9-17.

[3]. Burton A. J., Reflection, Nursing Practice and Education Panacea?, Journal of Advanced Nursing,31(5), 2000, 1009-1017.

[4]. Dewey J., How We Think. A Restatement of the Relation of Reflective Thinking to the Educative Process.( De Health Boston, 1993).

[5]. Dye V., 'Reflection, Reflection, Reflection. I'm thinking all the time, why do I need a theory or model of reflection? in McGregor, D. and Cartwright, L. Developing Reflective Practice: A guide for beginning teachers, Open University Press. 2011.

[6]. Enuku C. A. and Evawoma- Enuku U., the Need to Incorporate Reflective Practice into Nursing Education Curriculum In Nigeria. Journal of Nursing and Health Science 1(2), 2013, 57-62.

[7]. Gibbs G., The reflective cycle. Oxford: Further Education Unit, Oxford Polytechnic, 1988.

[8]. Gillett A., Hammond A., and Martala M, Successful academic writing (Harlow: Person Education Limited 2009).

[9]. Henter R., Indreica E. S., Reflective Journal Writing As a Metacognitve Tool International Conference of Scientific Paper Afases Brasov, 2014.

[10]. Huang J., Meta-cognition training in the Chinese University Classroom: An Action Research Study. Educational Action Research, 13(3), 2005, 413 - 434.

[11]. Reedand B., I. Ground, Philosophy for nursing. (Arnold, London, 1997).

[12]. McMillan-Coddington D., and Weyers J., Reflection through journal writing to educate registered nursing students on patient care. Teaching and Learning in Nursing, 8(2), 2013, 63-67.

[13]. Morris E., Sampling from Small Populations. www.google .com. accessed 17th March, 2017.

[14]. Papaleontiou - Louca E., Metacognition and Theory of Mind. (Cambridge Scholars Publishing, 2008).

[15]. Mahlanze H. T., Evaluation of the use of guided reflective journals during clinical learning and practice by undergraduate nursing students at the Durban University of Technology. Dissertation submitted in fulfilment of the requirements for the Degree of Master of Technology in Nursing in the Faculty of Health Sciences at the Durban University of Technology. 2014.

[16]. Olson J., C and Johnson S., Implementing journal writing in grade 8, Academic Research International, Part-II: Social Sciences and Humanities, 3(3), 2012. 
DOI: $10.21522 /$ TIJNR.2015.03.02.Art017

ISSN: $2520-3126$

[17]. Musah K. T., Okueso G. O., Ojo P. A., and Awodiya M.O., Influence of Reflective Journaling on Students' Clinical Learning and Practice a paper presented at the Department Seminar, Kwara State University, Malete, Nigeria. July, 2017.

[18]. RMIT University, Study and Learning Centre, (Melbourne, Australia. Reflective journals 2006

[19]. S. Mantzoukas, and M.A. Jasper. Reflective practice and daily ward reality: a covert power game. Issues in Clinical Nursing, 13(8), 2004, 925.

[20]. Spring Spring. A guide for writing a "reflective journal" (Adapted from Professor Wayne Iwaoka, the University of Hawaii at Manoa) SMS491/EDW472 Karp-Boss, Weller and Boss, 2007. 


\title{
Knowledge, Attitude and Behavior on Overweight and Obesity, Health Consequence and Adaptation to Lifestyle Changes among Early Middle Age Medical and Non-medical Health Care Staffs of NMC Day Care Centre, Abu Dhabi, UAE
}

\author{
Article by Anette Marina Rodrigues \\ $B S c, R N$, Texila American University \\ E-mail: annsweety39@gmail.com
}

\begin{abstract}
This non-experimental descriptive cross-sectional survey explored the knowledge, attitude and behavior (KAB Survey) related to overweight and obesity its health consequence and ways to manage ideal body image and balanced weight with diet, exercise and lifestyle modification among medical and non-medical staffs belonging to origin Indian, Nepalese, Middle east and Philippines of NMC day care center, AL wadi, Abu Dhabi, UAE.

Design and procedure: A non-experimental descriptive Random cross section study was conducted among (30) medical and non-medical staffs out of 120, who have joined the team for over a period of 1.5 to 2 years since 2014. Two months convenient sampling was done using Semi-structured questionnaire. Qualitative and quantitative data analyzed through Content analysis and Health Behavior Knowledge Scale.15 questions, including open ended Questions, choose correct answer from four options and fill in the blanks was used as method to assess Health and Behavior Knowledge.

Results: The findings showed that Random Sampling of 30 Staffs, from 2014 and who stayed in UAE. $73.3 \%$ had normal BMI, 23.3\% fall under Overweight, and 3.3\% fall under Obesity. In 2016, the result showed $36.6 \%$ have normal, 46.6\% Overweight, $10 \%$ Obese. The results of knowledge on diet were as follows $-73.3 \%$ had adequate information on diet and $26.6 \%$ lacked information on diet, whereas the attitude towards Overweight and Obesity, $66.6 \%$ were aware on negative health consequence and ways to handle them. With the knowledge on diet, $86.6 \%$ have adequate information on diet and $13.3 \%$ still have misconception on diet, whereas the attitude towards Overweight and Obesity was remarkable 100\% were aware on negative health consequence and ways to handle them

The vast significance which was alarming was in area of exercise. $33.3 \%$ had positive attitude towards exercise and $66.6 \%$ had negative attitude towards exercise. After training on Exercise for 1 month, results are as, $83.3 \%$ have positive attitude towards exercise, $13.3 \%$ have reduced weight and gained muscle strength through exercise and $16.6 \%$ have still misunderstood about concept of exercise.

The body Image Tool parameter results as follows using 9 figures, black and white of male and female, the current body image value is minimum shape of $4(n=7), 5(n=7), 6(n=9), 7(n=3)$ to maximum shape 8 $(n=1)$ and ideal body image minimum shape individuals want to attain,4(n=15), 5(n=6), to maximum shape $6(n=1)$, neutral $(n=1)$

Conclusion: The study reveals that individual have interest to follow correct pattern of diet, exercise and maintain their body image and control Overweight and Obesity, with minimum exercise of 30 minutes to lhour every three days in a week. One more point comes into consideration is $\underline{H}$ w to go about to attain measurable values to ideal Body weight and Image as long term goal.
\end{abstract}

Keywords: Knowledge, Attitude, Behavior, Lifestyle, Diet, Exercise, Body Image

\section{Introduction}

The purpose of study is determine the extent of knowledge, attitude and behavior on Overweight and Obesity, health consequence and ways to adapt to lifestyle changes among medical and non-medical staffs of my facility. 
DOI: $10.21522 /$ TIJNR.2015.03.02.Art018

ISSN: $2520-3126$

1. Identify total number of staff, fall under category of overweight and obesity.

2. Assess the knowledge on type of diet including $24 \mathrm{hrs}$. Menu.

3. Assess the behavior on prevention of health risk consequence before and after pre-and post, Semi Structured Questionnaire and Health Behavior Knowledge Scale.

4. Identify the effect of health education (leaflets) on exercise and adapt changes of lifestyle to give time for exercise, few hours every week.

5. Identify attitude of the staff to personal present body image and ideal body image

The target group identified is between age group of 23 to 35 years. The problem identified within two years is that Overweight and Obesity is gradually increasing and need to adapt lifestyle changes like diet control and exercise to reduce the Overweight and Obesity, to avoid health consequence in later years.

The existing solution is to provide adequate Knowledge on Healthy Diet, Exercises and identify the changes in attitude and behavior on balanced diet, exercise and lifestyle changes. The best solution would be spare 1 hour of time every alternate day to do Exercise and avoid unhealthy food, limit calories to 1500 in a day by following Diet Meal Plan for 24 hours. Limitation is long duty hours, late shifts and time constrains.

In order to be successful in following the plan, provide adequate Knowledge through PPT and Printouts on health-related effects of Overweight and Obesity like early CVS, Hypertension and Diabetes Mellitus. And have an adequate positive change in behavior and attitude of Staffs towards Overweight, Obesity and Health Consequence and adapt lifestyle changes in order to maintain their body Physique as they have imagined.

\section{Methods}

A non-experimental descriptive cross section study was done on 30 medical and non -medical staffs. Staffs were selected on basis of their stay in UAE for more than 18 months. The staffs' age more than 36 years were exempted from the research.

The KAB survey reveals the knowledge, attitude and behavior related to diet, exercise, health consequence related to overweight and obesity and misconception and misunderstanding that I would like to implement and potential barriers to behavior changes.

Consent was taken from the management and participants before starting the study.

Anthropometric and Demographics study including age, job class, education level and working hours. All participants fall within age group of 23 to 35 years, early middle age. (Figure -1). Observation method was used to assess the physical appearance of individuals, non-biased random selection with unstructured pretest and posttest Questionnaire and PPT was used with time frame of 1 months.

Body Image was assessed using the Body Image Assessment Methodology (Figure- 1A). Staffs were given card with black and white line drawn image of 9 male and female ranging from very thin to very Obese. Staffs were asked to indicate which drawing most resembled their current figure (current body size) and the figure they wished most to resemble (ideal body image), a high score indicate larger body size. A body diaspora score was derived from the discrepancy between current and ideal figures. A high score indicates greater discrepancy between ideal and current body size. (Ref-2).

Body Image tool-(Figure- 1A). 

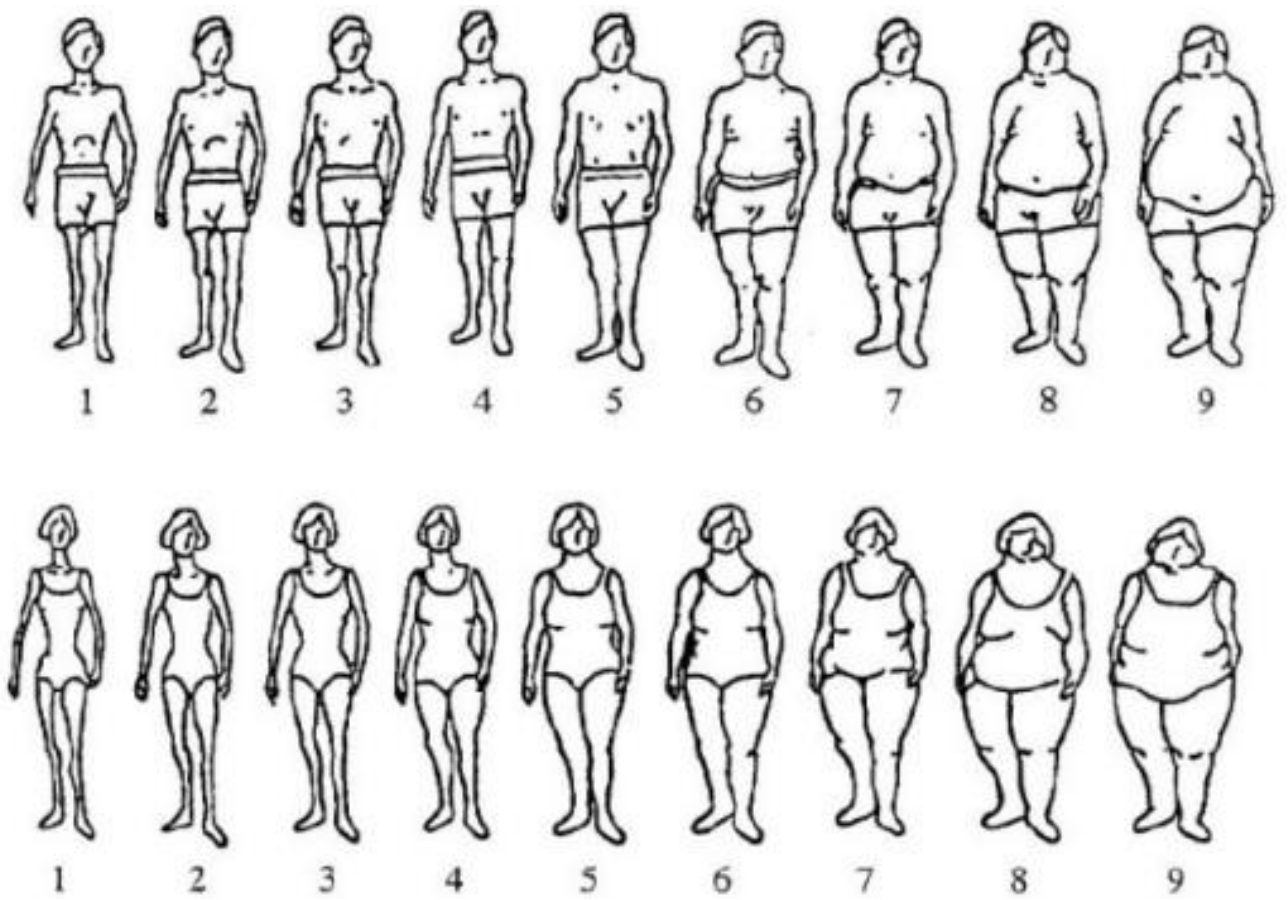

Health Behavior knowledge, physical activity knowledge and Balanced diet was done using power point presentation and handouts.

\section{Result}

The bar graph (Figure-2) represents the difference of BMI among different individual from different countries who live and work in UAE from past 1.5 to 2 years. The findings show that Random Sample of 30 Staffs, worked from 2014 work and stay in UAE 73.3\% had normal BMI, 23.3\% fall under Overweight, and $3.3 \%$ fall under Obesity. In 2016, currently 36.6\% have normal, 46.6\% Overweight, $10 \%$ Obese.

The results of knowledge on diet as follows $73.3 \%$ had adequate information on diet and $26.6 \%$ lacked information on diet (Figure-3A). After training on Diet for 1 month, results are as follows the knowledge on diet , 86.6\% have adequate information on diet and $13.3 \%$ still have misconception on diet. (Figure-3B). The result shows that staffs had adequate knowledge on health information, but did not have correct information on ill health and type of diseases like Hypertension, Diabetic Mellitus and Cardiovascular diseases which Intern may come earlier in life due to overweight and obesity.

The introduction of diet plan (Ref-1), vegetarian and non-vegetarian, depending on their choices, a diet plan for 24 hours was given. Individuals were given time period of one month to decide, adapt and implement. In the post assessment, I got positive results saying $10.6 \%$ increase in following the diet pattern and have decided and planned to adopt the desired calorie and type of food to be introduced into daily diet through pretest and posttest Questionnaire.

However, the vast significance which was alarming was only $33.3 \%$ had positive attitude towards exercise and $66.6 \%$ had negative attitude towards exercise (Figure-4A), after the information provided on exercise $83.3 \%$ have positive attitude towards exercise, $13.3 \%$ have reduced weight and gained muscle strength through exercise and $16.6 \%$ have still misunderstood about concept of exercise (Figure-4B). Knowledge on exercise, type of exercise like Zumba, walking, jogging, Aerobics, Cycling, Gym, Outdoor games and activities, advantages and disadvantages, type of exercise suitable for adjustment to duty hours and type of ergonomics to be used in hospital. After information on exercise there was $50 \%$ increase from pretest, in the individuals who were ready to adopt to follow in their routine, three times a week, at least 30 minutes of exercise and later increase depend on adjustment of time. 
DOI: $10.21522 /$ TIJNR.2015.03.02.Art018

ISSN: $2520-3126$

The body Image Tool parameter results as follows using 9 figures, black and white of male and female, the current body image value is minimum shape of $4(n=7), 5(n=7), 6(n=9), 7(n=3)$ to maximum shape 8 $(n=1)$ and ideal body image minimum shape individuals want to attain,4(n=15),5(n=6), to maximum shape $6(n=1)$, neutral $(n=1)$.(Figure-5). The concept of ideal body image had a great outcome require to be follow and maintain in long run. Right now staffs did not bother on body image due to work pressure and lack of time to follow diet and exercise, but ideal body image of 4 , shows about their thoughts to maintain balanced weight.

The attitude towards Overweight and Obesity was remarkable, $100 \%$ were aware on negative health consequence and ways to handle them and $80 \%$ of individuals had knowledge on health with their own past experiences and self-study and after the ppt presentation and posttest $100 \%$ individuals were able to gain adequate knowledge on health, diseases and its prevention the attitude towards Overweight and Obesity. (Figure-6).

\section{Discussion results comes first before discussion}

KAB Survey helped me to identify the need for change in knowledge, attitude and behavior of individual in short duration of time. The effectiveness of health teaching, teaching on diet, exercise and health consequence helped the individual a change their lifestyle and adapt to balanced health and nutrition.

The results have achieved target positive result in early middle aged individual who would adopt and have already started to adapt lifestyle changes in diet, health, exercise and body physique. It helps the management of health care to provide facilities like Yoga, Zumba and indoor Gym for the staffs and plans are going on for the same.

The results are in consistence to other researchers. Similar studies were conducted on Female Adolescents in Urban Philadelphia (Ref 3)-Use in-text citation instead

\section{Results}

Physical activity, inactivity and perception of ideal body size emerged as most important contributory factors to Obese Status. There was no statistically significant matched-pair difference in macro nutrient and micro nutrient intakes, self-esteem, eating attitudes, health behavior knowledge or maturation status of these individuals. Obese individuals had significantly lower levels of physical activity, higher inactivity and a larger perception of ideal body size than non-obese individuals.

\section{Discussion}

Knowledge and attitudinal factor (with exception of perception of ideal body size) had far less association with Obesity than activity related behavioral factors. These findings suggest that future intervention strategies should pay particular attention to physical activity, inactivity and body image attitudes.

Further question arise through my research findings is long term consistency in early middle age, in maintaining balanced health, lifestyle and exercise, balancing with work, stress and time and prevention of early entry of disease like Diabetic Mellitus, Hypertension and Cardio Vascular Diseases.

\section{Conclusion}

This study has helped staffs as health care members to take care of their health, diet and manage exercise as par to their work schedule in well balanced form. This will help them to follow regular routine, balance with work and time for self. They would plan out 30 minutes to 1 hour of exercise every three days in a week. This will have a positive effect on long term prevention of getting risk related diseases like Hypertension, Diabetes and Cardio vascular. The body Image parameters give an insight into oneself to

change one's lifestyle and maintain it. This research has helped staffs to think about the seriousness of one self, taking care of health and wellbeing. 


\section{Figures and tables}

Anthropometric and Demographic Study (Figure- 1)

\begin{tabular}{|c|c|c|}
\hline Content & & Percentage \\
\hline \multirow[t]{2}{*}{ Gender } & Male $(n=16)$ & $53.33 \%$ \\
\hline & Female $(n=14)$ & $46.66 \%$ \\
\hline Age & Years & $23-35$ \\
\hline Weight & Kilograms & $40-100+-5$ \\
\hline \multirow[t]{2}{*}{ BMI } & Male & $20-30.4+-4.4$ \\
\hline & Female & $15-25+-4.4$ \\
\hline \multirow[t]{4}{*}{ Country } & $\operatorname{Indian}(\mathrm{n}=18)$ & $60 \%$ \\
\hline & Nepalese $(n=4)$ & $13.3 \%$ \\
\hline & Middle East(n=2) & $6.6 \%$ \\
\hline & Philippine $(\mathrm{n}=6)$ & $20 \%$ \\
\hline \multirow[t]{2}{*}{ Education } & Medical Staff $(n=14)$ & $46.6 \%$ \\
\hline & Non-Medical Staff $(n=16)$ & $53.3 \%$ \\
\hline \multirow[t]{4}{*}{ Job Class } & Registered Nurse $(n=11)$ & $36.6 \%$ \\
\hline & Practical Nurse(n=3) & $10 \%$ \\
\hline & $\begin{array}{l}\text { Front Office } \\
\text { Executives(n=8) }\end{array}$ & $26.6 \%$ \\
\hline & messengers $(\mathrm{n}=8)$ & $26.6 \%$ \\
\hline \multirow[t]{4}{*}{ Years at NMC } & 0-6 months & Nil \\
\hline & 6-12 months & Nil \\
\hline & $13-16$ months $(\mathrm{n}=8)$ & $26.6 \%$ \\
\hline & $17-24$ months $(n=22)$ & $73.3 \%$ \\
\hline \multirow[t]{2}{*}{ Shift Hours } & $\begin{array}{l}\text { Split shift }(9: 00-21: 00) \\
\text { 4hrs break }(n=26)\end{array}$ & $86.6 \%$ \\
\hline & $\begin{array}{l}\text { Straight Shift }(9: 00-16: 30) \\
(\mathrm{n}=4)\end{array}$ & $13.3 \%$ \\
\hline
\end{tabular}


DOI: $10.21522 /$ TIJNR.2015.03.02.Art018

ISSN: $2520-3126$

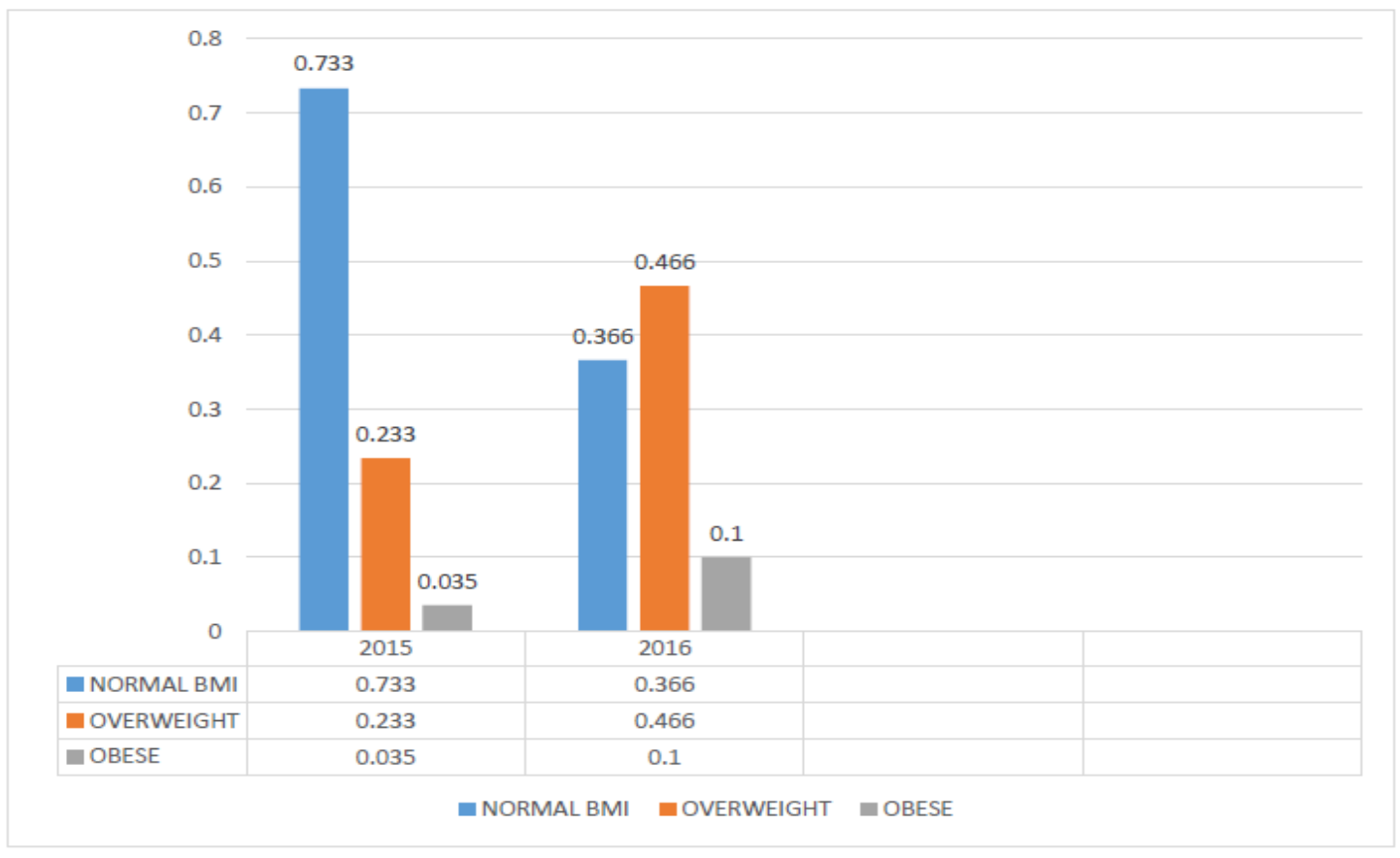

Figure 2. One year BMI statistics of individuals

\section{KNOWLEDGE ON DIET-PRETEST-Figure- 3A}

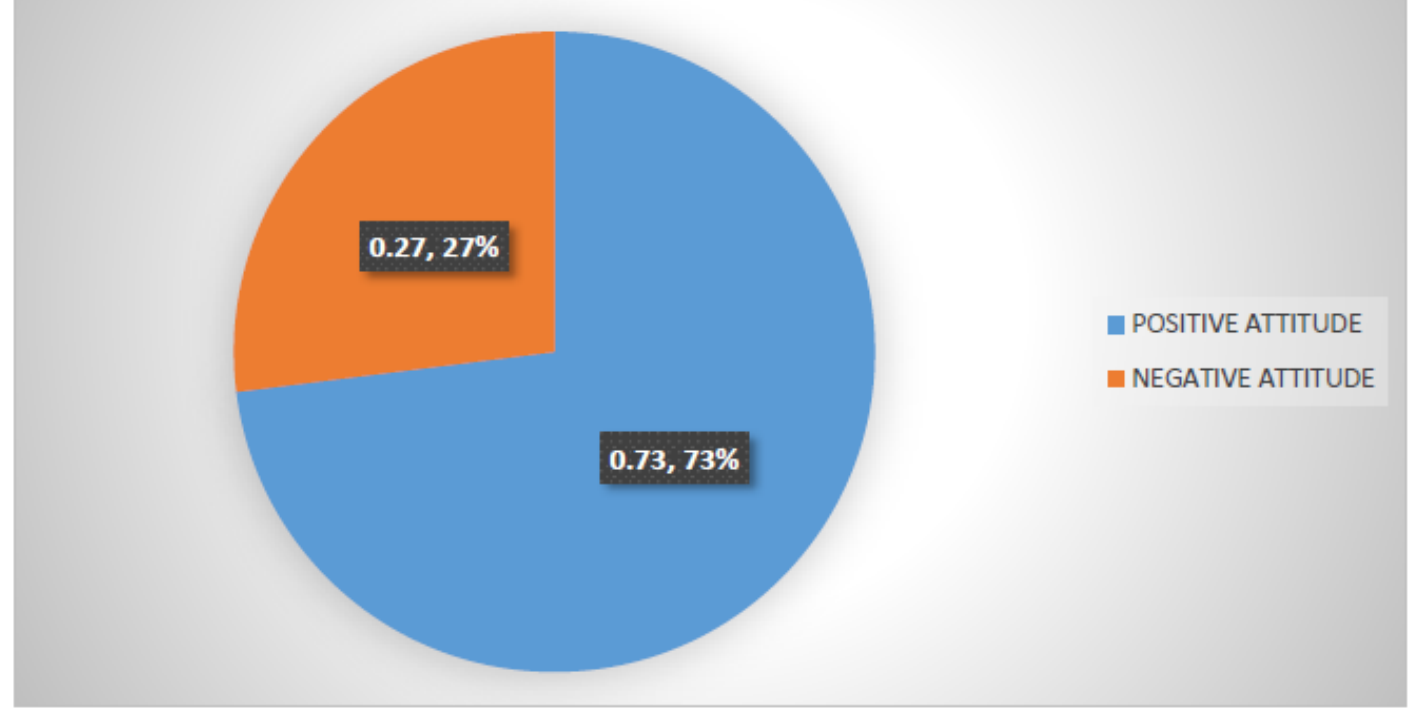

Figure 3a. Use instead here 


\section{KNOWLEDGE ON DIET-POST TEST Figure -3B}

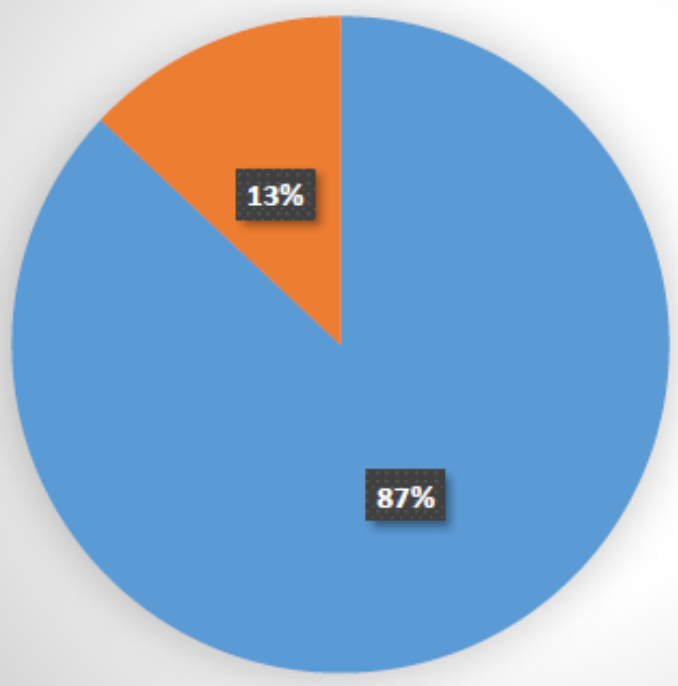

口 POSITIVE ATTITUDE

nEGATIVE ATTITUDE

\section{KNOWLEDGE ON EXERCISE-PRETEST Figure- 4A}

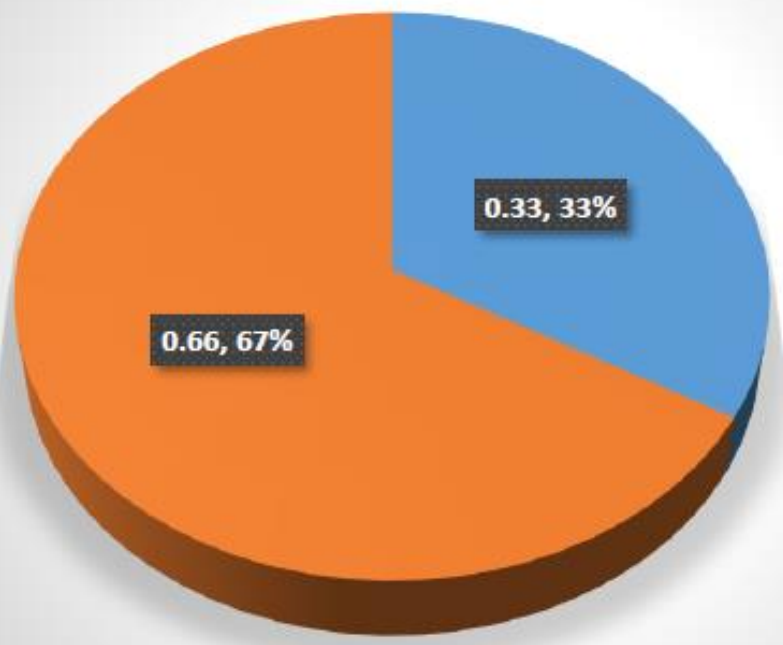

- POSITIVE

- LACKING 
DOI: $10.21522 /$ TIJNR.2015.03.02.Art018

ISSN: $2520-3126$
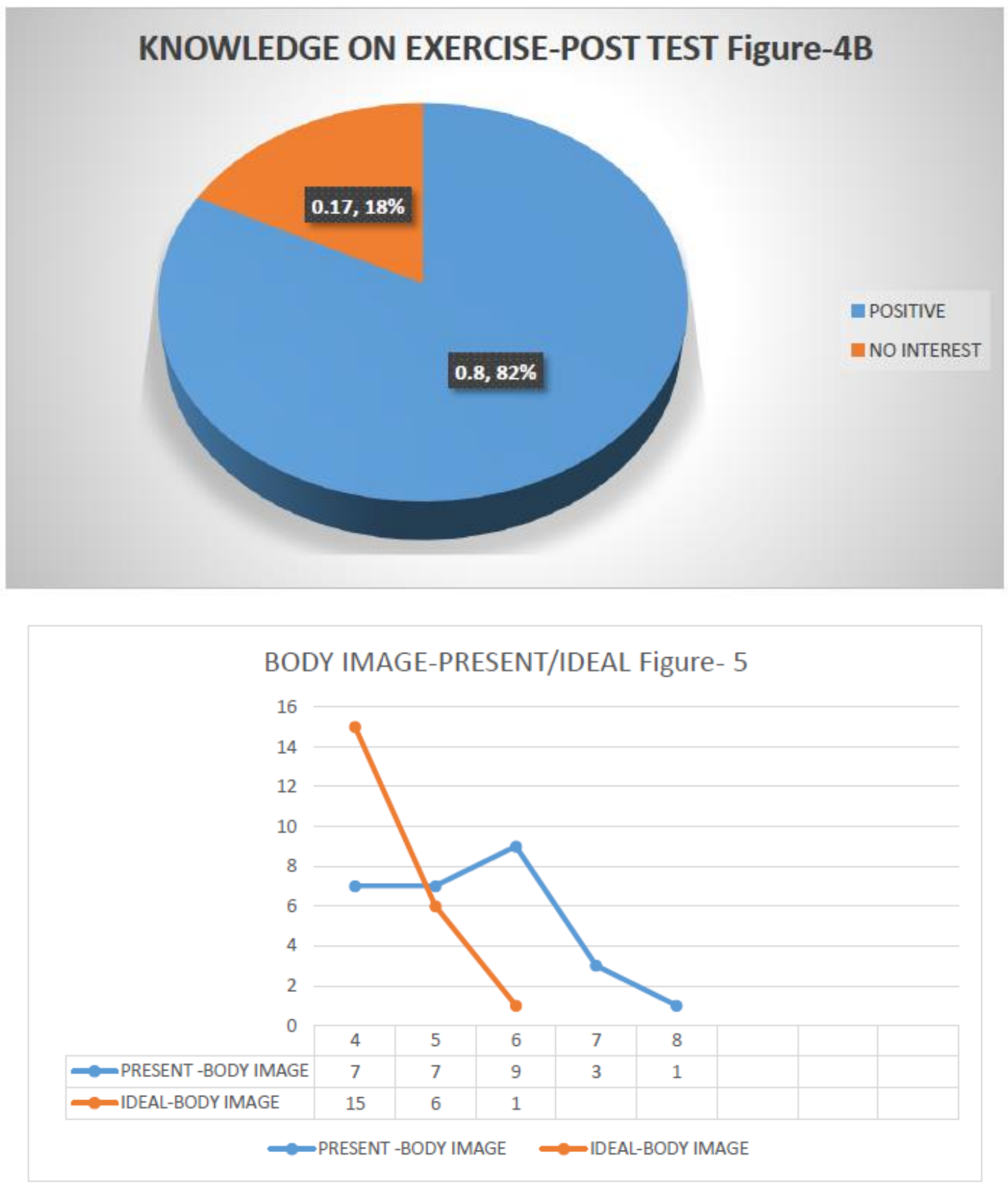


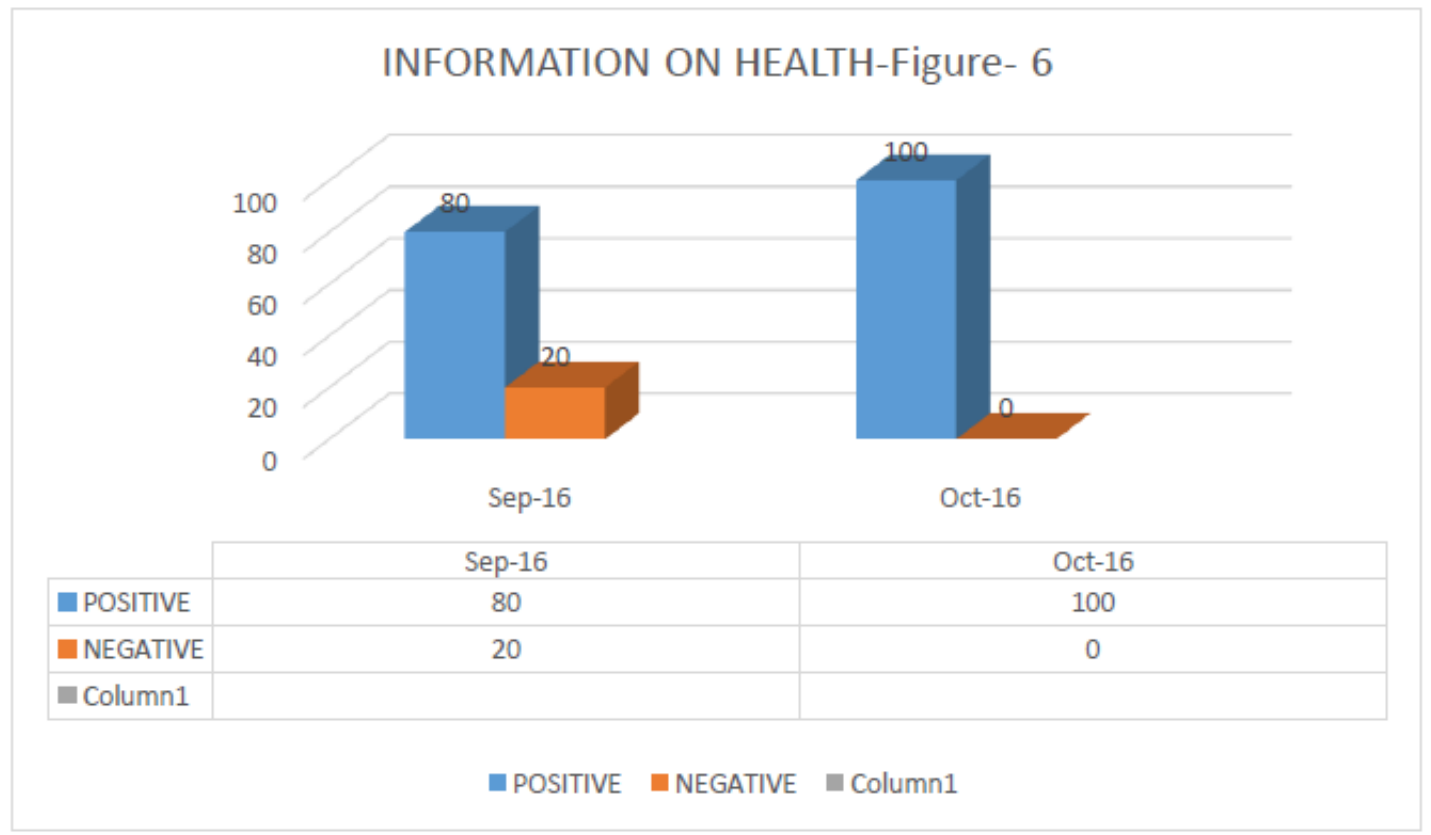

\section{Acknowledgment}

I acknowledge that this research is original, done on my own efforts, with my own ideas, knowledge and information. The content is true and reliable which is done on participant's approval.

\section{Reference}

[1]. A Study to Assess the Knowledge and Attitude of Adolescents on Obesity at Selected Senior Secondary Schools in Amritsar in a View to Develop and Distribute Information Booklet, International Journal of Education and applied research IJEAR Vol. 4, Issue 1, Jan - June 2014, ISSN: 2348-0033 (Online) ISSN: 2249-4944 (Print).

[2]. Obesity: preventing and managing the global epidemic. Report of a WHO Consultation. Geneva, World Health Organization, 2000 (WHO Technical Report; Series, No. 894).

[3]. Obesity-Related Knowledge, Attitudes, and Behaviors in Obese and Non-Obese Urban Philadelphia Female Adolescents, Department of Anthropology, University of Pennsylvania, Philadelphia, Pennsylvania. Address correspondence to Penny Gordon-Larsen, Department of Nutrition, University of North Carolina at Chapel Hill, Carolina Population Center, CB \#8120 University Square,123 West Franklin Street, Chapel Hill, NC 27516-3997.

E-mail: gordon_larsen@unc.edu Copyright @ 2001 NAASO. 


\title{
Importance of Tuberculosis (TB) Infection Prevention among Nurses and Patients at St. Dominic Mission Hospital
}

\author{
Article by Elizabeth Njovu \\ Nursing, Texila American University \\ E-mail:njovulisa@yahoo.com
}

\begin{abstract}
Tuberculosis infection control is the topic of great importance especially in developing countries where poor immunity, overcrowding, and some infections are a predisposing factor for Tuberculosis infection. The most common predisposing factors and measures to reduce the spread of TB infection from one person to the other are elaborated in this study. The findings reveal that even nurses taking care of the TB patients are at great risk of contracting the infection, hence strong TB infection prevention guidelines need to be strictly followed at all level of care.

Main Objective: To explore the knowledge and understanding of the qualified Nurses working in the out-patient department and medical ward in relation to Tuberculosis infection control and its impact on the hospital stay and patients outcome.

The method used: A cross-sectional study was conducted to identify predisposing factors to TB Infection. Data was collected by self-structured questionnaire of both closed and open-ended questions. A purposeful sample of 30 nurses from an out-patient department and male medical ward participated on a voluntary basis. I personally worked in these two departments to get the experience of what and how TB infection control is observed by nurses.

Results: 30 nurses participated: 19 females and 11 males; aged 21 to 50 years. Majority (82\%) diploma Holders, did registered nursing. Findings revealed that (75\%) appreciates the use of protective clothing - Masks while attending to TB infected patients while $25 \%$ did not, $45 \%$ finds it important to isolate those who are suspected to have TB and those having active TB, 100\% observed the guideline of keeping the doors and windows open for free movement of air.
\end{abstract}

Keywords: TB infection prevention, Environment control, Protective clothing, Isolation of the infected.

\section{Introduction}

Tuberculosis (TB) is an infectious disease that is caused by Mycobacterium tuberculin (MTB). Tuberculosis commonly affects the lungs, but can also affect other organs in the body. Most people especially those that have been exposed to the infection do not present with symptoms, this stage is known as a latent phase of tuberculosis. About $10 \%$ of this latent phase would develop into active disease. The classic symptoms of active TB are a chronic productive cough, most time with blood-stained sputum, fever, sweats, chest pain, anorexia and weight loss.

Tuberculosis is an airborne disease that is spread from one person to another when a person, with symptoms of active lung Tuberculosis cough, spit, speak, or sneeze. According to research, active TB infection is more common in $70 \%$ of people with HIV/AIDS and in those who have compromised immunity. Diagnosis of active TB is based on sputum examination (Smear microscopy, Gene-X-pert, and Culture), as well as microscopic examination and culture of body fluids. About $25 \%$ of people may not have any symptoms i.e. they remain "asymptomatic". (TB guidelines 2005)

According to the Zambia Ministry of Health, National TB and leprosy control program manual 2009 and the national Health Care workers TB evaluation protocol 2011, the national TB case notification rate was $337 / 100,000$ of the population. 
DOI: $10.21522 /$ TIJNR.2015.03.02.Art019

ISSN: $2520-3126$

\section{Purpose of the study}

The purpose of this study is to assess the requirements for the effective TB infection prevention and to identify an effective infection prevention policy and plan for St. Dominic Mission Hospital in Ndola. The project is based on the findings in the Hospital risk assessment and is consistent with the national Tuberculosis infection prevention guidelines for the patients and clients 2013.

It is also crucial for Nurses working in the outpatient department and medical ward because of their considerable involvement in the care of the TB patients. The issues to be explored in the study surround the understanding and knowledge of tuberculosis infection prevention and how Nurses can contribute to the effective TB infection prevention and patient's outcome.

\section{Background of the study}

Tuberculosis infection prevention depends on a number of factors. Other studies reveal that the most important risk factor globally is HIV; which account for $70 \%$. This is a significance problem in subSaharan Africa. (WHO Estimated HIV Prevalence in new TB cases, 2010) Only a few clients/patients without HIV will develop active TB disease. When a patient has both TB and HIV, priority is given to TB treatment before initiation of antiretroviral treatment.

Tuberculosis is associated with overcrowding, malnutrition, chronic lung disease and Smoking of cigarettes. Some illnesses like diabetes mellitus and habits like alcoholism can also increase the risk of developing tuberculosis.

In Zambia Tuberculosis prevention and control efforts rely primarily on the vaccination of infants, early detection of those infected and appropriate treatments of active cases. In children, Bacillus Calmette-Guérin vaccination has reduced the risk of getting the infection by $20 \%$ and the risk of latent phase turning into disease by $60 \%$. It is a national policy to screen all HIV-infected patients and all the exposed people for Tuberculosis, early detection and treatment have reduced the fatality of the diseases. The Ministry of Health through the help of PEPFAR has intensified the implementation of WHO 3I's which is:

- Intensified Case Finding

- Isoniazid Preventive Therapy

- Infection Control

\section{Practical aspect of tuberculosis infection prevention}

According to the research findings, the following were identified as practical ways to enhance TB infection prevention

- Personal hygiene: cover the mouth when coughing or sneezing, daily change of linen and clothing promotes good well being

- Good nutrition: eating a well-balanced diet will boost one's immunity that will help fight the infections

- Well ventilated and clean environment that prevent stagnation of air and bacterial growth. Open windows and doors will promote cross ventilation in the room. Prevent overcrowded.

- Isolation of the infected especially the $1^{\text {st }}$ two weeks of diagnosis and treatment when the bacteria are more active.

- Triage all those patients who are coughing, identify the coughers in the outpatient department give them face masks and attend to them as soon as possible.

- Practice hand wash before and after attending to every patient

- Decontamination and processing of linen and used instruments

- Proper disposal of waste using proper color codes

- Wearing of protective clothing

- Health education on personal hygiene to patients and caregivers 
Good planning, adequate funding and constant program monitoring and evaluation are very important in the TB infection prevention. Failure to adequately fund the program would risk the staff and patients being infected. Therefore the Hospital management needs to be committed to constantly and regularly provide resources through efficient budgeting and prioritizing.

\section{Research method}

The research was done at St. Dominic's Mission Hospital, Ndola district, Copperbelt province, Zambia. The research used a cross-sectional quantitative design, rationale being that cross-sectional is suitable as it saves time and resources (Saunders et al., 2007). Collected data gave details on TB infection prevention and control. Purposive sampling, a type of non-probability sampling, which is extremely useful was used to gain useful and rich, also in-depth information about nurses working in the outpatient department and medical wards, where nurses come in direct contact with TB patients.

Data collection method used was self-administered structured questionnaire of both open and closed ended questions. Questionnaires were hand delivered to 30 nurses and then hand-collected, to ensure confidentiality; and data collected were verified for quality. Apart from the questionnaire I personally worked in the outpatient department for one month and medical ward for another month. The information gathered is both from Nurses' experience and my own interaction with nurses and patients in the two departments

\section{Literature review}

Tuberculosis infection control program is based on the three levels of prevention, that is:

1. Administrative controls: This reduces the risk of exposure and is the number one and most important level of a TB infection control program. Administrative controls have the following activities:

- Assigning someone the responsibility and authority to coordinate TB infection control program at the health-care setting;

- Conducting a TB infection control risk assessment of the staff

- Developing and instituting a written TB infection-control plan to ensure prompt detection and treatment,

- Isolation and treatment of persons who are suspected or confirmed with TB disease;

- Ensuring the availability of recommended laboratory processing, testing, and reporting of results;

- Implementing effective work practices for managing patients who may have TB disease;

- Ensuring proper cleaning, sterilization, or disinfection of equipment that might be contaminated.

- Educating, training, and counseling HCWs, patients, and visitors about TB infection and disease;

- Annual screening of all health care workers

- Testing and evaluating workers who are at risk for exposure to TB disease;

2. Environmental controls: which prevents the spread and reduces the concentration of droplet nuclei. Adhering to the environmental factors for TB infection prevention would help a lot to reduce the spread of TB infection. The following factors reduce the spread of TB infection:

- Monitoring the flow of mechanical or natural air flow in the waiting area and examination room.

- Using posters and signs to remind patients and staff of proper cough etiquette (covering mouth when coughing) and respiratory hygiene.

- Signage to keep doors and windows open for free flow of air

- Avoid overcrowding of patients.

3. Personal Protective equipment: which further reduce the risk of exposure. Personal protective equipment when used together with other strategies of infection control reduces the risk of TB transmission to staff and others within the hospital. Masks and tissues are made available to the patients that are coughing.

Every patient suspected to have TB infection is nursed in an institution set up like a Hospital, Chest center or Chest clinic. In order to control TB infection among the patients who come to the hospital the following concepts should be considered seriously: 
DOI: $10.21522 /$ TIJNR.2015.03.02.Art019

ISSN: $2520-3126$

1. Good and well-structured organization: In the hospital, patients need to know who screens TB patients, who do the counseling, who dispenses the drugs

2. Proper planning and adequate staffing: Tuberculosis infection prevention activities require good planning for and adequate staff allocation for effective outcome

3. Systemic nursing and Health assessment of the patient: the nurse attending to patients with TB should have learned skills to systematic assess the patient for proper diagnosis and plan of patient care.

4. Proper History taking and physical examination, a detailed history and physical examination is obtained for the patient which aid in diagnosing the TB infection

5. Diagnosis and treatment: when the patient has been diagnosed with TB infection treatment are commenced immediately.

6. Prevention of complications of other systems: continuous monitoring of the patient with TB is very important to avoid other organs and body system getting affected. The patient is nursed in the hospital especially the $1^{\text {st }} 2$ weeks of treatment and in an isolation room

7. Proper documentation and reporting: the information is properly documented and kept well for future reference, or and to be used for reporting on program and patient outcome

\section{Recent study}

In the combined study by Dagmar Sissolak, Frederick Marais and Shaheen Mehtarhe on TB infection prevention and control's experiences of South African nurses, the authors describe that TB infection in South Africa is one that is characterized by the higher degree of TB and HIV co-infection. In their research, the authors assessed the nurses' experiences of factors influencing TB infection prevention and control practices to identify risks associated with potential ways of transmission. In their finding, they discovered that the nurses' had major concerns about the possible risk of TB transmission to both patients and staff. The authors' also discovered the following as factors that lead to non-adherence to infection prevention guidelines among nurses:

- Lack of facilities to isolate the TB-infected patient

- Inadequate personal protective equipment,

- Lack of a TB-IPC policy,

- Inadequate TB training for staff,

- Communication barriers between staff and patients,

- The work overload for nurses.

\section{Levels of TB infection prevention}

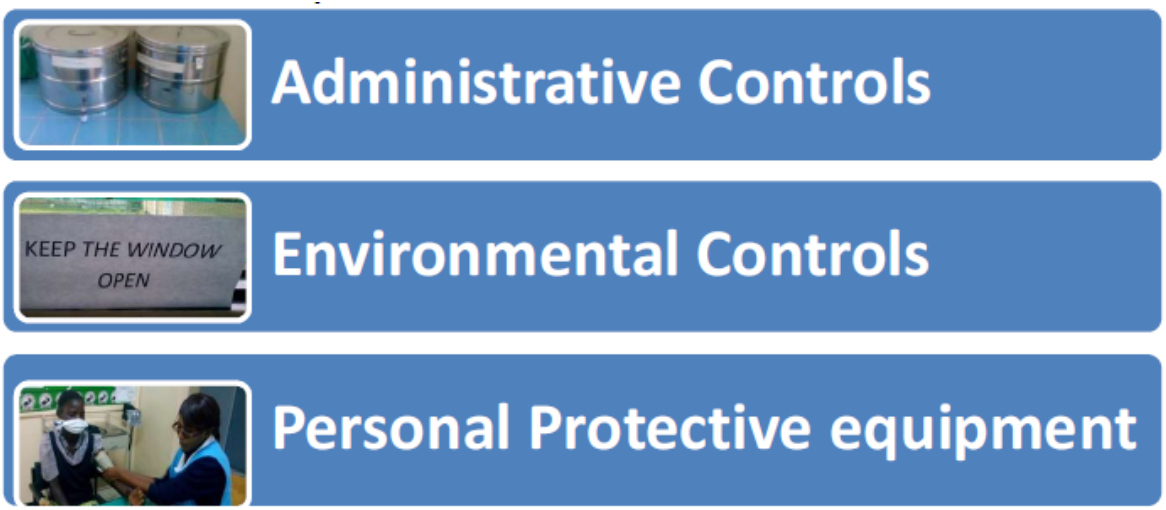




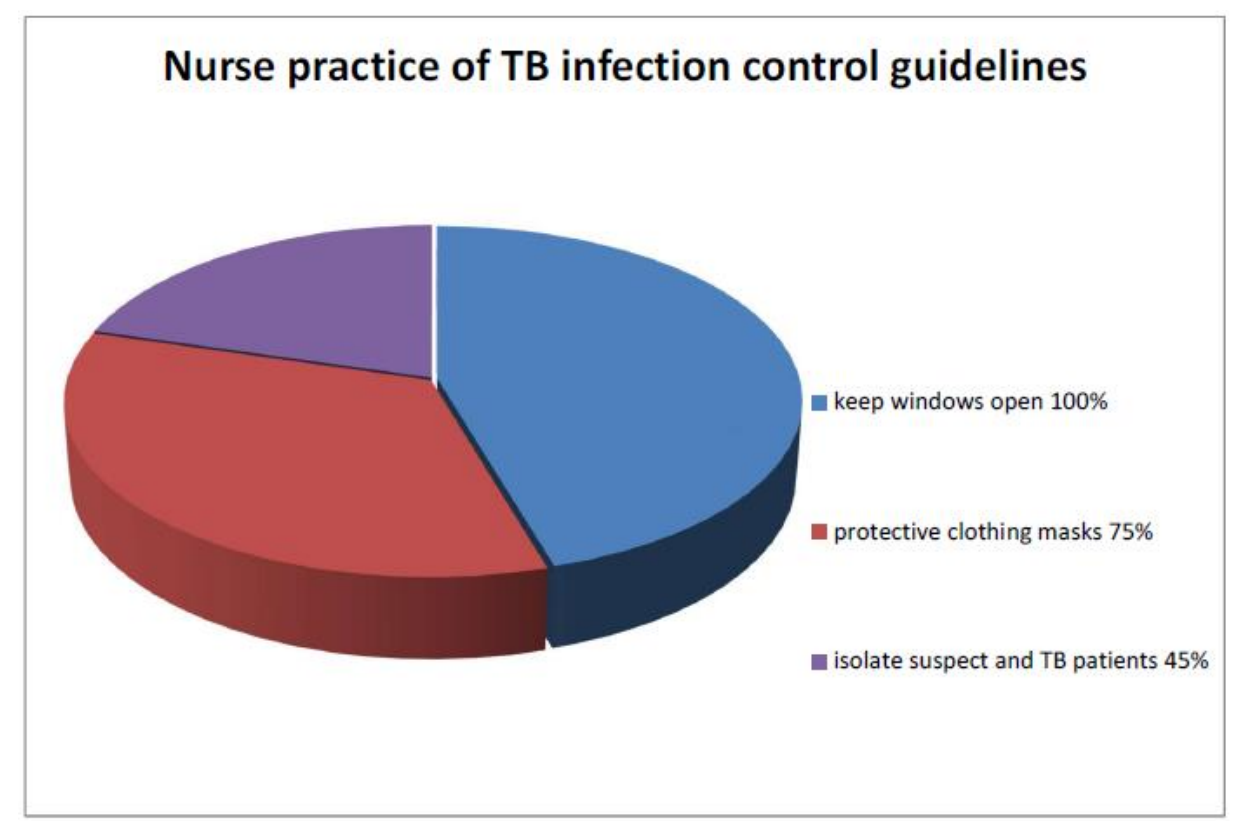

\section{Discussion}

Total numbers of study participants were 30 nurses: 19 females and 11 males; aged 21 to 50 years. Majority (82\%) diploma Holders, did registered nursing.

\section{Knowledge of nurses towards infection prevention and control}

Participants' had adequate knowledge about TB infection prevention as their responses gave this impression, and guidelines were available. The use of protective clothing was appreciated though they admitted that they were erratically supplied. The participants expressed that management did not priorities TB infection prevention in the budget.

The low response on isolating TB suspected patient signified noncompliance to TB infection prevention guidelines. Literature has specified that Tuberculosis infection control program is based on the three levels that are Administrative controls, Environmental controls, and Personal Protective equipment.

Equally, a study by Dagmar Sissolak, Frederick Marais and Shaheen Mehtahe on the TB infection prevention and control's experiences of nurses in South Africa, reveals that if guidelines are not followed, TB infection can be transmitted to both patients and staff. The authors' also discovered the main factors for nurses' non-adherence to infection prevention guidelines that could lead to the greater risk of transmitting infection from one person to the other:

\section{Recommendations}

Recommendations were based on findings from the research and analyzed data.

To healthcare providers (Nurses) at St. Dominic's Mission Hospital: Nurses are commended for the adequate knowledge on TB Infection Prevention. However, the following are some recommendations and suggestions that need to be implemented by all nurses:

- Should comply with TB infection prevention guidelines.

- Should continue working on improving attitude towards infection prevention, despite the pressure of work.

To St. Dominic's Mission Hospital management: The hospital is commended for having TB Infection Prevention guidelines and policy which are being used in various departments. The following are recommendations, so as to help nurses and other healthcare providers improve on TB Infection Prevention:

- Management should make TB infection prevention program a priority in the hospital budget. 
DOI: $10.21522 /$ TIJNR.2015.03.02.Art019

ISSN: $2520-3126$

- Should continue assigning a nurse to triage patients in the outpatients

To the Ministry of Health: The Ministry of Health is congratulated for continuous efforts being made on measures to improve health services to the society and recognize more and more the needs of healthcare providers.

However, the ministry should support and fund more research on TB Infection Prevention and deploy more nurses to the reduce workload on patients.

\section{Conclusion}

In order to reduce the risk of TB transmission to both the nurse and the clients at St. Dominic's Mission Hospital, an emphasis has been made to all nurses to strictly follow the guidelines and policies put in place by the hospital and those of the national. Despite the few nurses that have the negative attitude on following the guidelines, most of them appreciate and follow the guidelines. They are aware that not only patients are at risk of getting the infection but, they too are at even greater risk. One thing that the hospital administrator has done is the allocation of a nurse in the outpatient department to identify all patients with a cough, these patients are provided with a mask or a tissue to use while coughing. These patients are seen first in order to reduce the time spent with other patients in the outpatient department.

\section{References}

[1].Ajay K. Sethi, Charles W. Acher, Bruce Kirenga, Scott Mead, Curtis J. Donskey, Achilles Katamba M, 2012. Infection Control Knowledge, Attitudes, and Practices among Healthcare Workers, Kampala, Uganda.

[2].Brown, B., Crawford, P., Nerlich, B. \& Koteyko, N 2008. The habitus of hygiene: Discourses of cleanliness and infection control in nursing work, Social Science \& Medicine, Vol. 67, pp. 1047-1055.

[3].Claasens MM, van Schalkywk C, du Tolt E, Roest E, Lombard CJ, et al. Tuberculosis in health care workers and infection control measures at primary health care facilities in South Africa. PLoS One. 2013;8:e76272. doi: 10.1371/journal.pone.0076272.

[4].Dorothy Osigwe Chanda. Infection prevention manual for community and health care institutions in Developing countries.

[5].Infection control committee 2011. St. Dominic Mission Hospital TB infection control plan and policy.

[6].Katowa P. Muka to, C.M. Ngoma, M. Maimbolwa, 2007. Compliance with Infection Prevention Guidelines by Health Care Workers at Ronald Ross General Hospital, Mufulira district.

[7].Khaled M. Abd Elaziz and Iman M. Bakr, 2008, Cairo. Assessment of knowledge, Attitude.

[8].Kozier, Barbara F., et al., 2004. Fundamentals of Nursing: Concepts, Process, and Practice, 7th ed., Pearson Education South Asia, Pte Ltd.

[9].WHO policy on TB infection control in health-care facilities, congregate settings and households. Geneva: World Health Organization; 2009.

[10].Zambia Ministry of Health. National TB and leprosy control program manual 2009. 


\title{
Common HIV/AIDS Clinical Symptoms among HIV-Positive Pregnant Women under ARV Therapy: Clinical Indicators for Non- Adherence to Treatment
}

\author{
Article by Admirabilis Kalolella \\ Ifakara health institute, Dar es salaam, Tanzania \\ E-mail: kalolella@hotmail.com
}

\begin{abstract}
The objective of this study was to assess adherence to option B+ARV triple therapy and describe common HIV/AIDS clinical symptoms as indicators of non-adherence among women giving birth in Dar es Salaam Tanzania. We analyzed the prevalence of non- adherence through clinical assessment of common HIV/AIDS symptoms, indicators of non-adherence to treatment.

The cross section method, clinical assessment and self-report interview was used to identify clinical symptoms related to HIV/AIDS. The study analyzed symptoms with higher frequency of occurrence and were termed as common HIV/AIDS clinical symptoms, and were established as indicators of nonadherence. Women with three or more of these symptoms were identified as non- adherents to ART. The study also analyzed the relationship of demographic variables and adherence.

Result. Among the 105 HIV infected women under triple therapy, 63(60\%) of them developed at least three HIV/AIDS related symptoms indicating that they were not adhering to the treatment, while 42(40\%) adhered to the ARV therapy prescribed. The Adherence to ART Indicators tool was established presence or absence of persistent clinical symptoms of; fatigue, night sweat, muscle ache and frequently fever, extreme and unexplained tiredness, pneumonia, recurring fever, profuse night sweats, and rapid weight loss. Demographic variables were not significant related to adherence.

In conclusion, the majority of HIV infected pregnant women receiving B+ARV triple therapy developed common HIV/AIDS clinical symptoms, indicating they were not adhering to treatment.
\end{abstract}

Keywords: Clinical assessment, non-adherence to ART, HIV infected pregnant women, HIV/AIDS symptoms, B+ ARV triple therapy, PMTCT.

\section{Background}

Following new recommendation of preventing mother to child transmission of HIV (PMTCT) by WHO, Tanzania started implementing new B+ ARV triple therapy for HIV infected pregnant women as part of antenatal services (Ngarina et al., 2014). Nearly 86\% of HIV-positive pregnant women in Tanzania receive ARV triple therapy (Ngarina et al., 2014; Avert, 2016). For the past few years Tanzania has been implementing this new option with all PMTCT centers practicing the option $\mathrm{B}+$, whereby pregnant women of gestation age of 34 weeks and above are being treated with Zidovudine + Lamivudine + Nevirapine /Nelfinavir (Tanzania PMTCT, 2016; Ngarina et al., 2014). The new regime is faced with the challenges of non- adherence (Ngarina et al., 2014; Tanzania PMTCT, 2016). The current methods to detect non-adherence, the laboratory detection of viral load and CD4 count are expensive, unaffordable, and invisible to our clinics, particularly the rural antenatal clinics with inadequate resources and unequipped laboratory facilities. Detecting non adherence using visible and affordable method of assessing HIV/AIDS clinical indicators is critical in order to fight mother to child transmission of HIV.

The maternal treatment using Antiretroviral therapy (ART) has been associated with significant increase of CD4 counts and reduction of viral load, resulting into improvement of maternal health and suppression of maternal HIV/AIDS related symptoms (Kilewo et al., 2009; WHO, 2015; Suksomboon et al., 2007). The ART reduce viral load through suppression of viral replication, which reduces number of 
virus in the blood plasma and improve health status of pregnant mother (Siegfried et al., 2011; WHO, 2015; Suksomboon et al., 2007). Reduced virus in blood offer protection of transmission of HIV infection from a mother to a new born (Siegfried et al., 2011; Moodley \& Wennberg, 2005; Tanzania PMTCT, 2016).Women that adhere to ART do not develop opportunistic infections clinical symptoms, while the absence of clinical symptoms is the indicator of adherence to treatment (WHO, 2015; Tanzania PMTCT, 2016; Hill et al., 2013). The non-adherence to ARV among pregnant women increases chances of HIV transmission to unborn babies, while improved maternal health offers fetus protection from being infected with HIV during pregnancy and delivery ( Hill et al., 2013; Kilewo et al., 2009; Kowalska et al., 2003; Suksomboon et al., 2007).

The economic hardship, hopelessness, poverty and lack of motivation discouraged women to continue taking ARV therapy (Ngarina et al., 2013; Ngarina et al., 2014). Weaning of the child for some, and stigma for others intimidated to continue with recommended regime of $\mathrm{B}+$ triple therapy, while fear to disclose HIV status when taking drugs increased barriers to ART adherence (Ngarina et al., 2013; Ngarina et al., 2014; Tanzania PMTCT, 2016).

Describing and establishing common HIV clinical symptoms, indicators tool of non-adherence of ARV therapy among pregnant women will empower health care workers $(\mathrm{HCW})$ to increase identification of non- adherence for immediate attention. These clinical symptoms will form a non- adherence clinical indicators tool that can easily be used by any trained health care staffs in replacement of the current expensive laboratory method. Any trained health care staffs, even these with the lowest education, which are common staffs available in antenatal clinic in resource poor countries, can use the tool. With this tool, the identification of non-adherence will be affordable and visible method to be practiced by any HCW at any level, even these with the lowest health care educations, which are common HCW placed in antenatal clinics in resource poor countries. The $\mathrm{HCW}$ can clinically diagnose non- adherence and provide appropriate care before the HIV is advanced to AIDS stage, risk factor for HIV transmission (WHO, 2015; Ngarina et al., 2014; Tanzania PMTCT, 2016). The Adherence to ART Indicators tool to detect non- adherence among pregnant women is crucial to prevent transmission of HIV from mother to child.

The objective of this study was to assess the adherence to B+ ARV triple therapy and describe common HIV/ AIDS opportunistic infection clinical symptoms as indicators of ART adherence among HIV infected women giving birth in Dar es salaam, Tanzania.

\section{Procedures and method}

The cross sectional descriptive study design was used to collect data from HIV infected women immediately or few hours after giving birth in Dar es Salaam municipal hospitals providing obstetric services. Municipal hospitals were selected based on attendance of pregnant women in these facilities for delivery services. The selected area and facilities have higher numbers of pregnant women infected with HIV giving births. This study was part of an assessment of prevalence of HIV infection.

Participants were obtained from labor/maternity wards among women who just completed giving birth. The antenatal card of all women delivered was scrutinized for HIV test results. Women who tested HIV positive based on information on antenatal card were eligible for this study. The HIV infected woman was approached by a study staff to determine her eligibility and recruited into the study if she was eligible. All participants with medical conditions that needed emergency medical care and those vomiting, unable to speak and in severe illness were excluded from the study. All interested patients were directed to interviewers for the consent process. Informed consent was administered in local language and these consented were asked to undergo clinical assessment and self-report interviews. The clinical assessment and self-report interview were used to identify and disclosure of opportunistic infections symptoms indicators of non- adherence and determine HIV/AIDS progress and severity (HIV stages).

The checklist for clinical symptoms of opportunistic infections and HIV/AIDS stages was prepared based on WHO guideline (WHO 2015; WHO, 2007). With regard to this study, the study staff filled a checklist of HIV/AIDS related opportunistic infection symptoms that were persistent during pregnancy 
period till delivery. Study staffs grouped these clinical symptoms in to their respective stages. The information on demographic variables was also collected. The first part of the checklist collected information on the demographic characteristic; age, marital status, education level, and maternal characteristic of number of births. The second and third part was checklist for symptoms of opportunistic infections of early and late stage of HIV/AIDS respectively. Each question of the second and third part of the checklist form was marked as "Yes" if HIV/AIDS related opportunistic infection symptom was present or "No" if there was none.

\section{Ethical consideration}

The approval to conduct this research was obtained from the Medical Research Coordinating Committee of National Institute for Medical Research (NIMR Tanzania), while informed consent was sought from women to participate in the study.

\section{Data analysis}

The data analysis was conducted using SAS software version 9.4. The study assessed the prevalence of opportunistic infection clinical symptoms as indicators of non-adherence to B+ ARV triple therapy in HIV positive women. The woman was considered as not adhered to ARV therapy during antenatal period if she presented or reported at least three persistent opportunistic infection clinical symptoms (from any HIV stage) at delivery (WHO, 2015; WHO, 2007, UNAIDS 2012; Tanzania PMTCT, 2016).

The following opportunistic infection clinical symptoms and their respective stages were analyzed; Clinical symptoms in early HIV stage (WHO clinical stages 1 and 2) were; fever, chill, night sweats, rashes, productive cough, muscle aches, sore throat, fatigue, swollen lymph nodes, mouth ulcers (WHO, 2015; WHO, 2007, UNAIDS, 2012). Clinical symptoms in late HIV stage (WHO clinical stages 3 and 4) assessed were; rapid weight loss, recurring fever and profuse night sweats, extreme and unexplained tiredness, prolonged swollen lymph glands in the armpits, groin or neck (lymphadenopathy), diarrhea that lasts for more than a week, sores of the mouth, anus, or genitals, pneumonia, red, brown, pink or purple blotches on or under the skin or inside the mouth, nose or eyelids, depression, memory loss, and other neurological disorders, Kaposi's sarcoma or lymphoma (WHO, 2015; WHO, 2007, UNAIDS, 2012).

Frequency table was used to describe prevalence and percentage of women with at least three clinical symptoms and adherence, while cross tabulations were used to analyze if opportunistic infection clinical symptoms were associated with demographic variables; age, marital status, education status and number of births. The Chi- squire was used to test the significance of association and differences of categorical data. The differences or association of HIV/AIDS symptoms and demographic variables were considered significant if the $\mathrm{P}$ - values $<0.05$.

\section{Results}

The HIV positive women under ART triple therapy were screened for presence or absence of opportunistic infection clinical symptoms that defined adherence status. The information on the demographic backgrounds and maternal characteristics was also collected and included for data analysis.

Among 105 HIV positive women that were receiving triple therapy at antenatal clinics, 63(60\%) develop at least three or more symptoms of HIV, and thus did not adhere to the ART, while only, $42(40 \%)$ adhered to the ARV therapy prescribed (Table 1). The study indicates the common symptoms among women who did not adhere to the ART were; fatigue 46(43.8\%), night sweat 43(40.9\%), muscle ache 41(39\%), and frequently fever 39(37.1\%) (Table1). These symptoms were grouped as early HIV clinical conditions. The late HIV stage symptoms that were common among them; Extreme and unexplained tiredness 43(40.9\%), pneumonia 37(35.2\%), recurring fever and profuse night sweats 33(31.4\%), rapid weight loss 27(25.7\%) (Table1).

Based on HIV stages, among 63 women that did not adhered to ART 27 (42.8\%) had presented with only early HIV stage symptoms, and 4 (6.3\%) showed late HIV stage symptoms only, while $32(50.7 \%)$ developed symptoms of both HIV stages (Table 1). 
DOI: $10.21522 / \mathrm{TIJNR} .2015 .03 .02 . A r t 020$

ISSN: $2520-3126$

Among women enrolled, 22 (20.9\%) were aged between 18-25 years, 79 (75. 2\%) aged between 2640 , and $4(3.8 \%)$ were women between the age of 41-44, while $18(17.10 \%)$ stayed without a partner, and $87(82.8 \%)$ were living with their partners (Table 2). The data indicates that $19(18.1 \%)$ had delivered once, 76(72.3\%) delivered between 2-4 times and 10(9.5\%) of them had 5-9 births. More than half $62(59 \%)$ of them achieved primary level education, while $28(26.6 \%)$ completed secondary level education, $13(12.3 \%)$ had not attended any formal education or school, and only $2(1.9 \%)$ are college graduate (Table 2). The non-adherence was more observed in women age 26-40 (44.7\%), compared to other age groups of; $18-25(14.2 \%)$ and $41-44(0.95 \%)$, although the difference is not significant (Table $2)$. Women with primary level education were more found with non-adherence symptoms $(35.2 \%)$ than groups of women from other education levels of; college (1.9\%), secondary education (15.2\%) and these with no formal education (7.6\%) (Table 2), the difference was not significant. The participants that were living with their partners were observed with more none- adherent symptoms $(49.5 \%)$ compared to women who were living without their partners (10.4\%), the difference was not significant (Table 2). The none- adherence to ART was more in women with 2-4 birth (44.7), while other groups of single birth, none -adherence was $10.4 \%$ and women with 5-9 births was $4.7 \%$. The observed differences were not significant (Table 2).

Women age 26-40 reported more symptoms of both HIV stages (23.8\%) than other age groups of; 18 $25(18.1 \%)$ and $41-44(3.86 \%)$, although the difference is not significant (Table 2). Women with primary level education were more found with symptoms of both stages (17.1\%) than women from other education levels of; college education $0.95 \%$, secondary level $7.6 \%$, and these with no formal education (4.7\%) (Table 2), the difference was not significant. The participants that were living with their partners had more symptoms under both HIV stages $(25.7 \%)$ compared to women who were living without their partners $(4.7 \%)$, the difference was not significant (Table 2). The HIV positive women with 2-4 birth developed more symptoms of both HIV stages (24.7) than groups of single birth and women with 5-9 births $(2.8 \%)$ (Table 2$)$. The observed differences were not significant.

\section{Discussion}

This study was conducted in high HIV transmission area where almost $7 \%$ of pregnant women are infected with HIV (PMTCT Tanzania, 2016). In the study areas all pregnant women were initiated with ARV (B+) Triple therapy from antenatal clinics at 34 weeks of gestation period (PMTCT Tanzania, 2016).

Among 105 HIV positive women that were screened for adherence, more than half $(60 \%)$ of them did not adhere to B+ARV triple therapy based on opportunistic infection clinical symptoms. This indicates that the non- adherence to ART is overwhelming as barrier to continue with ARV increases and motivations to use the ART decreases (Ngarina et al., 2013; Ngarina et al., 2014). These women who did not adhere to ART presented with either early, late or both HIV stage symptoms. The most common HIV symptoms that were found among women that did not adhere to ART were; fatigue, night sweat, muscle ache and frequently fever. These symptoms are early HIV opportunistic infection indicators of nonadherence. Other common symptoms developed by these women were; extreme and unexplained tiredness, pneumonia, recurring fever, profuse night sweats, and rapid weight loss, which are late HIV opportunistic infection indicators of non- adherence. These collections of common HIV symptoms can be used as Adherence to ART Indicators tool for identification of pregnant women non adherents to ART at antenatal clinics

More than half of women with non-adherence (50.7\%) showed opportunistic clinical signs of both early and late HIV stages. This show that more women are developing AIDS symptoms, which may increase transmission rate in the country (WHO, 2015; WHO, 2007, UNAIDS 2012). The presence of late HIV stage symptoms is a red flag indicating escalating advancement of HIV infection among pregnant women that pose threat in fight against AIDS. 
The non-adherence was more observed in women with primary level education, the lowest education available in the country. The low level education may probably have affected the ability to understand the importance of ART. The low education level may have coupled with fear to disclose HIV status, poverty and economic hardship that discouraged long-term adherence (Ngarina et al., 2014; Ngarina et al., 2013; Tanzania PMTCT, 2016).

The participants that were living with their partners had more non- adherent symptoms compared to women who were living without their partners. This phenomenon may have been contributed by women living with partners not able to take drug to prevent their HIV status to be known to family members including their partners (Ngarina et al., 2014; Ngarina et al., 2013).

Currently antenatal clinic lacks a thoroughly clinical assessment that is important to identify nonadherence symptoms to strengthen PMTCT services in Tanzania. This study will inform the government on the importance of policy change with respect to antenatal clinics to replace expensive laboratory methods of detecting non- adherence to ART with Adherence to ART Indicators tool. This study will inform HCW to apply Adherence to ART Indicators tool for HIV infected women when providing antenatal services.

\section{Conclusion}

The HIV infected pregnant women under B+ triple therapy are not adhering to their ARV therapy during antenatal period because substantial number were found with indicators of non-adherence to treatment. The indicators of non- adherence during pregnancy were; fatigue, night sweat, muscle ache and frequently fever, extreme, unexplained tiredness, pneumonia, recurring fever, profuse night sweats, and rapid weight loss. These symptoms formed Adherence to ART Indicators tool. Demographic variables were not significant related to adherence. This result will inform clinicians on Adherence to ART Indicators tool that will help to quickly identify defaulters of ARV therapy at antenatal clinics and take appropriate health care measure. The study result should be used to address issues and challenges related to non-adherence.

Table 1.The adherence to art and common HIV infections symptoms at delivery

\begin{tabular}{|c|c|c|c|}
\hline Variable category & Description of variable & Number (n) & Percentage $(\%)$ \\
\hline \multirow{2}{*}{$\begin{array}{l}\text { Adherence status } \\
(\mathrm{N}=105)\end{array}$} & Non- adherence & 63 & 60 \\
\hline & Adherence & 42 & 40 \\
\hline \multirow{4}{*}{$\begin{array}{l}\text { * Common Early } \\
\text { HIV stage symptoms } \\
\text { (WHO clinical stage } \\
1 \& 2)(n=105)\end{array}$} & Fatigue & 46 & 43.81 \\
\hline & Night sweats & 43 & 40.95 \\
\hline & Muscle ache & 41 & 39.05 \\
\hline & Fever & 39 & 37.14 \\
\hline \multirow{4}{*}{$\begin{array}{l}\text { *Common Late HIV } \\
\text { stage symptoms } \\
\text { (WHO clinical stage } \\
3 \& 4)(\mathrm{N}=105)\end{array}$} & $\begin{array}{l}\text { Extreme and } \\
\text { unexplained tiredness }\end{array}$ & 43 & 40.95 \\
\hline & Pneumonia & 37 & 35.24 \\
\hline & $\begin{array}{l}\text { Recurring fever or } \\
\text { profuse night sweats }\end{array}$ & 33 & 31.43 \\
\hline & Rapid weight loss & 27 & 25.71 \\
\hline \multirow{3}{*}{$\begin{array}{l}\text { Women HIV stages } \\
(\mathrm{n}=63)\end{array}$} & Early HIV Stage only & 27 & 42.8 \\
\hline & $\begin{array}{l}\text { Late HIV (Advanced } \\
\text { AIDS) stage only }\end{array}$ & 4 & 6.34 \\
\hline & Both stage & 32 & 50.79 \\
\hline
\end{tabular}

*Please note that women may present with more than three HIV symptoms 


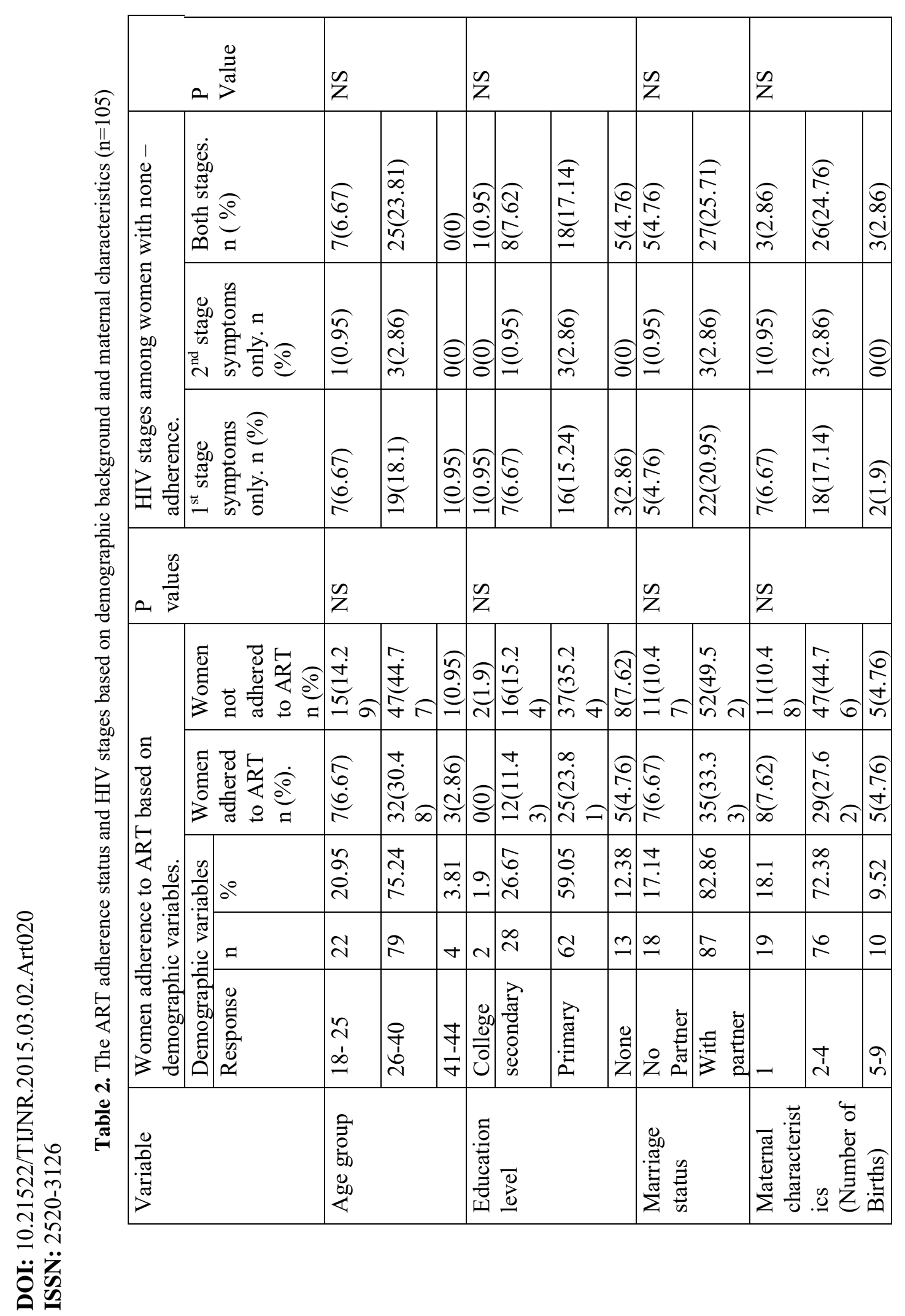




\section{References}

[1].Avert (2016). HIV and AIDS in Tanzania; UNAID gap report; Global information and education on HIV and AIDS Retrieved on 15february, 2016 from. http://www.avert.org/professionals/hiv-around-world/sub-saharanafrica/tanzania).

[2].Calvert C, Ronsmans C. (2015). Pregnancy and HIV disease progression: a systematic review and meta-analysis. Journal of Tropical Medicine and International Health, 20(2):122-45. Retrieved June 5, 2016, from PubMed.

[3].Kilewo Charles, Katarina Karlsson, Matilda Ngarina, Augustine Massawe, Eligius Lyamuya, Andrew Swai, Rosina Lipyoga, Fred Mhalu, Gunnel Biberfeld. Prevention of Mother to Child Transmission of HIV-1 through Breastfeeding by Treating Mothers with triple Antiretroviral Therapy in Dar es Salaam, Tanzania: The Mitra Plus study. Journal of Acquired Immune Deficiency Syndromes. 2009, 53: 406-41.

[4].Kowalska A, Niemiec T, El Midaoui A, Burkacka E. Effect of antiretroviral therapy on pregnancy outcome in HIV-1 positive women. Med Wieku Rozwoj. 2003 Oct-Dec; 7 (4 Pt 1):459-68.

[5].Kupka, R., Kassaye, T., Saathoff, E., Hertzmark, E., Msamanga, G. I. And Fawzi, W. W. (2009). Predictors of stillbirth among HIV-infected Tanzanian women. Journal of Acta Obstetricia et Gynecologica Scandinavica, 88: 584-592. Retrieved June 5, 2016, from PubMed.

[6].Moodley J, Wennberg JL. HIV in pregnancy. Curr Opin Obstet Gynecol. 2005 Apr; 17(2):117-21.

[7].Ngarina Matilda, Rebecca Popenoe, Charles Kilewo, Gunnel Biberfeld, Anna Mia Ekström. Reasons for poor adherence to antiretroviral therapy postnatally in HIV-1 infected women treated for their own health: experiences from the Mitra Plus study in Tanzania. BMC Public Health. 2013, 13:450.

[8].Ngarina M, Tarimo EAM, Naburi H, Kilewo C, Mwanyika-Sando M, Chalamilla G, et al. (2014) Women's Preferences Regarding Infant or Maternal Antiretroviral Prophylaxis for Prevention of Mother-To-Child Transmission of HIV during Breastfeeding and Their Views on Option B+ in Dar es Salaam, Tanzania. PLoS ONE 9(1): e85310. doi:10.1371/journal.pone.0085310.

[9].Reitter A ${ }^{1}$, Stücker AU, Linde R, Königs C, Knecht G, Herrmann E, Schlößer R, Louwen F, Haberl A. Pregnancy complications in HIV-positive women: 11-year data from the Frankfurt HIV Cohort. HIV Med. 2014 Oct; 15 (9):525-36. doi: 10.1111/hiv.12142. Epub 2014 Mar 6.

[10]. Siegfried $N^{1}$, van der Merwe L, Brocklehurst P, Sint TT. Antiretrovirals for reducing the risk of mother-tochild transmission of HIV infection. Cochrane Database Syst Rev. 2011 Jul 6; (7):CD003510. doi: 10.1002/14651858.CD003510.pub3.

[11]. Suksomboon N, Poolsup N, Ket-Aim S. Systematic review of the efficacy of antiretroviral therapies for reducing the risk of mother-to-child transmission of HIV infection. J Clin Pharm Ther. 2007 Jun; 32(3): 293-311.

[12]. Tanzania PMTCT. National resource centre for prevention of mother to child HIV transmission (2016). Retrieved June 152016 from http://pmtct.or.tz/pmtct-tanzania/pmtct-in-tanzania/.

[13]. UNAIDS .2012. Joint United Nations Programme on HIV/AIDS (Global report: UNAIDS report on the global AIDS epidemic 2012. Retrieved May 17, 2016, from

[14]. http://www.unaids.org/en/media/unaids/contentassets/documents/epidemiology/2012/gr2012/20121120_UNAI DS_Global_Report_2012_with_annexes_en.pdf.

[15]. WHO (2007). Who case definitions of HIV for surveillance and revised clinical staging and immunological classification of HIV-related disease in adults and children. Retrieved June 152016 from http://www.who.int/hiv/pub/guidelines/HIVstaging150307.pdf.

[16]. WHO (2015) Guideline on when to start antiretroviral therapy and on pre Exposure prophylaxis for HIV (pdf). Retrieved June 152016 from http://www.who.int/hiv/pub/guidelines/clinicalstaging.pdf). 


\title{
The Human Immunodeficiency Virus sero-Prevalence and AIDS- Related Opportunistic Infection Patterns among Women with Retained Placenta in Eastern Tanzania
}

\author{
Article by Admirabilis Kalolella \\ Ifakara health institute, Dar es salaam, Tanzania \\ E-mail: kalolella@hotmail.com
}

\begin{abstract}
The objective of this study was to characterize women with Retained Placenta (RP) attending obstetric care in eastern Tanzania. We assessed the HIV sero-prevalence, then screened for medical conditions related to RP and described their AIDS related opportunistic infection patterns for the women that were HIV-sero-positive.

The cross sectional study design using medical questionnaires and self-report checklist was used to collect data. The study assessed if there is any relationship between retained placenta and HIV serostatus, and if sero -status and HIV opportunistic infection patterns has relationship with pregnancy outcome and other medical conditions related to pregnancy.

In our study, HIV sero-positive was detected in 105 out of 251 women (42\%). HIV sero-positive women developed prolonged labor, 23(79.3\%), significantly more often compared to HIV sero-negative women, $6(20.6 \%)$, P value $<0.0001$. The HIV positive women are significantly more likely to develop Postpartum hemorrhage $(P$ value $=0.0031)$ and to undergo Caesarian section compared to pregnant women without HIV $(P$ value $=0.0113)$. The pregnant women under antenatal ARV Triple $(B+)$ therapy are significantly more likely to end up with preterm delivery $(P$ value $=0.0443)$. Women with HIV progressive symptoms of memory loss, depression, and other neurologic disorders had more underweight babies born $(P-$ Value $=0.0316)$, while women with pneumonia developed vaginal tears more often during delivery $(P-$ Value $=0.0693)$.

In conclusion, RP is common among women with HIV. The prolonged labor is the major medical condition currently faced by HIV infected pregnant women during delivery. Women with HIV progressive symptoms are at risk to give birth to underweight baby and get vaginal tear during delivery. The current $B+A R V$ treatment during antenatal period has positively changed some the pregnancy outcomes among HIV infected pregnant women.
\end{abstract}

Keywords: Retained placenta, sero-positive, HIV sero-status, prolonged labor, HIV opportunistic infection patterns, pregnant women, Post-partum hemorrhage, B+ARV triple therapy.

\section{Introduction}

Maternal HIV infection increases the risk of adverse pregnancy outcome including stillbirth and premature delivery, risk factors for retained placenta (RP) that leads to Post-Partum Haemorrhage (PPH), the major killer of women (Calvert \& Ronsmans, 2015; Kumar, 2016; Slyker et al., 2014). About 13 million premature deliveries occur each year worldwide that constitute of live births $11 \%$, most of them occur in developing countries (Slyker et al., 2014). Sub-Saharan Africa contributes more than one-fourth of these death making the region with the highest incidence of stillbirth in the world (Kumar, 2016; Slyker et al., 2014). The Sub Saharan Africa, experience the highest levels of HIV/AIDS, while millions of women of reproductive age currently live with HIV in sub-Saharan Africa. In Tanzania, more that 7\% of pregnant women are infected with HIV that probably affects the current situations of retained placenta in Tanzania (PMTCT Tanzania, 2016). To reduce adverse effects of HIV/AIDS during pregnancy, the country is implementing new B+ ARV triple therapy as a new program for antenatal services for pregnant 
DOI: $10.21522 / \mathrm{TIJNR} .2015 .03 .02 . A r t 022$

ISSN: $2520-3126$

women infected with HIV, regardless of their CD4 count (PMTCT Tanzania, 2016; Ngarina et al., 2014). In this regime, pregnant women who are sero-positive, with gestation age of 34 weeks and above are given three ARV medicine; Zidovudine + Lamivudine + Nevirapine /Nelfinavir (PMTCT Tanzania, 2016; Ngarina et al., 2014). This regime has been practiced for the past three years in the country.

Retained placenta in humans is referred as a placenta that has not undergone completely expulsion within 60 minutes after the baby's birth when the third stage of labor, between child delivery to the complete expulsion of placenta has been managed actively (Marshall \& Raynor (2014; Agrawal et al., 2013). When placenta is partially separates, the uterus cannot contract properly to compress blood vessels, and therefore the blood vessels inside the uterus will continue to bleed without stopping that result into PPH (Marshall\& Raynor, 2014; Kumar, 2016). Retained placenta brings risks of excessive hemorrhage and infection leading to puerperal sepsis (Kumar 2016; Marshall\& Raynor, 2014; Agrawal et al., 2013).

Studies indicate that pregnant women infected with HIV are at risk to give birth with gestation age of less than 28 weeks, which is called premature delivery (Slyker et al., 2014). Baby born with gestation age around or less than 28 weeks are always born as dead in the form of fresh stillbirth or macerated stillbirth which are risk factors for RP (Marshall\& Raynor, 2014; Kumar, 2016). Women with HIV infection are also at risk to deliver premature baby, one of the major factors contributing to RP (Slyker et al., 2014). The HIV and AIDS is the major cause of death that effect women of reproductive age in sub Saharan Africa, and the region experience the highest levels of HIV/AIDS infection and also highest maternal mortality much of the incidence presumably occur due to HIV infection (Calvert \& Ronsmans, 2015). Considering that millions of women of reproductive age currently living with HIV in sub-Saharan Africa, HIV and AIDS- related conditions may be responsible for a large number of stillbirths (Calvert \& Ronsmans, 2015). Some studies argued that pregnancy fuels advancement of HIV infection, while other observed increased obstetric complications among women living with HIV (Calvert \& Ronsmans, 2015).

Retained placenta is the main causes of PPH in developing countries where access to appropriate obstetrical care is limited (Slyker et al., 2014; Kumar, 2016). Studies indicate that independent risk factors associated with retained placenta include; inadequate utilization of antenatal health care services, history of previous uterine scar due to retained placenta, induced labor, caesarean section, delivery with full urine bladder, uterine abnormality, previous dilatation and curettage, pregnancy at age more than 35 years, many births during lifetime, preterm delivery and placenta with less than $501 \mathrm{~g}$ in weight (Marshall \& Raynor, 2014). Retained placenta membranes and tissue are responsible for postpartum hemorrhage (Kumar, 2016). The treatment of placenta is manual remove of placenta under general anesthesia. The removal of placenta is performed in operating theater with specialized medical staffs that are seldom available in rural areas (Duffy at el., 2014; Kumar 2016; Marshall\& Raynor, 2014).

PPH is defined as the excessive loss of blood after vaginal delivery of new born that is observed from the time of delivery up to forty-two days postpartum (Kumar, 2016; Marshall \& Raynor, 2014). The primary PPH is the most common which is defined as the blood loss estimated more that 500ml within the first twenty-four hours after delivery, while secondary PPH is the bleeding after twenty four hours up to six weeks after delivery (Marshall\& Raynor, 2014). The PPH may pose serious threat of death particularly to women with weak health status regardless of amount of blood loss (Marshall\& Raynor, 2014; Kumar, 2016). The PPH may be caused by failure of the uterus to contract adequately after delivery of baby (uterus atony), retained placenta, traumatized delivery canal, rupture of uterus, or maternal bleeding disorders (Kumar, 2016; Marshall \& Raynor, 2014). The most common treatment for PPH is to ensure stability of hemodynamic through intravenous fluid infusion and blood transfusion to replace lost blood and removing causative factors that exacerbate the situation (Kumar, 2016; Marshall\& Raynor, 2014). Such services are not always available in health facilities of rural area in resource poor countries where many women attend for delivery services and thus the need for pre-diagnostic efforts to prevent unexpected obstetric complication (Slyker et al., 2014; Illah et al., 2013).

It is estimated that $4 \%$ of maternal mortality in Sub-Saharan Africa are related to HIV infected persons 
(Calvert \& Ronsmans, 2015). According to Calvert \& Ronsmans (2015), HIV positive pregnant women are 8 times more likely to die compared to uninfected women.

The investigation that leads to identifying predictors of RP will serve women from unexpected adverse health conditions. Women that are pre-diagnosed of RP at antenatal had a lower blood loss in the range of $100-15000 \mathrm{ml}$ and required less volume of transfusion compared to other women with blood loss around 2500-17000ml (Tikkanen et al., 2011). The relationship of HIV status and RP is still under debate. Limited knowledge is available on relationship of HIV/AIDS to RP. The HIV /AIDS may be responsible for a large number of women with retained placenta. This investigation will help to find out if HIV/AIDS is one among predictors of RP.

Rationale. The RP is one of the leading causes of maternal hemorrhage contributing to high maternal mortality rate worldwide (Illah et al., 2013; Marshall \& Raynor, 2014). The limited health care resources and inadequacy of obstetric care, particularly in the rural areas fuels adverse effect of RP in Tanzania (Illah et al., 2013). In Tanzania, the prevalence of HIV among women who attend ANC is high that could probably affect the current situations of RP (PMTCT Tanzania, 2016). While many studies have previously assessed the relationship of clinical factors to retained placenta, and others assessed the relationship of stillbirth and premature delivery to HIV status, and several other studies are known to be in progress, the vast majority of these studies have been conducted exclusively in still birth, premature delivery in relation to HIV status without looking at HIV progress factors and patterns of AIDS related conditions and opportunistic infection (Slyker et al., 2014; Calvert \& Ronsmans, 2015). With the current changing context in health care technology, provision of health care services and life styles, risk factors for RP will be re-visited to see changes and magnitudes among these factors. Given the high proportion of HIV/AIDS among pregnant women in Tanzania, identifying predictors of RP is critical to reduce consequences of this obstetric complication.

This study examined the relationship between RP and HIV, the magnitude of clinical conditions - HIV progressive factor leading to RP in a Tanzanian context. The study established new way to pre-diagnose or predict RP through combination of medical conditions including serological, AIDS related conditions and its progressive factors. Identifying predictors of RP through medical symptoms will help health care workers to predict, forecast and plan for safe deliveries to serve women from unexpected health problems, reduce $\mathrm{PPH}$, blood transfusion cases and maternal mortality in the country.

The goal of this study was to characterize women with RP that presented to the hospital for obstetric care in eastern Tanzania. This was achieved as follows: We assessed the HIV sero-prevalence among women with RP, we described their AIDS related opportunistic infection progressive patterns of women with RP that are HIV-sero-positive, and we screened for other medical conditions related to RP.

Hypothesis: If HIV infected pregnant women are likely to deliver still birth and pre- term baby, risk factors for RP, then we hypothesize that with the current high prevalence of HIV infection in Tanzania, the HIV status and AIDS- related opportunistic infections are likely to emerge as main predictors of RP. For the past three years Tanzania has been implementing B+ Triple therapy for all pregnant women we also expected changes in pregnancy outcomes. All HIV infected women in Tanzania are required to start B+ ARV triple therapy, thus all women in this study were covered by B+ Triple ARV therapy as part of PMTCT program in Tanzania. We expected to find a high HIV sero-prevalence among women with RP, but also anticipated to find positive effect of ARV therapy counteracting HIV effect on clinical symptoms and pregnancy outcome.

\section{Methodology}

The cross sectional study design was used to collected descriptive data of 251 post- partum women with RP from maternity or labor wards in hospitals providing obstetric care in municipalities of Ubungo, Ilala, Temeke, and Kinondoni, that are located in eastern Tanzania. The data collection was conducted from September 2016 up to February 2017.The study investigated HIV sero-prevalence, HIV/AIDSopportunistic infection patterns and other clinical conditions related to RP. These municipalities have high 
DOI: $10.21522 / \mathrm{TIJNR} .2015 .03 .02 . A r t 022$

ISSN: $2520-3126$

HIV sero-prevalence and high number of deliveries. Women diagnosed or treated for RP formed the population of this study. Eligible participants were obtained from labor or maternity wards in hospitals. The patient was approached by a recruiter to determine her eligibility and recruited by registering her name and giving study identity number. All interested patients were directed to interviewers for the consent process. Informed consent was administered in local language and these consented were asked to undergo rapid clinical and laboratory assessment and interviews. Every patient diagnosed with RP was recruited sequentially to achieve an enrollment of sample size required. This design provided an estimated proportion of women with RP seeking obstetric care that actually have HIV infection, medical conditions related to RP, and description of AIDS- related conditions and opportunistic infection progress and patterns in patient with HIV infection. The HIV progress factors were divided into two categories: 1. HIV early stage symptoms (WHO clinical stages 1\&2) and, 2. HIV late (AIDS) stage symptoms (WHO clinical stages $3 \& 4)$. The study also collected information on general description of medical conditions among women with and without HIV infection.

The consented post- partum women with RP undergone clinical assessment to identify clinical conditions, signs and symptoms of opportunistic or HIV/AIDS related infections and other medical conditions. Rapid HIV test was done using HIV SD Bioline (SD South Korea) to determine sero-status. The HIV sero-status was confirmed by Uni-Gold HIV Rapid Test Kits, Trinity Biotech. The Participants were then clinical assessed and interviewed for self-report of clinical signs to determine HIV/AIDS progressive symptom patterns and severity.

Clients were enrolled for the study only if;

- they were diagnosed with retained placenta by hospital staffs or completed treatment for RP

- they consents to participate

- Potential participants were excluded if they were

- presenting with danger sign or signs of severe illness such as inability to speak, drink, and vomiting

- recent history of convulsions or eclampsia

- lethargic or unconscious

- Experiencing danger signs, or other conditions requiring immediately treatment.

The Medical questionnaire for Medical conditions, signs and symptoms of AIDS related complication was used to collect data. The first part of the questionnaire collected information on the demographic characteristic; age, marital status, education level, and number of births. The second and third part was checklist for sign and symptoms for HIV/AIDS related infections, while the fourth part was medical conditions checklist. Each question of checklist was defined as "Yes" if sign and symptom present or "No" if there was no such symptom. The last section collected information on HIV status and pregnancy outcomes.

\section{Ethical consideration}

The Tanzanian Medical Research Coordinating Committee of National Institute for Medical Research (NIMR) approved the study. The informed consent was administered to every postpartum woman with RP interested to participate in the study.

\section{Data analysis}

The data entry screen was developed from EpiData software. The data that were entered into the software were transferred to SAS version 9.4 for data analysis. The primary variables of interest were; HIV sero-prevalence among women with retained placenta. HIV/AIDS related symptoms and its progressive factors among women with reined placenta who are HIV positive. Medical conditions among women with RP were also documented to all patients regardless of their HIV status and then compared. Variables were categorized as: age, marital status, education level, and number of birth of women with 
retained placenta, HIV status, HIV early stage symptoms (WHO clinical stages $1 \& 2$ ), HIV late (AIDS) stage symptoms (WHO clinical stages 3\&4), other medical conditions that may be associated with RP, and pregnancy outcomes. Frequencies tables and cross tabulations were used to determine associations between variables. The chi- squire test was used to analyze categorical data to test statistical significance between these differences or association between variables. The association or the differences were considered significant if $\mathrm{P}$-values $<0.05$.

The early HIV stage symptoms observed were; fever, chill, night sweats, rashes, productive cough, muscle aches, sore throat, fatigue, swollen lymph nodes and mouth ulcers (WHO, 2015). The late stage symptoms are; rapid weight loss, recurring fever or profuse night sweats, extreme and unexplained tiredness, prolonged swollen lymph glands in the armpits, groin or neck, diarrhea that lasts for more than a week, sores of the mouth, anus, or genitals, pneumonia, red, brown, pink or purple blotches on or under the skin or inside the mouth, nose or eyelids, memory loss and depression and neurological disorders and Kaposi's sarcoma or lymphoma (WHO, 2015).

\section{Results}

A total of 251 women with retained placenta were screened for HIV status, HIV/ AIDS related symptoms, other medical conditions and pregnancy outcomes, and the information were included for data analysis. Among women participated, 46 (18\%) were aged between 18-25 years, and 196 (78\%) aged between 26- 40, while $9(3.6 \%)$ of them were women aged 41-44 (Table 1). The large proportion of them, $185(74 \%)$ had 1-3 births; while 62(24\%) women had 4-6 births, and 4 of them (1.5\%) had delivered 7-9 times. Majority of them, 169(67\%) achieved primary level education, while 59(23.5\%) completed secondary education, $20(8 \%)$ of these women had not attended any school, and only $3(1.2 \%)$ completed college education (Table 1).

The results indicate that among 251 pregnant women with retained placenta 105(41.8\%) were seropositive, while $146(58.1 \%)$ are sero-negative (Table 2). Pregnant women aged 26-40years, that are 79 (31.4\%) are more affected with HIV followed by the age of 18-25 years, 22(8.7\%), however, there is no significance difference of HIV prevalence among different groups of pregnant women (Table 2). In this regard, among pregnant women, the prevalence of HIV is independent of age, which is different among the women in general public where HIV prevalence is dependent of age groups.

Women with retained placenta that are HIV sero-positive reported significant more episodes of caesarean section operation, 21(61.7\%) during delivery compared to women that are sero-negative, 13(38.2\%) (P value=0.0113) (Table 3). Women with HIV have significantly more developed PPH 19(67.8\%) compared to women without HIV, 9(32.1\%) (P value=0.0031). (Table 3). The pregnant women with retained placenta that are sero-positive show significant more preterm deliveries $10(66.6 \%)$ compared to women who are sero-negative, 5(33.3\%), $\mathrm{P}$ value $=0.0443$. Women with HIV had less occasions of still born babies 4(28.5\%), than women without HIV, 10(71.4\%), however the association was not significant.

There are no significant differences in their baby weights and stillborn births among them probably due to ARV triple therapy current being received by all HIV- positive pregnant women in Tanzania (Table 3 ). Triple ARV therapy may probably enhanced baby weight during pregnancy. To the surprise, women without HIV show slightly higher number of still born baby deliveries compared to Women with HIV although the difference is not significant. In this situation, ARV triple therapy may have reduced still born babies among HIV sero-positive women. The occurrence of prolonged labor was more significant among HIV infected women 23(79.3\%), compared to HIV negative women 6(20.6\%), P-value <0.0001(Table $3)$. The study indicates new findings in pregnancy outcomes opposing other study findings where HIV sero-positive pregnant women were observed to deliver low weight and stillborn babies significantly more often compared to HIV sero-negative (WHO, 2015; Calvert \& Ronsmans, 2015). The previous episodes of retained placenta and history of myomectomy had no significant association with retained placenta in women of both group of HIV negative and positive (Table 3). 
DOI: $10.21522 / \mathrm{TIJNR} .2015 .03 .02 . A r t 022$

ISSN: $2520-3126$

The findings show that women with common HIV progressive persistent pneumonia which is among the late HIV/ AIDS stage (WHO clinical stage 3 \&4) symptoms had vaginal tears during birth more often (35.2\%) than did women who had no pneumonia during delivery (18.9\%), P- Value $=0.0693$ (Table 4). Women with memory loss, depression, and other neurologic disorders had more babies born with body weight below $2500 \mathrm{~g}$ (underweight baby) (20.8\%) compared to women without these symptoms $(6.1 \%)$, P- Value 0.0316 (Table 4). The symptoms of memory loss, depression, and other neurologic disorders are among the HIV progressive symptoms for individual with HIV in late AIDS stage (WHO clinical stage 3 \&4). Other HI/AIDS related progressive symptoms had no significant association with pregnancy outcomes.

\section{Discussion}

This study was conducted in public health facilities providing obstetric care in eastern Tanzania where low income women attend. The information was collected in municipalities with higher rate of HIV transmission. In Tanzania, almost $7 \%$ of pregnant women are infected with HIV, and all of them are expected to be on Prophylaxis ARV (B+) Triple therapy from antenatal clinics (PMTCT Tanzania, 2016, Ngarina et al., 2014). To understand the prevalence of HIV among women with the retained placenta is important step to inform health care workers to predict the possibility RP for treatment and prevention of PPH to reduce mortality.

Among 251 women with retained placenta, 105 (42\%) were HIV sero-positive. This indicates that RP is common among HIV infected pregnant women. The study indicates that prevalence of HIV among pregnant women with retained placenta is independent of age group; this is opposite when HIV prevalence is assessed through age groups in adult women without pregnancy (WHO, 2015; Calvert \& Ronsmans, 2015). Women with retained placenta that are HIV sero-positive are more likely to develop $\mathrm{PPH}$ as well as to undergo caesarean section operation compared to women that are sero-negative. Following ARV triple therapy, women with HIV had less occasions of still born babies compared to women without HIV although the association was not significant. The pregnant women with retained placenta that are sero-positive under ARV therapy show significant more preterm deliveries compared to women who are sero-negative. This finding corresponds to other similar studies (Calvert \& Ronsmans, 2015; Slyker et al., 2014). This finding of increased preterm deliveries were observed in various studies indicating that ARV therapy excessively increased preterm deliveries among HIV infected mothers (Aniji et al., 2013; Watts et al., 2013; Short et al., 2014). Women without HIV show slightly higher percentage of still born baby deliveries compared to Women with HIV although the difference is not significant. We observed no significant differences in their baby weights and stillborn births among women with different HIV status. The ARV triples therapy current being administered to all pregnant women that are seropositive in antenatal clinics may have influenced some of the observed results.

In the medical conditions, we observed phenomenon of prolonged labor (prolonged second or third stage of labor) that was more significant among HIV infected women. Study shows that women with HIV are significantly more likely to experience PPH and to undergo Caesarian section compared to women without HIV.

The pattern of AIDS related opportunistic infections among women with RP that are HIV-sero-positive indicate various pregnancy outcomes. Women with HIV progressive symptom of pneumonia which is among the late HIV/ AIDS stage (WHO clinical stage $3 \& 4$ ) symptoms are more likely to develop vaginal tears during birth than women without pneumonia. Women with memory loss, depression, and other neurologic disorders are more likely to give birth to underweight babies compared to women without these symptoms. The symptoms of memory loss, depression, and other neurologic disorders develop among HIV infected person during late AIDS stage (WHO clinical stage $3 \& 4$ ). Other HIV/AIDS related progressive symptoms had no significant association with pregnancy outcomes. 


\section{Conclusion}

The RP is common among women with HIV. The prolonged labor is the major medical condition currently faced by sero-positive pregnant women during delivery that need attention from health care workers. Women with retained placenta that are HIV sero-positive is more likely to develop PPH as well as to undergo caesarean section operation compared to women that are sero-negative. Majority of HIV Infected women develop prolonged labor when giving birth. The HIV/AIDS progressive symptom of pneumonia put a woman at risk to develop vaginal tear during delivery, while symptoms of memory loss, depression, and other neurologic disorders subject pregnant women at risk of giving birth to underweight baby. The current $\mathrm{B}+$ treatment during antenatal period has changed positively some of the pregnancy outcomes among HIV positive pregnant women.

\section{Acknowledgements}

We would like to thank and express our sincere gratitude to the municipal medical officers, in-charges of municipal hospital and maternity wards of these hospitals, medical doctors and midwifes of all maternity sections and all participants for their support and their willingness participate and disclose their clinical symptoms and to accept this study.

Table 1. The demographic characteristics of women with retained placenta $(\mathrm{n}=251)$

\begin{tabular}{|l|l|l|l|}
\hline Demographic backgrounds & \multicolumn{4}{l|}{} \\
\hline Variable & Response & Frequency & Percent \\
\hline Age group in years & $18-25$ & 46 & $18 \%$ \\
\hline & $26-40$ & 196 & $78 \%$ \\
\hline Number of births & $41-44$ & 9 & $3.6 \%$ \\
\hline & $1-3$ & 185 & $74 \%$ \\
\hline & $4-6$ & 62 & $24 \%$ \\
\hline Education level & $7-9$ & 4 & $1.5 \%$ \\
\hline & Primary & 169 & $67 \%$ \\
\hline & Secondary & 59 & $23.5 \%$ \\
\hline & College & 3 & $1.2 \%$ \\
\hline Total & None & 20 & $8 \%$ \\
\hline
\end{tabular}

Table 2. The HIV status among women with Retained placenta based on the age group $(\mathrm{n}=251)$

\begin{tabular}{|l|l|l|l|}
\hline \multirow{2}{*}{ Age Group } & \multicolumn{2}{|l|}{ HIV status } & \multirow{2}{*}{ P value } \\
\cline { 2 - 3 } & HIV Negative $(\mathrm{n}=146)$ & HIV Positive $(\mathrm{n}=105)$ & \\
\cline { 2 - 3 } & $(\mathrm{n}, \%)$ & $(\mathrm{n}, \%)$ & \\
\hline $18-25$ & $24(9.56)$ & $22(8.76)$ & \\
\hline $26-40$ & $117(46.61)$ & $79(31.47)$ & \\
\hline $41-44$ & $5(1.99)$ & $4(1.59)$ & \\
\hline Total & $146(58.1)$ & $105(41.8)$ & \\
\hline
\end{tabular}


DOI: $10.21522 /$ TIJNR.2015.03.02.Art022

ISSN: $2520-3126$

Table 3. The Common medical conditions among women with retained placenta based on HIV status $(n=251)$

\begin{tabular}{|c|c|c|c|}
\hline \multirow{3}{*}{$\begin{array}{l}\text { Medical } \\
\text { conditions }\end{array}$} & \multicolumn{2}{|c|}{ HIV status $n=251$} & \multirow[t]{3}{*}{$\mathrm{P}$ value } \\
\hline & HIV Negative & HIV positive & \\
\hline & $\mathrm{n},(\%)$ & $\mathrm{n},(\%)$ & \\
\hline $\begin{array}{l}\text { Caesarean } \\
\text { section }\end{array}$ & $13(38.2)$ & $21(61.7)$ & 0.0113 \\
\hline Myomectomy & $2(40)$ & $3(60)$ & 0.4055 \\
\hline $\mathrm{PPH}$ & $9(32.1)$ & $19(67.8)$ & 0.0031 \\
\hline Baby weight & $11(52.3)$ & $10(47.6)$ & 0.5744 \\
\hline $\begin{array}{l}\text { Prematurely } \\
\text { delivery }\end{array}$ & $5(33.3)$ & $10(66.6)$ & 0.0443 \\
\hline Prolonged labor & $6(20.6)$ & $23(79.3)$ & $<0.0001$ \\
\hline Stillborn baby & $10(71.4)$ & $4(28.5)$ & 0.3006 \\
\hline $\begin{array}{l}\text { Previous } \\
\text { retained placenta }\end{array}$ & $7(43.7)$ & $9(56.2)$ & 0.227 \\
\hline
\end{tabular}


泀

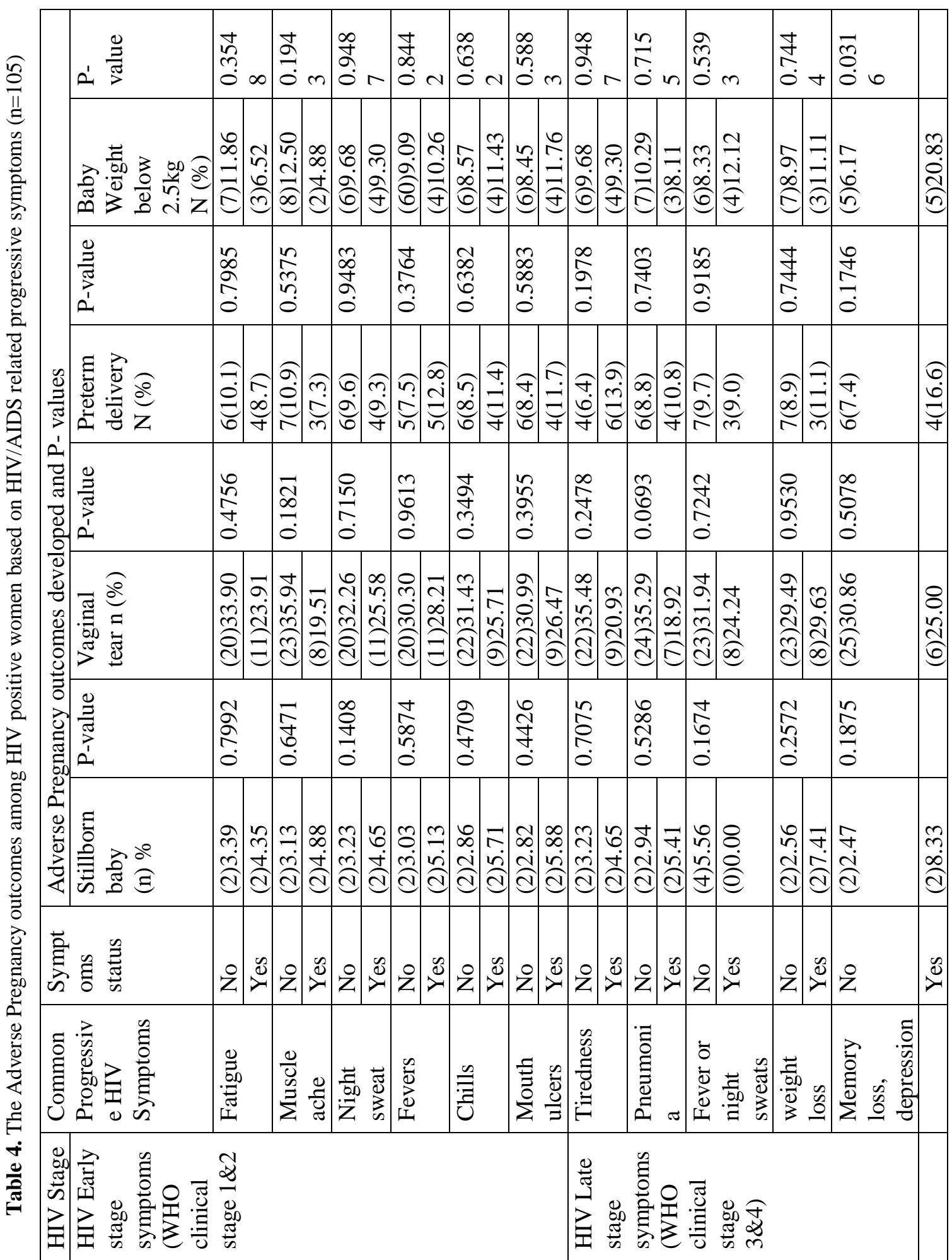


DOI: $10.21522 /$ TIJNR.2015.03.02.Art022

ISSN: $2520-3126$

\section{References}

[1]. Agrawal, A. Thakur, A. Rijal, P. Basnet, P. Ghimire, A \& Uprety, D. (2013). Management of retained placenta in patient with valvular heart disease with pulmonary oedema. Health Renaissance, 201(1), 199-205.

[2]. Aniji C D,1 FCOG (SA); O A Towobola,1 PhD; M E Hoque,2 MSc; T J Mashamba,1 MB ChB; S Monokoane,1 FCOG (SA) (2013). Impact of antiretroviral therapy on pregnancy outcomes. S Afr J HIV Med 2013; 14(4):176-178. DOI:10.7196/SAJHIVMED.834.

[3]. Calvert C, Ronsmans C. (2015). Pregnancy and HIV disease progression: a systematic review and metaanalysis. Journal of Tropical Medicine and International Health, 20(2):122-45. Retrieved June 5, 2016, from PubMed.

[4]. Illah E, Mbaruku G, Masanja H, Kahn K. (2013). Causes and risk factors for maternal mortality in rural Tanzania--case of Rufiji Health and Demographic Surveillance Site (HDSS). Afr J Reprod Health. 2013 Sep; 17(3):119-30.

[5]. Jayne E, Marshall, Maureen D Raynor (2014). Myles' Textbook for Midwives, $16^{\text {th }}$ Edition, UK: Elsevier Health Sciences.

[6]. Jennifer A Slyker, Janna Patterson, Gwen Ambler, Barbra A Richardson, Elizabeth Maleche-Obimbo, Rose Bosire, Dorothy Mbori-Ngacha, Carey Farquhar, and Grace John-Stewart (2014). Correlates and outcomes of preterm birth, low birth weight, and small for gestational age in HIV-exposed uninfected infants. BMC Pregnancy and Childbirth 201414:7. DOI: 10.1186/1471-2393-14-7.

[7]. Kumar, N. (2016). Postpartum Hemorrhage; a Major Killer of Woman: Review of Current Scenario. Obstetrics \& Gynecology International Journal, 4(4). Published online.

[8]. Ngarina M, Tarimo EAM, Naburi H, Kilewo C, Mwanyika-Sando M, Chalamilla G, et al. (2014) Women's Preferences Regarding Infant or Maternal Antiretroviral Prophylaxis for Prevention of Mother-To-Child Transmission of HIV during Breastfeeding and Their Views on Option B+ in Dar es Salaam, Tanzania. PLoS ONE 9(1): e85310. doi:10.1371/journal.pone.0085310.

[9]. PMTCT Tanzania. National resource centre for prevention of mother to child HIV transmission (2016). Retrieved June 152016 from http://pmtct.or.tz/pmtct-tanzania/pmtct-in-tanzania/.

[10]. Short C-ES, M Douglas, JH Smith and GP Taylor (2014) Preterm delivery risk in women initiating antiretroviral therapy to prevent HIV mother-to-child transmission. HIV medicine 201415, 233-238. DOI: 10.111/hiv.12083.

[11]. Tikkanen $\mathrm{M}^{1}$, Paavonen J, Loukovaara M, \& Stefanovic V. (2011) Antenatal diagnosis of placenta accreta leads to reduced blood loss. Journal of Acta Obstetricia et Gynecologica Scandinavica, 90(10), 1140-6.

[12]. Watts DH ${ }^{1}$, Williams PL, Kacanek D, Griner R, Rich K, Hazra R, Mofenson LM, Mendez HA; Pediatric HIV/AIDS Cohort Study (2013). Combination antiretroviral use and preterm birth. J Infect Dis. 2013 Feb 15; 207(4):612-21. doi: 10.1093/infdis/jis728.

[13]. WHO (2015) Guideline on when to start antiretroviral therapy and on pre Exposure prophylaxis for HIV (pdf). Retrieved June 152016 from http://www.who.int/hiv/pub/guidelines/clinicalstaging.pdf). 


\section{TEXILA JOURNAL}

Texila American University Ltd, Unit T 1/F, Mau Lam Comm Building, 16-18 Mau Lam Street, Jordan, Kowloon, Hong Kong.

E-mail: ejournal.assist@tau.edu.org Skype: texila.aco32

Whatsapp: +918056580933 